

\title{
Degradation modeling of concrete submitted to biogenic acid attack
}

Haifeng Yuan

\section{To cite this version:}

Haifeng Yuan. Degradation modeling of concrete submitted to biogenic acid attack. Other. Université Paris-Est, 2013. English. NNT : 2013PEST1148 . pastel-00985468

\section{HAL Id: pastel-00985468 https://pastel.archives-ouvertes.fr/pastel-00985468}

Submitted on 29 Apr 2014

HAL is a multi-disciplinary open access archive for the deposit and dissemination of scientific research documents, whether they are published or not. The documents may come from teaching and research institutions in France or abroad, or from public or private research centers.
L'archive ouverte pluridisciplinaire HAL, est destinée au dépôt et à la diffusion de documents scientifiques de niveau recherche, publiés ou non, émanant des établissements d'enseignement et de recherche français ou étrangers, des laboratoires publics ou privés. 
THĖSE

Présentée pour obtenir le grade de

DOCTEUR DE

L'UNIVERSITÉ PARIS-EST

Domaine : Génie Civil

Présentée par :

\section{Haifeng Yuan}

Sujet de la thèse :

\section{Degradation modeling of concrete submitted to biogenic acid attack}

Modélisation de la dégradation du béton due aux attaques acides biogéniques.

Mémoire provisoire

Jury :

Dr. Laurent de WINDT

Prof. Gilles ESCADEILLAS

Prof. Denis DAMIDOT

Dr. Patrick DANGLA

Dr. Patrice CHATELLIER

Dr. Thierry CHAUSSADENT

\author{
Maître de recherche HDR Mines-ParisTech \\ Professeur INSA de Toulouse \\ Professeur Ecole des Mines de Douai \\ IFSTTAR, U. Paris-Est \\ IFSTTAR \\ IFSTTAR
}

Rapporteur

Rapporteur

Examinateur

Directeur de thèse

Conseiller d'études

Conseiller d'études 


\section{Résumé}

La biodétérioration du béton, très courante dans les systèmes d'égouts et de traitement des eaux usées, entraîne une dégradation significative de la structure. Normalement, le processus peut être décrit par les deux étapes suivantes : 1) Des réactions biochimiques produisent des espèces agressives dans les biofilms qui tapissent la surface du béton. L'un des plus importants acides biogéniques que l'on trouve dans les canalisations d'égout est l'acide sulfurique $\left(\mathrm{H}_{2} \mathrm{SO}_{4}\right)$ que est produit par des bactéries sulfo-oxydante (BSO) à partir de l'hydrogène sulfuré $\left(\mathrm{H}_{2} \mathrm{~S}\right)$. 2) Les réactions chimiques entre les espèces agressives biogéniques et les produits d'hydratation du ciment sont responsables de la détérioration du béton.

Un modèle de transport réactif est proposé afin de simuler les processus des détériorations chimique et biochimique des matériaux cimentaires en contact avec les BSO et le $\mathrm{H}_{2} \mathrm{~S}$ ou une solution d'acide sulfurique. L'objectif de ce modèle est de résoudre simultanément le transport et la biochimie / chimie dans les biofilms et les matériaux cimentaires par une approche globale couplée.

Afin de fournir un environnement approprié pour la croissance des BSO, la neutralisation de la surface du béton (i.e., l'absorption de $\mathrm{H}_{2} \mathrm{~S}$ et la corrosion aqueuse de $\mathrm{H}_{2} \mathrm{SO}_{4}$ ) est considérée. Pour obtenir la quantité de $\mathrm{H}_{2} \mathrm{SO}_{4}$ biogénique, la bio-oxydation du $\mathrm{H}_{2} \mathrm{~S}$ par l'activation des bactéries est simulée par un modèle simplifié. Puis, pour alimenter un environnement convenable pour la croissance des BSO, la réduction abiotique du $p \mathrm{H}$ du béton est introduite. Le taux de production de $\mathrm{H}_{2} \mathrm{SO}_{4}$ est régi par la valeur du $\mathrm{pH}$ dans les biofilms et la quantité de $\mathrm{H}_{2} \mathrm{~S}$ dans le gaz.

On fait l'hypothèse que tous les processus chimiques sont en équilibre thermodynamique. La dissolution de la portlandite $(\mathrm{CH})$ et du silicate de calcium hydratés (C-S-H), ainsi que la précipitation de gypse (C̄̄H2) et du sulfure de calcium sont décrites par la loi d'action de masse et le seuil des produits d'activité ionique. Pour prendre en compte la décroissante continue du rapport $\mathrm{Ca} / \mathrm{Si}$ lors de la dissolution de la C-S-H, une généralisation de la loi d'action de masse est appliquée.

En simplifiant le processus de précipitation du gypse, un modèle d'endommagement est introduit pour caractériser la détérioration du béton due au gonflement du gypse. Ainsi, l'évolution de la porosité et de la profondeur de la détérioration pendant le processus de dégradation sont pris en compte. 
Seule la diffusion des espèces aqueuses est considérée. Différents coefficients de diffusion sont utilisés pour divers ions et l'équation de Nernst-Planck est implémentée. L'effet, pendant la détérioration, de la modification de la microstructure sur les propriétés de transport est aussi considéré. Pour les biofilms et les matériaux cimentaires, les équations d'équilibre de masse totale de chaque atome $(\mathrm{Ca}, \mathrm{Si}, \mathrm{S}, \mathrm{K}, \mathrm{Cl})$ sont utilisées pour coupler les équations de transport et les réactions (bio) chimiques.

Le modèle est implémenté dans un code volumes finis, Bil. Grâce à l'introduction de la méthode des volumes finis, on illustre le couplage du processus bio-chimie dans les biofilms et le processus de la chimie des matériaux cimentaires.

Par ce modèle, certaines expériences rapportées dans la littérature, dont des tests d'immersion chimiques (condition de la solution statique et condition de la solution d'écoulement) et des simulations microbiologiques, sont simulées. Les résultats numériques et les observations expérimentales sont comparés et discutés. L'influence des propriétés des matériaux cimentaires (porosité initiale, couche carbonatée, etc.) et les facteurs d'environnement (concentration de $\mathrm{H}_{2} \mathrm{SO}_{4}$ quantité de $\mathrm{H}_{2} \mathrm{~S}$ etc) sont aussi étudiés par ce modèle. En outre, une prédiction à long terme est menée.

\section{Mots-clés:}

Bio-détérioration, Canalisations d'égout, Béton, Acide sulfurique, Biofilm, Modélisation du transport réactif, Portlandite, C-S-H, Gypse 


\section{Abstract}

Bio-deterioration of concrete, which is very common in sewer system and waste water treatment plant, results in significant structure degradation. Normally, the process can be described by the two following parts: 1) Biochemistry reactions producing biogenic aggressive species in biofilms which are spread on the surface of concrete. As one of the most significant biogenic acid in sewer pipes, sulfuric acid $\left(\mathrm{H}_{2} \mathrm{SO}_{4}\right)$ is produced by sulfur oxidizing bacteria (SOB). 2) Chemical reactions between biogenic aggressive species and cement hydration products which is responsible for concrete deterioration.

A reactive transport model is proposed to simulate the bio-chemical and chemical deterioration processes of cementitious materials in contact with $\mathrm{SOB}$ and $\mathrm{H}_{2} \mathrm{~S}$ or sulfuric acid solution. This model aims at solving simultaneously transport and biochemistry/chemistry in biofilms and cementitious materials by a global coupled approach.

To provide an appropriate environment for SOB to grow, the surface neutralization of concrete (i.e., the absorption of $\mathrm{H}_{2} \mathrm{~S}$ and aqueous $\mathrm{H}_{2} \mathrm{~S}$ corrosion) is considered. To obtain the amount of biogenic $\mathrm{H}_{2} \mathrm{SO}_{4}$, the bio-oxidation of $\mathrm{H}_{2} \mathrm{~S}$ by the activation of bacteria is simulated via a simplified model. To provide a suitable environment for $\mathrm{SOB}$ to grow, the abiotic $p \mathrm{H}$ reduction of concrete process is introduced. The production rate of $\mathrm{H}_{2} \mathrm{SO}_{4}$ is governed by the $p \mathrm{H}$ in the biofilms and the content of $\mathrm{H}_{2} \mathrm{~S}$ in gas.

It is assumed that all chemical processes are in thermodynamical equilibrium. The dissolution of portlandite $(\mathrm{CH})$ and calcium silicate hydrates $(\mathrm{C}-\mathrm{S}-\mathrm{H})$ and the precipitation of gypsum $(\mathrm{C} \overline{\mathrm{S}} \mathrm{H} 2)$ and calcium sulfide are described by mass action law and threshold of ion activity products. To take into account the continuous decrease of the $\mathrm{Ca} / \mathrm{Si}$ ratio during the dissolution of $\mathrm{C}-\mathrm{S}-\mathrm{H}$ a generalization of the mass action law is applied.

By simplifying the precipitation process of gypsum, a damage model is introduced to characterize the deterioration of concrete due to the swelling of gypsum. Thus, the porosity evolution and deterioration depth during deterioration process are taken into account.

Only diffusion of aqueous species are considered. Different diffusion coefficients are employed for various ions and Nernst-Planck equation was implemented. The effect of the microstructure change during 
deterioration on transport properties is considered as well. For both biofilms and cementitious materials, the balance equations of total mass of each atom $(\mathrm{Ca}, \mathrm{Si}, \mathrm{S}, \mathrm{K}, \mathrm{Cl})$ are used to couple transport equations and (bio-)chemical reactions.

The model is implemented within a finite-volume code, Bil. Following the introduction of principle of the finite volume method, the coupling of the bio-chemistry process in biofilms and chemistry process in cementitious materials is illustrated.

By this model, some experiments reported in literature, including chemical immersion tests (statical solution condition and flow solution condition) and microbiological simulation tests, are simulated. The numerical results and the experimental observations are compared and discussed. The influence of properties of cementitious materials (initial porosity, carbonated layer, etc.) and environmental factors (concentration of $\mathrm{H}_{2} \mathrm{SO}_{4}$, content of $\mathrm{H}_{2} \mathrm{~S}$, etc.) are investigated by this model as well. Furthermore, a long term prediction is conducted.

\section{Keywords:}

Bio-deterioration, Sewer pipe, Concrete, Sulfuric acid, Biofilm, Reactive transport modelling, Portlandite, C-S-H, Gypsum 


\section{Contents}

1 Introduction $\quad 1$





1.3 Recent research works about biodeterioration of cementitious materials . . . . . . . . 6

1.4 Research objectives . . . . . . . . . . . . . . . . . . . . . . 10



2 The production of $\mathrm{H}_{2} \mathrm{SO}_{4}$ by micro-organisms in biofilm $\quad 13$



2.2 Neutralization of pipe surface during early stage $\ldots \ldots \ldots \ldots \ldots$

2.3 The production of $\mathrm{H}_{2} \mathrm{SO}_{4}$ by sulfur-oxidizing bacteria $\ldots \ldots \ldots \ldots$



3 Degradation of cementitious materials subjected to sulfuric acid attack 27







3.4 Decalcification of calcium silicate hydrates $(\mathrm{C}-\mathrm{S}-\mathrm{H}) \ldots \ldots \ldots \ldots \ldots \ldots$

3.5 Examples of the evolution of $p \mathrm{H}$ and solid compositions $\ldots \ldots \ldots$



4 Porosity evolution and damage of cementitious materials 41







4.4 Porosity change during $\mathrm{H}_{2} \mathrm{SO}_{4}$ attack $\ldots \ldots \ldots \ldots \ldots \ldots$ 
4.5 Examples of the evolution of porosity and solid volume . . . . . . . . . . . . . 49



5 Reactive transport modeling and numerical procedures $\quad 53$







5.4 Introduction of numerical procedures $\ldots \ldots \ldots \ldots \ldots \ldots \ldots \ldots \ldots \ldots \ldots$

5.5 Examples of bio-deterioration modeling $\ldots \ldots \ldots \ldots \ldots \ldots$



6 Simulation in the case of constant $\mathrm{H}_{2} \mathrm{SO}_{4}$ solution $\quad 73$

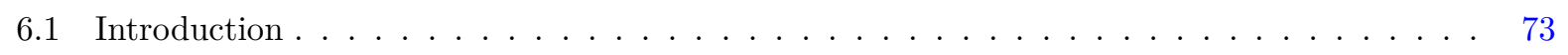

6.2 High $\mathrm{H}_{2} \mathrm{SO}_{4}$ concentration condition $(p \mathrm{H}=1) \ldots \ldots \ldots \ldots \ldots \ldots$

6.3 Low $\mathrm{H}_{2} \mathrm{SO}_{4}$ concentration condition $(p \mathrm{H}=2) \ldots \ldots \ldots \ldots \ldots$

6.4 Analysis of the discrepancy between simulation results and experimental results . . . . . . 89

6.5 Long-term prediction . . . . . . . . . . . . . . . . . . . . . 94



$\begin{array}{lll}7 & \text { Simulation in the case of biofilms condition } & 97\end{array}$



7.2 Immersion test condition . . . . . . . . . . . . . . . . . . . . . . . 99

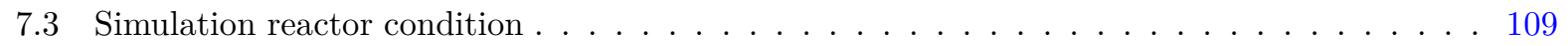





8 Conclusions and further discussion $\quad 117$





A Introduction of discrete and solid solution models of C-S-H dissolution 135

B The finite volume method $\quad 141$ 


\section{List of Figures}

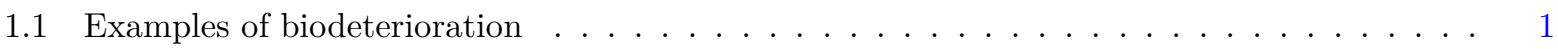

1.2 Examples of MICC of sewer pipe . . . . . . . . . . . . . . . . . . 3

1.3 Schematic of biogenic sulphuric acid attack in a sewerage (Herisson et al., 2013)). . . . . . 3

1.4 Theoretical changes in the biological and physical properties of concrete with time during the deterioration process, (Islander et al., 1991) . . . . . . . . . . . . . . . . . 4

1.5 (a) Concrete coupons exposed to the sewer atmosphere (Okabe et al., 2007); (b) Scanning electron microphotograph of gypsum crystals in the cement paste (Monteny et al., 2000). • 6

2.1 Schematic outline of the $\mathrm{H}_{2} \mathrm{~S}$ production process. (Jensen et al., 2008) . . . . . . . . . . 14

2.2 Schematics of the pilot scale reactors. (Vollertsen et al., 2008) . . . . . . . . . . . 15

$2.3 \mathrm{H}_{2} \mathrm{~S}$ absorption rate at different $\mathrm{H}_{2} \mathrm{~S}$ gas content. . . . . . . . . . . . . . . . . . 16

2.4 Decrease in surface $p \mathrm{H}\left(p \mathrm{H}_{(\text {initial })}-p \mathrm{H}_{(\text {exposed })}\right)$ after 1 year. . . . . . . . . . . . . 18

2.5 Succession of SOB in different $p \mathrm{H}$ range (Herisson, 2012) . . . . . . . . . . . . . . . . 19

2.6 Sulfur oxidation states typical in sewer. (Biologic pathway is shown with full lines; chemical, with dashed lines.) (Islander et al., 1991) . . . . . . . . . . . . . . . . . . . . . 19

$2.7 \quad \mathrm{H}_{2} \mathrm{SO}_{4}$ production rate and $p \mathrm{H} \ldots \ldots \ldots \ldots \ldots$. . . . . . . . . . . . . . . 21

2.8 The pathway used to describe the hydrogen sulfide and oxygen consumption pattern observed in the experiments on biotic hydrogen sulfide oxidation (Jensen, 2008). . . . . . . . . . . 22

2.9 Oxidation rate : (a) $\mathrm{H}_{2} \mathrm{~S}$; (b) element $\mathrm{S}$. . . . . . . . . . . . . . . . . . . . 24

2.10 The $p \mathrm{H}$ evolution in pure SOB media with different $\mathrm{H}_{2} \mathrm{~S}$ level. . . . . . . . . . . . . . . . . 24

3.1 Stability domains of portlandite and gypsum . . . . . . . . . . . . . . . . . 31

3.2 A typical pattern of the relationship between $\frac{Q_{\mathrm{SH}_{t}}}{K_{\mathrm{SH}_{t}}}$ and $\frac{Q_{\mathrm{CH}}}{K_{\mathrm{CH}}} \ldots \ldots . . \ldots$

3.3 Composition of a calcium-silicon solution in equilibrium with its solid phase vs. Ca/Si ratio. 35

3.4 Concentration of $\mathrm{H}_{2} \mathrm{~S}$ species and $p \mathrm{H}$ vs. time in $\mathrm{REV}$ of cement paste . . . . . . . . . 36

3.5 Evolution of the solid composition vs. $\mathrm{H}_{2} \mathrm{~S}$ concentration in REV of cement paste . . . . . 37 
3.6 Concentration of $\mathrm{H}_{2} \mathrm{SO}_{4}$ species and $p \mathrm{H}$ vs. time in $\mathrm{REV}$ of cement paste $\ldots \ldots \ldots$

3.7 Evolution of the solid composition vs. $\mathrm{H}_{2} \mathrm{SO}_{4}$ concentration in $\mathrm{REV}$ of cement paste $\ldots . .38$

$4.1 V_{\text {C-S-H }}$ and $\mathrm{H}_{2} \mathrm{O} /$ Si ratio $z$ vs. $\mathrm{Ca} /$ Si ratio $x \ldots \ldots \ldots \ldots \ldots \ldots \ldots$

4.2 (a) OPC Mortar after 350 Days of biogenic sulfuric acid corrosion in simulation chamber. Samples on left side is reference sample,whereas on right side sample exposed to corrosion condition. (Ehrich et al., 1999); (b) The appearance of concrete coupons exposed to the sewer atmosphere for 1 year. (Okabe et al., 2007) . . . . . . . . . . . . . . . . . 44

4.3 Schematics of the microstructure of cementitous materials with uncompressed gypsum inclusion: (a) Through-solution mechanism (Beddoe and Dorner, 2005); (b) Deposition in pores mechanism (Kawai et al., 2005) . . . . . . . . . . . . . . . . . . . . 44

4.4 Schematics of the microstructure of cementitous materials with uncompressed gypsum inclusion 46

4.5 Schematics of the microstructure of cementitous materials with compressed gypsum inclusion 46

4.6 Schematics of the relationship between the saturation degree of gypsum and inner pressure. $\quad 47$



4.8 Schematics of the microstructure of damaged cementitous materials _ . . . . . . . . . 49

4.9 Evolution of the solid volume and porosity vs. $\mathrm{H}_{2} \mathrm{~S}$ concentration in REV of cement paste . 50

4.10 Evolution of the solid volume and porosity vs. $\mathrm{H}_{2} \mathrm{SO}_{4}$ concentration in REV of cement paste 51

4.11 Evolution of inner pressure vs. content of $\mathrm{CH}$ and $\mathrm{C} \overline{\mathrm{S}} \mathrm{H} 2$ in $\mathrm{REV}$ of cement paste . . . . . . 51

4.12 Concrete coupons exposed to the sewer atmosphere $\left[\mathrm{H}_{2} \mathrm{~S}, 30 \mathrm{ppm}\right]$ for 42 days (A), 102 days (B), and 1 year (C and D), showing the progression of concrete corrosion. (Okabe et al., 2007) 51

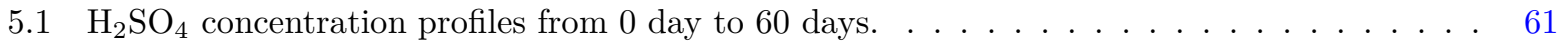

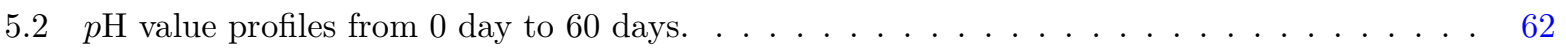

5.3 Solid profiles after 15 days immersion $\ldots \ldots \ldots \ldots$

5.4 Evolution of porosity and solid compositions of material versus immersion time. . . . . . . 63

$5.5 \mathrm{CH}$ and $\mathrm{C} \overline{\mathrm{S}} \mathrm{H} 2$ content, $\zeta_{\mathrm{Ca}}$ and $\log \left(z_{\mathrm{H}_{2} \mathrm{SO}_{4}}\right)$ after 15 days immersion $\ldots \ldots \ldots . \ldots . \ldots$

5.6 Concentration of $\mathrm{SO}_{4}^{2-}$ and $\mathrm{Ca}^{2+}$ and $\zeta_{\mathrm{Ca}}$ after 15 days immersion $\ldots \ldots \ldots \ldots$

5.7 Flow of calcium and sulfur and $\zeta_{\mathrm{Ca}}$ after 15 days immersion $\ldots \ldots \ldots \ldots$

$5.8 \mathrm{Ca} / \mathrm{Si}$ ratio of $\mathrm{C}-\mathrm{S}-\mathrm{H}$ and $\log \left(q_{\mathrm{CH}}\right)$ after 15 days immersion $\ldots \ldots \ldots 6$

$5.9 V_{\mathrm{C}-\mathrm{S}-\mathrm{H}}$ of $\mathrm{C}-\mathrm{S}-\mathrm{H}$ and $\log \left(q_{\mathrm{CH}}\right)$ after 15 days immersion $\ldots \ldots \ldots \ldots$

5.10 In SOB solution without cement paste: (a) $p \mathrm{H}$ and the concentration of total sulfate ions ;

(b) Concentration of $\mathrm{H}_{2} \mathrm{SO}_{4}{ }^{0}, \mathrm{HSO}_{4}^{-}$and $\mathrm{SO}_{4}^{2-} \ldots \ldots \ldots \ldots \ldots \ldots$

$5.11 p \mathrm{H}$ and $\mathrm{H}_{2} \mathrm{SO}_{4}$ concentration in $\mathrm{SOB}$ solution containing cement paste . . . . . . . . 68 
5.12 Flow of aqueous species across the interface at 1 day $\ldots \ldots \ldots$. . . . . . . . 69

$5.13 \mathrm{pH}$ value profiles from 0 day to 60 days. . . . . . . . . . . . . . . . . . 69



6.1 After 90 days immersion test: (a) Observation of deterioration of sample; (b) XRD patterns of surface area of sample. (Method 1, $p \mathrm{H}=1$ ) (Kawai et al., 2005) $\ldots \ldots \ldots \ldots$

6.2 The calculated penetration of $\mathrm{H}_{2} \mathrm{SO}_{4}$ and $p \mathrm{H}$ evolution profiles from 0 days to 90 days: (a)



6.3 After 10 days of immersion: (a) Solid concentration and porosity ; (b) Solid volume and $\mathrm{Ca} / \mathrm{Si}$ ratio of C-S-H . D $\mathrm{D}_{\text {Simulation }}$ and $\mathrm{D}_{\text {Experiment }}$ represent the degradation depth of the sample in simulation and experiment individually. (Method $1, p \mathrm{H}=1) \ldots \ldots \ldots$

6.4 After 30 days of immersion: (a) Solid concentration and porosity ; (b) Solid volume and $\mathrm{Ca} / \mathrm{Si}$ ratio of C-S-H . $\mathrm{D}_{\text {Simulation }}$ and $\mathrm{D}_{\text {Experiment }}$ represent the degradation depth of the sample in simulation and experiment individually. (Method $1, p \mathrm{H}=1) \ldots \ldots \ldots 7$

6.5 After 90 days of immersion: (a) Solid concentration and porosity ; (b) Solid volume and $\mathrm{Ca} / \mathrm{Si}$ ratio of C-S-H. $\mathrm{D}_{\text {Simulation }}$ and $\mathrm{D}_{\text {Experiment }}$ represent the degradation depth of the sample in simulation and experiment individually. (Method $1, p \mathrm{H}=1$ ) . . . . . . .

6.6 At $5 \mathrm{~mm}$ depth of sample (a) Solid concentration, Ca/Si ratio of C-S-H and porosity ; (b) Solid volume and inner pressure $($ Method $1, p \mathrm{H}=1) \ldots \ldots \ldots \ldots$

6.7 The predicted evolution of porosity and corrosion depth profiles from 0 days to 90 days: (a) Porosity; (b) Corrosion depth. (Method 1, $p \mathrm{H}=1$ ) . . . . . . . . . . . . . . 79

6.8 After 90 days immersion test: (a) Observation of deterioration of sample; (b) XRD patterns of surface area of sample. (Method 2, $p \mathrm{H}=1$ ) (Kawai et al., 2005) . . . . . . . . . . 79

6.9 The calculated penetration of $\mathrm{H}_{2} \mathrm{SO}_{4}$ and $p \mathrm{H}$ evolution profiles from 0 days to 90 days: (a) $\mathrm{H}_{2} \mathrm{SO}_{4}$ concentration; (b) $p \mathrm{H}$ value. (Method $\left.2, p \mathrm{H}=1\right) \ldots \ldots \ldots \ldots$

6.10 After 10 days of immersion: (a) Solid concentration and porosity ; (b) Solid volume and $\mathrm{Ca} / \mathrm{Si}$ ratio of C-S-H . D $\mathrm{D}_{\text {Simulation }}$ and $\mathrm{D}_{\text {Experiment }}$ represent the degradation depth of the sample in simulation and experiment individually. (Method $2, p \mathrm{H}=1$ ) . . . . . . .

6.11 After 30 days of immersion: (a) Solid concentration and porosity ; (b) Solid volume and $\mathrm{Ca} / \mathrm{Si}$ ratio of C-S-H . D $\mathrm{D}_{\text {Simulation }}$ and $\mathrm{D}_{\text {Experiment }}$ represent the degradation depth of the sample in simulation and experiment individually. (Method $2, p \mathrm{H}=1$ ) . . . . . . .

6.12 After 90 days of immersion: (a) Solid concentration and porosity ; (b) Solid volume and $\mathrm{Ca} / \mathrm{Si}$ ratio of C-S-H . D $\mathrm{D}_{\text {Simulation }}$ and $\mathrm{D}_{\text {Experiment }}$ represent the degradation depth of the sample in simulation and experiment individually. (Method $2, p \mathrm{H}=1$ ) . . . . . . . 
6.13 The calculated $\mathrm{Ca}^{2+}$ concentration profiles during immersion: (a) Method 1 ; (b) Method 2



6.14 The calculated diffusion of calcium during immersion: (a) Method 1 ; (b) Method 2 . ( $p \mathrm{H}$ $=1)$

6.15 The predicted evolution of porosity and corrosion depth profiles from 0 days to 90 days: (a) Porosity; (b) Corrosion depth. (Method $2, p \mathrm{H}=1) \ldots \ldots \ldots \ldots$

6.16 The concentration of $\mathrm{HSO}_{4}^{-}$and $\mathrm{SO}_{4}^{2-}$ in the sample after 70 days immersion. (Method 2,

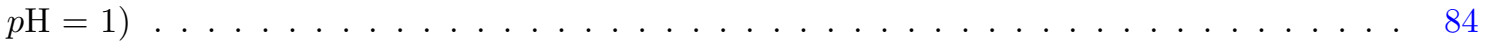

6.17 The calculated penetration of $\mathrm{H}_{2} \mathrm{SO}_{4}$ with different $p \mathrm{H}$ : (a) Method 1; (b) Method 2. . . . 85

6.18 The evolution of $p \mathrm{H}$ with different $p \mathrm{H}$ : (a) Method 1; (b) Method 2. . . . . . . . . . . 85

6.19 The evolution of solid volume, $\mathrm{Ca} / \mathrm{Si}$ ration of $\mathrm{C}-\mathrm{S}-\mathrm{H}$ and porosity after 10 days immersion : (a) Method 1; (b) Method 2. $(p \mathrm{H}=2) \ldots \ldots \ldots \ldots \ldots$

6.20 The evolution of solid volume, $\mathrm{Ca} / \mathrm{Si}$ ration of $\mathrm{C}-\mathrm{S}-\mathrm{H}$ and porosity after 30 days immersion : (a) Method 1; (b) Method 2. $(p \mathrm{H}=2) \ldots \ldots \ldots \ldots \ldots$

6.21 The evolution of solid volume, $\mathrm{Ca} / \mathrm{Si}$ ration of $\mathrm{C}-\mathrm{S}-\mathrm{H}$ and porosity after 90 days immersion : (a) Method 1; (b) Method 2. $(p \mathrm{H}=2) \ldots \ldots \ldots \ldots \ldots \ldots$

6.22 The concentration of $\mathrm{HSO}_{4}^{-}$and $\mathrm{SO}_{4}^{2-}$ after 90 days immersion with different $p \mathrm{H}$ : (a) Method



6.23 The flux of sulfur after 90 days immersion with different $p \mathrm{H}$ : (a) Method 1; (b) Method 2. . 88

6.24 After 90 days immersion : (a) The concentration of $\mathrm{Ca}^{2+} 1$; (b) Flux of calcium (Method 1) 88

6.25 The evolution of $p \mathrm{H}$ from 10 days to 90 days for the sample with carbonated layer: (a) Method $1 ;$ (b) Method 2. $(p \mathrm{H}=1) \ldots \ldots \ldots \ldots \ldots \ldots$

6.26 The evolution of solid volume, Ca/Si ration of C-S-H and porosity of samples with carbonated layer after 10 days immersion : (a) Method 1; (b) Method 2. $(p \mathrm{H}=1) \ldots \ldots$. . . . . . 91

6.27 The corrosion depth profiles of simulation and experiments from 10 days to 90 days: (a)



6.28 Solid compositions, Ca/Si ratio of C-S-H and porosity profiles after 30 days of immersion under high $\mathrm{H}_{2} \mathrm{SO}_{4}$ concentration condition $(p \mathrm{H}=0.5)$ : (a) W/C $=0.35$; (b) W/C $=0.5 .99$

6.29 Solid compositions, $\mathrm{Ca} / \mathrm{Si}$ ratio of C-S-H and porosity profiles after 30 days of immersion high $\mathrm{H}_{2} \mathrm{SO}_{4}$ concentration condition $(p \mathrm{H}=2)$ : (a) initial porosity $=0.3$; (b) initial porosity



6.30 Prediction of degradation depth of long exposure time. . . . . . . . . . . . . . . . . . 95 
7.1 Experiment setup of immersion test of biodeterioration: (a) (Vincke et al., 2000); (b) (De Belie et al., 2004). . . . . . . . . . . . . . . . . . . . . . . . . . . . 98

7.2 Experiment setup of biodeterioration by simulation reactors: (a) (Mori et al., 1992); (b)



7.3 A sample of the concrete before (A) and after (B) eight cycles of the microbiological test. A loss of cement paste is clearly visible, while the aggregates remain relatively unaffected. (De Muynck et al., 2009). . . . . . . . . . . . . . . . . . . . . . . 100

7.4 The calculated absorption of $\mathrm{H}_{2} \mathrm{~S}$ and $p \mathrm{H}$ evolution profiles from 0 days to 2 days: (a) Aqueous $\mathrm{H}_{2} \mathrm{~S}$ concentration; (b) $p \mathrm{H}$ value. $\left(\mathrm{H}_{2} \mathrm{~S}\right.$ level $\left.=200 \mathrm{ppm}\right) \quad \ldots \ldots$. . . . . . . . 101

7.5 The calculated absorption of $\mathrm{H}_{2} \mathrm{~S}$ profiles from 0 days to 2 days: (a) Aqueous $\mathrm{H}_{2} \mathrm{~S}$ concentration and $p \mathrm{H}$ evolution at surface; (b) Diffusion of sulfur. $\left(\mathrm{H}_{2} \mathrm{~S}\right.$ level $\left.=200 \mathrm{ppm}\right)$. . . . 101

7.6 After 1 day of exposure: (a) Solid concentration and porosity ; (b) Solid volume and Ca/Si



7.7 After 2 days of exposure: (a) Solid concentration and porosity ; (b) Solid volume and Ca/Si ratio of C-S-H. $\left(\mathrm{H}_{2} \mathrm{~S}\right.$ level $\left.=200 \mathrm{ppm}\right) \ldots \ldots \ldots \ldots$. . . . . . . . . . . . . 103

7.8 The concentration of $\mathrm{CaS}$ and aqueous $\mathrm{H}_{2} \mathrm{~S}$ at surface from 0 days to 2 days $\left(\mathrm{H}_{2} \mathrm{~S}\right.$ level $=200$

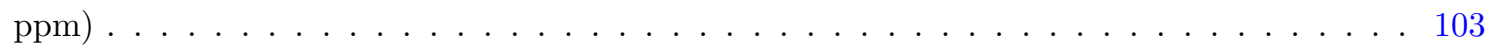

7.9 After 10 days of exposure: (a) Solid concentration and porosity ; (b) Solid volume and Ca/Si



7.10 The evolution of $p \mathrm{H}$ in pure SOB suspension from 0 days to 10 days . . . . . . . . . 105

7.11 Initial concrete sample with neutralized surface: (a) $p \mathrm{H}$ and porosity ; (b) Solid volume and $\mathrm{Ca} / \mathrm{Si}$ ratio of C-S-H. . . . . . . . . . . . . . . . . . . . . . 106

7.12 The calculated $\mathrm{H}_{2} \mathrm{SO}_{4}$ and $p \mathrm{H}$ evolution profiles in $\mathrm{SOB}$ suspension and concrete from 0 days to 10 days: (a) $\mathrm{H}_{2} \mathrm{SO}_{4}$ concentration; (b) $p \mathrm{H}$ value. . . . . . . . . . . . . . . . . 106

7.13 The $p \mathrm{H}$ evolution and production rate of $\mathrm{H}_{2} \mathrm{SO}_{4}$ from 0 to 10 days: (a) bulk SOB suspension; (b) SOB closed to concrete surface. . . . . . . . . . . . . . . . . . . . 107

7.14 After 10 days of immersion in SOB suspension: (a) Solid concentration and porosity ; (b)

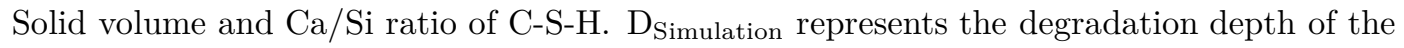
sample in simulation . . . . . . . . . . . . . . . . . . . . . . . . . 108

7.15 The predicted and measured corrosion depth. . . . . . . . . . . . . . . . . . . 108

7.16 Mortar specimens exposed to $\mathrm{H}_{2} \mathrm{~S}$ gas: (a) Water; (b) Sewage. (Mori et al., 1992). . . . . . 109

7.17 When surface $p \mathrm{H}$ decreases to 9.5: (a) Aqueous $\mathrm{H}_{2} \mathrm{~S}$ concentration and $p \mathrm{H}$ evolution at surface; (b) Solid concentration and porosity of mortar sample. $\left(\mathrm{H}_{2} \mathrm{~S}\right.$ level $\left.=400 \mathrm{ppm}\right)$. . 110 
7.18 The oxidation of $\mathrm{H}_{2} \mathrm{~S}$ and $\mathrm{S}$ versus their concentration in the biofilms: (a) Aqueous $\mathrm{H}_{2} \mathrm{~S}$;

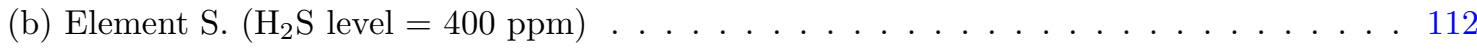

7.19 The calculated $p \mathrm{H}$ evolution profiles (a) $p \mathrm{H}$ evolution in biofilms ; (b) $p \mathrm{H}$ change in biofilms and mortar. $\left(\mathrm{H}_{2} \mathrm{~S}\right.$ level $\left.=400 \mathrm{ppm}\right) \quad \ldots \ldots \ldots \ldots \ldots \ldots \ldots \ldots \ldots$

7.20 After 40 days of test in simulation reactor: (a) Solid concentration and porosity ; (b) Solid volume and $\mathrm{Ca} / \mathrm{Si}$ ratio of $\mathrm{C}-\mathrm{S}-\mathrm{H} .\left(\mathrm{H}_{2} \mathrm{~S}\right.$ level $\left.=400 \mathrm{ppm}\right) \ldots \ldots \ldots \ldots \ldots$

7.21 After 80 days of test in simulation reactor: (a) Solid concentration and porosity ; (b) Solid volume and $\mathrm{Ca} / \mathrm{Si}$ ratio of $\mathrm{C}-\mathrm{S}-\mathrm{H} .\left(\mathrm{H}_{2} \mathrm{~S}\right.$ level $\left.=400 \mathrm{ppm}\right) \ldots \ldots \ldots \ldots \ldots$

7.22 After 180 days of test in simulation reactor: (a) Solid concentration and porosity ; (b) Solid volume and $\mathrm{Ca} / \mathrm{Si}$ ratio of C-S-H. $\left(\mathrm{H}_{2} \mathrm{~S}\right.$ level $\left.=400 \mathrm{ppm}\right) \ldots \ldots \ldots \ldots \ldots$

7.23 After 1 year of test in simulation reactor: (a) Solid concentration and porosity ; (b) Solid volume and $\mathrm{Ca} / \mathrm{Si}$ ratio of C-S-H. $\left(\mathrm{H}_{2} \mathrm{~S}\right.$ level $\left.=400 \mathrm{ppm}\right) \ldots \ldots \ldots \ldots \ldots$

7.24 The lag time of surface neutralization process with different $\mathrm{H}_{2} \mathrm{~S}$ level. $\ldots \ldots \ldots \ldots$

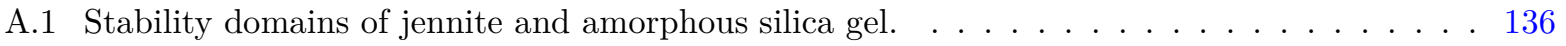

A.2 Stability domains of jennite, tobermorite and amorphous silica gel. . . . . . . . . . . 137

A.3 Mole fraction of different poles and $\mathrm{Ca} / \mathrm{Si}$ evolution $v s . q_{\mathrm{CH}} \ldots \ldots \ldots \ldots \ldots$ 


\section{List of Tables}

1.1 Some problems associated with the presence of biofilms on materials (Allsopp et al., 2004) . 2

1.2 Biodeterioration rate of concrete in sewage systems $\ldots \ldots \ldots \ldots \ldots \ldots \ldots$

1.3 Characteristics of Thiobacillus in biofilm (Islander et al., 1991) _ . . . . . . . . . . . 6

2.1 Definition of the parameters in WATS model . . . . . . . . . . . . . . . 23

2.2 Value of the parameters in $\mathrm{H}_{2} \mathrm{SO}_{4}$ production model. (Jensen et al., 2008) . . . . . . . . 23

3.1 Chemical reactions taking place in the aqueous solution $\ldots \ldots \ldots \ldots$



5.2 Diffusion coefficients of different aqueous species at $\mathrm{T}=298 \mathrm{~K} \ldots \ldots \ldots$

5.3 The key parameters of $\mathrm{CH}-\mathrm{CS} H 2$ equilibrium at different stable states $\ldots \ldots \ldots$

5.4 Governing equations and primary variables in the model $\ldots \ldots \ldots \ldots$

5.5 Boundary and initial conditions of the $\mathrm{H}_{2} \mathrm{SO}_{4}$ attack example $\ldots \ldots \ldots \ldots$. . . . . . 61

5.6 Boundary and initial conditions of the biogenic $\mathrm{H}_{2} \mathrm{SO}_{4}$ attack example $\ldots \ldots \ldots$. . . . . 66

6.1 Boundary and initial conditions of the $\mathrm{H}_{2} \mathrm{SO}_{4}$ attack with Method $1 \ldots \ldots \ldots$

6.2 Boundary and initial conditions of the $\mathrm{H}_{2} \mathrm{SO}_{4}$ attack with Method $2 \ldots \ldots$. . . . . 80

6.3 Boundary and initial conditions of the $\mathrm{H}_{2} \mathrm{SO}_{4}$ attack with $(p \mathrm{H}=2) \quad \ldots \ldots \ldots$

6.4 Boundary and initial conditions of the $\mathrm{H}_{2} \mathrm{SO}_{4}$ attack of the sample with carbonated layer . 90

7.1 Boundary and initial conditions of the $\mathrm{H}_{2} \mathrm{~S}$ attack $(200 \mathrm{ppm}) \ldots \ldots \ldots$

7.2 Boundary and initial conditions of biodeterioration by SOB suspension . . . . . . . . . 105

7.3 Boundary and initial conditions of biodeterioration by biofilms $\ldots \ldots \ldots \ldots \ldots$

A.1 Different C-S-H type proposed by (Lothenbach et al., 2008) . . . . . . . . . . . . . . . 135

A.2 Poles of a solid solution of $\mathrm{C}-\mathrm{S}-\mathrm{H} \ldots \ldots \ldots \ldots \ldots \ldots$ 


\section{Chapter 1}

\section{Introduction}

\subsection{Background}

During the service life of materials, biodeterioration is an important cause of the reduction of the performance and durability of materials as well as physical and chemical deterioration. Hueck (Hueck, 1968) first proposed that biodeterioration is "any undesirable change in the properties of a material caused by the vital activities of organisms".

In biodeterioration, the organisms vary widely, such as marine borers (including mollusks and crustaceans), insects, fungi, prokaryotes (including bacteria and archea) and plants (Sanchez-Silva and Rosowsky, 2008). They form specific communities that interact with materials and external environment in many different ways. As organisms exist everywhere, they can accelerate deterioration of a wide range of materials (as shown in Fig. 1.1), including inorganic minerals (Mitchell and Gu, 2000), concrete (Gu et al., 1998; Cwalina, 2008), stones (Warscheid and Braams, 2000; Perry IV et al., 2005), metals (Cragnolino and Tuovinen, 1984), and natural and synthetic polymers (Guezennec et al., 2006; Flemming, 1998).
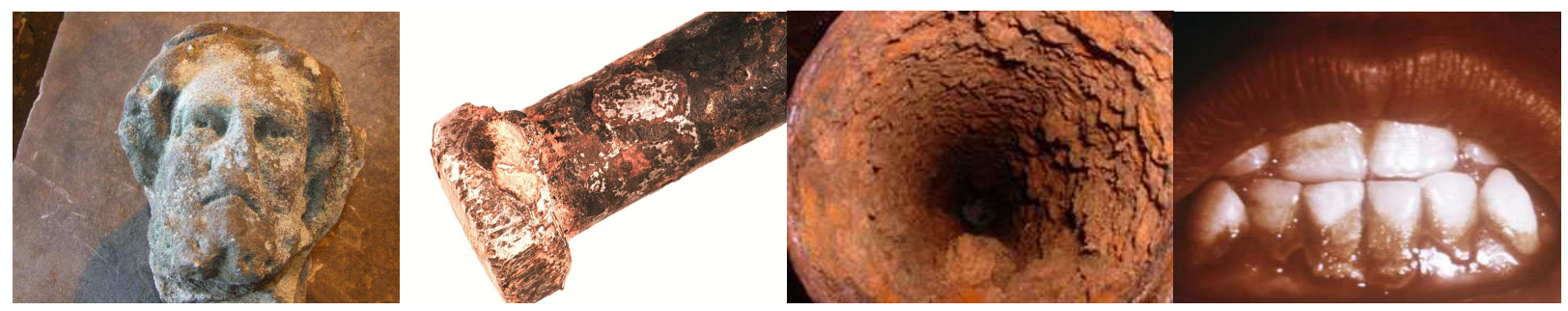

Figure 1.1: Examples of biodeterioration

Specifically, microorganisms play major role in deterioration. According to US estimation, the contribution of microbiologically induced corrosion (MIC) to the deterioration of materials as a whole is about $30 \%$ (Sand, 2008). In many cases, MIC is due to the presence of a surface layer of microorganisms and 
their products. Such microbial layers are known as biofilms and are defined as surface accumulations of the organic products of biological activity. Generally, biofilms are in direct contact with the material rather than dispersed in the surrounding environment. Thus, the aggressive products of microorganisms are concentrated and result in severe damage of materials. Some examples are shown in Table 1.1.

Table 1.1: Some problems associated with the presence of biofilms on materials (Allsopp et al., 2004)

\begin{tabular}{lc}
\hline Biofilm location & Effects \\
\hline Teeth & Tooth decay, caries \\
Sewer pipe & Decreased durability, reduced flow \\
Cooling towers & Degradation of material, reduced heat transfer \\
Drinking water distribution systems & Decreased water quality, health risks \\
Oil industry pipelines & Blockage and corrosion \\
\hline
\end{tabular}

As one of the most widely used materials, concrete suffers from biodeterioration. The first mention of microbiologically induced concrete corrosion (MICC) in literatures was by Olmstead and Hamlin (Olmstead and Hamlin, 1900). Most of MICC were detected in constructions like sewer pipes (Diercks et al., 1991; Mori et al., 1992; Cho and Mori, 1995), waste water treatment facilities (Redner et al., 1991), cooling towers (Zherebyateva et al., 1991), gas and oil platforms (Edyvean, 1987), marine structures (Hughes et al., 2013), and many others where various microorganisms (like bacteria, microscopic fungi, algae and lichen) are usually present at high concentrations (Viitanen et al., 2010).

The most rapid cases of deterioration always occur in the places with high $\mathrm{H}_{2} \mathrm{~S}$ concentration, moisture, and oxygen in the atmosphere. Such conditions are commonly found in sewage collection systems (as shown in Table 1.2).

Table 1.2: Biodeterioration rate of concrete in sewage systems

\begin{tabular}{lcc}
\hline Location of samples & Biodeterioration rate $(\mathbf{m m} /$ year) & Reference \\
\hline Sewer pipe in treatment plant & $4.3-4.7$ & (Mori et al., 1992) \\
Manhole in treatment plant & $5.7-7.6$ & (Hudon et al., 2011) \\
Urban sewer pipe in Houston & 3.1 & (Davis et al., 1998) \\
Urban sewer pipe in Hamburg & $8-10$ & (Milde et al., 1983) \\
\hline
\end{tabular}

Besides sewer pipes, approximately $40 \%$ of a wastewater system is made up of concrete structures. About $40 \%$ of the damage in concrete pipeline is caused by biodeterioration (Kaempfer and Berndt, 1999). As shown in Fig.1.2, MICC in sewerage system can lead to fragmentation of pipe surface, debonding of concrete, collapse of the physical and mechanical properties of structures. Thus, huge money is being spent on the repair and maintenance of sewerage collection system. For Germany, a cost of approximately 100 billion Euros is estimated for maintenance and repair of private and public sewage systems (Kaempfer and Berndt, 1998). ASCE's report also estimates that the United States will need 390 billion dollars during 
the next 20 years to repair and replace the existing wastewater infrastructure and construct new facilities, including collection systems (Gutiérrez-Padilla et al., 2010).
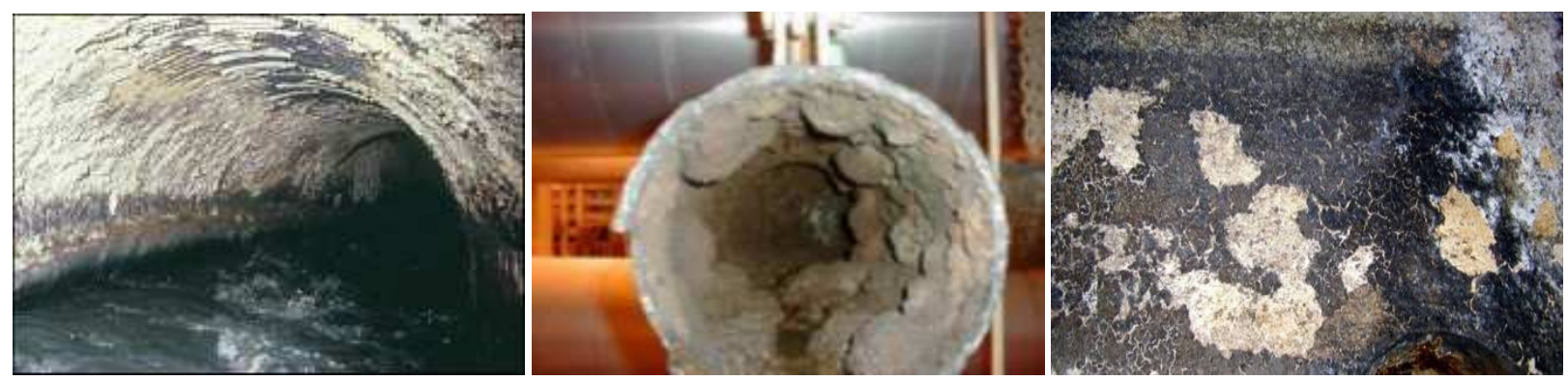

Figure 1.2: Examples of MICC of sewer pipe

Thus, there is great interest in predicting the corrosion rate and the service life of sewer pipes. To simulate the biodeterioration process, it is necessary to understand the mechanisms of biodeterioration of sewer pipe including the bio-activity in biofilm as well as the chemical reactions between concrete and biogenic sulfuric acid.

\subsection{Mechanisms of biodeterioration of sewer pipes}

Because of the alkalinity of concrete and the acidity of environment in sewer pipes, the main cause of biodeterioration of these structures is biogenic sulphuric acid attack (BSA). According to experimental observations, the process of BSA of cementitious materials in sewer pipes can be divided into two parts which are schematically indicated in Fig.1.3.



Figure 1.3: Schematic of biogenic sulphuric acid attack in a sewerage (Herisson et al., 2013)).

A) Hydrogen sulfide $\left(\mathrm{H}_{2} \mathrm{~S}\right)$ formation in wastewater.

Sulfate is commonly present in wastewater. At the bottom of pipe where water is anoxic, sulfate can be converted into hydrogen sulfide $\left(\mathrm{H}_{2} \mathrm{~S}\right)$. This conversion is performed by sulfate-reducing bacteria (SRB), 
which are heterotrophic bacteria found in almost any environmental sample (Barton and Tomei, 1995). SRB can use oxidized sulfur compounds as electron acceptor by following reactions (Wood et al., 2005).

$$
\begin{aligned}
\mathrm{SO}_{4}^{2-}+4 \mathrm{H}_{2} \mathrm{O}+8 \mathrm{e}^{-} \stackrel{\mathrm{SRB}}{\longrightarrow} \mathrm{S}^{2-}+8 \mathrm{OH}^{-} \\
\mathrm{SO}_{4}^{2-}+\text { organic } \quad \text { substance } \stackrel{\mathrm{SRB}}{\longrightarrow} \mathrm{S}^{2-}+\mathrm{H}_{2} \mathrm{O}+\mathrm{CO}_{2} \\
\mathrm{HS}^{-} \rightleftharpoons \mathrm{H}^{+}+\mathrm{S}^{2-} \\
\mathrm{H}_{2} \mathrm{~S}_{(a q)} \rightleftharpoons \mathrm{H}^{+}+\mathrm{HS}^{-}
\end{aligned}
$$

In normal sewage, $p \mathrm{H}$ is between 5 and 6 . Since $\mathrm{H}_{2} \mathrm{~S}$ is poorly soluble $(\mathrm{p} K=7.05)$, it is degassed in the arcal part of the pipe following Henry's Law.

B) Biodeterioration of concrete in the arcal part of pipes. The deterioration process can be described by the following three steps as shown in Fig.1.4.

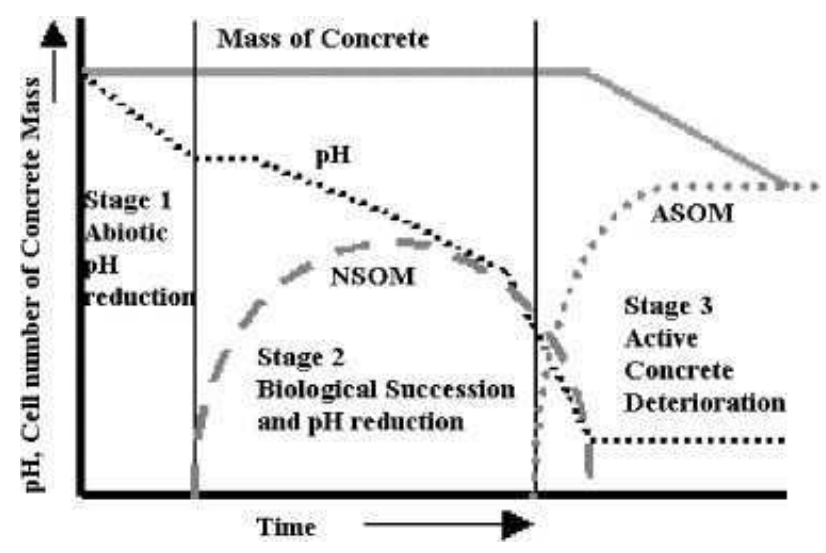

Figure 1.4: Theoretical changes in the biological and physical properties of concrete with time during the deterioration process, (Islander et al., 1991).

Step 1: Abiotic $p \mathrm{H}$ reduction of concrete.

The $p \mathrm{H}$ of fresh concrete (11-13) is too high for the sulfur-oxidizing bacteria (SOB) to survive. $\mathrm{CO}_{2}$ and $\mathrm{H}_{2} \mathrm{~S}$ are both present in the arcal part of sewer pipes. Experiment observations (Ismail et al., 1993; Joseph et al., 2012) revealed that such acidic gases can reduce the $p \mathrm{H}$ of concrete surface to less than 9 as described in reaction (1.2a) and (1.2b).

$$
\begin{aligned}
\mathrm{CH}+\mathrm{CO}_{2} & \rightleftharpoons \mathrm{CaCO}_{3}+\mathrm{H}_{2} \mathrm{O} \\
\mathrm{CH}+2 \mathrm{H}_{2} \mathrm{~S} & \rightleftharpoons \mathrm{Ca}(\mathrm{HS})_{2}+2 \mathrm{H}_{2} \mathrm{O}
\end{aligned}
$$


Step 2: Microbial colonization and production of $\mathrm{H}_{2} \mathrm{SO}_{4}$ by biofilm.

Once the $p \mathrm{H}$ of the surface of concrete is reduced to 9, with sufficient nutrients (element sulfur), moisture and oxygen, some species of SOB like Thiobacillus sp. can grow on the concrete surface and form biofilms (Rigdon and Beardsley, 1956; Mori et al., 1992). Although the bio-activity in biofilms is not fully understood, it is generally believed that firstly $\mathrm{H}_{2} \mathrm{~S}$ in biofilms is oxidized to element sulfur by metal catalyst (Zivica and Bajza, 2002) or neutrophilic sulfur-oxidizing microorganisms (NSOM) (Bielefeldt et al., 2009) as follows:

$$
\mathrm{H}_{2} \mathrm{~S}+\frac{1}{2} \mathrm{O}_{2} \underset{\text { metalcatalyst }}{\stackrel{\text { NSOM }}{\longrightarrow}} \mathrm{S}^{0}+\mathrm{H}_{2} \mathrm{O}
$$

Not only element sulfur, but also a few sulfuric acid is produced by NSOM. After $p \mathrm{H}$ has decreased to 4-5, acidophilic sulfur-oxidizing microorganisms (ASOM) like T.thiooxidans can use element sulfur to produce large amounts of sulfuric acid as reaction (1.4), which makes the main contribution to the biodeterioration of sewer pipe (Parker, 1945, 1951). With sufficient sulfur source, the $p \mathrm{H}$ of concrete surface can be reduced to 1 by T.thiooxidans (Mori et al., 1992). That is destructive to concrete.

$$
\mathrm{S}^{0}+\mathrm{H}_{2} \mathrm{O}+\frac{3}{2} \mathrm{O}_{2} \stackrel{\mathrm{ASOM}}{\longrightarrow} \mathrm{SO}_{4}^{2-}+2 \mathrm{H}^{+}
$$

Step 3: Chemical reaction between $\mathrm{H}_{2} \mathrm{SO}_{4}$ and concrete.

During the final step of the biodeterioration process, the biogenic sulfuric acid penetrates into concrete and reacts with portlandite $(\mathrm{CH})^{1}$ and calcium silicate hydrate $(\mathrm{C}-\mathrm{S}-\mathrm{H})$ which are the main Portland cement hydrates. This step is characterized by the production of a corroded layer on the surface of concrete. XRD patterns (Davis et al., 1998; Kawai et al., 2005), and other experimental observations (as Fig.1.5) of corroded layer revealed that corrosion products consist of gypsum $\left(\mathrm{CaSO}_{4} \cdot 2 \mathrm{H} 2 \mathrm{O}\right.$, noted as $\left.\mathrm{C} \overline{\mathrm{S}} \mathrm{H} 2\right)$, silica gel $\left(\mathrm{SiO}_{2}\right.$, noted as $\left.\mathrm{S}\right)$ and moisture. Thus, during deterioration $\mathrm{CH}$ and $\mathrm{C}-\mathrm{S}-\mathrm{H}$ are dissolved, while gypsum and silica gel precipitate as reactions (1.5a) and (1.5b).

$$
\begin{aligned}
\mathrm{CH}+\mathrm{H}_{2} \mathrm{SO}_{4} & \rightleftharpoons \mathrm{C} \overline{\mathrm{S}} \mathrm{H} 2 \\
\mathrm{C}_{x} \mathrm{~S}_{y} \mathrm{H}_{z}+x \mathrm{H}_{2} \mathrm{SO}_{4} & \rightleftharpoons x \mathrm{C} \overline{\mathrm{S}} \mathrm{H} 2+y \mathrm{SiO}_{2}+(z-x) \mathrm{H}_{2} \mathrm{O}
\end{aligned}
$$

Since gypsum is swelling while it has barely no strength, $\mathrm{H}_{2} \mathrm{SO}_{4}$ attack could reduce the performance of concrete, and even lead to the eventual structural failure of the facility.

1. Cement chemistry notation is used throughout the paper: $\mathrm{C}=\mathrm{CaO}, \mathrm{S}=\mathrm{SiO}_{2}, \mathrm{H}=\mathrm{H}_{2} \mathrm{O}, \overline{\mathrm{S}}=\mathrm{SO}_{3}$. 




(a)

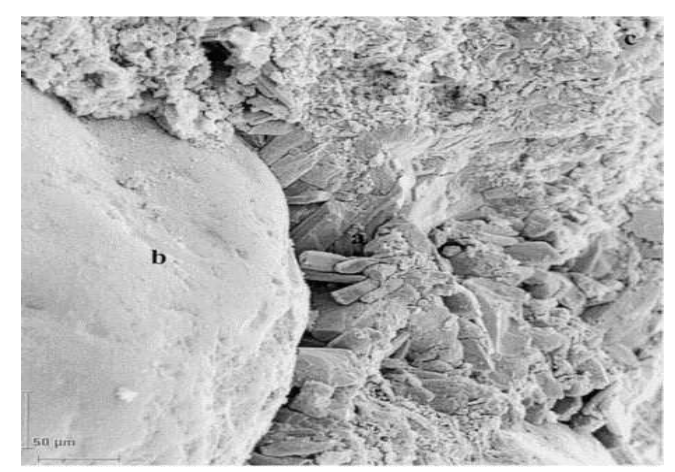

(b)

Figure 1.5: (a) Concrete coupons exposed to the sewer atmosphere (Okabe et al., 2007); (b) Scanning electron microphotograph of gypsum crystals in the cement paste (Monteny et al., 2000).

\subsection{Recent research works about biodeterioration of cementitious materials}

To understand and to fight against such a biodeterioration process involving a succession of bacterial in biofilms and resulting in a change of concrete properties, many research works were conducted focusing on different aspects. Not only experimental (in-situ/laboratory) researches, but also modeling researches were conducted.

Samples of biofilm taken from sewer or cultured in laboratory, were monitored. The type, number and succession of SOB were measured by conventional culture-dependent techniques (Harrison Jr, 1984), conventional cultivation techniques and molecular tools (Vincke et al., 2001), and gene-cloning analysis (Herisson et al., 2013). The understanding of microbial community structures of SOB and their activities in biofilm has been improving continuously. It is generally believed that five species of Thiobacillus play important roles: T.thioparus, T.novellus, T.neapolitanus, T.intermedius and T.thiooxidans. The characteristics of these SOB are listed in Table 1.3. Since (Kempner, 1966) has found that the activity of T.thiooxidans is slowed at $p \mathrm{H}$ below 0.9 , it is expected that if sulfur source is sufficient, the $p \mathrm{H}$ of biofilm would be limited around 1 .

Table 1.3: Characteristics of Thiobacillus in biofilm (Islander et al., 1991)

\begin{tabular}{lcc}
\hline Species & $p \mathbf{H}$ range for growth & Products \\
\hline T.thioparus & $4.5-10$ & Sulfur, polythionic acids \\
T.novellus & $5-9.2$ & Sulfur \\
T.neapolitanus & $4-9$ & Polythionic acids, sulfuric acid \\
T.intermedius & $1.7-9$ & Polythionic acids, sulfuric acid \\
T.thiooxidans & $0.5-4$ & Sulfur, sulfuric acid \\
\hline
\end{tabular}

To figure out the components of corrosion products, in the in-situ experiments carried out by Davis 
(Davis et al., 1998), samples of concrete were drilled from the Houston's sewage collection pipes. Several tests revealed that the average compressive strength of the concrete undergoing degradation was reduced by more than $20 \%$. The mineralogical analysis found that the corrosion layer of concrete contained large amounts of gypsum, which is expansive and has no strength, and yet ettringite was not present. Such observations were reported by other experimental laboratory researches (Ehrich et al., 1999; Vincke et al., 2000) as well. It was explained that ettringite forms at $p \mathrm{H}$ ranging from 12.5 to 12 , while it starts decomposing



To study the consequences of gypsum precipitation, $\mathrm{C}_{3} \mathrm{~S}$ mortar and paste specimens were exposed to $\mathrm{Na}_{2} \mathrm{SO}_{4}$ solution (Tian and Cohen, 2000). The physical properties and chemical composition of samples after corrosion were tested. The experimental results suggest that during gypsum formation tensile stresses may play a role in expansion and subsequent cracking.

To study the behaviour of cementitious materials corroded by $\mathrm{H}_{2} \mathrm{SO}_{4}$, researchers (Jahani et al., 2001; Bassuoni and Nehdi, 2007; Kawai et al., 2005) conducted experiments to simulate the chemical corrosion process of concrete in contact with $\mathrm{H}_{2} \mathrm{SO}_{4}$ solution.

In the experiment of (Kawai et al., 2005) ordinary Portland cement cubes were immersed in $\mathrm{H}_{2} \mathrm{SO}_{4}$ solution with $p \mathrm{H}=1$ in order to simulate the chemical corrosion process in sewer pipe. To keep the concentration of $\mathrm{H}_{2} \mathrm{SO}_{4}$ in the solution constant, $\mathrm{H}_{2} \mathrm{SO}_{4}$ was added suitably to the solution, and the solution was statical (Method 1) or circulated with a pump and flew into the tank (Method 2). In method 2, the specimens were subjected to the shearing force of the solution flow. Therefore the reaction products were driven out by the flow of solution without precipitating on the sample surfaces. During the tests, the corrosion depth was measured. In Method 1, a layer of reaction products was observed on the surface of the mortar samples. The XRD patterns of this degraded layer showed that reaction products of sulfuric acid attack are mainly gypsum and silica gel. With method 2, few products can be seen on the sample surfaces since most of the reaction products were swept by the solution flow. The solution flow washed the new surface of reaction, thus the samples immersed with Method 2 degraded much deeper and faster than those with the Method 1. In Kawai's experiment, an immersion test using a solution with low $\mathrm{H}_{2} \mathrm{SO}_{4}$ concentration solution $(p \mathrm{H}=2)$ was carried out as well. It turned out that corrosion process is very sensitive to $\mathrm{H}_{2} \mathrm{SO}_{4}$ concentration: all of the samples immersed in $\mathrm{H}_{2} \mathrm{SO}_{4}$ solution of $p \mathrm{H}=2$ were almost uncorroded either with Method 1 or Method 2.

In order to investigate the effect of biofilm on the bio-degradation process, some experiments have been done to simulate the biodeterioration process of sewer pipe (De Muynck et al., 2009; Gutiérrez-Padilla et al., 2010; Alexander and Fourie, 2011).

In the experiments conducted by (De Muynck et al., 2009), CEM I cement cylinders were subjected to 
8 cycles of accelerated test. Each cycle consisted in 4 steps: (1) incubation in $\mathrm{H}_{2} \mathrm{~S}$ (200 ppm) for 2 days; (2) submersion in 1.5 L of mixed cultures of SOB obtained from a sewer pipe biofilm (medium composition: $10 \mathrm{~g} / \mathrm{L}$ element sulfur, $3 \mathrm{~g} / \mathrm{L} \mathrm{KH}_{2} \mathrm{PO}_{4}, 0.1 \mathrm{~g} / \mathrm{L} \mathrm{NH}_{4} \mathrm{Cl}, 0.1 \mathrm{~g} / \mathrm{L} \mathrm{MgCl} \cdot \mathrm{H}_{2} \mathrm{O}$ ) for 10 days; (3) submersion in distilled water for 2 days; (4) drying at room temperature for 1 day. In the second and third steps, the SOB suspension and water were rotated. The degradation products were removed at the third step. The last step could eliminate SOB remaining on the concrete surface. During the second step, the $p \mathrm{H}$ in the SOB suspensions was measured frequently. In the experiment, as a result of the conversion of element sulfur to sulfuric acid by cultures of SOB, a decrease of $p \mathrm{H}$ was observed 3-4 days after submersion. The $p \mathrm{H}$ continued to decrease to around 1 after 10 days of testing.

In the works of (Gutiérrez-Padilla et al., 2010), the biodeterioration of low and high quality concrete under conditions simulating sewer pipes were compared with laboratory experiments. With the same conditions of $\mathrm{H}_{2} \mathrm{~S}$ and bacteria, the concrete with low W/C (0.33) showed higher resistance to biogenic sulfuric acid attack than the concrete with high W/C (0.42). While in another research work (Ehrich, 1998), the weight loss of mortar samples with different $\mathrm{W} / \mathrm{C}$ ratio of $0.35,0.40,0.45,0.5,0.55$ were measured respectively. The results of that experiment stated that the lowest weight losses were determined on samples with a $\mathrm{W} / \mathrm{C}$ ratio of 0.5 and the resistance of mortars was reduced for both high and low $\mathrm{W} / \mathrm{C}$ ratios. This can be explained as the concrete with a high $\mathrm{W} / \mathrm{C}$ has larger and more pores. The pores play the role of a capacity to absorb expansion caused by the production of gypsum (Kawai et al., 2005). The influence of $\mathrm{W} / \mathrm{C}$ of concrete is discussed in Chapter 6 of this thesis as well.

It is necessary to improve the understanding of the specific influence of environmental variables, such as $\mathrm{H}_{2} \mathrm{~S}$ level, temperature, and relative humidity. (Joseph et al., 2012) examined changes in the surface chemistry of concrete during the early stages of corrosion by exposing concrete coupons to thirty-six independent conditions in well-controlled laboratory chambers that simulated conditions typically found in various sewer environments across Australia. The results indicated that the role of $\mathrm{CO}_{2}$ on initial surface $p \mathrm{H}$ reduction is insignificant as compared to the influence of $\mathrm{H}_{2} \mathrm{~S}$. Within the first 12 months, a decrease in surface $p \mathrm{H}$ by 4.8 units was observed for coupons exposed to $30^{\circ} \mathrm{C}$ and $50 \mathrm{ppm} \mathrm{H}_{2} \mathrm{~S}$ while significantly lower $p \mathrm{H}$ reductions of 3.5 and 1.8 units were detected for coupons exposed to $25^{\circ} \mathrm{C}$ and $18^{\circ} \mathrm{C}$ respectively, and $50 \mathrm{ppm} \mathrm{H}_{2} \mathrm{~S}$. However, (Ismail et al., 1993) claimed that under quite high $\mathrm{CO}_{2}$ gas concentration, bio-corrosion rate would decrease due to formation of much calcite which could reduce the porosity of pipe surface. The role of carbonation layer is investigated in Chapter 6.

Furthermore, some works have been done to improve the biodeterioration resistance of sewer pipes. A set of in-situ experiments to determine the biochemical parameters influencing the behaviors of ordinary Portland cement (OPC) and calcium aluminate cement (CAC) materials was conducted by (Herisson 
et al., 2013). It has been found that CAC materials perform better than those with OPC, and the biomass that develops on the surface of the former is different and less abundant. The good behavior of CAC materials could be due to their high aluminum content, which could inhibit the growth of microorganisms. (De Muynck et al., 2009) investigated the effectiveness of different admixtures, and surface treatments towards biogenic sulfuric acid corrosion of concrete. The best protective method is epoxy coating, while the strongest degradation was observed for the cementitious coating. The addition of hydrous silicate failed to improve the resistance performance.

In addition to experiments, some researches have been done on modeling. Existing models mainly focus on the biochemical process or the chemical process separately.

For the chemical corrosion process, which directly results in the degradation of materials, (Jahani et al., 2001) proposed a diffusion-reaction based model with a moving boundary to predict the corrosion rate. (Chalupeckỳ et al., 2012) consider a two-scale reaction diffusion system containing one microscopic scale (pore scale) and one macroscopic scale (sewer pipe scale). In both of them, only dissolution of portlandite or calcite was considered. As another important solid component in cementitious materials, decalcification of C-S-H gel was absent. In addition, only the front of acid neutralization and gypsum formation were captured by the modeling.

In such a biogenic degradation process, the concentration of sulfuric acid is not constant or given, but imposed by the biochemical reactions in the SOB community. Thus the modeling of biochemistry reactions taking place in the biofilm is needed as well.

To simulate the biochemical process, models such as "Wastewater Aerobic/anaerobic Transformations in Sewer (WATS)" model (Jensen et al., 2009) and sulfide oxidation modelling (Nielsen et al., 2005) were developed. Based on experiment data, kinetics and stoichiometry of sulfur oxidation by biofilm were investigated, while rate equations and stoichiometry constants were proposed. These simulations indicated that oxidation of accumulated slowly degradable element sulfur could cause a steady production of sulfuric acid, even when hydrogen sulfide is not present. However, the relationship between $p \mathrm{H}$ and $\mathrm{H}_{2} \mathrm{SO}_{4}$ production in biofilm is not found in previous research results.

Few modeling focus on the coupling of biochemical process and chemical corrosion process. With HYTEC, (De Windt and Devillers, 2010) simulate a bioleaching test applied to ordinary Portland cement pastes during 15 months. By coupling of (bio)chemical alteration, porosity and diffusion evolutions, the long term performance of cementitious materials subjected to biodeterioration was assessed. Various species were considered in this work, and yet their diffusion coefficient were uniform. Moreover, a continuous approach of C-S-H dissolution is absent in this modeling and the effect of swelling of gypsum on the microstructure of concrete was not considered either. 


\subsection{Research objectives}

Apparently, there is a lot of financial implications to change or reinforce the networks of pipes. Thus, it is necessary to develop a tool to address questions such as the service life of current pipes, or the durability of the new pipes made of other materials or protected by new methods. Since the present modeling are still imperfect, the objectives of this $\mathrm{PhD}$ study are to improve the understanding of the biogenic acid attack of concrete, and propose a method to predict the performance of concrete servicing in such extreme conditions. The biochemistry process in biofilm and the chemical process in cement paste are investigated and coupled with each other. A reactive transport model to predict the behaviour of cement paste in contact with $\mathrm{H}_{2} \mathrm{SO}_{4}$ solution or sulfur-oxidizing bacteria community is expected to be proposed. Therefore, the main parts of biogenical acid attack should be included in this model as follows:

1. Production variation of $\mathrm{H}_{2} \mathrm{SO}_{4}$ with $p \mathrm{H}$ in biofilm.

2. Dissolution and precipitation reactions of portlandite $(\mathrm{CH})$ and gypsum $(\mathrm{CS} H 2)$.

3. Continuous variation (decrease) of the $\mathrm{Ca} / \mathrm{Si}$ ratio during the dissolution reaction of $\mathrm{C}-\mathrm{S}-\mathrm{H}$.

4. Diffusion of different species and thermodynamical equilibrium.

5. Changes of porosity and damage of materials induced by the production of gypsum.

6. Coupling of $\mathrm{H}_{2} \mathrm{SO}_{4}$ production, transport equations and chemical reactions.

7. Effect of pore clogging resulting from carbonation on the biodeterioration rate during early time.

The model is implemented within a finite-volume code Bil (http://perso.lcpc.fr/dangla.patrick/bil). Coupled with the $\mathrm{H}_{2} \mathrm{SO}_{4}$ degradation modeling of concrete, the change of $p \mathrm{H}$ in biofilm and the composition of cement paste are expected to be calculated during the biodeterioration process. Furthermore, the degradation rate of concrete submitted to biogenic acid attack will be predicted. Simulations results of a set of chemical exposure tests (external sulfuric acid solution attack, conducted by (Kawai et al., 2005; Vincke et al., 1999)) and accelerated micro-biological tests conducted by (De Muynck et al., 2009) are presented and compared with experimental results. Due to the lack of bacteria activity data (such as the relationship between $\mathrm{H}_{2} \mathrm{SO}_{4}$ production rate of various bacteria and $p \mathrm{H}$ in biofilm), this study only simulates the biological process of biofilm by fitting on the measured experimental data.

\subsection{Outline of thesis}

Since this thesis focuses on the biodeterioration of cementitious materials induced by an existing SOB community in an environment containing $\mathrm{H}_{2} \mathrm{~S}$ gas, the incubation process of bacterial and the production process of $\mathrm{H}_{2} \mathrm{~S}$ in wastewater is not addressed. In Chapter 2, some details of the mechanisms of $\mathrm{H}_{2} \mathrm{SO}_{4}$ production in the biofilm are presented. The influence of environmental factors, such as temperature, 
concentration of $\mathrm{H}_{2} \mathrm{~S}$ in atmosphere, $p \mathrm{H}$ are considered. The modeling of $\mathrm{H}_{2} \mathrm{SO}_{4}$ production in biofilm is described in detail. The inhibition/promotion of $\mathrm{H}_{2} \mathrm{SO}_{4}$ production by the change of $p \mathrm{H}$ during the microbial metabolic process is introduced in the modeling. The $\mathrm{H}_{2} \mathrm{SO}_{4}$ production modeling is verified at the end of Chapter 2 .

After $\mathrm{H}_{2} \mathrm{SO}_{4}$ production is described, the deterioration of cementitious materials subjected to $\mathrm{H}_{2} \mathrm{SO}_{4}$ attack is taken into account. Chapter 3 introduces the major chemical reactions taking place during $\mathrm{H}_{2} \mathrm{SO}_{4}$ attack. Since the cementitious minerals are expected to completely dissolve, dissolution and precipitation reactions of $\mathrm{CH}$ and gypsum $(\mathrm{C} \overline{\mathrm{SH}} 2)$ are described by mass action laws and threshold of ion activity products. An innovative approach for the C-S-H is applied to explain the continuous decalcification and facilitate the numerical modeling.

Resulting from the precipitation-dissolution of the various minerals, the porosity of cementitious materials will change. Thus the diffusion of species would be influenced as well. Regarding the swelling of gypsum, Chapter 4 introduces a simplified damage model of the microstructure of cement paste. Based on the balance of volume, the microstructure evolution is accounted for by adjusting the porosity using different methods during different damage stages.

Chapter 5 introduces the reactive transport modeling and numerical procedures. To both of the biofilm and cement paste, the field equations are presented. Different diffusion coefficients are employed for various ions, yet only transport of aqueous species are considered. Following the introduction of principle of the finite volume method, coupling of the bio-chemistry process in biofilm and chemistry process in cement paste is illustrated.

In Chapter 6, several calculations are carried out to simulate experimental works from (Kawai et al., 2005; Vincke et al., 1999) where cement samples are directly immersed in $\mathrm{H}_{2} \mathrm{SO}_{4}$ solution with constant or cyclical variable concentrations. Simulation results of different conditions, e.g., statical solution and circulated solution, are compared with experiment observations. The sensitivity of $\mathrm{H}_{2} \mathrm{SO}_{4}$ concentration, initial porosity, and damage criterion are analyzed. The effect of initial porosity and carbonation layer in early time are investigated as well.

After the modeling of chemical deterioration has been verified, in Chapter 7 the experiment conducted by (De Muynck et al., 2009) is simulated to predict the bio-degradation process. The simulation results of $p \mathrm{H}$ evolution in biofilm and the change of cement paste properties are compared with experimental results. Effect of environmental factors (such as $\mathrm{H}_{2} \mathrm{~S}$ content) is discussed and a long term prediction is presented. Finally, the conclusion of this thesis and some future improvements are presented in Chapter 8. 


\section{Chapter 2}

\section{The production of $\mathrm{H}_{2} \mathrm{SO}_{4}$ by micro-organisms in biofilm}

\subsection{Introduction}

For biogenic sulfuric acid attack, $\mathrm{H}_{2} \mathrm{SO}_{4}$ production is a fundamental process, which provides the strong corrosion medium causing the deterioration of concrete. Thus, the first step to simulate the bio-deterioration of sewer pipes is the calculation of the production of $\mathrm{H}_{2} \mathrm{SO}_{4}$ in biofilms. As the major issue associated with the corrosion of concrete, the relationship between $\mathrm{H}_{2} \mathrm{~S}$ gas level and the corrosion rate of the sewer pipes is still a major research question (Apgar et al., 2007). As introduced in Chapter $1, \mathrm{H}_{2} \mathrm{~S}$ absorption by biofilms and concrete surface provides the sulfur source of $\mathrm{H}_{2} \mathrm{SO}_{4}$ production, whose rate is controlled by the oxidation of $\mathrm{H}_{2} \mathrm{~S}$ in biofilms (see Fig.2.1). In this paper, the generation and emission of $\mathrm{H}_{2} \mathrm{~S}$ from wastewater is not considered and the level of $\mathrm{H}_{2} \mathrm{~S}$ gas in sewer pipes is constant.

For sulfur-oxidizing bacteria (SOB), the initial $p \mathrm{H}$ of ordinary Portland cement concrete is too high to grow. (Mori et al., 1992; Rigdon and Beardsley, 1956) proposed that the microbial activity on the concrete surface is initiated at $p \mathrm{H}$ around 9 and thereafter, a succession of microbial communities develops, which can utilize sulfide and/or its oxidized forms, such as element sulfur (Joseph et al., 2012). The abiotic $p \mathrm{H}$ reduction of concrete surface results to an initial lag period before the start of active corrosion phase (Islander et al., 1991).

Therefore, the primary stage is the reduction of $p \mathrm{H}$ at the concrete surface, where $p \mathrm{H}$ decreases from about 12.5 to 9 by chemical acid reactions of $\mathrm{CO}_{2}$ and $\mathrm{H}_{2} \mathrm{~S}$ with concrete. The experimental researches of (Joseph et al., 2012) suggested that $\mathrm{H}_{2} \mathrm{~S}$ gas is the major factor for the surface $p \mathrm{H}$ reduction in sewers during early stages of exposure rather than carbonation. 




Figure 2.1: Schematic outline of the $\mathrm{H}_{2} \mathrm{~S}$ production process. (Jensen et al., 2008)

According to literatures (Harrison Jr, 1984; Islander et al., 1991; Herisson et al., 2013), different types of SOB are involved in $\mathrm{H}_{2} \mathrm{~S}$ oxidation process which is influenced by various factors, such as the amount of sulfur source, $p \mathrm{H}$ and temperature. For such a complex process, there is a lack of fundamental understanding of the quantitative relationship among these factors. However, the kinetics and stoichiometry of sulfide oxidation by biofilms can be described by Wastewater aerobic/anaerobic Transformations in Sewer (WATS) model (Jensen et al., 2009; Nielsen et al., 2005) regardless the influence of $p \mathrm{H}$. Yet, to our knowledge, no attempt has been made to model both the neutralization of concrete surface and $\mathrm{H}_{2} \mathrm{SO}_{4}$ production in biofilms.

This chapter studies first with the absorption of $\mathrm{H}_{2} \mathrm{~S}$ gas by concrete surface. Then, the chemical reactions of $\mathrm{H}_{2} \mathrm{~S}$ and concrete with constant temperature and humidity is described. For the specific biofilms, we model the production of $\mathrm{H}_{2} \mathrm{SO}_{4}$ by fitting the measurements of the $p \mathrm{H}$ evolution in biofilms. For a more general condition with varying $\mathrm{H}_{2} \mathrm{~S}$ content, we follow the WATS model to calculate the production rate based on $\mathrm{H}_{2} \mathrm{~S}$ content.

\subsection{Neutralization of pipe surface during early stage}

\subsubsection{Absorption of $\mathrm{H}_{2} \mathrm{~S}$}

Since only aqueous $\mathrm{H}_{2} \mathrm{~S}$ can react with concrete or be oxidized by SOB, the transferring of $\mathrm{H}_{2} \mathrm{~S}$ from sewer gas to concrete surface or biofilms is a crucial step. $\mathrm{H}_{2} \mathrm{~S}$ can be absorbed into pore solution of concrete and biofilms from gas phase in sewer pipes. The adsorption of $\mathrm{H}_{2} \mathrm{~S}$ governs the time of surface neutralization and the production of $\mathrm{H}_{2} \mathrm{SO}_{4}$. (EPA, 1974) suggested that all released $\mathrm{H}_{2} \mathrm{~S}$ from wastewater 
is immediately absorbed by concrete surface, resulting in zero $\mathrm{H}_{2} \mathrm{~S}$ in the gas phase. However, experimental results of (Vollertsen et al., 2008; Nielsen et al., 2008) revealed that transferring of $\mathrm{H}_{2} \mathrm{~S}$ from the gas phase to the concrete surface is not an instantaneous process and absorption kinetics should be taken into account. By experiments with pilot-scale sewer reactors as in Fig. 2.2, (Vollertsen et al., 2008) found that the absorption rate $\left(F_{\mathrm{H}_{2} \mathrm{~S}}\right)$ could be described as a power function in the gas phase $\mathrm{H}_{2} \mathrm{~S}$ concentration $\left(p_{\mathrm{H}_{2} \mathrm{~S}}\right)$.



Figure 2.2: Schematics of the pilot scale reactors. (Vollertsen et al., 2008)

Furthermore, (Nielsen et al., 2012) presented an empirical relationship between the Reynolds (Re) number of the gas flow and the absorption rate. For the sake of simplicity, the effect of gas flow regime is ignored in this paper. The $n^{\text {th }}$ order kinetics of $\mathrm{H}_{2} \mathrm{~S}$ absorption of concrete surface and biofilms is described as follows:

$$
F_{\mathrm{H}_{2} \mathrm{~S}}=k_{\mathrm{abs}} p_{\mathrm{H}_{2} \mathrm{~S}}^{n}
$$

where, $p_{\mathrm{H}_{2} \mathrm{~S}}$ is the content of $\mathrm{H}_{2} \mathrm{~S}$ gas (ppm). $k_{\text {abs }}$ is the surface specific $\mathrm{H}_{2} \mathrm{~S}$ absorption rate constant, which is reported to vary between $6.25 \times 10^{-8}$ and $3.12 \times 10^{-7} \mathrm{~mol} \mathrm{~S} \mathrm{~m}^{-2} \mathrm{~s}^{-1}\left(\mathrm{ppm} \mathrm{H}_{2} \mathrm{~S}\right)^{-n}$ depending on temperature (Vollertsen et al., 2008). The reaction order $n$ is correlated with $k_{\text {abs }}$, with $n$ approximately 0.5 for low $k_{\text {abs }}$ and 0.8 for high $k_{\text {abs }}$. Since temperature is constant at $25^{\circ} \mathrm{C}$ in this paper, $k_{\text {abs }}$ is determined as $2 \times 10^{-7} \mathrm{~mol} \mathrm{~S} \mathrm{~m}^{-2} \mathrm{~s}^{-1}\left(\mathrm{ppm} \mathrm{H}_{2} \mathrm{~S}\right)^{-n}$ and $n=0.75$. Then the absorption rate of $\mathrm{H}_{2} \mathrm{~S}$ versus content of $\mathrm{H}_{2} \mathrm{~S}$ in gas phase is plotted in Fig. 2.3.

\subsubsection{Chemical reaction between aqueous $\mathrm{H}_{2} \mathrm{~S}$ and concrete}

Although the acidification of aqueous hydrogen sulfide is much weaker than that of $\mathrm{H}_{2} \mathrm{SO}_{4}$, it dissociates in the same manner as sulfuric acid and releases $\mathrm{H}^{+}$as follows (Tsonopoulos et al., 1976; Su et al., 1997):

$$
\begin{aligned}
& \mathrm{H}_{2} \mathrm{~S} \rightleftharpoons \mathrm{HS}^{-}+\mathrm{H}^{+} \quad K_{\mathrm{H}_{2} \mathrm{~S}}=8.9 \times 10^{-8} \\
& \mathrm{HS}^{-} \rightleftharpoons \mathrm{S}^{2-}+\mathrm{H}^{+} \quad K_{\mathrm{HS}^{-}}=1.2 \times 10^{-13}
\end{aligned}
$$






Figure 2.3: $\mathrm{H}_{2} \mathrm{~S}$ absorption rate at different $\mathrm{H}_{2} \mathrm{~S}$ gas content.

where the equilibrium constant is at $298 \mathrm{~K}$ which keeps constant. Thus calcium hydroxide could be dissolved and calcium sulfide forms when $\mathrm{H}_{2} \mathrm{~S}$ is absorbed by concrete surface. These global reactions can be understood by combining three basic dissociation reactions Eq.(2.4)-Eq.(2.6), which involve the minerals and the aqueous species in pore solution.

$$
\begin{aligned}
\mathrm{CH} & \rightleftharpoons \mathrm{Ca}^{2+}+2 \mathrm{OH}^{-} \\
\mathrm{C}_{x} \mathrm{~S}_{y} \mathrm{H}_{z} & \rightleftharpoons x \mathrm{Ca}^{2+}+2 x \mathrm{OH}^{-}+y \mathrm{SiO}_{2}^{0}+(z-x) \mathrm{H}_{2} \mathrm{O} \\
\mathrm{CaS} & \rightleftharpoons \mathrm{Ca}^{2+}+\mathrm{S}^{2-}
\end{aligned}
$$

Furthermore, CaS precipitation is not stable in acidic solution. When there is enough $\mathrm{H}_{2} \mathrm{~S}$, calcium hydrogen sulfide, which is soluble, would be produced as follows (Idriss et al., 2001):

$$
\mathrm{CaS}+\mathrm{H}_{2} \mathrm{~S} \rightleftharpoons \mathrm{Ca}(\mathrm{HS})_{2}
$$

The equilibrium condition of these dissociation reactions are depended on the concentration of $\mathrm{H}_{2} \mathrm{~S}$. The dissolution of $\mathrm{CH}$ and the decalcification of C-S-H are the same as those with $\mathrm{H}_{2} \mathrm{SO}_{4}$ attack, which are detailed in Chapter 3. Taking the equilibrium between $\mathrm{CH}$ and $\mathrm{CaS}$ for instance, we have

$$
\frac{Q_{\mathrm{CaS}}}{K_{\mathrm{CaS}}}=\frac{Q_{\mathrm{CH}}}{K_{\mathrm{CH}}} \frac{\rho_{\mathrm{H}_{2} \mathrm{~S}}}{\rho_{\mathrm{H}_{2} \mathrm{~S}}^{\mathrm{CH}}}
$$


where, $K$ and $Q$ are the equilibrium constant and ion activity product of $\mathrm{CH}$ and $\mathrm{CaS}$ respectively. $K_{\mathrm{CH}}$ $=6.5 \times 10^{-6}$ and $K_{\mathrm{CaS}}=7.9 \times 10^{-7} \cdot \rho_{\mathrm{H}_{2} \mathrm{~S}}^{\mathrm{CH}}$ is the value of $\rho_{\mathrm{H}_{2} \mathrm{~S}}$ defined by the coexistence of $\mathrm{CH}, \mathrm{CaS}$ and aqueous phase. It can be calculated by a given function of the solubility constants of other species as Eq.(2.9).

$$
\rho_{\mathrm{H}_{2} \mathrm{~S}}^{\mathrm{CH}}=\frac{K_{\mathrm{H}_{2} \mathrm{O}}^{2} K_{\mathrm{CaS}}}{K_{\mathrm{H}_{2} \mathrm{~S}} K_{\mathrm{HS}^{-}} K_{\mathrm{CH}}}
$$

With the help of the constants mentioned above, $\rho_{\mathrm{H}_{2} \mathrm{~S}}^{\mathrm{CH}} \approx 8.90 \times 10^{-10} \mathrm{~mol} / \mathrm{L}$. Hence, CaS would not precipitate when $\rho_{\mathrm{H}_{2} \mathrm{~S}}<\rho_{\mathrm{H}_{2} \mathrm{~S}}^{\mathrm{CH}}$, while dissolution of $\mathrm{CH}$ takes place when $\rho_{\mathrm{H}_{2} \mathrm{~S}}>\rho_{\mathrm{H}_{2} \mathrm{~S}}^{\mathrm{CH}}$.

In the model, the $\mathrm{CH}$ dissolution process is governed by a simple kinetic law which is assumed to be governed only by the difference of chemical potentials of $\mathrm{H}_{2} \mathrm{~S}$ between the current state $\left(\mu_{\mathrm{H}_{2} \mathrm{~S}(\mathrm{current})}\right)$ and the equilibrium state $\left(\mu_{\mathrm{H}_{2} \mathrm{~S}(\mathrm{eq})}\right)$. Details of the kinetic and decalcification of C-S-H is demonstrated in Chapter 3, as well as an example of $\mathrm{H}_{2} \mathrm{~S}$ attack.

\subsection{3 $p \mathrm{H}$ reduction of concrete surface}

With the absorption of $\mathrm{H}_{2} \mathrm{~S}$ in gas phase and the chemical reaction of $\mathrm{H}_{2} \mathrm{~S}$ with concrete mentioned above, the $p \mathrm{H}$ reduction of concrete surface can be calculated.

(Roberts et al., 2002) experimentally reproduced a reduction of $p \mathrm{H}$ in pore water by exposing fresh concrete samples to hydrogen sulfide gas concentrations of 50, 100, and $250 \mathrm{ppm}$. The pH reduction is given by

$$
4.4 \times 10^{-5} p \mathrm{H} \text { unit/day/ppm of } \mathrm{H}_{2} \mathrm{~S} \cdot p_{\mathrm{H}_{2} \mathrm{~S}}+0.021 p \mathrm{H} \text { unit/day }
$$

(Okabe et al., 2007) measured the $p \mathrm{H}$ reduction rate for mortar coupons placed in sewers with $\mathrm{H}_{2} \mathrm{~S}$ of $30 \mathrm{ppm} \pm 20 \mathrm{ppm}$ for a period of 56 days. The result was $0.06 \mathrm{pH}$ unit/day, which is approximately 3 times of the result of Eq.(2.10). However, the experiment was in-situ, where microbial processes could be involved in.

Thus, we simulate a set of experiments conducted and clearly described by (Joseph et al., 2012). In the experiments, concrete coupons were exposed to different $\mathrm{H}_{2} \mathrm{~S}$ gas level $(4.5,7.5,15.8,26.5,48.9$ ppm) in well-controlled laboratory chambers, where the temperature is $25^{\circ} \mathrm{C}$, for 1 year. The surface $p \mathrm{H}$ of the samples before exposure was $10.6 \pm 0.3$, which is near the $p \mathrm{H}$ of a carbonated sample, indicating that the samples were carbonated during the manufacturing and/or transportion. Therefore, in our simulation calcite is considered as the solid phase of samples instead of portlandite. After exposure of 1 year, the simulation results and experimental results of the decrease of $p \mathrm{H}$ in surface are compared in Fig.2.4. 




Figure 2.4: Decrease in surface $p \mathrm{H}\left(p \mathrm{H}_{(\text {initial })}-p \mathrm{H}_{(\text {exposed })}\right)$ after 1 year.

For Fig.2.4, our modeling can predict the $p \mathrm{H}$ reduction of pipe surface during initial time fairly well. The solid compositions evolution during $\mathrm{H}_{2} \mathrm{~S}$ attack will be illustrated by a simulation example of representative elementary volume (REV) in Chapter 3.

\subsection{The production of $\mathrm{H}_{2} \mathrm{SO}_{4}$ by sulfur-oxidizing bacteria}

When the environment of pipe surface is suitable for the microbial succession, biofilms starts to form. With the supply of hydrogen sulfide, these microorganisms can produce biogenic sulfuric acid which attacks the concrete. Some experimental results (Herisson et al., 2013) indicated that the oxidation rate of $\mathrm{H}_{2} \mathrm{~S}$ is controlled by the activity and the amount of $\mathrm{SOB}$, which is determined by the $p \mathrm{H}$ in $\mathrm{SOB}$ media, $\mathrm{H}_{2} \mathrm{~S}$ content in sewer, temperature and the concentration of $\mathrm{Al}^{3+}$ in the biofilm. However, the quantitative effect of these factors on $\mathrm{H}_{2} \mathrm{SO}_{4}$ production is not clear for now.

Different types of SOB are responsible to different deterioration degree of concrete as listed in Table 1.2. They are active in different ranges of $p \mathrm{H}$ (see Fig.2.5) and produce $\mathrm{H}_{2} \mathrm{SO}_{4}$ with different rates. Two general categories of SOB can be differentiated based on their optimal $p H$ for growth (Hudon et al., 2011): Neutrophilic Sulfur-Oxidizing Bacteria (NSOB), which develops at pH near neutral and are found at the beginning of biodeterioration; Acidophilic Sulfur-Oxidizing Bacteria (ASOB), which prefer acidic media. Normally, the $\mathrm{H}_{2} \mathrm{SO}_{4}$ production rate of NSOB is much slower than that of ASOB. Thus, NSOB only can cause slight deterioration.

Most types of SOB are not able to oxidize sulfide directly. Fig.2.6 summarizes the possible oxidation 
pathways in biofilms, which can occur concurrently (Hudon et al., 2011; Islander et al., 1991).

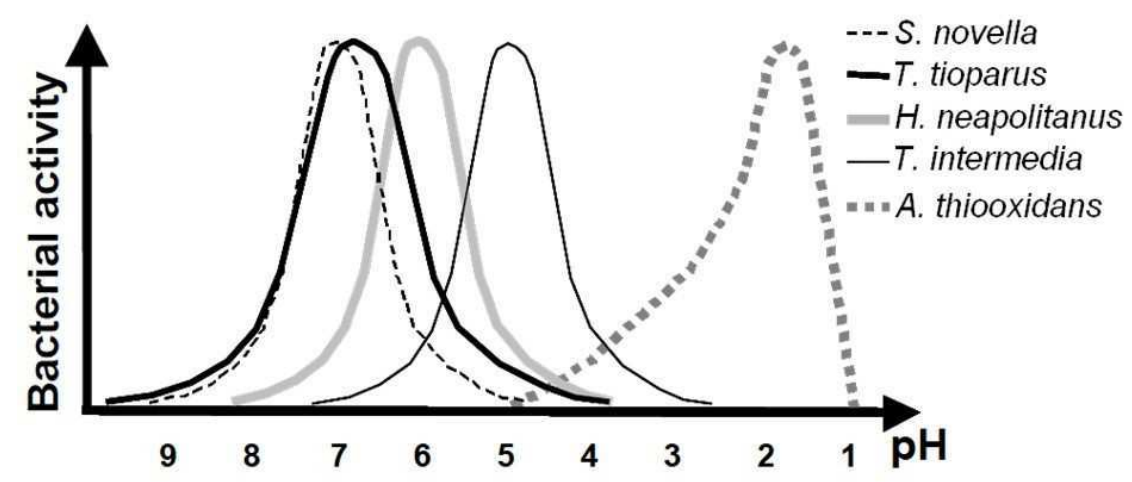

Figure 2.5: Succession of SOB in different $p \mathrm{H}$ range (Herisson, 2012)



Figure 2.6: Sulfur oxidation states typical in sewer. (Biologic pathway is shown with full lines; chemical, with dashed lines.) (Islander et al., 1991)

For heavily deteriorated sewer pipes, Acidithiobacillus thiooxidans bacteria is normally detected in biofilms (Okabe et al., 2007; Cho and Mori, 1995; Nica et al., 2000). Most of the present laboratory researches are carried out based on the presence of Acidithiobacillus thiooxidans, whose oxidation process is modeled by WATS model (Hvitved-Jacobsen et al., 1998; Nielsen et al., 2005; Jensen et al., 2009). (Jensen et al., 2009) showed that in the corrosion products of concrete, $\mathrm{H}_{2} \mathrm{~S}$ is rapidly oxidized to a mix of elemental sulfur and $\mathrm{H}_{2} \mathrm{SO}_{4}$. They observed two fractions of elemental sulfur: a readily degradable fraction which was oxidized almost as fast as the oxidation of $\mathrm{H}_{2} \mathrm{~S}$, and a slowly degradable fraction which was oxidized much slower. 
If $\mathrm{H}_{2} \mathrm{~S}$ is continuously present during the early time, slowly degradable elemental sulfur would accumulate and cause a delayed formation of sulfuric acid even if $\mathrm{H}_{2} \mathrm{~S}$ is no longer absorbed later.

There is still a lack of the quantitative understanding of the $\mathrm{H}_{2} \mathrm{SO}_{4}$ production, the succession of different types of SOB and the influence of environmental factors. Among them, $\mathrm{Al}^{3+}$ ion has bacteriostatic effect Herisson (2012). Since we deal with the Portland cement based sewer pipes in this paper, $\mathrm{Al}^{3+}$ is neglected. For sewer pipes degraded heavily, the temperature is normally $25^{\circ} \mathrm{C}$ to $30^{\circ} \mathrm{C}$ (Yongsiri et al., 2004). Therefore, in our modeling the temperature and humidity is constant. In this paper, dealing with different experimental conditions, $\mathrm{H}_{2} \mathrm{SO}_{4}$ production controlled by $p \mathrm{H}$ and $\mathrm{H}_{2} \mathrm{~S}$ content are considered respectively.

\subsubsection{Modeling of $\mathrm{H}_{2} \mathrm{SO}_{4}$ production with given $p \mathrm{H}$ evolution in biofilm}

In some experimental researches, the $p \mathrm{H}$ evolution in biofilms or SOB suspension with time were measured (Vincke et al., 1999; De Muynck et al., 2009). Thus, it is possible to model the $\mathrm{H}_{2} \mathrm{SO}_{4}$ production process by fitting the $p \mathrm{H}$ evolution.

In the sewer pipes degraded heavily, the content of $\mathrm{H}_{2} \mathrm{~S}$ gas in sewer could reach $400 \mathrm{ppm}$ (Mori et al., 1992). In some laboratory researches focusing on the deterioration process, element sulfur content in SOB culture was quite high and the concrete samples were incubated by $\mathrm{H}_{2} \mathrm{~S}$ gas or biological sulfur solution (Vincke et al., 1999; De Muynck et al., 2009). For such conditions, we assume that element S source is always enough for SOB. Thus, in this simplified modeling the production of $\mathrm{H}_{2} \mathrm{SO}_{4}$ is controlled by $p \mathrm{H}$ which itself is determined by the amount of $\mathrm{H}_{2} \mathrm{SO}_{4}$. According to the experimental observations (Ehrich et al., 1999), the activity of SOB increases until $p \mathrm{H}$ is reduced to a critical value, depending on the type of bacteria species. When $p \mathrm{H}$ is lower than the critical value, $\mathrm{H}_{2} \mathrm{SO}_{4}$ production rate drops rapidly. In this paper, the production process of sulfuric acid in SOB media is divided into two step:

NSOB dominating step: When $p \mathrm{H}$ in $\mathrm{SOB}$ media is higher than the value of $p \mathrm{H}_{\mathrm{NSOB}}, \mathrm{H}_{2} \mathrm{SO}_{4}$ is produced by NSOB, whose production rate is quite low.

ASOB dominating step: When $p \mathrm{H}$ in $\mathrm{SOB}$ media is lower than the value of $p \mathrm{H}_{\mathrm{NSOMB}}, \mathrm{H}_{2} \mathrm{SO}_{4}$ is produced by ASOB rather than NSOB which can't survive in acidic environment. The production rate of $\mathrm{H}_{2} \mathrm{SO}_{4}$ keeps increasing until $p \mathrm{H}$ reaches $p \mathrm{H}_{\mathrm{ASOB}}$, where the metabolic activity of ASOB reaches peak value. With $p \mathrm{H}$ below $p \mathrm{H}_{\mathrm{ASOB}}$, the metabolic activity of ASOB is limited. Consequently, $\mathrm{H}_{2} \mathrm{SO}_{4}$ production rate is reduced.

Such process can be expressed by a function of $p \mathrm{H}$ as follows: 


$$
\begin{aligned}
& \mathrm{NSOB}: \quad R_{\mathrm{H}_{2} \mathrm{SO}_{4}-\mathrm{NSOB}}=\frac{\alpha_{0}}{\sigma \sqrt{2 \pi}} e^{-\frac{\left(p \mathrm{H}_{\mathrm{NSOB}}-p \mathrm{H}_{\mathrm{ASOB}}\right)^{2}}{2 \sigma}} 10^{p \mathrm{H}_{\mathrm{NSOB}}-p \mathrm{H}} \\
& \mathrm{ASOB}: \quad R_{\mathrm{H}_{2} \mathrm{SO}_{4}-\mathrm{ASOB}}=\frac{\alpha_{0}}{\sigma \sqrt{2 \pi}} e^{-\frac{\left(p \mathrm{H}-p \mathrm{H}_{\mathrm{ASOB}}\right)^{2}}{2 \sigma}}
\end{aligned}
$$

where, $\alpha_{0}$ and $\sigma$ are constants depending on SOB numbers and activity. In this paper, the value of $\alpha_{0}$ and $\sigma$ are determined by fitting experimental measurement. To simulate the experiments conducted by (De Muynck et al., 2009), which will be introduced in Chapter 7, we set $p \mathrm{H}_{\mathrm{NSOB}}=2.5$ and $p \mathrm{H}_{\mathrm{ASOB}}=1.5$. When $p \mathrm{H}>p \mathrm{H}_{\mathrm{ASOB}}, \alpha_{0}=8 \times 10^{-7} \mathrm{~mol} / \mathrm{L} \cdot \mathrm{s}, \sigma=0.48$; while $\alpha_{0}=4 \times 10^{-7} \mathrm{~mol} / \mathrm{L} \cdot \mathrm{s}, \sigma=0.24$, when $p \mathrm{H}<$ $p \mathrm{H}_{\mathrm{ASOB}}$.

The relationship between $\mathrm{H}_{2} \mathrm{SO}_{4}$ production rate and $\mathrm{pH}$ is plotted in Fig.2.7, which indicates that few $\mathrm{H}_{2} \mathrm{SO}_{4}$ is produced until $p \mathrm{H}$ decreases to 4 . With further decreasing of $p \mathrm{H}$, lots of $\mathrm{H}_{2} \mathrm{SO}_{4}$ is produced by ASOB and the production rate rises sharply. Once $p \mathrm{H}$ was decreased below 1.5, the $\mathrm{H}_{2} \mathrm{~S}$ production rate drops rapidly. The verification of this relationship could be found in Chapter 7 , where the experiment of (De Muynck et al., 2009) is simulated and analysed.



Figure 2.7: $\mathrm{H}_{2} \mathrm{SO}_{4}$ production rate and $p \mathrm{H}$

\subsubsection{Modeling of $\mathrm{H}_{2} \mathrm{SO}_{4}$ production with given $\mathrm{H}_{2} \mathrm{~S}$ content in gas phase}

Under in-situ conditions, $\mathrm{H}_{2} \mathrm{~S}$ is not always at high level and it is easier to monitor $\mathrm{H}_{2} \mathrm{~S}$ level in gas phase than $p \mathrm{H}$ in SOB media. According to experimental researches (Jensen et al., 2008; Vollertsen et al., 
2008, 2011) where $\mathrm{H}_{2} \mathrm{~S}$ content was measured, content of $\mathrm{H}_{2} \mathrm{~S}$ is an important factor which can control the corrosion rate of sewer pipes.

With given $\mathrm{H}_{2} \mathrm{~S}$ content in gas phase, WATS model is employed to calculate the $\mathrm{H}_{2} \mathrm{SO}_{4}$ production by considering the kinetics of $\mathrm{H}_{2} \mathrm{~S}$ oxidation. WATS concept was originally presented in 1998 and continuously developed (Hvitved-Jacobsen et al., 1998; Vollertsen et al., 2008; Jensen, 2008). Based on experimental observation, WATS model suggests that hydrogen sulfide is initially oxidized to readily biodegradable elemental sulfur (Sf). This elemental sulfur is partly aged to slowly biodegradable elemental sulfur (Ss) and partly oxidized to sulfuric acid. The slowly biodegradable elemental sulfur is also oxidized to sulfuric acid, only at a lower rate (see Fig.2.8).



Figure 2.8: The pathway used to describe the hydrogen sulfide and oxygen consumption pattern observed in the experiments on biotic hydrogen sulfide oxidation (Jensen, 2008).

However, biofilms are considered as containing a general mixture of SOB of $A$. thiooxidans, i.e., the difference between NSOB and ASOB is neglected in WATS model. Thus, the effect of $p \mathrm{H}_{\text {on }} \mathrm{H}_{2} \mathrm{SO}_{4}$ production is neglected. The oxidation rate is governed by the concentration of biomass, the amount of aqueous $\mathrm{H}_{2} \mathrm{~S}$ and $\mathrm{O}_{2}$. In WATS model, the oxidation rate of $\mathrm{H}_{2} \mathrm{~S}$ to $\mathrm{Sf}\left(R_{\mathrm{H}_{2} \mathrm{~S}, \text { wATS }}\right)$, Sf to $\mathrm{H}_{2} \mathrm{SO}$ $\left(R_{\mathrm{Sf}, \mathrm{WATS}}\right)$, Ss to $\mathrm{H}_{2} \mathrm{SO}_{4}\left(R_{\mathrm{Ss}, \mathrm{WATS}}\right)$ and the ageing rate of $\mathrm{Sf}$ to $\mathrm{Ss}\left(R_{\mathrm{Sf}-\mathrm{Ss}, \mathrm{WATS}}\right)$ are described by Eq.(2.13) - Eq.(2.16).

$$
\begin{aligned}
R_{\mathrm{H}_{2} \mathrm{~S}, \mathrm{WATS}} & =k_{\mathrm{oxi}-\mathrm{H}_{2} \mathrm{~S}} X_{\mathrm{SOB}} \frac{\rho_{\mathrm{H}_{2} \mathrm{~S}}}{\rho_{\mathrm{H}_{2} \mathrm{~S}}+H_{\mathrm{H}_{2} \mathrm{~S}}} \frac{\rho_{\mathrm{O}_{2}}}{\rho_{\mathrm{O}_{2}}+H_{\mathrm{O}_{2}, \mathrm{H}_{2} \mathrm{~S}}} \\
R_{\mathrm{Sf}, \mathrm{WATS}} & =k_{\mathrm{oxi}-\mathrm{Sf}} X_{\mathrm{SOB}} \frac{\rho_{\mathrm{Sf}}}{\rho_{\mathrm{Sf}}+H_{\mathrm{Sf}}} \frac{\rho_{\mathrm{O}_{2}}}{\rho_{\mathrm{O}_{2}}+H_{\mathrm{O}_{2}, \mathrm{Sf}}} \\
R_{\mathrm{Ss}, \mathrm{WATS}} & =k_{\mathrm{oxi}-\mathrm{Sf}} X_{\mathrm{SOB}} \rho_{\mathrm{O}_{2}}^{c} \\
R_{\mathrm{Sf}-\mathrm{Ss}, \mathrm{WATS}} & =k_{\mathrm{Sf}-\mathrm{Ss}} \rho_{\mathrm{Sf}}
\end{aligned}
$$

where all parameters are defined in Table 2.1. Obviously, the production rate of $\mathrm{H}_{2} \mathrm{SO}_{4}$ equals to the sum of oxidation rate of Sf and Ss.

In our modeling, the oxidation pathways are simplified as $\mathrm{H}_{2} \mathrm{~S}$ - element $\mathrm{S}-\mathrm{H}_{2} \mathrm{SO}_{4}$, i.e., the slowly biodegradable elemental sulfur is neglected. Oxygen is always sufficient for the sake of simplification. Thus, 
Table 2.1: Definition of the parameters in WATS model

\begin{tabular}{lll}
\hline Parameter & Definition & Unit \\
\hline$R_{\mathrm{H}_{2} \mathrm{~S}, \mathrm{WATS}} / R_{\mathrm{Sf}, \text { WATS }} / R_{\mathrm{Ss}, \text { WATS }}$ & Oxidation rate of $\mathrm{H}_{2} \mathrm{~S} / \mathrm{Sf} / \mathrm{Ss}$ in SOB media & $\mathrm{mol} \mathrm{m}^{-3} \mathrm{~s}^{-1}$ \\
$k_{\mathrm{Oxi}-\mathrm{H}_{2} \mathrm{~S}} / k_{\mathrm{oxi}-\mathrm{Sf}} / k_{\mathrm{oxi}-\mathrm{Ss}}$ & Rate constant for biotic oxidation of $\mathrm{H}_{2} \mathrm{~S} / \mathrm{Sf} / \mathrm{Ss}$ & $\mathrm{s}^{-1}$ \\
$R_{\mathrm{Sf}-\mathrm{Ss}, \text { WATS }}$ & Ageing rate of Sf & $\mathrm{mol} \mathrm{m}^{-3} \mathrm{~s}^{-1}$ \\
$k_{\mathrm{Sf}-\mathrm{Ss}}$ & Rate constant for the ageing rate of Sf & $\mathrm{s}^{-1}$ \\
$X_{\mathrm{SOB}}$ & SOB concentration in SOB media & $\mathrm{g} \mathrm{m}^{-3}$ \\
$\rho_{\mathrm{H}_{2} \mathrm{~S}} / \rho_{\mathrm{Sf}} / \rho_{\mathrm{Ss}} / \rho_{\mathrm{O}_{2}}$ & Concentration of aqueous $\mathrm{H}_{2} \mathrm{~S} / \mathrm{Sf} / \mathrm{Ss} \mathrm{in} \mathrm{SOB} \mathrm{media}$ & $\mathrm{mol} \mathrm{m}^{-3}$ \\
$H_{\mathrm{H}_{2} \mathrm{~S}} / H_{\mathrm{Sf}}$ & Half saturation constant for aqueous $\mathrm{H}_{2} \mathrm{~S} / \mathrm{Sf}$ & $\mathrm{mol} \mathrm{m}^{-3}$ \\
$H_{\mathrm{O}_{2}, \mathrm{H}_{2} \mathrm{~S}} / H_{\mathrm{O}_{2}, \mathrm{Sf}}$ & Half saturation constant for $\mathrm{O}_{2}$ in the oxidation of $\mathrm{H}_{2} \mathrm{~S} / \mathrm{Sf}$ & $\mathrm{mol} \mathrm{m}^{-3}$ \\
$c$ & Reaction order for the oxidation of $\mathrm{Ss}$ & $/$ \\
\hline
\end{tabular}

the oxidation rate of $\mathrm{H}_{2} \mathrm{~S}$ and $\mathrm{S}$ are expressed as follows:

$$
\begin{aligned}
\mathrm{H}_{2} \mathrm{~S} \text { oxidation : } & R_{\mathrm{H}_{2} \mathrm{~S}-\mathrm{oxi}}=k_{\mathrm{H}_{2} \mathrm{~S}-\mathrm{oxi}} X_{\mathrm{SOB}} \frac{\rho_{\mathrm{H}_{2} \mathrm{~S}}}{\rho_{\mathrm{H}_{2} \mathrm{~S}}+H_{\mathrm{H}_{2} \mathrm{~S}}} \\
\text { S oxidation: } & R_{\mathrm{S}-\mathrm{oxi}}=k_{\mathrm{S}-\mathrm{oxi}} X_{\mathrm{SOB}} \frac{\rho_{\mathrm{S}}}{\rho_{\mathrm{S}}+H_{\mathrm{S}}}
\end{aligned}
$$

To simulate the corrosion of sewer pipes in the experiments of (Jensen et al., 2008; Vollertsen et al., 2011), which is detailed in Chapter 7, the value of parameters in Eq.(2.17) and Eq.(2.18) are listed in Table 2.2. The oxidation rate of $\mathrm{H}_{2} \mathrm{~S}$ and $\mathrm{S}$ are plotted in Fig.2.9.

Table 2.2: Value of the parameters in $\mathrm{H}_{2} \mathrm{SO}_{4}$ production model. (Jensen et al., 2008)

\begin{tabular}{ll}
\hline Parameter & Value \\
\hline$k_{\mathrm{H}_{2} \mathrm{~S}-\text { oxi }}$ & $1.1 \times 10^{-8} \mathrm{~s}^{-1}$ \\
$k_{\mathrm{S}-\text { oxi }}$ & $4.1 \times 10^{-9} \mathrm{~s}^{-1}$ \\
$X_{\mathrm{SOB}}$ & $1941 \mathrm{~g} / \mathrm{L}$ \\
$H_{\mathrm{H}_{2} \mathrm{~S}}$ & $8.0 \times 10^{-4} \mathrm{~mol} / \mathrm{L}$ \\
$H_{\mathrm{S}}$ & $2.8 \times 10^{-5} \mathrm{~mol} / \mathrm{L}$ \\
\hline
\end{tabular}

Combining the absorption of $\mathrm{H}_{2} \mathrm{~S}$ and the oxidation of $\mathrm{H}_{2} \mathrm{~S}$, the $p \mathrm{H}$ evolution in pure SOB media with different $\mathrm{H}_{2} \mathrm{~S}$ level are plotted in Fig.2.10, which indicates that $\mathrm{H}_{2} \mathrm{SO}_{4}$ is produced faster with high $\mathrm{H}_{2} \mathrm{~S}$ level than that with low $\mathrm{H}_{2} \mathrm{~S}$ level. 


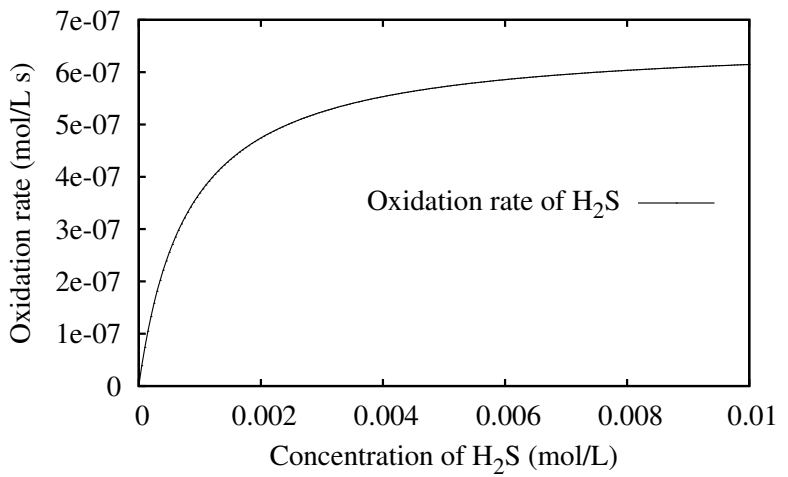

(a)

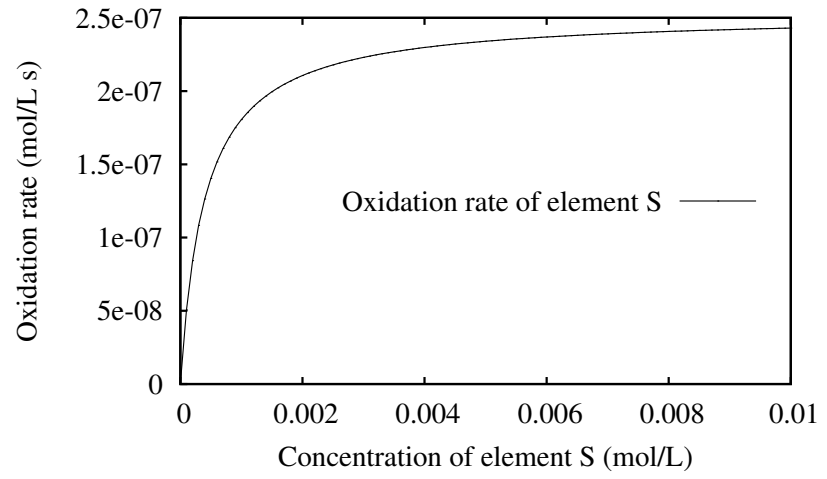

(b)

Figure 2.9: Oxidation rate : (a) $\mathrm{H}_{2} \mathrm{~S}$; (b) element $\mathrm{S}$.



Figure 2.10: The $p \mathrm{H}$ evolution in pure SOB media with different $\mathrm{H}_{2} \mathrm{~S}$ level. 


\subsection{Conclusions}

This chapter starts with the introduction of the mechanisms of $\mathrm{H}_{2} \mathrm{SO}_{4}$ production by sulfide-oxidizing bacteria (SOB). Before SOB starts to grow on the surface of sewer pipes, the concrete is neutralized by $\mathrm{H}_{2} \mathrm{~S}$ in gas phase. The absorption of $\mathrm{H}_{2} \mathrm{~S}$ gas in pore solution of concrete or SOB media is considered. The chemical reaction of $\mathrm{H}_{2} \mathrm{~S}$ and concrete is introduced into our modeling as well. Thus, the surface neutralization process of biodeterioration of sewer pipes can be simulated. The lag time of the start of active corrosion can be predicted.

By simulating the experiment conducted by (Joseph et al., 2012), the $p \mathrm{H}$ reduction of carbonated concrete surface with different $\mathrm{H}_{2} \mathrm{~S}$ gas level are calculated. The simulation results coincide with experimental observations.

Dealing with different given conditions, the production rate of $\mathrm{H}_{2} \mathrm{SO}_{4}$ by SOB media is calculated by fitting measured $p \mathrm{H}$ evolution or WATS model. With given $p \mathrm{H}$ evolution in SOB media with sufficient sulfur source, $\mathrm{H}_{2} \mathrm{SO}_{4}$ production rate is governed by a function of $p \mathrm{H}$. The succession and activity of ASOB and NSOB with different $p \mathrm{H}$ range are considered. With given $\mathrm{H}_{2} \mathrm{~S}$ level in gas phase, $\mathrm{SOB}$ is simplified as a general type of bacteria with constant biomass and activity. $\mathrm{H}_{2} \mathrm{SO}_{4}$ is produced by oxidation of element sulfur which accumulates in SOB media by oxidation of aqueous $\mathrm{H}_{2} \mathrm{~S}$. By WAST model, the oxidation rate of $\mathrm{H}_{2} \mathrm{~S}$ and that of element $\mathrm{S}$ are governed by functions of concentration of $\mathrm{H}_{2} \mathrm{~S}$ and $\mathrm{S}$ respectively.

When the values of parameters in both methods are determined, the production rate of $\mathrm{H}_{2} \mathrm{SO}_{4}$ during the experiments of (De Muynck et al., 2009) and (Vollertsen et al., 2011) are plotted. When biogenic sulfuric acid is produced, it starts to corrode concrete. The chemical reaction of $\mathrm{H}_{2} \mathrm{SO}_{4}$ attack of concrete will be introduced in the next chapter. 


\section{Chapter 3}

\section{Degradation of cementitious}

\section{materials subjected to sulfuric acid}

\section{attack}

\subsection{Introduction}

Once $\mathrm{H}_{2} \mathrm{SO}_{4}$ is produced by biofilms, cement-based materials are directly in contact with $\mathrm{H}_{2} \mathrm{SO}_{4}$ which diffuses into the pores of concrete. As a strong acid, a series of homogeneous chemical reactions between $\mathrm{H}_{2} \mathrm{SO}_{4}$ and concrete could result in the reduction of the concrete alkalinity and the dissolution of the calcium hydroxide. In pore solution of concrete, the ionization of $\mathrm{H}_{2} \mathrm{SO}_{4}$ is influenced by other ions. Unlike pure solution, it is difficult to determine the concentration of $\mathrm{H}_{2} \mathrm{SO}_{4}$ by $p \mathrm{H}$ in pore solution. Thus, the

concentration of unionized molecules of $\mathrm{H}_{2} \mathrm{SO}_{4}$ (noted as $\rho_{\mathrm{H}_{2} \mathrm{SO}_{4}}^{0}$ ) is employed to indicate the amount of $\mathrm{H}_{2} \mathrm{SO}_{4}$ in pore solution of equilibrium state in this study. When $\rho_{\mathrm{H}_{2} \mathrm{SO}_{4}}^{0}$ is high enough $\left(\geq 3.9 \times 10^{-32}\right.$ $\mathrm{mol} / \mathrm{L}$ at $298 \mathrm{~K}$, i.e., $p \mathrm{H} \leq 12.4)$, portlandite $\left(\mathrm{Ca}(\mathrm{OH})_{2}\right.$, noted as $\mathrm{CH}$ in this study) will start to dissolve. As the concentration of $\mathrm{H}_{2} \mathrm{SO}_{4}$ getting higher, decalcification process of calcium silicate hydrate $\left(x \mathrm{CaO} \cdot y \mathrm{SiO}_{2}\right.$. $z \mathrm{H}_{2} \mathrm{O}$, noted as C-S-H) will take place.

The sulfuric acid corrosion product is a layer of white precipitate that accumulates on the concrete surface. This corroded layer consists of a combination of sand particles, unreacted cement particles and calcium sulfate mineral. By electron microscopy, (Bock and Sand, 1986) identified the main part of the corrosion products as gypsum $\left(\mathrm{CaSO}_{4} \cdot 2 \mathrm{H}_{2} \mathrm{O}\right.$, noted as $\mathrm{CS} H 2$ in this paper) with no structural strength. Some publications (Mori et al., 1992; Redner et al., 1994) claimed that the ample supply of sulfate and 
the intrusion of the acid may result in the formation of ettringite $\left(3 \mathrm{CaO} \cdot \mathrm{Al}_{2} \mathrm{O}_{3} \cdot 3 \mathrm{CaSO}_{4} \cdot 32 \mathrm{H}_{2} \mathrm{O}\right)$ which is expansive. However, in other experimental observations (Ehrich et al., 1999; Vincke et al., 2000) ettringite was not present. According to the investigations conducted by (Gabrisova et al., 1991; Allahverdi and Skvára, 2000), ettringite starts to form at $p \mathrm{H}$ ranging from 12.5 to 12 . When $p \mathrm{H}$ decreases below 10.7, ettringite starts to decompose into gypsum. Since normally $p \mathrm{H}$ in biofilms is less than 3 , ettringite exists temporarily and occasionally appears in the corrosion products during the biodeterioration of sewer pipes. Therefore, in this paper only the precipitation of gypsum is considered during the sulfuric acid attack process.

Not much modeling researches about the sulfuric acid attack of cementitious materials were reported for now. Based on a moving-boundary system, (Böhm et al., 1998) firstly proposed a modeling of corrosion of sewer pipes. In this modelling, the chemical reactions are simplified to the dissolution of calcite $\left(\mathrm{CaCO}_{3}\right)$. Such simplification was still employed in recent research (Fatima and Muntean, 2012). Dissolution of portlandite and C-S-H gel were mentioned in the modeling research of (Beddoe and Dorner, 2005). However, the quantities of portlandite and C-S-H gel were given by the total calcium content rather than taken into account individually. In addition, the equilibrium between solid phases was not considered.

In the modeling of biogenic acid attack based on HYTEC, (De Windt and Devillers, 2010) studied the thermodynamic equilibrium of the chemical reactions. The dissolution of portlandite and C-S-H gel were described separately. However, a discrete approach of C-S-H dissolution was used by considering three end members with $\mathrm{Ca} / \mathrm{Si}$ ratio of $1.8,1.1$ and 0.8 .

In this chapter, the approach of chemical reactions between $\mathrm{H}_{2} \mathrm{SO}_{4}$ and cement-based materials are detailed. Chemical reactions taking place in aqueous phase and solid phases are profiled in the first section. The effects of the chemical activity are disregarded as a first approximation (the activity coefficient is assumed to be one throughout the paper). The dissolution of $\mathrm{CH}$ and $\mathrm{C}-\mathrm{S}-\mathrm{H}$, and the precipitation are thereafter described in the next two sections. A general approach to describe the C-S-H dissolution is employed. The proposed approach provides a method to characterize the continuous decalcification of the C-S-H during $\mathrm{H}_{2} \mathrm{SO}_{4}$ attack and facilitates the numerical modeling. With the help of chemical equilibrium between portlandite and calcium sulfide $(\mathrm{CaS})$ introduced in Chapter 2, an example of $\mathrm{H}_{2} \mathrm{~S}$ attack is conducted on representative elementary volume (REV). The evolution of $p \mathrm{H}$ and solid composition during $\mathrm{H}_{2} \mathrm{SO}_{4}$ attack are illustrated via a $\mathrm{REV}$ example as well.

\subsection{Chemical reactions in pore solution}

For Portland cementitious materials, portlandite and calcium silicate hydrates are the solid components which react with sulfuric acid to form gypsum ( $\mathrm{CS} H 2)$. These global reactions can be understood by com- 
bining three basic dissociation reactions Eq.(3.1)-(3.3), which involve the minerals and the aqueous species in pore solution. The equilibrium condition of these dissociation reactions depends on the concentration of $\mathrm{H}_{2} \mathrm{SO}_{4}$.

$$
\begin{aligned}
\mathrm{CH} & \rightleftharpoons \mathrm{Ca}^{2+}+2 \mathrm{OH}^{-} \\
\mathrm{CS} \mathrm{H} 2 & \rightleftharpoons \mathrm{Ca}^{2+}+\mathrm{SO}_{4}^{2-}+2 \mathrm{H}_{2} \mathrm{O} \\
\mathrm{C}_{x} \mathrm{~S}_{y} \mathrm{H}_{z} & \rightleftharpoons x \mathrm{Ca}^{2+}+2 x \mathrm{OH}^{-}+y \mathrm{SiO}_{2}^{0}+(z-x) \mathrm{H}_{2} \mathrm{O}
\end{aligned}
$$

Therefore the ingress of $\mathrm{H}_{2} \mathrm{SO}_{4}$ solution will cause a series of homogeneous chemical reactions gathered in the Table 3.1, where the equilibrium constant are given at 298K. Throughout this paper, two points should be noticed: 1) We use a superscript 0 in the chemical formula of any species (e.g. in $\left.\mathrm{SiO}_{2}^{0}\right)$ as a convention to denote the dissolved form of this species; 2) We assume infinite dilution approximation for aqueous species. Thus the activity of each aqueous species is equal to the molar concentration expressed in

\begin{tabular}{|c|c|c|c|}
\hline \multicolumn{3}{|c|}{ Aqueous reactions } & \multirow{2}{*}{$\begin{array}{l}\text { Equilibrium constant }= \\
K_{\mathrm{H}_{2} \mathrm{O}}=1.0 \times 10^{-14}\end{array}$} \\
\hline $\mathrm{H}_{2} \mathrm{O}$ & $\rightleftharpoons$ & $\mathrm{H}^{+}+\mathrm{OH}^{-}$ & \\
\hline $\mathrm{H}_{2} \mathrm{SO}_{4}$ & $\rightleftharpoons$ & $\mathrm{HSO}_{4}^{-}+\mathrm{H}^{+}$ & $K_{\mathrm{H}_{2} \mathrm{SO}_{4}}=1.0 \times 10^{6}$ \\
\hline $\mathrm{HSO}_{4}^{-}$ & $\rightleftharpoons$ & $\mathrm{SO}_{4}^{2-}+\mathrm{H}^{+}$ & $K_{\mathrm{HSO}_{4}^{-}}=1.0 \times 10^{-2}$ \\
\hline $\mathrm{CaOH}^{+}$ & $\rightleftharpoons$ & $\mathrm{Ca}^{2+}+\mathrm{OH}^{-}$ & $K_{\mathrm{CaOH}^{+}}=1.66 \times 10^{1}$ \\
\hline $\mathrm{Ca}^{2+}+\mathrm{SO}_{4}^{2-}$ & $\rightleftharpoons$ & $\mathrm{CaSO}_{4}^{0}$ & $K_{\mathrm{CaSO}_{4}^{0}}=1.4 \times 10^{3}$ \\
\hline $\mathrm{Ca}^{2+}+\mathrm{HSO}_{4}^{-}$ & $\rightleftharpoons$ & $\mathrm{CaHSO}_{4}^{+}$ & $K_{\mathrm{CaHSO}_{4}^{+}}^{4}=1.276 \times 10^{1}$ \\
\hline $\mathrm{Ca}^{2+}+\mathrm{H}_{2} \mathrm{SiO}_{4}^{2-}$ & $\rightleftharpoons$ & $\mathrm{CaH}_{2} \mathrm{SiO}_{4}^{0}$ & $K_{\mathrm{CaH}_{2} \mathrm{SiO}_{4}^{0}}=3.89 \times 10^{4}$ \\
\hline $\mathrm{Ca}^{2+}+\mathrm{H}_{3} \mathrm{SiO}_{4}^{-}$ & $\rightleftharpoons$ & $\mathrm{CaH}_{3} \mathrm{SiO}_{4}^{+}$ & $K_{\mathrm{CaH}_{3} \mathrm{SiO}_{4}^{+}}=1.58 \times 10^{1}$ \\
\hline $\mathrm{SiO}_{2}^{0}+2 \mathrm{H}_{2} \mathrm{O}$ & $\rightleftharpoons$ & $\mathrm{H}_{4} \mathrm{SiO}_{4}^{0}$ & $K_{\mathrm{SiO}_{2}^{0}}=1.94 \times 10^{-3}$ \\
\hline $\mathrm{H}_{4} \mathrm{SiO}_{4}^{0}$ & $\rightleftharpoons$ & $\mathrm{H}_{3} \mathrm{SiO}_{4}^{-}+\mathrm{H}^{+}$ & $K_{\mathrm{H}_{4} \mathrm{SiO}_{4}^{0}}=1.55 \times 10^{-10}$ \\
\hline $\mathrm{H}_{3} \mathrm{SiO}_{4}^{-}$ & $\rightleftharpoons$ & $\mathrm{H}_{2} \mathrm{SiO}_{4}^{2-}+\mathrm{H}^{+}$ & $K_{\mathrm{H}_{3} \mathrm{SiO}_{4}^{-}}=4.68 \times 10^{-14}$ \\
\hline
\end{tabular}
$\mathrm{mol} / \mathrm{L}$, and that of each solid component equals to 1 ( $\mathrm{CH}$ and $\mathrm{CS} H 2)$ except the different poles of C-S-H.

Table 3.1: Chemical reactions taking place in the aqueous solution

* The equilibrium constants are reported by (Galíndez and Molinero, 2010; Stronach and Glasser, 1997; Westall et al., 1976)

In Table 3.1, each ion, $i$, takes a valence number, $z_{i}$, which depends on the charge carried by the ion. Since electroneutrality must be kept in the medium and the solid phase is not charged, the total charge of the aqueous solution is 0 as Eq.3.4.

$$
\sum_{i} z_{i} \rho_{i}=0
$$


where, $\rho_{i}$ represents the concentration of ion $i(\mathrm{~mol} / \mathrm{L})$. From Table 3.1, we can found that the concentration of $\mathrm{H}_{2} \mathrm{SO}_{4}, \mathrm{Ca}^{2+}$ and $\mathrm{H}_{4} \mathrm{SiO}_{4}^{0}$ are key variables. With known value of $\rho_{\mathrm{H}_{2} \mathrm{SO}_{4}}, \rho_{\mathrm{Ca}^{2+}}$ and $\rho_{\mathrm{H}_{4} \mathrm{SiO}_{4}^{0}}, \rho_{\mathrm{H}^{+}}$can be derived via Eq.3.4. Consequently, the concentration of the other species can be calculated from Table 3.1 .

In addition, alkali $\mathrm{K}^{+} / \mathrm{Na}^{+}$are included in the model. For the electroneutrality, the same amount of anion (such as $\mathrm{Cl}^{-}$and $\mathrm{OH}^{-}$) should introduced as well. Since those species are not involved in any chemical reaction in this study, an unified form as $\mathrm{KCl}$ is considered.

\subsection{Dissolution of portlandite}

The stability of the thermodynamical equilibrium of reactions (3.1) and (3.2) can be characterized by a threshold of the ion activity products as follows:

$$
\begin{aligned}
& Q_{\mathrm{CH}}=\rho_{\mathrm{Ca}^{2}} \rho_{\mathrm{OH}^{-}}^{2} \leq K_{\mathrm{CH}} \\
& Q_{\mathrm{C} \overline{\mathrm{S}} \mathrm{H} 2}=\rho_{\mathrm{Ca}^{2+}} \rho_{\mathrm{SO}_{4}^{2-}} \rho_{\mathrm{H}_{2} \mathrm{O}}^{2} \leq K_{\mathrm{C} \overline{\mathrm{S}} 2}
\end{aligned}
$$

where, $K$ and $Q$ are the equilibrium constant and ion activity products of $\mathrm{CH}$ and $\mathrm{C} \overline{\mathrm{S}} \mathrm{H} 2$ respectively. $K_{\mathrm{CH}}=6.5 \times 10^{-6}$ and $K_{\mathrm{CS} H 2}=2.5 \times 10^{-5}$. According to Table $3.1, \rho_{\mathrm{SO}_{4}^{2-}}$ is governed by three chemical equilibriums:

$$
\begin{aligned}
K_{\mathrm{H}_{2} \mathrm{O}} & =\rho_{\mathrm{H}^{+}} \rho_{\mathrm{OH}^{-}} \\
K_{\mathrm{H}_{2} \mathrm{SO}_{4}} & =\frac{\rho_{\mathrm{H}^{+}} \rho_{\mathrm{HSO}_{4}^{-}}}{\rho_{\mathrm{H}_{2} \mathrm{SO}_{4}}} \\
K_{\mathrm{HSO}_{4}^{-}} & =\frac{\rho_{\mathrm{H}^{+}} \rho_{\mathrm{SO}_{4}^{2-}}}{\rho_{\mathrm{HSO}_{4}^{-}}}
\end{aligned}
$$

Combining Eq.(3.7), Eq.(3.8) and Eq.(3.9), $\rho_{\mathrm{SO}_{4}^{2-}}$ can be derived as follows:

$$
\rho_{\mathrm{SO}_{4}^{2-}}=\frac{K_{\mathrm{H}_{2} \mathrm{SO}_{4}} K_{\mathrm{HSO}_{4}^{-}}}{K_{\mathrm{H}_{2} \mathrm{O}}^{2}} \rho_{\mathrm{H}_{2} \mathrm{SO}_{4}} \rho_{\mathrm{OH}^{-}}^{2}
$$

Substituting Eq.(3.10) into Eq.(3.6), the ion activity of gypsum can be expressed by the key variables as Eq.(3.11).

$$
Q_{\mathrm{CS} H 2}=\rho_{\mathrm{Ca}^{2+}} \frac{K_{\mathrm{H}_{2} \mathrm{SO}_{4}} K_{\mathrm{HSO}_{4}^{-}}}{K_{\mathrm{H}_{2} \mathrm{O}}^{2}} \rho_{\mathrm{H}_{2} \mathrm{SO}_{4}} \rho_{\mathrm{OH}^{-}}^{2}
$$

The relationship between the ion activity of portlandite and that of gypsum can be derived from Eq.(3.5) 
and Eq.(3.11) as follows:

$$
Q_{\mathrm{CS} H 2}=Q_{\mathrm{CH}} \frac{K_{\mathrm{H}_{2} \mathrm{SO}_{4}} K_{\mathrm{HSO}_{4}^{-}}}{K_{\mathrm{H}_{2} \mathrm{O}}^{2}} \rho_{\mathrm{H}_{2} \mathrm{SO}_{4}}
$$

Thus, the equilibrium relationship between $\mathrm{CH}$ and $\mathrm{C} \overline{\mathrm{S}} \mathrm{H} 2$ can be written as:

$$
\frac{Q_{\mathrm{C} \overline{\mathrm{S}} 2}}{K_{\mathrm{C} \overline{\mathrm{S}} 2}}=\frac{Q_{\mathrm{CH}}}{K_{\mathrm{CH}}} \frac{\rho_{\mathrm{H}_{2} \mathrm{SO}_{4}}}{\rho_{\mathrm{H}_{2} \mathrm{SO}_{4}}^{\mathrm{CH}}}
$$

where, $\rho_{\mathrm{H}_{2} \mathrm{SO}_{4}}^{\mathrm{CH}}$ is the value of $\rho_{\mathrm{H}_{2} \mathrm{SO}_{4}}$ defined by the coexistence of $\mathrm{CH}, \mathrm{CS} H 2$ and aqueous phase. It can be calculated by a given function of the solubility constants of other species as Eq.(3.14).

$$
\rho_{\mathrm{H}_{2} \mathrm{SO}_{4}}^{\mathrm{CH}}=\frac{K_{\mathrm{H}_{2} \mathrm{O}}^{2} K_{\mathrm{CS} \mathrm{H} 2}}{K_{\mathrm{H}_{2} \mathrm{SO}_{4}} K_{\mathrm{HSO}_{4}^{-}} K_{\mathrm{CH}}}
$$

With the help of the constants listed in Table 3.1, $\rho_{\mathrm{H}_{2} \mathrm{SO}_{4}}^{\mathrm{CH}} \approx 3.90 \times 10^{-32} \mathrm{~mol} / \mathrm{L}$. Hence, CS̄H2 would not precipitate when $\rho_{\mathrm{H}_{2} \mathrm{SO}_{4}}<\rho_{\mathrm{H}_{2} \mathrm{SO}_{4}}^{\mathrm{CH}}$, while dissolution of $\mathrm{CH}$ takes place when $\rho_{\mathrm{H}_{2} \mathrm{SO}_{4}}>\rho_{\mathrm{H}_{2} \mathrm{SO}_{4}}^{\mathrm{CH}}$.

These stability domains are summarized in Fig.3.1. For the fresh ordinary Portland cement paste, $p H$ is approximately 12.4, which means $\rho_{\mathrm{H}_{2} \mathrm{SO}_{4}}<\rho_{\mathrm{H}_{2} \mathrm{SO}_{4}}^{\mathrm{CH}}$. Thus portlandite is stable and no gypsum exists. When $\mathrm{H}_{2} \mathrm{SO}_{4}$ penetrates into the pores of cement paste and further exceeds $\rho_{\mathrm{H}_{2} \mathrm{SO}_{4}}^{\mathrm{CH}}$, portlandite starts to dissolve and $\mathrm{C} \overline{\mathrm{S}} \mathrm{H} 2$ forms.



Figure 3.1: Stability domains of portlandite and gypsum

In this modelling, the sample is water saturated. The possibility that the precipitation of C $\bar{S} H 2$ occurs around $\mathrm{CH}$ crystals is neglected. Thus we assume that $\mathrm{C} \overline{\mathrm{S}} \mathrm{H} 2$ precipitation is homogeneous within the porosity. The $\mathrm{CH}$ dissolution process is governed by a simple kinetic law in the model. To facilitate numerical convergence, a characteristic time, $\tau_{\mathrm{CH}}$, is introduced to govern the dissolution rate of $\mathrm{CH}$ as 
follows:

$$
\frac{\mathrm{d} n_{\mathrm{CH}}}{\mathrm{d} t}=-\frac{n_{\mathrm{CH}}}{\tau_{\mathrm{CH}}}\left(\frac{\mu_{\mathrm{H}_{2} \mathrm{SO}_{4} \text { (current) }}-\mu_{\mathrm{H}_{2} \mathrm{SO}_{4}(\mathrm{eq})}}{R T}\right)=-\frac{n_{\mathrm{CH}}}{\tau_{\mathrm{CH}}} \ln \left(\frac{\rho_{\mathrm{H}_{2} \mathrm{SO}_{4}}}{\rho_{\mathrm{H}_{2} \mathrm{SO}_{4}}^{\mathrm{CH}}}\right)
$$

The kinetics is simplified to be governed only by the difference of chemical potentials of $\mathrm{H}_{2} \mathrm{SO}_{4}$ between


be as low as $1, \tau_{\mathrm{CH}}$ should be set in practice small enough to oblige the reaction to be close to equilibrium. Combined with sulfate ions, the dissolved calcium ions will precipitate as $\mathrm{C} \overline{\mathrm{S}} \mathrm{H} 2$ with almost at the same rate as that of the portlandite dissolution.

\subsection{Decalcification of calcium silicate hydrates (C-S-H)}

As a very important solid phase, C-S-H contributes to the strength of cement-based materials. The dissolution of C-S-H gel during $\mathrm{H}_{2} \mathrm{SO}_{4}$ attack, is presented by reactions Eq.(3.3). Dissolution modeling of $\mathrm{C}-\mathrm{S}-\mathrm{H}$ is important to understand the degradation process of cement hydrates.

Compared to $\mathrm{CH}, \mathrm{C}-\mathrm{S}-\mathrm{H}$ is a very complex hydration product whose composition is not specific. Thus the same approach as the one adopted for the $\mathrm{CH}$ dissolution is inappropriate for C-S-H. According to the researches about the structure and stoichiometry of C-S-H (Greenberg and Chang, 1965; Chen et al., 2004; Constantinides and Ulm, 2004), the ratio of calcium to silica (Ca/Si ratio), which is generally used to characterize the C-S-H, is about 1.7 for fresh hydrated Portland cement and tends to decrease during the dissolution process.

Literatures provide several methods to model the thermodynamic properties of C-S-H and its incongruent behaviour as well. Comparing with the empirical or semi-empirical models of the early method (Reardon, 1990) and solid solution method (Kulik and Kersten, 2001), a more general characterization method is proposed to address the continuous change of the stoichiometric coefficients of C-S-H during decalcification. For a better understanding of the new approach, the discrete model and solid solution model are introduced in Appendix A.

Based on thermodynamics, the new approach encompasses the solid solution model. There is no explicit mention of end-members in this approach. The Gibbs energy of C-S-H gel is eventually assessed directly by experimental measurements as a function of the $\mathrm{Ca} / \mathrm{Si}$ ratio rather than being assumed to fit a mixture of given members. Thus, this approach is expected to be more general than solid solution model. The $\mathrm{Ca} / \mathrm{Si}$ ratio of C-S-H is taken as a variable in the model. Defining the unit mole content of C-S-H with a unit mole content of Si (i.e., $y=1$ ), the dissociation reaction of an infinitesimal small amount of C-S-H can be written as: 


$$
\mathrm{C}_{x} \mathrm{~S}_{1} \mathrm{H}_{z} \rightleftharpoons x \mathrm{Ca}^{2+}+2 x \mathrm{OH}^{-}+\mathrm{SiO}_{2}^{0}+(z-x) \mathrm{H}_{2} \mathrm{O}
$$

where, $x$ stands for the current $\mathrm{Ca} / \mathrm{Si}$ ratio and $z$ for the Water/Si ratio. Obviously, the solid content of $\mathrm{Si}\left(n_{\mathrm{Si}}\right)$ is equal to the content of C-S-H $\left(n_{\mathrm{C}-\mathrm{S}-\mathrm{H}}\right)$. Thus, the molar Gibbs energy of C-S-H depends on $x$ and $z$ which is assumed as a function of $x$. We write the molar Gibbs energy of C-S-H as $g(x)$. During an infinitesimal small variation of C-S-H content, $\mathrm{d} n_{\mathrm{Si}}$, the reaction Gibbs free energy, $G$, must decrease spontaneously:

$$
\mathrm{d} G=-\mu_{\mathrm{Ca}^{2+}} \mathrm{d}(n x)-\mu_{\mathrm{OH}^{-}} \mathrm{d}(2 n x)-\mu_{\mathrm{SiO}_{2}^{0}} \mathrm{~d} n-\mu_{\mathrm{H}_{2} \mathrm{O}} \mathrm{d}(n(z-x))+\mathrm{d}(n g(x)) \leq 0
$$

where, $\mu_{i}$ is the chemical potential of each specie. At equilibrium condition, $G$ is minimum. Therefore, for arbitrary increment $\mathrm{d} n$ and C-S-H mole content $n$, Eq.(3.17) can be changed to Eq.(3.18).

$$
\begin{aligned}
& {\left[-x\left(\mu_{\mathrm{Ca}^{2+}}+2 \mu_{\mathrm{OH}^{-}}\right)-\mu_{\mathrm{SiO}_{2}^{0}}-(z-x) \mu_{\mathrm{H}_{2} \mathrm{O}}+g(x)\right] \mathrm{d} n} \\
& \quad+\left[-\mu_{\mathrm{Ca}^{2+}}-2 \mu_{\mathrm{OH}^{-}}-(z-1) \mu_{\mathrm{H}_{2} \mathrm{O}}+\frac{\partial g}{\partial x}\right] n \mathrm{~d} x=0
\end{aligned}
$$

Since the chemical potential is independent on amount, both of the two terms of Eq.(3.18) are equal to 0. Thus,

$$
\begin{aligned}
& \mathcal{A}=x\left(\mu_{\mathrm{Ca}^{2+}}+2 \mu_{\mathrm{OH}^{-}}\right)+\mu_{\mathrm{SiO}_{2}^{0}}+(z-x) \mu_{\mathrm{H}_{2} \mathrm{O}}-g(x)=0 \\
& \frac{\partial \mathcal{A}}{\partial x}=\quad\left(\mu_{\mathrm{Ca}^{2+}}+2 \mu_{\mathrm{OH}^{-}}\right)+\left(z^{\prime}-1\right) \mu_{\mathrm{H}_{2} \mathrm{O}}-\frac{\partial g}{\partial x} \quad=0
\end{aligned}
$$

where, $z^{\prime}=\mathrm{d} z / \mathrm{d} x$.

Eq. (3.19) indicates that the chemical affinity of reaction (3.16), $\mathcal{A}$, vanishes at equilibrium. Eq. (3.20) indicates that the chemical affinity keeps at 0 . Thus, equilibrium must hold during the decalcification of the C-S-H. Note that we have the expression of the chemical potential of $\mathrm{CH}$ and $\mathrm{SH}_{t}$ as follows:

$$
\begin{aligned}
\mu_{\mathrm{Ca}^{2+}}+2 \mu_{\mathrm{OH}^{-}} & =\mu_{\mathrm{CH}}^{0}+R T \ln \frac{Q_{\mathrm{CH}}}{K_{\mathrm{CH}}} \\
\mu_{\mathrm{SiO}_{2}^{0}}+t \mu_{\mathrm{H}_{2} \mathrm{O}} & =\mu_{\mathrm{SH}_{t}}^{0}+R T \ln \frac{Q_{\mathrm{SH}_{t}}}{K_{\mathrm{SH}_{t}}}
\end{aligned}
$$

where, $t$ is the hydration level of the amorpheous silica $\mathrm{SH}_{t}$ which can be obtained after a complete 
decalcification of the C-S-H. $K_{\mathrm{CH}}$ and $K_{\mathrm{SH}_{t}}\left(Q_{\mathrm{CH}}\right.$ and $\left.Q_{\mathrm{SH}_{t}}\right)$ are the equilibrium constants (ion activity products) of portlandite and amorpheous silica. Combining Eq. (3.19), Eq.(3.21) and (Eq.3.22), a basic relationship between the ion activity products of portlandite and that of amorphous silica is derived as (Eq.(3.23) and Eq.(3.24).

$$
\begin{aligned}
x \ln \left(\frac{Q_{\mathrm{CH}}}{K_{\mathrm{CH}}}\right)+\ln \left(\frac{Q_{\mathrm{SH}_{t}}}{K_{\mathrm{SH}_{t}}}\right) & =\ln a(x) \\
\ln \left(\frac{Q_{\mathrm{CH}}}{K_{\mathrm{CH}}}\right) & =\frac{\partial \ln a}{\partial x}
\end{aligned}
$$

where, $\ln a(x)=\left(g(x)-x \mu_{\mathrm{CH}}^{0}-\mu_{\mathrm{SH}_{t}}^{0}-(z-t-x) \mu_{\mathrm{H}_{2} \mathrm{O}}\right) / R T$. Given that the molar Gibbs energy of the amorphous silica in the form of $g(0)$ equals to $\mu_{\mathrm{SH}_{t}}^{0}, \ln a(0)=0$.

Eq. (3.24) indicates a constitutive-like equation as a one to one relationship between the $\mathrm{Ca} / \mathrm{Si} \mathrm{ratio}$ and $\frac{Q_{\mathrm{CH}}}{K_{\mathrm{CH}}}: x=\chi\left(\frac{Q_{\mathrm{CH}}}{K_{\mathrm{CH}}}\right)$. Consequently, a general mass action law in the form of the differential equation is then derived from Eq. (3.23) and Eq. (3.24) as follows:

$$
\mathrm{d}\left(\ln \frac{Q_{\mathrm{SH}_{t}}}{K_{\mathrm{SH}_{t}}}\right)+x \mathrm{~d}\left(\ln \frac{Q_{\mathrm{CH}}}{K_{\mathrm{CH}}}\right)=0
$$

entailing

$$
\ln \frac{Q_{\mathrm{SH}_{t}}}{K_{\mathrm{SH}_{t}}}=-\int_{0}^{\frac{Q_{\mathrm{CH}}}{K_{\mathrm{CH}}}} \frac{\chi(q)}{q} d q
$$

According to Eq.(3.26), the relationship between $\frac{Q_{\mathrm{SH}_{\mathrm{t}}}}{K_{\mathrm{SH}_{\mathrm{t}}}}$ and $\frac{Q_{\mathrm{CH}}}{K_{\mathrm{CH}}}$ is shown in Fig. 3.2. In the following parts of this study, note $q_{\mathrm{CH}}=\frac{Q_{\mathrm{CH}}}{K_{\mathrm{CH}}}$ as the saturation degree of dissolved $\mathrm{CH}$.

To confirm this relationship, we employ the results of an experiment conducted by Greenberg and Chang (Greenberg and Chang, 1965). In the experiment the solubilities of reaction mixtures of calcium oxide, silica and water were investigated $\left(0.805 \mathrm{~g}\right.$ of $\mathrm{SiO}_{2}$ was poured in $100 \mathrm{~mL}$ of water with varying additions of $\mathrm{CaO})$. The calcium ion concentration, the silicic acid concentration $\left(\rho_{\mathrm{H}_{4} \mathrm{SiO}_{4}}+\rho_{\mathrm{H}_{3} \mathrm{SiO}_{4}^{-}}+\rho_{\mathrm{H}_{2} \mathrm{SiO}_{4}^{2-}}\right)$ and the $p \mathrm{H}$ were measured. In Fig.3.3, we plot $\frac{Q_{\mathrm{SH}_{t}}}{K_{\mathrm{SH}_{t}}}$ obtained from Eq.(3.26), and that from the Greenberg's results. To perform the latter calculation, the ion activity product of silica gel, $Q_{\mathrm{SH}_{t}}$, is approximated by the concentration of the monosilicic acid $\mathrm{H}_{4} \mathrm{SiO}_{4}^{0}$. The solubility constant, $K_{\mathrm{SH}_{t}}$, is 1.93 mM. The model results fit the the experiments fairly well.

Furthermore, this theory encompasses the solid solution model involving any number of poles (detailed in Appendix A). 


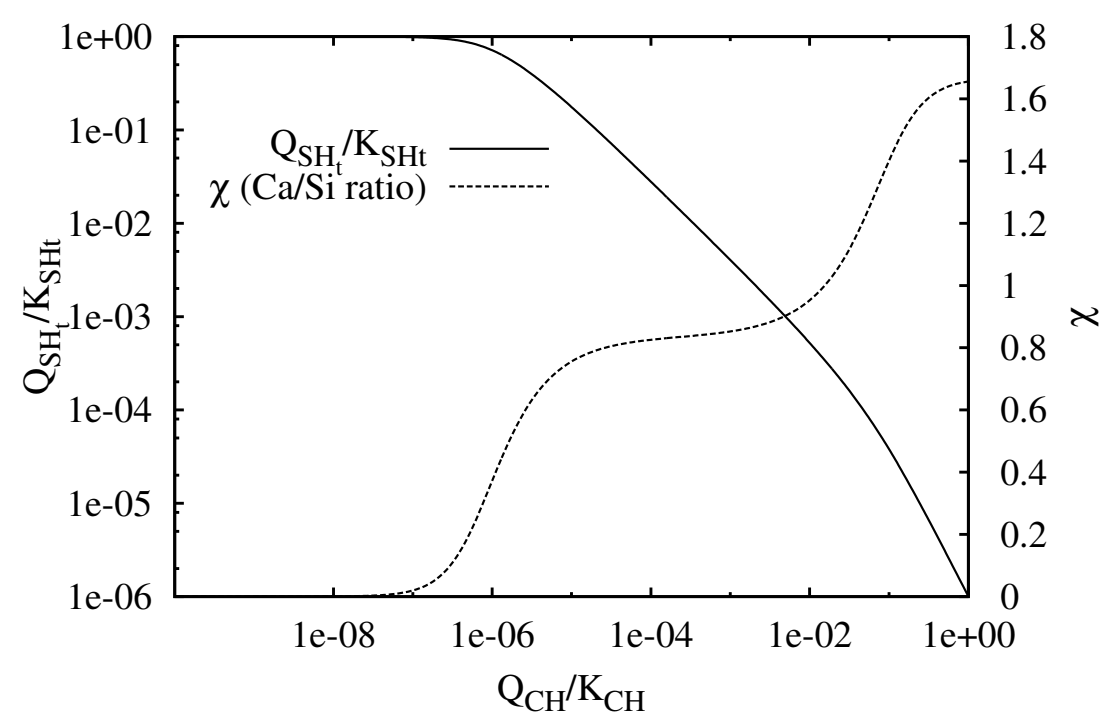

Figure 3.2: A typical pattern of the relationship between $\frac{Q_{\mathrm{SH}_{t}}}{K_{\mathrm{SH}_{t}}}$ and $\frac{Q_{\mathrm{CH}}}{K_{\mathrm{CH}}}$



Figure 3.3: Composition of a calcium-silicon solution in equilibrium with its solid phase vs. Ca/Si ratio. 


\subsection{Examples of the evolution of $p \mathbf{H}$ and solid compositions}

To illustrate the evolution of $p \mathrm{H}$ and solid compositions, the $\mathrm{H}_{2} \mathrm{~S}$ attack and $\mathrm{H}_{2} \mathrm{SO}_{4}$ attack of homogeneous representative volume element (RVE) of hydrated cement paste are presented separately. The cement paste contains initially $5.2 \mathrm{~mol} / \mathrm{L}$ of portlandite $(\mathrm{CH})$ and $3.5 \mathrm{~mol} / \mathrm{L}$ of jennite (i.e. $\mathrm{C}_{1.66} \mathrm{SH}_{2.6}$ ), the same value as a well hydrated Class $\mathrm{H}$ cement with water/cement ratio (W/C) of 0.38 (Huet et al., 2010). There is no mass transport at the boundary due to diffusion. In the simulation, the model given by Eq. (3.26) is employed to describe the dissolution of C-S-H and the $\mathrm{Ca} / \mathrm{Si}$ ratio evolution is shown in Fig.3.2.

For $\mathrm{H}_{2} \mathrm{~S}$ attack, a small value (about $1 \times 10^{-9} \mathrm{~mol} / \mathrm{L}$ ) is assigned as the initial aqueous $\mathrm{H}_{2} \mathrm{~S}$ concentration in the pore solution to keep the portlandite stable. The aqueous $\mathrm{H}_{2} \mathrm{~S}$ concentration increases to $0.19 \mathrm{~mol} / \mathrm{L}$ (the $p \mathrm{H}$ reaches about 9) in $86400 \mathrm{~s}$ (i.e., 1 day). There is no $\mathrm{H}_{2} \mathrm{~S}$ absorption through the concrete surface. Concentration of aqueous $\mathrm{H}_{2} \mathrm{~S}, \mathrm{HS}^{-}$and $\mathrm{S}^{2-}$, and $p \mathrm{H}$ evolution are shown in Fig.3.4. Since the ionization constant of $\mathrm{H}_{2} \mathrm{~S}$ is very low $\left(8.9 \times 10^{-8}\right)$, the $p \mathrm{H}$ drops from 12.4 to 9 even if $\rho_{\mathrm{H}_{2} \mathrm{~S}}$ reaches up to $0.19 \mathrm{~mol} / \mathrm{L}$. Due to the lower ionization constant of $\mathrm{HS}^{-}\left(1.2 \times 10^{-13}\right), \rho_{\mathrm{HS}^{-}}$is always higher than $\rho_{\mathrm{H}_{2} \mathrm{~S}}$.

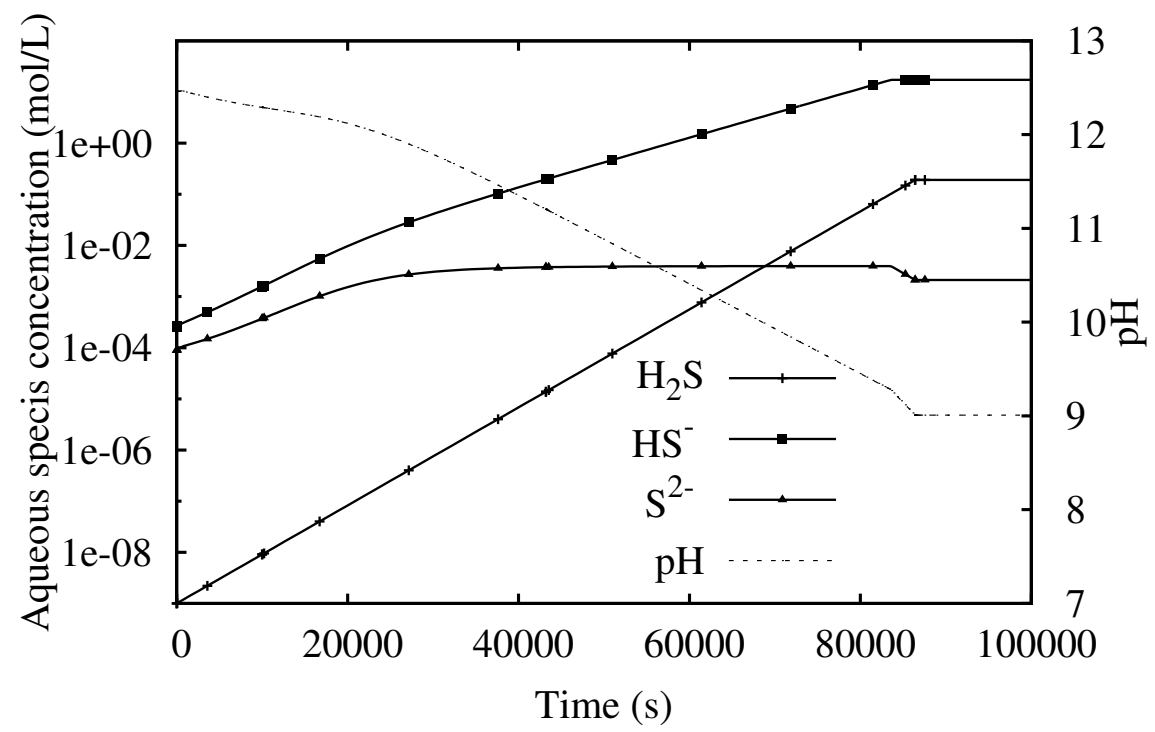

Figure 3.4: Concentration of $\mathrm{H}_{2} \mathrm{~S}$ species and $p \mathrm{H}$ vs. time in $\mathrm{REV}$ of cement paste

Solid composition evolution of cement paste versus aqueous $\mathrm{H}_{2} \mathrm{~S}$ concentration is shown in Fig.3.5. The characteristic time of the dissolution of $\mathrm{CH}, \tau_{C H}$, is $2000 \mathrm{~s}$. Once $\rho_{\mathrm{H}_{2} \mathrm{~S}}$ reaches $1.2 \times 10^{-9}$, portlandite starts to dissolve. Meanwhile, dissolution of C-S-H takes place as well. Compared to the dissolution of portlandite, which is very quick, the Ca/Si ratio of C-S-H decreases gradually. When $\rho_{\mathrm{H}_{2} \mathrm{~S}}$ exceeds 0.1 $\mathrm{mol} / \mathrm{L}$, the decalcification process of C-S-H is complete. With the dissolution of $\mathrm{CH}$ and C-S-H, calcium sulfide keeps precipitating until $\rho_{\mathrm{H}_{2} \mathrm{~S}}$ increasing to $0.0025 \mathrm{~mol} / \mathrm{L}$. In presence of excess aqueous $\mathrm{H}_{2} \mathrm{~S}$, calcium 
sulfide is decomposed.

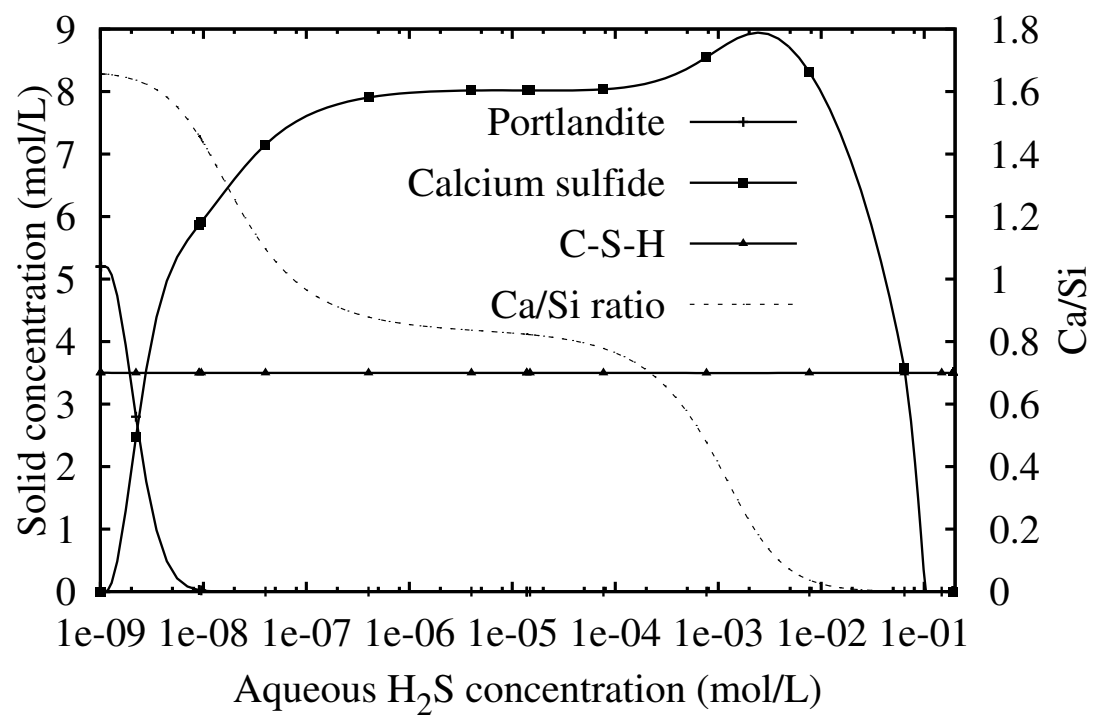

Figure 3.5: Evolution of the solid composition vs. $\mathrm{H}_{2} \mathrm{~S}$ concentration in $\mathrm{REV}$ of cement paste

Similarly, for $\mathrm{H}_{2} \mathrm{SO}_{4}$ attack, $1 \times 10^{-31.5} \mathrm{~mol} / \mathrm{L}$ is assigned as the initial $\mathrm{H}_{2} \mathrm{SO}_{4}$ concentration in the pore solution to prevent the dissolution of portlandite. The $\mathrm{H}_{2} \mathrm{SO}_{4}$ concentration increases to $1 \times 10^{-8} \mathrm{~mol} / \mathrm{L}$ (the $p \mathrm{H}$ value is about 1 ) in 86400 s (i.e., 1 day). There is no mass transport at the boundary. Concentration of $\mathrm{H}_{2} \mathrm{SO}_{4}, \mathrm{HSO}_{4}^{-}$and $\mathrm{SO}_{4}^{2-}$, and $p \mathrm{H}$ evolution are shown in Fig.3.6. As a very strong acid, only a few amount $\left(1 \times 10^{-7.8} \mathrm{~mol} / \mathrm{L}\right)$ of $\mathrm{H}_{2} \mathrm{SO}_{4}$ could reduce $p \mathrm{H}$ to 1 .

Fig.3.7 profiles the evolution of solid compositions versus $\mathrm{H}_{2} \mathrm{SO}_{4}$ concentration. Due to the sufficient supply of $\mathrm{H}^{+}, \mathrm{Ca} / \mathrm{Si}$ ratio of $\mathrm{C}-\mathrm{S}-\mathrm{H}$ decreases faster than that during $\mathrm{H}_{2} \mathrm{~S}$ attack. Thanks to the stability of gypsum, at normal atmospheric temperature gypsum keeps depositing in pores rather than dissolving in $\mathrm{H}_{2} \mathrm{SO}_{4}$ solution. 


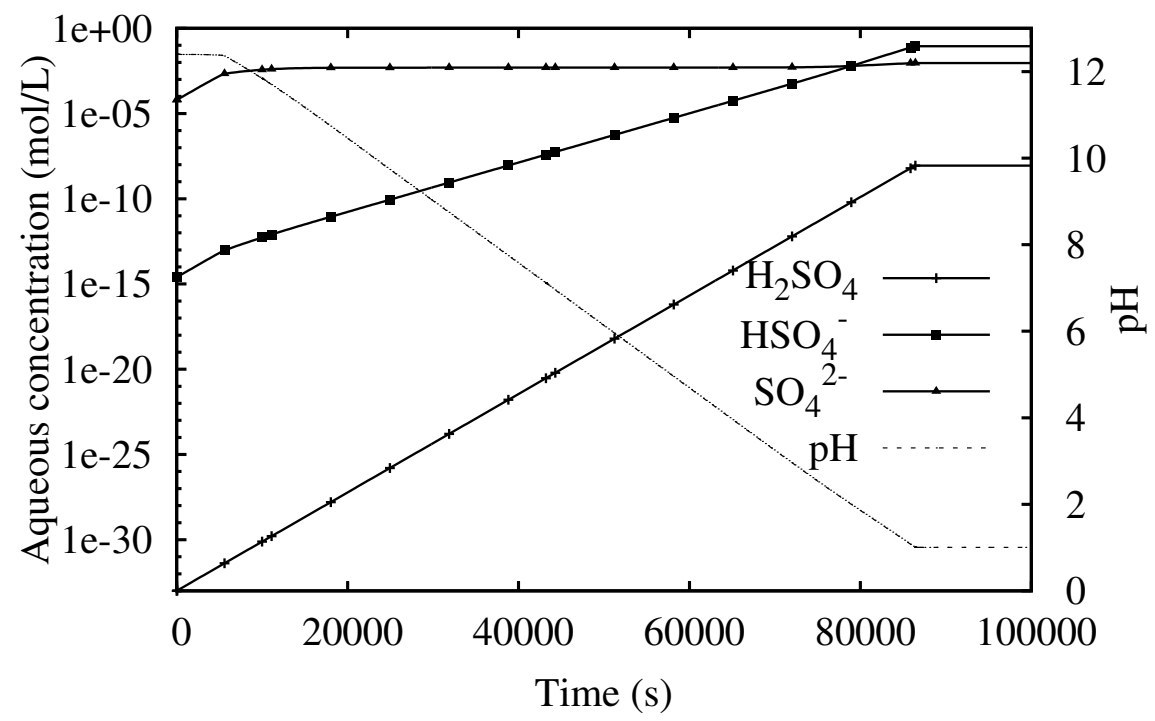

Figure 3.6: Concentration of $\mathrm{H}_{2} \mathrm{SO}_{4}$ species and $p \mathrm{H} v$ s. time in REV of cement paste

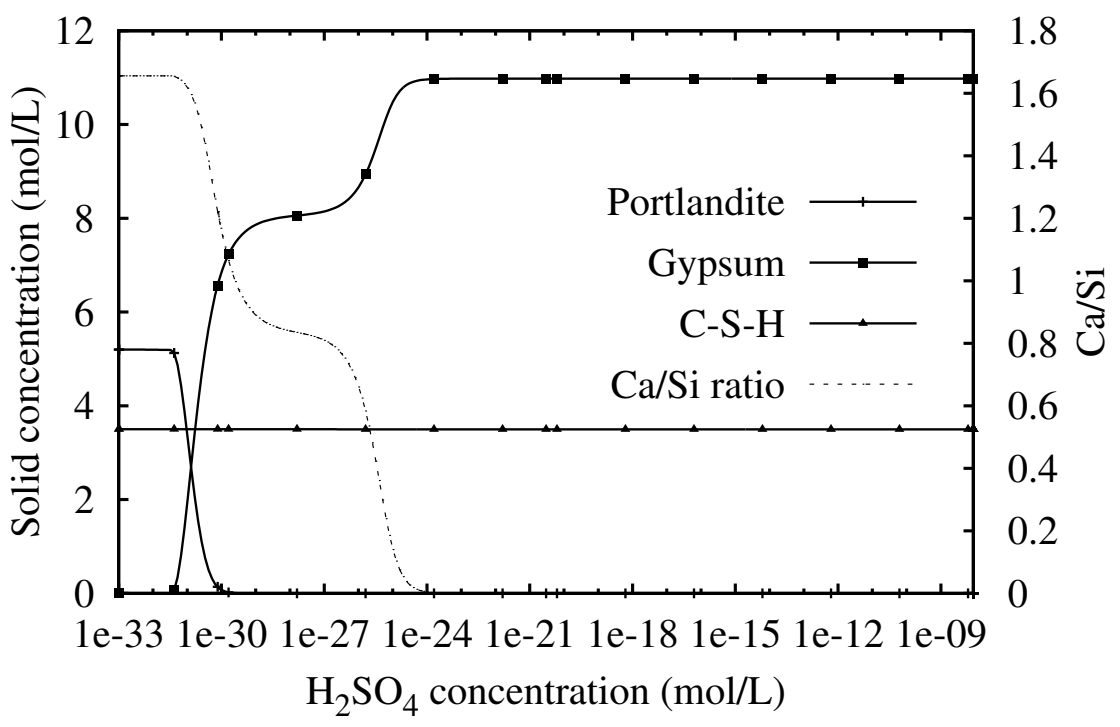

Figure 3.7: Evolution of the solid composition vs. $\mathrm{H}_{2} \mathrm{SO}_{4}$ concentration in $\mathrm{REV}$ of cement paste 


\subsection{Conclusion}

This chapter introduces the chemical reaction part of biogenic sulfuric acid attack modelling. Homogeneous chemical reactions are considered in the pore solution of cementitious materials. It is assumed that all the aqueous reactions are in thermodynamical equilibrium governed by equilibrium constant.

The threshold of ion activity products are employed to determine the stability of $\mathrm{CH}$ and $\mathrm{C} \overline{\mathrm{S}} \mathrm{H} 2$. With mass action laws, the equilibrium between $\mathrm{CH}$ and $\mathrm{CS} H 2$ is calculated. A simplified chemical kinetics for the dissolution of $\mathrm{CH}$ is introduced to facilitate numerical convergence. In heavily corroded sewer pipe, the $p \mathrm{H}$ of biofilm is normally below 2. Thus the characteristic time of $\mathrm{CH}$ dissolution is chosen as small as possible during simulation to achieve a quick dissolution.

Rather than discrete or solid solution methods, a general approach is applied to characterize the continuous decalcification of C-S-H gel. A generalization of the mass action law is employed for C-S-H dissolution. Comparing with discrete or solid solution methods, this approach encompasses the solid solution model involving any number of poles of coefficient, and is easy to implement in a transport-reaction modelling.

The evolution of $p \mathrm{H}$ and solid composition during $\mathrm{H}_{2} \mathrm{~S}$ and $\mathrm{H}_{2} \mathrm{SO}_{4}$ attack are illustrated by the study of simple cases of representative volume element. Qualitatively, the profiles of simulation results coincide with experimental observations. However, due to the lack of transport terms, the simulation results can not be compared with the experimental results quantitatively. The influence of the decomposition of calcium sulfide and the deposition of gypsum on the porosity of materials will be discussed in the next chapter. 
4\$eptember 16, 2013Degradation of cementitious materials subjected to sulfuric acid attack 


\section{Chapter 4}

\section{Porosity evolution and damage of cementitious materials}

\subsection{Introduction}

As a porous media, the physical/chemical performance of cementitious materials depends not only on solid compositions but also on pore structure, which plays important role in this model as well. Diffusion of aqueous species is considered in this paper, then the diffusivity of all ionic species is governed by a function of pore structure (given in Section 5.3). The corrosion depth is determined by the damage of pore structure as well. The characteristic parameters of pore structure are various (such as porosity, pore size distribution, specific internal area etc. (Hall et al., 1997)). However, the purpose of our study is to propose a method to model the whole process of biodeterioration of cementitious materials rather than the specific effect of pore structure. In this paper, our model accounts for the microstructure evolution by adjusting the porosity.

During the abiotic $p \mathrm{H}$ reduction process of concrete surface and the sulfuric acid attack process, solid phases such as portlandite and C-S-H gel are dissolved. For $\mathrm{H}_{2} \mathrm{~S}$ attack, CaS, whose molar volume is less than $\mathrm{CH}$ and C-S-H, precipitates in pores. Furthermore, when $\mathrm{H}_{2} \mathrm{~S}$ is enough, $\mathrm{CaS}$ could be dissolved. Obviously, when the phases which occupied the initial solid volume of materials disappear, the pore volume would increase.

While for $\mathrm{H}_{2} \mathrm{SO}_{4}$ attack process, corrosion product is gypsum, which is expansive and insoluble. Observations revealed that the volume of solid substances increases largely (Okabe et al., 2007; Davis et al., 1998). Compared to $\mathrm{H}_{2} \mathrm{~S}$ attack, the evolution of porosity during $\mathrm{H}_{2} \mathrm{SO}_{4}$ attack process is much more complex. 
Firstly, the molar volume of C-S-H and the porosity evolution during $\mathrm{H}_{2} \mathrm{~S}$ attack will be introduced in this chapter. The next section introduces the swelling of gypsum precipitation. Using different methods for different conditions, the porosity evolution during $\mathrm{H}_{2} \mathrm{SO}_{4}$ attack process is calculated. In the last section, two simple examples without transport are presented to illustrate the evolution of the solid volume assemblage of $\mathrm{H}_{2} \mathrm{~S}$ and $\mathrm{H}_{2} \mathrm{SO}_{4}$ attack separately.

\subsection{Porosity change during $\mathrm{H}_{2} \mathrm{~S}$ attack}

Let us note the initial porosity of the sample materials and the porosity after deterioration as $\phi_{0}$ and $\phi_{\mathrm{H}_{2} \mathrm{~S}}$ respectively. Induced by the precipitation/dissolution of the various solid compounds, the porosity change can be easily addressed by a simple balance of volume as Eq.(4.1).

$$
\phi_{\mathrm{H}_{2} \mathrm{~S}}-\phi_{0}=-V_{\mathrm{CH}}\left(n_{\mathrm{CH}}-n_{\mathrm{CH}}^{0}\right)-V_{\mathrm{CaS}}\left(n_{\mathrm{CaS}}-n_{\mathrm{CaS}}^{0}\right)-V_{\mathrm{C}-\mathrm{S}-\mathrm{H}} n_{\mathrm{Si}}+V_{\mathrm{C}-\mathrm{S}-\mathrm{H}}^{0} n_{\mathrm{Si}}^{0}
$$

where, $V_{i}$ is the molar volume of the solid compound $i(\mathrm{~L} / \mathrm{mol}) . n_{i}$ and $n_{i}^{0}$ represent the current and initial solid content of $i(\mathrm{~mol} / \mathrm{L}) . V_{\mathrm{CH}}=33 \mathrm{~cm}^{3} / \mathrm{mol}$ is used for the molar volume of portlandite. For CaS, the molar volume $V_{\mathrm{CaS}}$ is chosen as $28 \mathrm{~cm}^{3} / \mathrm{mol}$ (Wiberg, 2001; Zekker et al., 2011).

However there is a lack of data regarding the molar volume of C-S-H, which is theoretically a function of the $\mathrm{Ca} / \mathrm{Si}$ ratio, $x$, and the $\mathrm{H}_{2} \mathrm{O} / \mathrm{Si}$ ratio, $z$. According to (Jennings, 2004), the molar volume of $\mathrm{C}_{1.7} \mathrm{SH}_{1.4}$ is approximately $64.5 \mathrm{~cm}^{3} / \mathrm{mol}$, that of $\mathrm{C}_{1.7} \mathrm{SH}_{2.1}$ is $78.8 \mathrm{~cm}^{3} / \mathrm{mol}$ and that of $\mathrm{C}_{1.7} \mathrm{SH}_{4}$ is $113.6 \mathrm{~cm}^{3} / \mathrm{mol}$. On the other hand, the molar volume of amorpheous silica is approximately $29 \mathrm{~cm}^{3} / \mathrm{mol}$ (Lothenbach et al., 2008). In this paper, we choose the values provided by (Thiéry et al., 2011; Morandeau et al., 2012), i.e., $V_{\mathrm{C}_{1.67} \mathrm{SH}_{2.6}}=81.3 \mathrm{~cm}^{3} / \mathrm{mol}, V_{\mathrm{C}_{0.83} \mathrm{SH}_{1.83}}=54.8 \mathrm{~cm}^{3} / \mathrm{mol}, V_{\mathrm{SH}_{2}}=43 \mathrm{~cm}^{3} / \mathrm{mol}$.

In absence of knowledge, assuming volume and $\mathrm{H}_{2} \mathrm{O} / \mathrm{Si}$ ratio of three end members, linear functions for $V_{\mathrm{C}-\mathrm{S}-\mathrm{H}}(x)$ are used as follows:

$$
V_{\mathrm{C}-\mathrm{S}-\mathrm{H}}(x)= \begin{cases}\frac{x-x^{\mathrm{Tob}}}{x^{\mathrm{Jen}}-x^{\mathrm{Tob}}} V_{\mathrm{C}-\mathrm{S}-\mathrm{H}}^{\mathrm{Jen}}+\left(1-\frac{x-x^{\mathrm{Tob}}}{x^{\mathrm{Jen}}-x^{\mathrm{Tob}}}\right) V_{\mathrm{C}-\mathrm{S}-\mathrm{H}}^{\mathrm{Tob}} & , x \geq x^{\text {Tob }} \\ \frac{x}{x^{\mathrm{Tob}}} V_{\mathrm{C}-\mathrm{S}-\mathrm{H}}^{\mathrm{Tob}}+\left(1-\frac{x}{x^{\mathrm{Tob}}}\right) V_{\mathrm{SH}_{t}} & , x \leq x^{\text {Tob }}\end{cases}
$$

where, $x^{\mathrm{Jen}}=1.667$ and $x^{\mathrm{Tob}}=0.8333$ represents the $\mathrm{Ca} / \mathrm{Si}$ of Jennite and Tobermorite respectively. $V_{\mathrm{C}-\mathrm{S}-\mathrm{H}}^{\mathrm{Jen}}=81.3 \mathrm{~cm}^{3} / \mathrm{mol}$ and $V_{\mathrm{C}-\mathrm{S}-\mathrm{H}}^{\text {Tob }}=54.8 \mathrm{~cm}^{3} / \mathrm{mol}$ are the molar volume of Jennite and Tobermorite. Similarly, $z(x)$ can be expressed as follows:

$$
z(x)= \begin{cases}\frac{x-x^{\mathrm{Tob}}}{x^{\mathrm{Jen}}-x^{\mathrm{Tob}}} z^{\mathrm{Jen}}+\left(1-\frac{x-x^{\mathrm{Tob}}}{x^{\mathrm{Jen}}-x^{\mathrm{Tob}}}\right) z^{\mathrm{Tob}} & , x \geq x^{\text {Tob }} \\ \frac{x}{x^{\mathrm{Tob}}} z^{\mathrm{Tob}}+\left(1-\frac{x}{x^{\mathrm{Tob}}}\right) t & , x \leq x^{\text {Tob }}\end{cases}
$$


where, $z^{\mathrm{Jen}}=2.6$ and $z^{\mathrm{Tob}}=1.83$ represent the $\mathrm{H}_{2} \mathrm{O} / \mathrm{Si}$ of Jennite and Tobermorite respectively, and $t=$ 2. The change of $V_{\mathrm{C}-\mathrm{S}-\mathrm{H}}$ and $\mathrm{H}_{2} \mathrm{O} / \mathrm{Si}$ ratio with the change of $\mathrm{Ca} / \mathrm{Si}$ ratio is shown in Fig.4.1.



Figure 4.1: $V_{\text {C-S-H }}$ and $\mathrm{H}_{2} \mathrm{O} / \mathrm{Si}$ ratio $z$ vs. Ca/Si ratio $x$.

\subsection{Expansion of gypsum precipitation}

Lots of observations (Monteny et al., 2000; Ehrich et al., 1999) found that biodeterioration forms gypsum with an increase in volume that results in significant expansion of concrete (as shown in Fig.4.2a). The molar volume of gypsum is $75 \mathrm{~cm}^{3} / \mathrm{mol}$, which is more than 2 times of that of portlandite. The volume of the dissolution products of 1 mole Jennite (i.e., 1.67 mole $\mathrm{CS} H 2$ and 1 mole $\mathrm{SH}_{2}$ ) is about $168 \mathrm{~cm}^{3}$, while the molar volume of Jennite is $81.3 \mathrm{~cm}^{3}$. Therefore, unlike $\mathrm{H}_{2} \mathrm{~S}$ attack, $\mathrm{H}_{2} \mathrm{SO}_{4}$ attack leads to volume expansion.

Furthermore, the gypsum forming during $\mathrm{H}_{2} \mathrm{SO}_{4}$ attack process is a kind of softy gel which provides no structural strength (Vincke et al., 2000). Normally, it is a white-powder like deposition saturated with water (having the consistency of "cottage cheese") as shown in Fig.4.2b and loosely connected with uncorroded concrete core (Israel et al., 1997). The porosity of the gypsum gel is about 0.85 - 0.92 (Jahani et al., 2005).

Although the formation of gypsum as a result of sulfuric acid attack of concrete has been reported frequently, there is no agreement on its mechanism.

Since gypsum layer loosely connects with uncorroded concrete core and very few sulfur was detected beyond this zone, (Beddoe and Dorner, 2005; Cohen and Mather, 1991) claimed that gypsum forms via a through-solution mechanism. In this way, $\mathrm{Ca}^{2+}$ is depleted by an ion exchange reaction with $\mathrm{H}^{+}$, and 


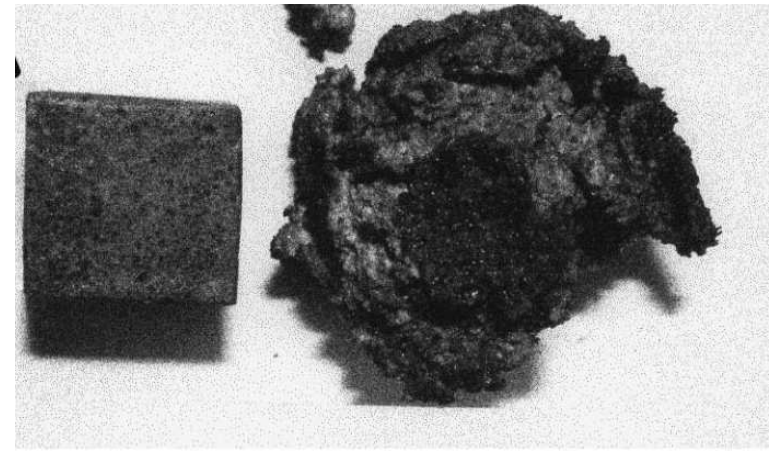

(a)



(b)

Figure 4.2: (a) OPC Mortar after 350 Days of biogenic sulfuric acid corrosion in simulation chamber. Samples on left side is reference sample,whereas on right side sample exposed to corrosion condition. (Ehrich et al., 1999); (b) The appearance of concrete coupons exposed to the sewer atmosphere for 1 year. (Okabe et al., 2007)

thereafter diffuses towards the acid solution. By a reaction with sulfate anion from the acid solution, the deposition of gypsum forms the corroding layer (illustrated by Fig.4.3a). Thus, the expansion and damage process of pore structure can be dismissed.

On the other hand, (Lawrence, 1990) had found that substantial deposits of gypsum forms in concrete and cause expansion. Similarly, (Gollop and Taylor, 1995) reported cracking and expansion in the gypsum layer, and the spontaneous spalling of gypsum layer was observed by (Torii and Kawamura, 1994). Therefore, sulfuric acid penetrates into mortar or concrete and reacts with calcium hydroxide of cement hydrates to produce gypsum. The volume of solid substances increases largely, which causes expansion of reaction products resulting in the damage of pore structure.

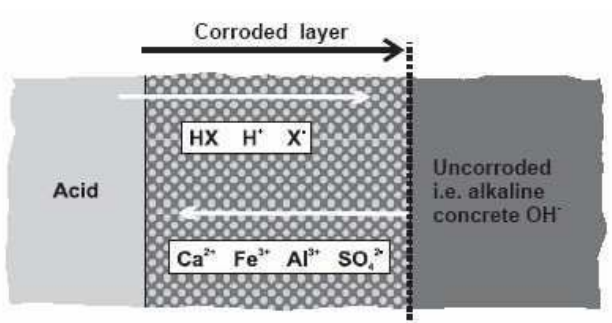

(a)

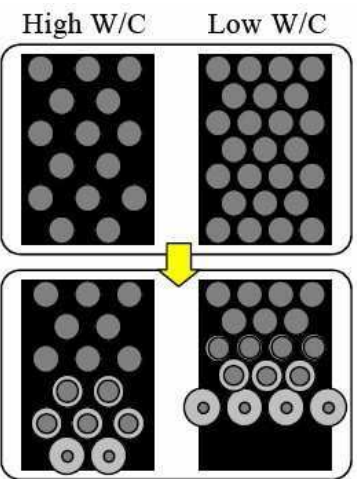

(b)

Figure 4.3: Schematics of the microstructure of cementitous materials with uncompressed gypsum inclusion: (a) Through-solution mechanism (Beddoe and Dorner, 2005); (b) Deposition in pores mechanism (Kawai et al., 2005)

Moreover, some investigations mentioned the effect of w/c ratios of cement paste on the resistance to 
$\mathrm{H}_{2} \mathrm{SO}_{4}$ attack. It is well known that, a low w/c brings low porosity which normally leads to more durability. However, researches revealed that $\mathrm{H}_{2} \mathrm{SO}_{4}$ solution showed greater degradation for low w/c ratio than for high w/c ratio samples (Fattuhi and Hughes, 1988; Hughes and Guest, 1978; Kawai et al., 2005).

The possible reason is that samples with a high water cement ratio has larger and more pores than the samples with a low water cement ratio. These pores play the role of a capacity to absorb expansion caused by the production of gypsum. Hence samples with a high w/c ratio has a higher capacity to absorb the expansion gypsum than samples with a low water cement ratio. Moreover, lower w/c ratio samples contain more calcium hydroxide than that with high w/c samples. That is to say more gypsum is precipitated in pores with low w/c samples. This mechanism is schematically illustrated in Fig.4.3.

Therefore, in this paper we consider that the pores will be filled with gypsum during the early time of $\mathrm{H}_{2} \mathrm{SO}_{4}$ attack. Since gypsum gel is compressible (Azam, 2007), it is assumed that gypsum will be compressed after a complete filling of pores. Under this condition, the sample can be treated as cementitious pore structure with gypsum inclusion. The gypsum accumulation leads to pressure rising until the inner pressure exceeds the ultimate bearing capacity of the materials. If so, the pore structure will be damaged. The zone, where the pore structure is damaged by inner pressure, should be treated as uncompressed gypsum with unreacted solid compounds inclusion (such as silica gel, remaining cement hydrates, etc.).

Our model accounts for the microstructure evolution by adjusting the porosity using different methods for different conditions. The schematic figures of three conditions are shown in Fig.4.4,Fig.4.5 and Fig.4.8.

\subsection{Porosity change during $\mathrm{H}_{2} \mathrm{SO}_{4}$ attack}

\subsubsection{Porosity of cementitous materials with uncompressed gypsum inclusion}

The initial porosity of the sample materials is noted as $\phi_{0}$, and the porosity of uncompressed gypsum is $\phi_{\mathrm{CS} H 2}^{0}$. Resulting from the dissolution of the portlandite and C-S-H gel, the porosity of cementitious materials will increase to $\phi_{\mathrm{C}}^{0}$ as follows:

$$
\phi_{\mathrm{C}}^{0}=\phi_{0}-V_{\mathrm{CH}}\left(n_{\mathrm{CH}}-n_{\mathrm{CH}}^{0}\right)-V_{\mathrm{C}-\mathrm{S}-\mathrm{H}} n_{\mathrm{Si}}+V_{\mathrm{C}-\mathrm{S}-\mathrm{H}}^{0} n_{\mathrm{Si}}^{0}
$$

If $V_{\mathrm{C} \overline{\mathrm{S}} 2}^{\mathrm{s} 2}=75 \mathrm{~cm}^{3} / \mathrm{mol}$ is the molar volume of the solid phase of gypsum, the molar volume of uncompressed gypsum,$V_{\mathrm{C} \overline{\mathrm{S}} \mathrm{H} 2}^{0}$, is $V_{\mathrm{C} \overline{\mathrm{S}} \mathrm{H} 2}^{\mathrm{s}} /\left(1-\phi_{\mathrm{C} \overline{\mathrm{S}} \mathrm{H} 2}^{0}\right)$. Before the saturation degree of gypsum has reached 1 , neither gypsum nor the pore structure are subjected to pressure. Therefore, during this phase $V_{\mathrm{C} \overline{\mathrm{S}} \mathrm{H} 2}$ and $\phi_{\mathrm{C}}$ is equal to $V_{\mathrm{C} \overline{\mathrm{H}} 2}^{0}$ and $\phi_{\mathrm{C}}^{0}$ respectively. The porosity of the sample is therefore given by Eq.(4.5).

$$
\phi=\phi_{\mathrm{C}}^{0}-V_{\mathrm{CS} H 2}^{\mathrm{s}}\left(n_{\mathrm{CS} H 2}-n_{\mathrm{C} \overline{\mathrm{S}} \mathrm{H} 2}^{0}\right)
$$






Figure 4.4: Schematics of the microstructure of cementitous materials with uncompressed gypsum inclusion

\subsubsection{Porosity of cementitous materials with compressed gypsum inclusion}

After gypsum has filled the pore volume, the gypsum gel starts to exert pressure on the pore wall. Subjected to the pressure $p$, the gypsum will be compressed while the pore volume will be expanded.

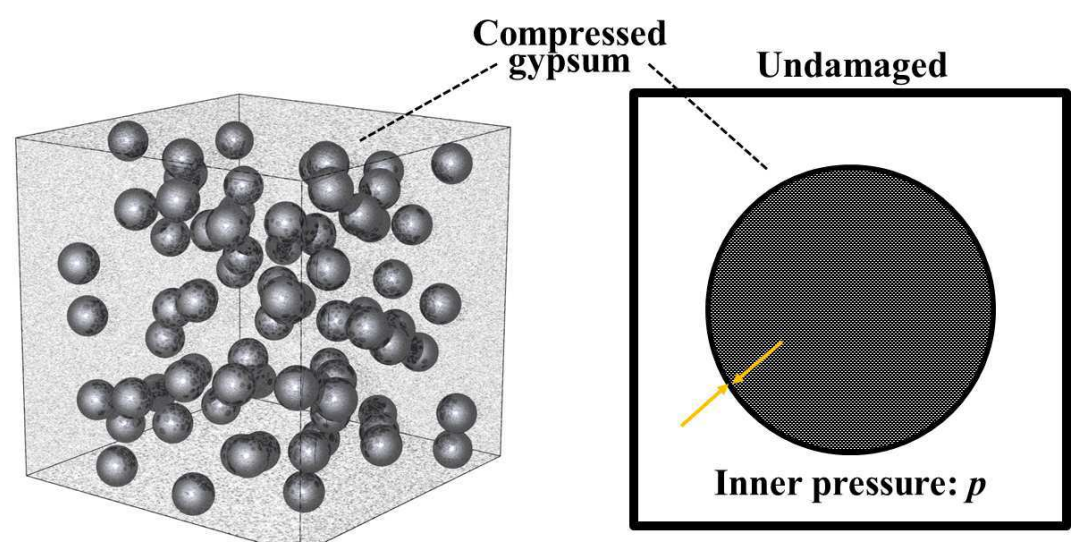

Figure 4.5: Schematics of the microstructure of cementitous materials with compressed gypsum inclusion

As gypsum precipitates in the pores, the saturation degree of gypsum can be written as:

$$
S_{\mathrm{C} \overline{\mathrm{S}} \mathrm{H} 2}=\frac{n_{\mathrm{C} \overline{\mathrm{S}} \mathrm{H} 2} V_{\mathrm{C} \overline{\mathrm{S}} \mathrm{H} 2}}{\phi_{\mathrm{C}}}
$$

where, $V_{\mathrm{CS} H 2}$ and $\phi_{\mathrm{C}}$ are the molar volume of gypsum gel and the porosity of cementitious material respectively. The inner pressure is 0 until the saturation degree of gypsum reaches 1 (see Figure.4.6 ).

In the condition of gypsum saturated, the porosity of cementitious material and gypsum can be described as 




Figure 4.6: Schematics of the relationship between the saturation degree of gypsum and inner pressure.

$$
\begin{gathered}
\phi_{\mathrm{C}}=\phi_{\mathrm{C}}^{0}+\varphi_{\mathrm{C}} \\
\phi_{\mathrm{C} \overline{\mathrm{S}} \mathrm{H} 2}=\phi_{\mathrm{C} \overline{\mathrm{S}} \mathrm{H} 2}^{0}+\varphi_{\mathrm{C} \overline{\mathrm{S}} \mathrm{H} 2}
\end{gathered}
$$

where, $\varphi_{\mathrm{C}}$ and $\varphi_{\mathrm{CS} H 2}$ represent the porosity changes of cementitious materials and gypsum caused by pressure. It is assumed that the behaviour of the porous material is elastic linear and brittle as shown in Fig.4.7. The relationship between pressure and porosity change is:

$$
\begin{aligned}
\varphi_{\mathrm{C}} & =\phi_{\mathrm{C}}^{0} \frac{p}{K_{\mathrm{C}}} \\
\varphi_{\mathrm{C} \overline{\mathrm{S}} \mathrm{H} 2} & =-\phi_{\mathrm{C} \overline{\mathrm{S}} \mathrm{H} 2}^{0} \frac{p}{K_{\mathrm{C} \overline{\mathrm{S}} \mathrm{H} 2}}
\end{aligned}
$$

where, $K_{\mathrm{C}}$ and $K_{\mathrm{CS} H 2}$ are the compression coefficients of cementitious material and gypsum respectively. The elastic modulus of mortar, which is approximately $10 \mathrm{GPa}$, is employed as $K_{\mathrm{C}}$ in the model. Regarding the compression property of gypsum, few data can be found. However, the similar gypsum was found in soil (Azam, 2007). Therefore, the compression coefficient of soil, which is approximately $5 \mathrm{MPa}$, is applied as a first approximation of $K_{\mathrm{CS} H 2}$.

Since a change of molar volume of gypsum gel is induced by the decreasing of the pore volume of gypsum, according to Eq.(4.8b) it can be derived that:

$$
\frac{V_{\mathrm{C} \overline{\mathrm{S}} \mathrm{H} 2}-V_{\mathrm{C} \overline{\mathrm{S}} \mathrm{H} 2}^{0}}{V_{\mathrm{C} \overline{\mathrm{S}} \mathrm{H} 2}^{0}}=\frac{\varphi_{\mathrm{C} \overline{\mathrm{S}} \mathrm{H} 2}}{\phi_{\mathrm{C} \overline{\mathrm{S}} \mathrm{H} 2}^{0}}=-\frac{p}{K_{\mathrm{C} \overline{\mathrm{S}} \mathrm{H} 2}}
$$




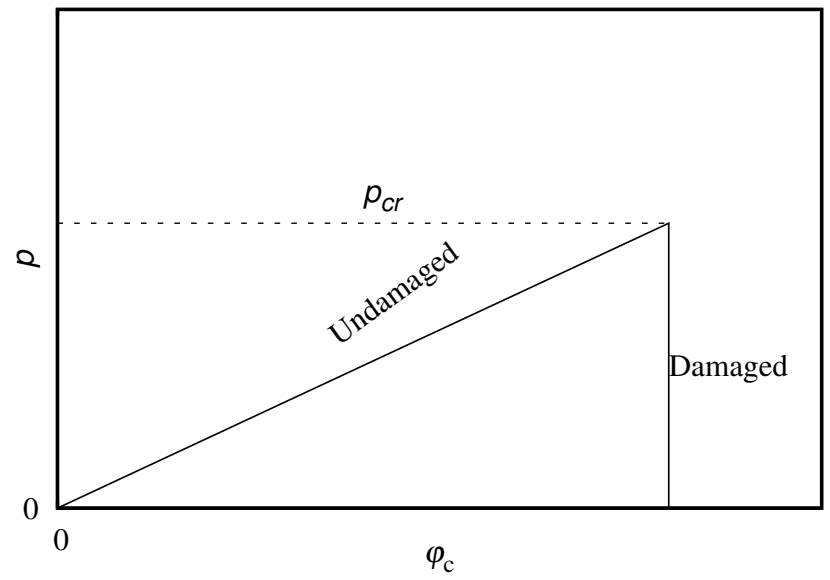

Figure 4.7: Elastic-Brittle behaviour of cementitious materials

Thus, the molar volume of gypsum gel under pressure $p$ is given by:

$$
V_{\mathrm{C} \overline{\mathrm{S}} \mathrm{H} 2}=V_{\mathrm{C} \overline{\mathrm{S}} \mathrm{H} 2}^{0}\left(1-\frac{p}{K_{\mathrm{C} \overline{\mathrm{S}} \mathrm{H} 2}}\right)
$$

Note that the saturation degree of gypsum, $S_{\mathrm{C} \overline{\mathrm{S}} \mathrm{H}}$, is equal to 1 during this stage. Substituting Eq.(4.10) into Eq.(4.6), pressure $p$ can be obtained as:

$$
p=K_{\mathrm{C} \overline{\mathrm{S}} \mathrm{H} 2}\left(1-\frac{\phi_{\mathrm{C}}}{n_{\mathrm{C} \overline{\mathrm{S}} \mathrm{H} 2} \phi_{\mathrm{C} \overline{\mathrm{S}} \mathrm{H} 2}^{0}}\right)
$$

Substituting Eq.(4.8a) into Eq.(4.11), the pressure can be further calculated by:

$$
p=\frac{\left(V_{\mathrm{C} \overline{\mathrm{S}} \mathrm{H} 2}^{0} n_{\mathrm{C} \overline{\mathrm{S}} \mathrm{H} 2}-\phi_{\mathrm{C}}^{0}\right) K_{\mathrm{C} \overline{\mathrm{S}} \mathrm{H} 2} K_{\mathrm{C}}}{K_{\mathrm{C} \overline{\mathrm{S}} \mathrm{H} 2} \phi_{\mathrm{C}}^{0}+V_{\mathrm{C} \overline{\mathrm{S}} \mathrm{H} 2}^{0} n_{\mathrm{C} \overline{\mathrm{S}} \mathrm{H} 2} K_{\mathrm{C}}}
$$

Consequently, the porosity of gypsum and cementitious materials can be derived from the assembly of Eq.(4.12), Eq.(4.4), Eq.(4.8) and Eq.(4.7).

For the whole sample, the porosity is the ratio of pore volume to the total volume. For $S_{\mathrm{C} \overline{\mathrm{S}} 2}=1$, the pore volume of the whole sample is the pore volume in gypsum gel. Thus the porosity of the sample is:

$$
\phi=\phi_{\mathrm{C} \overline{\mathrm{S}} \mathrm{H} 2} \phi_{\mathrm{C}}
$$

\subsubsection{Porosity of damaged cementitous materials}

Along with the accumulation of gypsum in cementitious material pores, the inner pressure could exceed the tensile strength of the cementitious material $\left(p^{\text {cr }}\right.$, which is 2-5 MPa for normal concrete (CEB-FIP, 1990 ) and set as 3.5 MPa in this paper). In that case, the pore structure is damaged. For now, the damage 
process is simplified in Fig.4.7 with abrupt softening.

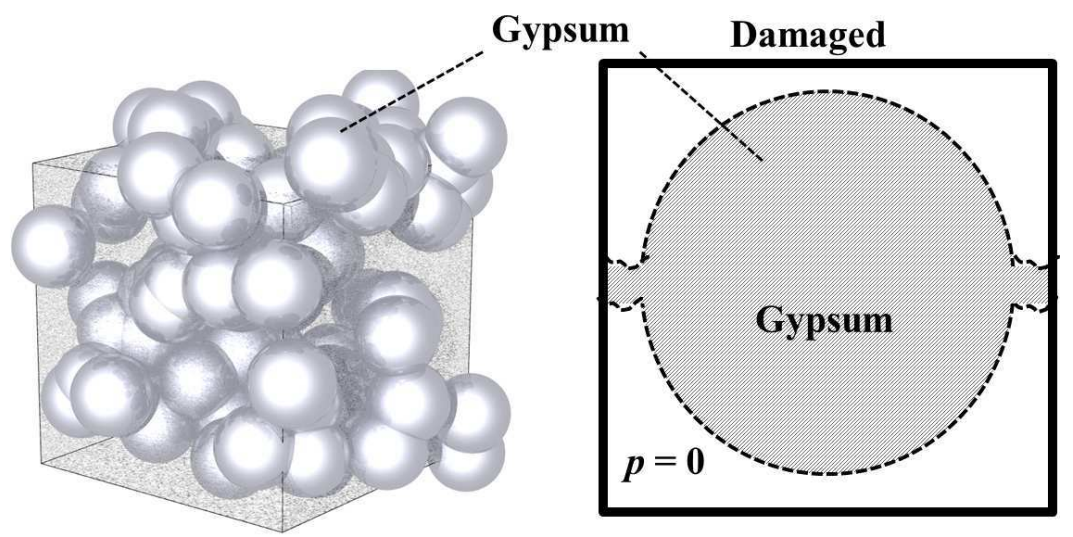

Figure 4.8: Schematics of the microstructure of damaged cementitous materials

Once the failure criterion $\left(p>p^{\mathrm{cr}}\right)$ is reached, the pore structure is fully damaged and characterized by a compression modulus equal to 0 . For the damaged materials, the inner pressure will be released $(p=0)$ and gypsum gel will swell freely. The microstructure of such sample can be considered as uncompressed gypsum gel with a porosity of $\phi_{\mathrm{C} \overline{\mathrm{S}} 2}^{0}$, and remained solid particles compounds such as unreacted portlandite and C-S-H, quartz and other non-reactive phases. The volume of remained solid particle, $V_{\text {remainedsolid }}$, can be calculated as follows:

$$
V_{\text {remained-solid }}=\left(1-\phi_{0}\right)-V_{\mathrm{CH}}\left(n_{\mathrm{CH}}^{0}-n_{\mathrm{CH}}\right)-\left(V_{\mathrm{C}-\mathrm{S}-\mathrm{H}}^{0} n_{\mathrm{Si}}^{0}-V_{\mathrm{C}-\mathrm{S}-\mathrm{H}} n_{\mathrm{Si}}\right)
$$

Therefore, the pore volume of the whole sample equals to pore volume of the gypsum fraction of sample and the porosity can be expressed as follows:

$$
\phi=\left(1-V_{\text {remained-solid }}\right) \phi_{\mathrm{C} \overline{\mathrm{S}} \mathrm{H} 2}^{0}
$$

\subsection{Examples of the evolution of porosity and solid volume}

To illustrate the evolution of the porosity and solid volume, the $\mathrm{H}_{2} \mathrm{~S}$ attack and $\mathrm{H}_{2} \mathrm{SO}_{4}$ attack are simulated in a REV similar to the case in Section 3.5.

For $\mathrm{H}_{2} \mathrm{~S}$ attack, solid volume assembling for calcium sulfide, $\mathrm{CH}$ and $\mathrm{C}-\mathrm{S}-\mathrm{H}$ is profiled in Fig.4.9. The volume occupied by portlandite decreases with the fast dissolution of portlandite. On the other hand, the space occupied by calcium sulfide, which starts to precipitate, increases. Since the molar volume of calcium sulfide is slightly less than that of portlandite, porosity increases from 0.33 to 0.36 when portlandite is completely dissolved. Compared to portlandite, the dissolution product of C-S-H (i.e., amorphous silica) 
occupies some space rather than decomposing in pore solution. Therefore, during the decrease of $\mathrm{Ca} / \mathrm{Si}$ ratio of C-S-H, porosity increases very little. However, after $\rho_{\mathrm{H}_{2} \mathrm{~S}}$ exceeds $0.0025 \mathrm{~mol} / \mathrm{L}$, a fast rising of porosity results from the dissolution of calcium sulfide. When calcium sulfide is fully dissolved, the only solid phase occupying space is amorphous silica and porosity reaches 0.64 .



Figure 4.9: Evolution of the solid volume and porosity vs. $\mathrm{H}_{2} \mathrm{~S}$ concentration in REV of cement paste

For $\mathrm{H}_{2} \mathrm{SO}_{4}$ attack, Fig.4.10 profiles the evolution of porosity and solid volume assembling versus $\mathrm{H}_{2} \mathrm{SO}_{4}$ concentration. Since the molar volume of gypsum is much bigger than that of portlandite, porosity decreases since the very initial time of gypsum precipitation. Very soon, porosity starts to increase because the pore structure damage by the inner pressure. The evolution of inner pressure is shown in Fig. 4.11. During the precipitation of gypsum, the inner pressure increases very fast. Once the inner pressure exceeds the strength of extension of sample, the pore structure fails. Consequently, the inner pressure is released and porosity starts to rise.

After C-S-H is fully decalcified, $95 \%$ of initial volume of REV is occupied by gypsum and amorphous silica, while porosity increases to 0.62 . Hence, the total volume of corrosion products is 2.5 times larger of the volume of initial sample. In the experiment conducted by (Okabe et al., 2007), a mortar sample with thickness of $8 \mathrm{~mm}$ was exposed to the sewer atmosphere for 1 year. According to the measurement of mortar surface, about $4 \mathrm{~mm}$ of mortar was corroded and the thickness of gypsum layer is $10 \mathrm{~mm}$ (as shown in Fig.4.12). Thus, the simulation result agrees with experiment observation. 


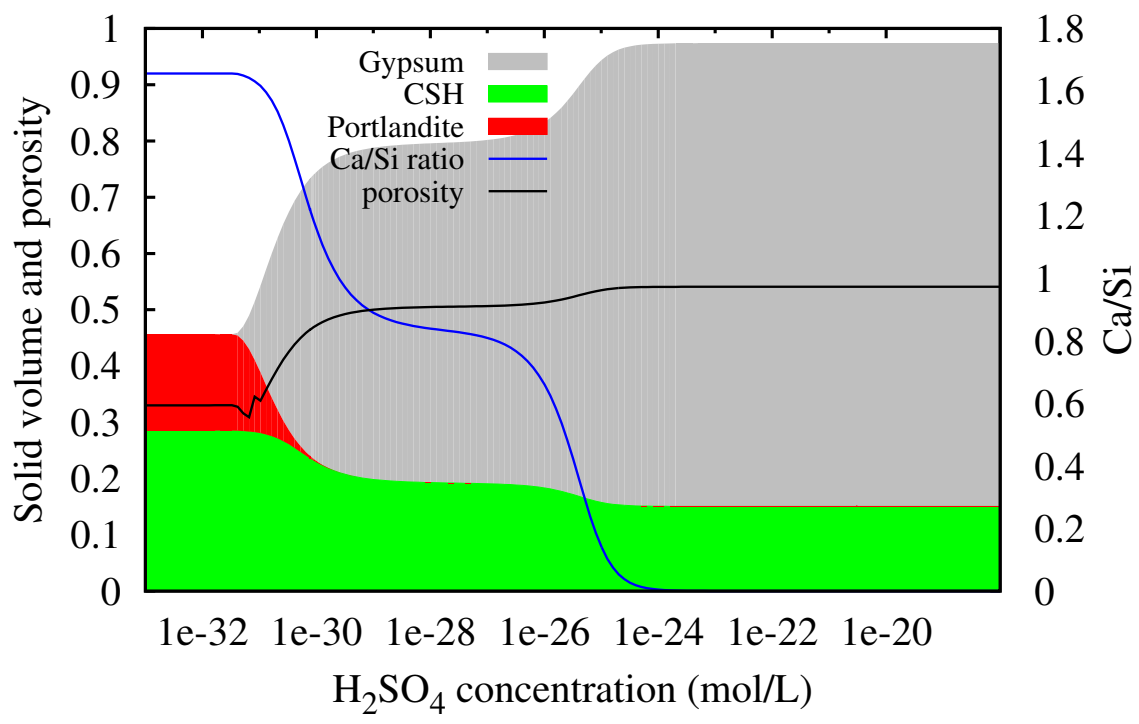

Figure 4.10: Evolution of the solid volume and porosity vs. $\mathrm{H}_{2} \mathrm{SO}_{4}$ concentration in REV of cement paste

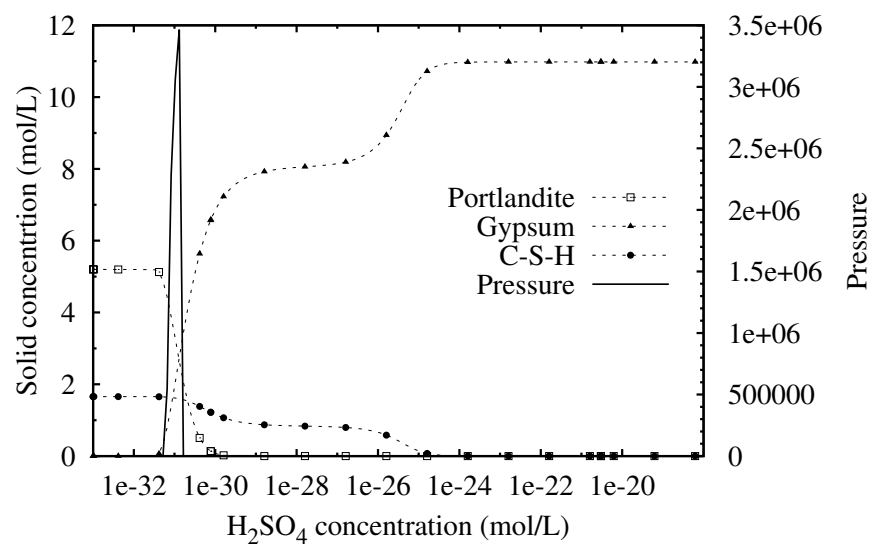

Figure 4.11: Evolution of inner pressure vs. content of $\mathrm{CH}$ and $\mathrm{C} \overline{\mathrm{S}} \mathrm{H} 2$ in REV of cement paste

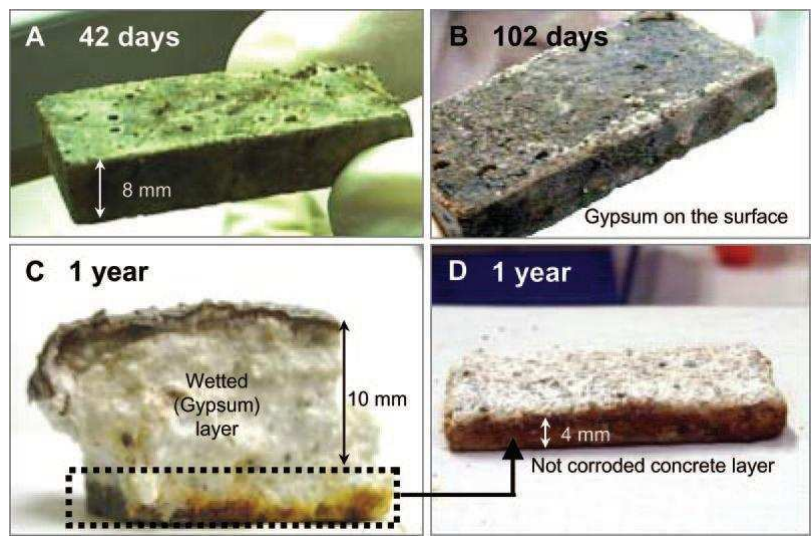

Figure 4.12: Concrete coupons exposed to the sewer atmosphere $\left[\mathrm{H}_{2} \mathrm{~S}, 30 \mathrm{ppm}\right]$ for 42 days (A), 102 days (B), and 1 year (C and D), showing the progression of concrete corrosion. (Okabe et al., 2007) 


\subsection{Conclusion}

This chapter introduces the porosity evolution induced by the precipitation and dissolution reactions during $\mathrm{H}_{2} \mathrm{~S}$ attack and $\mathrm{H}_{2} \mathrm{SO}_{4}$ attack. The molar volume of C-S-H depending on Ca/Si ratio is assumed by a bilinear function. When reacting with $\mathrm{H}_{2} \mathrm{~S}$, the volume of sample does not change and the change in porosity is calculated by the volume balance equation. Then the mechanism of the formation of gypsum is discussed. Thereafter, the failure of pore structure is taken into account, and the change in porosity is addressed by different methods for different conditions.

By simple cases of RVE without transport, the evolution of porosity and solid volume are illustrated. Both of $\mathrm{H}_{2} \mathrm{~S}$ and $\mathrm{H}_{2} \mathrm{SO}_{4}$ leads to the increase of porosity. During $\mathrm{H}_{2} \mathrm{~S}$ attack, the smaller molar volume and dissolution of $\mathrm{CaS}$ cause the reduction of solid volume which is responsible for the increase of porosity. For $\mathrm{H}_{2} \mathrm{SO}_{4}$ attack, the expansion of gypsum fills pores to reduce the porosity during early time. When the material is damaged, porous gypsum occupies most of the space and the sample expands to about 2.5 times of the initial volume.

Since no publication reports the porosity of the corrosion layer of $\mathrm{H}_{2} \mathrm{~S}$ or $\mathrm{H}_{2} \mathrm{SO}_{4}$ attack, the simulation results of porosity evolution can not be verified quantitatively and directly. On the other hand, the volume of initial and corroded sample is much easier to measure. For the expansion of gypsum layer, the simulation results are in good agreement with experimental observations.

In our study, we just applied a simplified damage model to determine the porosity change. To make a more precise prediction, a more detailed description of the physical behaviour of gypsum precipitation may be implemented. For example, according to Azam Azam (2007), the relationship between log of pressure and reduction of porosity of gypsum gel is linear, and the compression index is 0.12 . Furthermore, as more and more cement hydrates dissolve, the cementitious materials is soften gradually, while in our study the material is soften abruptly. 


\section{Chapter 5}

\section{Reactive transport modeling and}

\section{numerical procedures}

\subsection{Introduction}

The deterioration process is not only controlled by the chemical equilibrium but also by the transport of different species. In this paper, only diffusion of various species in saturated porous media is considered. Furthermore, the change of porosity, which is the result of dissolution/precipitation of solid phases, leads to the change of the diffusion rate of aqueous species. The coupling of transport and chemical equilibrium could be approached by reactive transport modeling.

To simulate the whole process of biodeterioration of sewer pipe, two types of porous materials are considered. One is cementitious materials which initially contains portlandite and C-S-H gel as hydration products and some non-reactive solid parts. The other one is biofilm which contains bacteria producing $\mathrm{H}_{2} \mathrm{SO}_{4}$. The chemical reactions and bio-chemical reactions are considered in cementitious materials part and biofilm part separately. Yet the various species diffuse not only in the cement part and biofilm but also across the interface between the two materials.

This work is implemented within the modeling platform, Bil ${ }^{1}$, based on the finite volume methods. Comparing with other reactive transport codes (Xu et al., 2008; Steefel, 2001; Lichtner, 2001), Bil can solve the couplings between the chemical reactions and the transport equations in one step.

In this chapter, the explanation of the field equations governing the coupling of transport and reactions is followed by the introduction of electro-diffusion equation of aqueous species. Then, the numerical tool Bil is introduced briefly. Numerical procedures and the coupling of transport equations and reaction equations

1. Bil is developed by Patrick Dangla. The source code can be downloaded at http://perso.lcpc.fr/dangla.patrick/bil/ 
are presented. By a simple biodeterioration example (a hydrated cement paste immersed in mixed culture of SOB which produces $\mathrm{H}_{2} \mathrm{SO}_{4}$ at a constant rate), the coupling of biofilm and cementitious materials is illustrated.

\section{$5.2 \quad$ Field equations}

\subsubsection{Mass balance equation of element}

The coupling of the transport and the chemical reactions is treated with the help of a set of mass balance equations. In this paper, the mass balance equations are applied to atoms such as sulfur (S), calcium (Ca), silicon $(\mathrm{Si})$, potassium $(\mathrm{K})$ and chlorine $(\mathrm{Cl})$. The amount of each element $\mathrm{A}(\mathrm{A}=\mathrm{S}, \mathrm{Ca}, \mathrm{Si}, \mathrm{K}, \mathrm{Cl})$ keeps balance in the system as follows:

$$
\frac{\partial n_{\mathrm{A}}}{\partial t}=-\operatorname{div} \underline{w_{\mathrm{A}}}
$$

where $n_{\mathrm{A}}$ represents the total molar content of element A per unit volume of porous medium (mol/L). There are two contributions to $n_{\mathrm{A}}$ associated to the liquid and solid (or gel) phases: $n_{\mathrm{A}}=\phi \rho_{\mathrm{A}}^{\mathrm{L}}+n_{\mathrm{A}}^{\mathrm{S}}$, where $\rho_{\mathrm{A}}^{\mathrm{L}}$ is the concentration of element $\mathrm{A}$ in pore solution $(\mathrm{mol} / \mathrm{L})$ and $n_{\mathrm{A}}^{\mathrm{S}}$ is the amount of element $\mathrm{A}$ in solid phase per litre of porous medium (mol/L). The concentration of each element can be found in Table 5.1 , where $n_{\mathrm{C}-\mathrm{S}-\mathrm{H}}$ represents the amount of element $\mathrm{Si}$ in all types of C-S-H gel with different Ca/Si ratio. Obviously, the total molar flow of $\mathrm{A}, \underline{w_{\mathrm{A}}}\left(\mathrm{mol} / \mathrm{m}^{2} \cdot \mathrm{s}\right)$, can be decomposed in the same manner as $n_{\mathrm{A}}$. The transport of species will be given in the following sections.

Table 5.1: Concentration of each element

\begin{tabular}{|c|c|c|c|}
\hline & Element & In the liquid phase $\left(\rho_{\mathrm{A}}^{\mathrm{L}}\right)$ & In the solid phase $\left(n_{\mathrm{A}}^{\mathrm{S}}\right)$ \\
\hline \multirow{2}{*}{ S } & $\mathrm{H}_{2} \mathrm{SO}_{4}$ attack & $\begin{array}{l}\rho_{\mathrm{H}_{2} \mathrm{SO}_{4}}+\rho_{\mathrm{HSO}_{4}^{+}}+\rho_{\mathrm{SO}_{4}^{2+}} \\
+\rho_{\mathrm{CaHSO}_{4}^{+}}+\rho_{\mathrm{CaSO}_{4}^{0}} \\
\end{array}$ & $n_{\mathrm{CS}} \mathrm{H} 2$ \\
\hline & $\mathrm{H}_{2} \mathrm{~S}$ attack & $\begin{array}{l}\rho_{\mathrm{H}_{2} \mathrm{~S}}+\rho_{\mathrm{HS}^{-}}+\rho_{\mathrm{S}^{2-}} \\
+\rho_{\mathrm{CaHS}^{+}}+\rho_{\mathrm{CaS}^{0}} \\
\end{array}$ & $n_{\mathrm{CaS}}$ \\
\hline \multirow{2}{*}{$\mathrm{Ca}$} & $\mathrm{H}_{2} \mathrm{SO}_{4}$ attack & $\begin{array}{l}\rho_{\mathrm{Ca}^{2+}}+\rho_{\mathrm{CaHSO}_{4}^{+}}+\rho_{\mathrm{CaOH}^{+}} \\
+\rho_{\mathrm{CaSO}_{4}^{0}}+\rho_{\mathrm{CaH}_{3} \mathrm{SiO}_{4}^{+}}+\rho_{\mathrm{CaH}_{2} \mathrm{SiO}_{4}}\end{array}$ & $n_{\mathrm{CH}}+n_{\mathrm{C} \overline{\mathrm{S}} \mathrm{H} 2}+x n_{\mathrm{C}-\mathrm{S}-\mathrm{H}}$ \\
\hline & $\mathrm{H}_{2} \mathrm{~S}$ attack & $\begin{array}{l}\rho_{\mathrm{Ca}^{2+}}+\rho_{\mathrm{CaHS}^{+}}+\rho_{\mathrm{CaOH}^{+}} \\
+\rho_{\mathrm{CaS}^{0}}+\rho_{\mathrm{CaH}_{3} \mathrm{SiO}_{4}^{+}}+\rho_{\mathrm{CaH}_{2} \mathrm{SiO}_{4}}\end{array}$ & $n_{\mathrm{CH}}+n_{\mathrm{CaS}}+x n_{\mathrm{C}-\mathrm{S}-\mathrm{H}}$ \\
\hline $\mathrm{Si}$ & $\mathrm{H}_{2} \mathrm{SO}_{4} / \mathrm{H}_{2} \mathrm{~S}$ attack & $\begin{array}{l}\rho_{\mathrm{H}_{2} \mathrm{SiO}_{4}^{2-}}+\rho_{\mathrm{H}_{3} \mathrm{SiO}_{4}^{-}}+\rho_{\mathrm{H}_{4} \mathrm{SiO}_{4}^{0}} \\
+\rho_{\mathrm{CaH}_{3} \mathrm{SiO}_{4}^{+}}+\rho_{\mathrm{CaH}_{2} \mathrm{SiO}_{4}}+\rho_{\mathrm{SiO}_{2}^{0}}\end{array}$ & $n_{\mathrm{C}-\mathrm{S}-\mathrm{H}}$ \\
\hline
\end{tabular}




\subsubsection{Balance equation of charge}

Each molecule, $i$, takes a fixed valence number, $z_{i}$, hence carrying a constant charge. Beside mass balance of elements, for each chemical reaction the charge keeps balanced (there is no source of charge in the chemical reactions). Such hypothesis of null current is commonly used in reactive transport models to take into account the ionic interactions (Xu et al., 2008; Steefel, 2001; Lichtner, 2001). As a consequence, the charge is governed by a global balance equation as follows:

$$
\operatorname{div} \underline{i}=0
$$

where $\underline{i}$ stands for the ionic current written as:

$$
\underline{i}=\sum_{i} z_{i} \underline{w_{i}}
$$

where the summation applies on the set of electrolyte ions. The ionic flow $\underline{w_{i}}\left(\mathrm{~mol} / \mathrm{m}^{2} \cdot \mathrm{s}\right)$, is given by a Nernst-Planck equation (Eq.(5.5)). Therefore an electric potential is generated in the medium providing electrostatic force on each ion so as to form an electroneutral pore solution. It follows that electroneutrality must be held in the medium:

$$
\sum_{i} z_{i} \rho_{i}=0
$$

Eqs.(5.1-5.5) are the set of the field equations governing the coupling of transport and chemistry.

\subsection{Transport of aqueous species}

Concerning the transport equations, we only consider the diffusion of aqueous species in saturated porous materials. The electro-diffusion (Nernst-Plank equation) as Eq.(5.5) is employed.

$$
\underline{w_{i}}=-D_{i}\left(\underline{\nabla \rho_{i}}+\rho_{i} \frac{F z_{i}}{R T} \underline{\nabla \psi}\right)
$$

where, $D_{i}$ represents the effective diffusion coefficient $\left(\mathrm{m}^{2} \cdot \mathrm{s}^{-1}\right)$ of species $i . F$ is the Faraday's constant $\left(96485 \mathrm{C} \cdot \mathrm{mol}^{-1}\right) . R$ is the gas constant $\left(8.31 \mathrm{~J} \cdot \mathrm{mol}^{-1} \mathrm{~K}^{-1}\right) . T$ is the absolute temperature in K. $z_{i}$ and $\rho_{i}$ stand for the ionic valence and the concentration species $i$. The first term in Eq.(5.5) refers to the diffusion effect due to the concentration gradient (in agreement with the Fick's law), and the second part accounts for the electrostatic effect.

For a saturated cement paste, $D_{i}$ of each species $i$ depends on the porosity. According to an empir- 
ical relationship between the effective diffusion coefficient and the porosity of sound materials (Eq.(5.6)) (Mainguy et al., 2000), when $\phi<0.92, D_{i}$ can be calculated as follows:

$$
D_{i}=D_{i}^{0} 2.9 \times 10^{-4} e^{9.95 \phi}
$$

The diffusion coefficient in pure water, $D_{i}^{0}$ could be obtained from experimental measurement. When experimental data is not available, $D_{i}^{0}$ is obtained from Stokes- Einstein equation (Eq.5.7) as follow:

$$
D_{i}^{0}=\frac{k_{B} T}{6 \pi \mu_{L} r_{i}}
$$

where $k_{B}=1.380648810^{-23} \mathrm{~J} / \mathrm{K}$ is Boltzmann's constant. $\mu_{L}$ is liquid water viscosity $(\mathrm{Pa} \cdot \mathrm{s})$. And $r_{i}$ is the radius of the aqueous species $i$, which is taken from (Lide, 2004; Conway and Conway, 1981). The collected diffusion coefficients of different aqueous species at $\mathrm{T}=298 \mathrm{~K}$ are listed in Table 5.2. Note that the diffusion coefficients of $\mathrm{Na}^{+}$and $\mathrm{K}^{+}$are quite similar, it is thus acceptable to assimilate these two species.

Table 5.2: Diffusion coefficients of different aqueous species at $\mathrm{T}=298 \mathrm{~K}$

\begin{tabular}{llc}
\hline Species & Value $\left(\mathrm{dm}^{2} / \mathrm{s}\right)$ & Reference \\
\hline$D_{\mathrm{OH}^{-}}^{0}$ & $5.273 \times 10^{-7}$ & (Weast et al., 1988) \\
$D_{\mathrm{H}^{+}}^{0}$ & $9.311 \times 10^{-7}$ & (Weast et al., 1988$)$ \\
$D_{\mathrm{H}_{2} \mathrm{~S}_{(a q)}}^{0}$ & $2.0 \times 10^{-7}$ & (Nesic et al., 2008$)$ \\
$D_{\mathrm{HS}^{-}}^{0}$ & $1.731 \times 10^{-7}$ & (Lide, 2004$), \mathrm{r}=1.91 \times 10^{-10} \mathrm{~m}$ \\
$D_{\mathrm{S}^{2-}}^{0}$ & $9.55 \times 10^{-8}$ & $\mathrm{r}=1.89 \times 10^{-10} \mathrm{~m}$ \\
$D_{\mathrm{H}_{2} \mathrm{SO}_{4}}^{0}$ & $1.545 \times 10^{-7}$ & $($ Lide, 2004$)$ \\
$D_{\mathrm{HSO}_{4}^{-}}^{0}$ & $1.385 \times 10^{-7}$ & (Weast et al. 1988$), \mathrm{r}=2.21 \times 10^{-10} \mathrm{~m}$ \\
$D_{\mathrm{SO}_{4}^{2-}}^{0}$ & $5.32 \times 10^{-8}$ & $\mathrm{r}=2.25 \times 10^{-10} \mathrm{~m}$ \\
$D_{\mathrm{Ca}^{2+}}^{0}$ & $7.92 \times 10^{-8}$ & $(\mathrm{Thiery}, 2006)$ \\
$D_{\mathrm{CaHSO}_{4}^{+}}^{0}$ & $1.07 \times 10^{-7}$ & $\mathrm{r}=2 . \times 10^{-10} \mathrm{~m}$ \\
$D_{\mathrm{CaHS}^{+}}^{0}$ & $1.07 \times 10^{-7}$ & $\mathrm{r}=2 . \times 10^{-10} \mathrm{~m}$ \\
$D_{\mathrm{CaOH}^{+}}^{0}$ & $1.07 \times 10^{-7}$ & $\mathrm{r}=2 . \times 10^{-10} \mathrm{~m}$ \\
$D_{\mathrm{CaSO}_{4(\mathrm{aq})}}^{0}$ & $1.43 \times 10^{-7}$ & $\mathrm{r}=1.5 \times 10^{-10} \mathrm{~m}$ \\
$D_{\mathrm{CaS}_{(\mathrm{aq})}}^{0}$ & $1.43 \times 10^{-7}$ & $\mathrm{r}=1.5 \times 110^{-10} \mathrm{~m}$ \\
$D_{\mathrm{H}_{4} \mathrm{SiO}_{4}^{0}}^{0}$ & $1.07 \times 10^{-7}$ & $\mathrm{r}=2 . \times 10^{-10} \mathrm{~m}$ \\
$D_{\mathrm{H}_{3} \mathrm{SiO}_{4}^{-}}^{0}$ & $1.07 \times 10^{-7}$ & $\mathrm{r}=2 . \times 110^{-10} \mathrm{~m}$ \\
$D_{\mathrm{H}_{2} \mathrm{SiO}_{4}^{2-}}^{2-}$ & $1.07 \times 10^{-7}$ & $\mathrm{r}=2 . \times 10^{-10} \mathrm{~m}$ \\
$D_{\mathrm{CaH}_{2} \mathrm{SiO}_{4}^{0}}^{0}$ & $1.07 \times 10^{-7}$ & $\mathrm{r}=2 . \times 10^{-10} \mathrm{~m}$ \\
$D_{\mathrm{CaH}_{3} \mathrm{SiO}_{4}^{+}}^{0}$ & $1.07 \times 10^{-7}$ & $\mathrm{r}=2 . \times 10^{-10} \mathrm{~m}$ \\
$D_{\mathrm{K}^{+}}^{0}$ & $1.957 \times 10^{-7}$ & $($ Weast et al., 1988$)$ \\
$D_{\mathrm{Cl}^{-}}^{0}$ & $2.032 \times 10^{-7}$ & $($ Weast et al., 1988$)$ \\
$D_{\mathrm{Na}^{+}}^{0}$ & $1.334 \times 10^{-7}$ & $($ Weast et al., 1988$)$ \\
\hline & & \\
& & \\
& &
\end{tabular}




\subsection{Introduction of numerical procedures}

\subsubsection{Introduction of finite volume method and Bil}

To solve the coupling of chemical equations and transport equations, a modeling platform, Bil, based on finite volume method is employed. The finite volume method is a discretization method which is well suited for the numerical simulation of various types of conservation laws. Similar to the finite difference method or finite element method, values are calculated at the nodes of a mesh. "Finite volume" refers to the small volume surrounding each node point of a mesh. In the finite volume method, volume integrals in a partial differential equation that contains a divergence term are converted to surface integrals, using the divergence theorem. These terms are then evaluated as fluxes at the surfaces of each finite volume. This method is widely used in computational fluid dynamics packages. In Appendix B, a more precisely introduction of the finite volume method is conducted through a simple example.

The modeling platform Bil, which is based on finite volume method, is dedicated to couple problems involved in environmental engineering, geomechanical engineering, material sciences, etc.(it can be downloaded on http://perso.lcpc.fr/dangla.patrick/bil). The structure of the code facilitates the development of new models. Bil is written in $\mathrm{C}$ language and runs on Linux-based OS. This platform is developed for 1D, 2D and 3D problems. It doesn't include mesh generator for 2D and 3D problems or post-processing treatment of outputs. However, it can read mesh files created by open-source software like Gmsh (Geuzaine and Remacle, 2009). The output files created by Bil can easily be used by some plotting programs such as Gnuplot (Racine, 2006). Compared to other numerical simulation tools used for the (biogenic) sulfuric acid attack (Jahani et al., 2001; Chalupeckỳ et al., 2012; De Windt and Devillers, 2010), Bil has two major advantages: first it solves the coupling of the chemical reactions and the transport equations in one step; second it uses different diffusion coefficients for each aqueous species. This is essential since the change in composition of cement-based material is generally diffusion controlled under saturated conditions. In addition, it handles the influence of the porosity changing on diffusion.

\subsubsection{Numerical procedures of dissolution and precipitation of solid phases}

As described in Chapter 3, dissolution and precipitation of any solid phases are controlled by a thermodynamical equilibrium. Out of the stability domain, solid component would dissolve completely. Thus for the stable solid component, $i$, the ion activity products $\left(Q_{i}\right)$ is equal to the equilibrium constant $\left(K_{i}\right)$. While at $Q_{i}<K_{i}$, the content of solid phase, $n_{i}$ (mol/L), is equal to 0. Thus Eq.5.8 can be obtained.

$$
n_{i} \cdot \log \left(\frac{Q_{i}}{K_{i}}\right)=0
$$


Obviously, $n_{i}$ is no less than 0 , while $\log \left(\frac{Q_{i}}{K_{i}}\right) \leq 0$ at stable state. Then, a variable, $\zeta_{i}$, can be introduced to determine if a solid component $i$ exists is dissolved as follows:

$$
\zeta_{i}=\frac{n_{i}}{n_{i}^{0}}+\log \left(\frac{Q_{i}}{K_{i}}\right)
$$

where, $n_{i}^{0}$ is the initial content of solid component $i(\mathrm{~mol} / \mathrm{L})$. At stable state, $Q_{i}$ is no bigger than $K_{i}$. Thus, $\zeta_{i}>0$ means that $i$ exists stable and $\zeta_{i}$ is noted as $\zeta_{i}^{+}=\frac{n_{i}}{n_{i}^{0}} . \zeta_{i}<0$ represents the dissolved $i$ and $\zeta_{i}$ is noted as $\zeta_{i}^{-}=\log \left(\frac{Q_{i}}{K_{i}}\right)$.

In this section, we take $\mathrm{H}_{2} \mathrm{SO}_{4}$ attack for instance to describe the numerical procedures of dissolution/precipitation progress. For the equilibrium between $\mathrm{CH}$ and $\mathrm{C} \overline{\mathrm{S}} \mathrm{H} 2$, according to the equilibrium equation (Eq.3.13), Table 5.3 can be obtained easily.

Table 5.3: The key parameters of CH-C $\overline{\mathrm{S}} \mathrm{H} 2$ equilibrium at different stable states

\begin{tabular}{|c|c|c|c|}
\hline Stable phase & $\frac{\rho_{\mathrm{H}_{2} \mathrm{SO}_{4}}}{\rho_{\mathrm{H}_{2} \mathrm{SO}_{4}}^{\mathrm{CH}}}$ & $\frac{Q_{\mathrm{CH}}}{K_{\mathrm{CH}}}$ & $\frac{Q_{\mathrm{C} \overline{\mathrm{S}} \mathrm{H} 2}}{K_{\mathrm{C} \overline{\mathrm{S}} \mathrm{H} 2}}$ \\
\hline $\begin{array}{l}\text { Only CH } \\
n_{\mathrm{CH}} \geq 0\end{array}$ & $<1$ & $=1$ & $<1$ \\
\hline 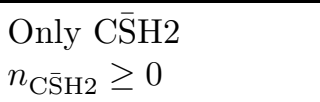 & $>1$ & $<1$ & $=1$ \\
\hline $\begin{array}{l}\mathrm{CH} \& \mathrm{C} \overline{\mathrm{S}} \mathrm{H} 2 \\
n_{\mathrm{CH}} \geq 0, n_{\mathrm{C} \overline{\mathrm{S}} \mathrm{H} 2} \geq 0\end{array}$ & $=1$ & $=1$ & $=1$ \\
\hline
\end{tabular}

Thus, it is possible to illustrate the dissolution of both $\mathrm{CH}$ and $\mathrm{CS} H 2$ with one variable $\zeta_{\mathrm{Ca}}$, defined as follows:

$$
\zeta_{\mathrm{Ca}}=\frac{n_{\mathrm{CH}}+n_{\mathrm{C} \overline{\mathrm{S}} \mathrm{H} 2}}{n_{\mathrm{Ca}}^{0}}+\log \left[\max \left(\frac{Q_{\mathrm{CH}}}{K_{\mathrm{CH}}}, \frac{Q_{\mathrm{C} \overline{\mathrm{S}} \mathrm{H} 2}}{K_{\mathrm{C} \overline{\mathrm{S}} \mathrm{H} 2}}\right)\right]
$$

where $n_{\mathrm{Ca}}^{0}$ is the initial $\mathrm{CH}$ content. Therefore, when $\rho_{\mathrm{H}_{2} \mathrm{SO}_{4}}>\rho_{\mathrm{H}_{2} \mathrm{SO}_{4}}^{\mathrm{CH}}, \mathrm{CH}$ is not stable. $\zeta_{\mathrm{Ca}}$ is in the form as:

$$
\zeta_{\mathrm{Ca}}=\frac{n_{\mathrm{CH}}+n_{\mathrm{C} \overline{\mathrm{S}} \mathrm{H} 2}}{n_{\mathrm{Ca}}^{0}}+\log \left(\frac{Q_{\mathrm{C} \overline{\mathrm{S}} \mathrm{H} 2}}{K_{\mathrm{C} \overline{\mathrm{S}} \mathrm{H} 2}}\right)
$$

For $\zeta_{\mathrm{Ca}}>0$, gypsum can precipitate. If $\zeta_{\mathrm{Ca}}<0$, gypsum is not stable either.

If $\rho_{\mathrm{H}_{2} \mathrm{SO}_{4}} \leq \rho_{\mathrm{H}_{2} \mathrm{SO}_{4}}^{\mathrm{CH}}, \mathrm{CS} \mathrm{H} 2$ is not stable. We have:

$$
\zeta_{\mathrm{Ca}}=\frac{n_{\mathrm{CH}}+n_{\mathrm{C} \overline{\mathrm{S}} 2}}{n_{\mathrm{Ca}}^{0}}+\log \left(\frac{Q_{\mathrm{CH}}}{K_{\mathrm{CH}}}\right)
$$

For $\zeta_{\mathrm{Ca}}>0$, portlandite can precipitate and for $\zeta_{\mathrm{Ca}}<0$, portlandite is not stable.

Let's assume that at time $t$, the system of $\mathrm{CH} / \mathrm{CS} H 2$ contains $n_{\mathrm{CH}}^{t}$ and $n_{\mathrm{C} \overline{\mathrm{S}} 2}^{t}$. After a time difference, 
$\mathrm{d} t$, the concentration of $\mathrm{H}_{2} \mathrm{SO}_{4}$ changes to $\rho_{\mathrm{H}_{2} \mathrm{SO}_{4}}$. Using the simple kinetic law of the dissolution of $\mathrm{CH}$ given by Eq.(3.15), as indicated in Chapter 3, the change in the amount of $\mathrm{CH}$ is $\mathrm{d} n_{\mathrm{CH}}$ as follows:

$$
d n_{\mathrm{CH}}=-n_{\mathrm{CH}} \frac{d t}{\tau_{\mathrm{CH}}} \ln \left(\frac{\rho_{\mathrm{H}_{2} \mathrm{SO}_{4}}}{\rho_{\mathrm{H}_{2} \mathrm{SO}_{4}}^{\mathrm{CH}}}\right)
$$

Thus, after $d t$ the amount of $\mathrm{CH}$ can be expressed as follows:

$$
n_{\mathrm{CH}}^{t+d t}=n_{\mathrm{CH}}^{t}+d n_{\mathrm{CH}}
$$

With the help of $\zeta_{\mathrm{Ca}}$, the amount of $\mathrm{C} \overline{\mathrm{S}} \mathrm{H} 2$ is changed to $n_{\mathrm{C} \overline{\mathrm{S}} \mathrm{H} 2}^{t+d t}$ as follows:

$$
n_{\mathrm{CS} H 2}^{t+d t}=\zeta_{\mathrm{Ca}}^{+} n_{\mathrm{Ca}}^{0}-n_{\mathrm{CH}}^{t+d t}
$$

where, $\zeta_{\mathrm{Ca}}^{+}=\max \left(\zeta_{\mathrm{Ca}}, 0\right)$ is the positive part of variable $\zeta_{\mathrm{Ca}}$.

For the dissolution of C-S-H we can employ a similar variable $\zeta_{\mathrm{Si}}$, defined as:

$$
\zeta_{\mathrm{Si}}=\frac{n_{\mathrm{C}-\mathrm{S}-\mathrm{H}}}{n_{\mathrm{C}-\mathrm{S}-\mathrm{H}}^{0}}+\log \left(\frac{Q_{\mathrm{SH}_{t}}}{Q_{\mathrm{SH}_{t}(e q)}}\right)
$$

where, $n_{\mathrm{C}-\mathrm{S}-\mathrm{H}}$ is the molar content of C-S-H in the form of $\mathrm{C}_{x} \mathrm{~S}_{1} \mathrm{H}_{z}$ including $\mathrm{SH}_{t}$. $n_{\mathrm{C}-\mathrm{S}-\mathrm{H}}^{0}$ is the initial molar content of C-S-H. $Q_{\mathrm{SH}_{\mathrm{t}}}$ is the ion activity product of the dissociation reaction of $\mathrm{SH}_{\mathrm{t}} \cdot Q_{\mathrm{SH}_{\mathrm{t}}(\mathrm{eq})}$ is the equilibrium ion activity product of $\mathrm{SH}_{\mathrm{t}}$ at given $\mathrm{Ca} / \mathrm{Si}$ ratio. $Q_{\mathrm{SH}_{\mathrm{t}}(\mathrm{eq})}$ can be calculated by Eq. (5.17) discussed in Section 3.4:

$$
\ln \left(\frac{Q_{\mathrm{SH}_{t}(\mathrm{eq})}}{K_{\mathrm{SH}_{t}}}\right)=-\int_{0}^{\frac{Q_{\mathrm{CH}}}{K_{\mathrm{CH}}}} \frac{\chi(q)}{q} d q
$$

In Eq. (5.16), $\frac{n_{\mathrm{C}-\mathrm{S}-\mathrm{H}}}{n_{\mathrm{C}-\mathrm{S}-\mathrm{H}}^{0}}$ represents the molar content of $\mathrm{Si}$ in solid phase. When $\zeta_{\mathrm{Si}}>0, Q_{\mathrm{SH}_{\mathrm{t}}}=Q_{\mathrm{SH}_{\mathrm{t}}(\mathrm{eq})}$, which means that in equilibrium with C-S-H solid $Q_{\mathrm{SH}_{\mathrm{t}}}$ is a function of only $\frac{Q_{\mathrm{CH}}}{K_{\mathrm{CH}}}$. When $\zeta_{\mathrm{Si}}<0$, there is no C-S-H solid. In such case, $Q_{\mathrm{SH}_{\mathrm{t}}}$ can be attained by $\zeta_{\mathrm{Si}}^{-}$and $\frac{Q_{\mathrm{CH}}}{K_{\mathrm{CH}}}$.

\subsubsection{Governing equations and primary variables}

As introduced in Chapter 3, with known value of $\rho_{\mathrm{H}_{2} \mathrm{SO}_{4}} / \rho_{\mathrm{H}_{2} \mathrm{~S}}, \rho_{\mathrm{Ca}^{2+}}$, and $\rho_{\mathrm{H}_{4} \mathrm{SiO}_{4}^{0}}$, the concentration of all aqueous species (except $\rho_{\mathrm{K}^{+}}$and $\rho_{\mathrm{Cl}^{-}}$) can be calculated from Table.3.1. Through the primary variables $\left(p_{\mathrm{H}_{2} \mathrm{~S}}, \rho_{\mathrm{H}_{2} \mathrm{SO}_{4}}, \zeta_{\mathrm{Ca}}\right.$ and $\left.\zeta_{\mathrm{Si}}\right)$, the secondary variables such as $\rho_{\mathrm{H}_{2} \mathrm{~S}}^{0}, \rho_{\mathrm{Ca}^{2+}}$ and $\rho_{\mathrm{H}_{4} \mathrm{SiO}_{4}^{0}}$ can be computed. $\rho_{\mathrm{K}^{+}}$and $\rho_{\mathrm{Cl}^{-}}$are considered as primary variables as well.

Governing equations versus primary variables in the model are listed in Table 5.4. 
Table 5.4: Governing equations and primary variables in the model

\begin{tabular}{ll}
\hline Governing Equations & Primary Variables \\
\hline Sulfur $(\mathrm{S})$ & $\rho_{\mathrm{H}_{2} \mathrm{SO}_{4}} /$ Gas pressure of $\mathrm{H}_{2} \mathrm{~S} P_{\mathrm{H}_{2} \mathrm{~S}}$ or $\rho_{\mathrm{H}_{2} \mathrm{~S}}^{0}$ \\
Calcium $(\mathrm{Ca})$ & $\zeta_{\mathrm{Ca}}$ \\
Silicon $(\mathrm{Si})$ & $\zeta_{\mathrm{Si}}$ \\
Potassium $(\mathrm{K})$ & $\rho_{\mathrm{K}}^{+}$ \\
Chlorine $(\mathrm{Cl})$ & $\rho_{\mathrm{Cl}}^{-}$ \\
Charge & Electric potential $\psi$ \\
\hline
\end{tabular}

Taking $\mathrm{H}_{2} \mathrm{SO}_{4}$ attack for instance, according to section 5.4.2 $Q_{\mathrm{C} \overline{\mathrm{S}} 2}$ can be expressed as follows:

$$
Q_{\mathrm{C} \overline{\mathrm{S}} 2}=10^{\left(\zeta_{\mathrm{Ca}}^{-}\right)} \min \left(z_{\mathrm{H}_{2} \mathrm{SO}_{4}}, 1\right) K_{\mathrm{C} \overline{\mathrm{S}} 2}
$$

where, $z_{\mathrm{H}_{2} \mathrm{SO}_{4}}=\frac{\rho_{\mathrm{H}_{2} \mathrm{SO}_{4}}}{\rho_{\mathrm{H}_{2} \mathrm{SO}_{4}}^{\mathrm{SH}_{4}}}$. Thus, $\rho_{\mathrm{Ca}^{2+}}$ can be calculated by the following equation:

$$
\rho_{\mathrm{Ca}^{2+}}=\frac{Q_{\mathrm{C} \overline{\mathrm{S}} 2}}{\rho_{\mathrm{SO}_{4}^{2-}}}
$$

where, $\rho_{\mathrm{SO}_{4}^{2-}}$ can be easily obtained with $\rho_{\mathrm{H}_{2} \mathrm{SO}_{4}}$ and Eq. (3.10).

Similarly, $\rho_{\mathrm{H}_{4} \mathrm{SiO}_{4}^{0}}$ can be attained as follows:

$$
\rho_{\mathrm{H}_{4} \mathrm{SiO}_{4}^{0}}=Q_{\mathrm{SH}_{\mathrm{t}}}=10^{\zeta_{\mathrm{Si}}^{-}} Q_{\mathrm{SH}_{\mathrm{t}}(\mathrm{eq})}(\text { see Eq. }(5.16))
$$

where $Q_{\mathrm{SH}_{\mathrm{t}}(\mathrm{eq})}$ is defined in Eq. (5.17).

\subsection{Examples of bio-deterioration modeling}

\subsubsection{Coupling of transport and chemical reactions}

For a better understanding of the coupling of bio-chemistry process and chemistry process, it is necessary to demonstrate the chemistry process firstly. A simple $\mathrm{H}_{2} \mathrm{SO}_{4}$ attack example is employed to illustrate the coupling of transport and chemical reactions. A cement paste cube with side length of $1 \mathrm{~cm}$ is considered and divided into 100 nodes. The cement paste contains initially $5.2 \mathrm{~mol} / \mathrm{L}$ of portlandite and $3.9 \mathrm{~mol} /$ of jennite (i.e., $\mathrm{C}_{1.67} \mathrm{SH}_{2.6}$ ), with porosity $33 \%$. The material is saturated with water and immersed in $\mathrm{H}_{2} \mathrm{SO}_{4}$ solution. To simulate a severe acid environment, the concentration of unionized molecules of $\mathrm{H}_{2} \mathrm{SO}_{4}$, $\rho_{\mathrm{H}_{2} \mathrm{SO}_{4}}^{0}$, at the sample surface is constant at $1.0 \times 10^{-8} \mathrm{~mol} / \mathrm{L}$ (i.e., the concentration of total sulfate ions is $8.0 \times 10^{-2} \mathrm{~mol} / \mathrm{L}$ is and the approximate $p \mathrm{H}$ keeps at 1$)$. Due to the high concentration of hydrogen ion, the characteristic time $\tau_{\mathrm{CH}}$ and $\tau_{\mathrm{CS} H 2}$ is $2000 \mathrm{~s}$. For the sake of simplicity, no alkali is added in the example. Given the very small solubility of $\mathrm{CS} H 2$ and $\mathrm{SH}_{t}$ in low $p \mathrm{H}$ condition, the leaching of calcium and silicon 
should be prevented at the sample surface. Thus, no diffusion is allowed at boundary. Considering that the surface of sample is in contact with $\mathrm{H}_{2} \mathrm{SO}_{4}$ solution, the schematic of sample is summarized in Table 5.5 as well as the initial and boundary conditions. Due to symmetry, only half of the sample is discretized.

Table 5.5: Boundary and initial conditions of the $\mathrm{H}_{2} \mathrm{SO}_{4}$ attack example

\begin{tabular}{|c|c|c|}
\hline $\begin{array}{c}\text { Balance } \\
\text { Equation }\end{array}$ & $\begin{array}{c}\text { Boundary conditions } \\
\text { Surface }\end{array}$ & $\begin{array}{c}\text { Initial conditions } \\
\text { Cement paste }\end{array}$ \\
\hline Sulfur $(\mathrm{S})$ & $\begin{array}{c}\text { diffusion allowed } \\
\rho_{\mathrm{H}_{2} \mathrm{SO}_{4}}=10^{-8} \mathrm{~mol} / \mathrm{L}\end{array}$ & $\rho_{\mathrm{H}_{2} \mathrm{SO}_{4}}=10^{-31.5} \mathrm{~mol} / \mathrm{L}$ \\
\hline Calcium $(\mathrm{Ca})$ & no diffusion & $\zeta_{\mathrm{Ca}}=1$ \\
\hline Silicon $(\mathrm{Si})$ & no diffusion & $\zeta_{\mathrm{Si}}=1$ \\
\hline Sodium/Potassium & no diffusion & $\rho_{\mathrm{K}}^{+}=0$ \\
\hline Chlorine $(\mathrm{Cl})$ & no diffusion & $\rho_{\mathrm{Cl}}^{-}=0$ \\
\hline Charge & $\psi=0$ & $\psi=0$ \\
\hline
\end{tabular}

The distribution of $\mathrm{H}_{2} \mathrm{SO}_{4}$ concentration and the evolution of $p \mathrm{H}$ in the material from 0 to 60 days are profiled in Fig.5.1 and Fig.5.2 Note that the direction of $\mathrm{H}_{2} \mathrm{SO}_{4}$ attack is from right to left. With $\mathrm{H}_{2} \mathrm{SO}_{4}$ penetrating into sample, $p \mathrm{H}$ of the materials decreases form 12.4, which is the value of $p \mathrm{H}$ in the uncorroded zone, to 1 gradually.

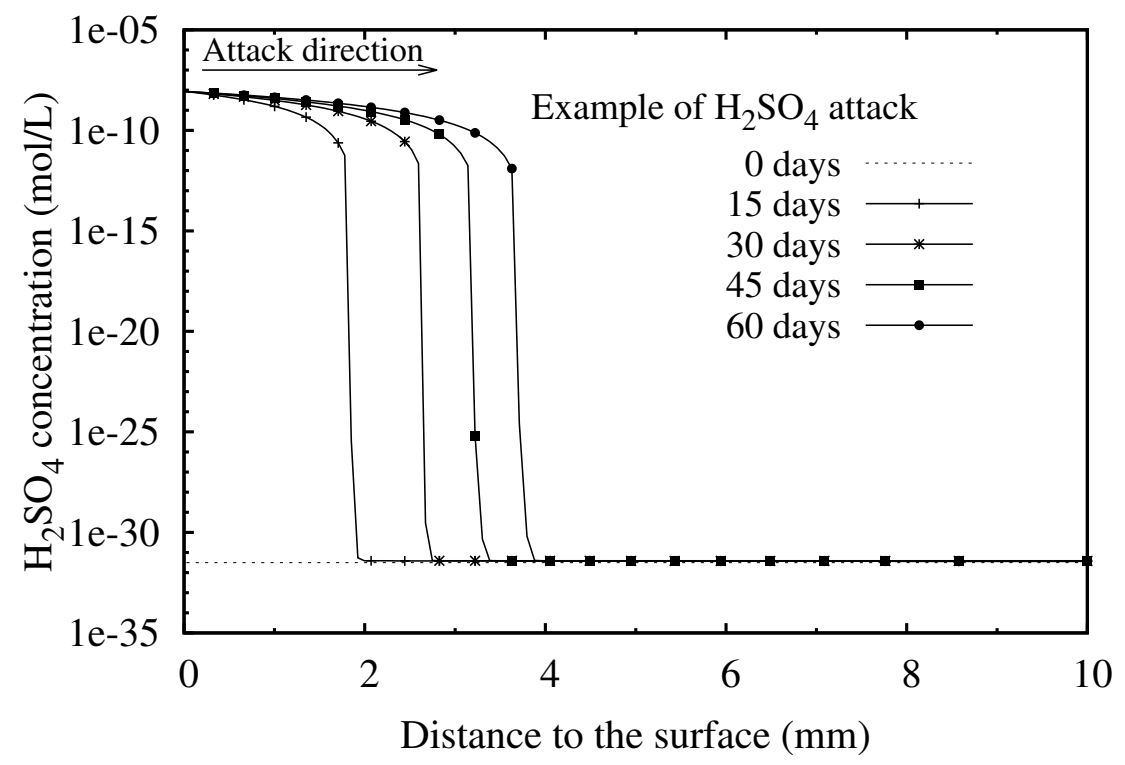

Figure 5.1: $\mathrm{H}_{2} \mathrm{SO}_{4}$ concentration profiles from 0 day to 60 days.

While reacting with $\mathrm{H}_{2} \mathrm{SO}_{4}$, solid compositions of the sample starts to change. To illustrate the evolution of solid compositions, some definitions should be made to indicate the fronts and zones. Taking the solid volume profiles after 15 days immersion for instance (see Fig. 5.3):

Portlandite dissolution front, indicated by Pf: The place where $\mathrm{CH}$ starts to dissolve.

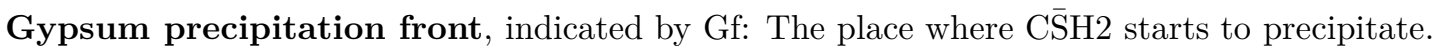




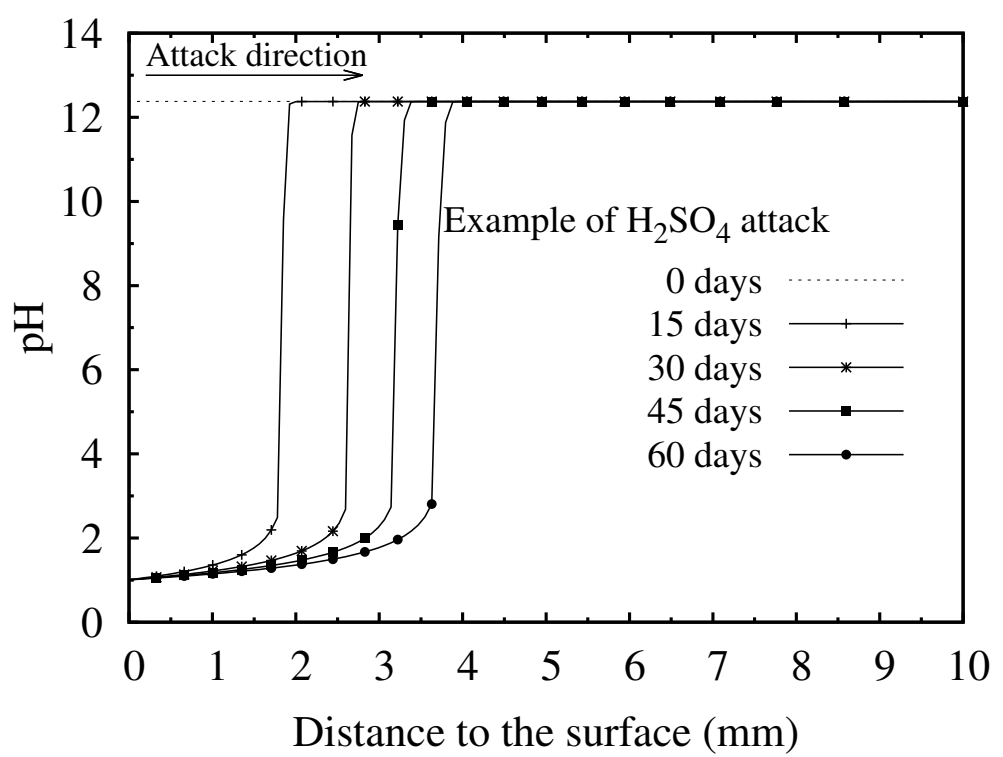

Figure 5.2: $p \mathrm{H}$ value profiles from 0 day to 60 days.

C-S-H decalcification front, indicated by $\mathrm{Cf}$ : The place where the Ca/Si ratio of C-S-H starts to decrease.

$\mathbf{S H}_{t}$ precipitation front, indicated by Sf: The place where the decalcification process of C-S-H is complete (i.e., only $\mathrm{SH}_{t}$ remains).

Damage front, indicated by dash line: The place where the material is fully damaged.

With the help of these fronts, several zones can be distinguished:

Uncorroded zone: The zone between the core of the sample and portlandite dissolution front, where the material remains intact.

C-S-H decalcification zone: The zone between C-S-H decalcification front and $\mathrm{SH}_{t}$ precipitation front, where the $\mathrm{Ca} / \mathrm{Si}$ ratio decreases gradually.

Gypsum layer: The zone between gypsum precipitation front and the material surface in contact with $\mathrm{H}_{2} \mathrm{SO}_{4}$, where gypsum accumulates. The volume of this layer is larger than the volume of uncorroded material.

Damaged zone: The zone between damage front and the initial surface of material, where pore structure is damaged and the material has no strength. In this study, we take the thickness of this layer as the corrosion depth which is commonly measured to evaluate the deterioration in experiments.

Fully degraded zone: The zone between $\mathrm{SH}_{t}$ precipitation front and the material surface in contact with $\mathrm{H}_{2} \mathrm{SO}_{4}$, where only gypsum, amorphous silica gel and unreactable solid phased exists.

With the change in the solid compositions, the porosity changes as well. From Fig.5.3, the porosity starts to increase at the same point of the portlandite dissolution front. In the damaged zone, porosity 


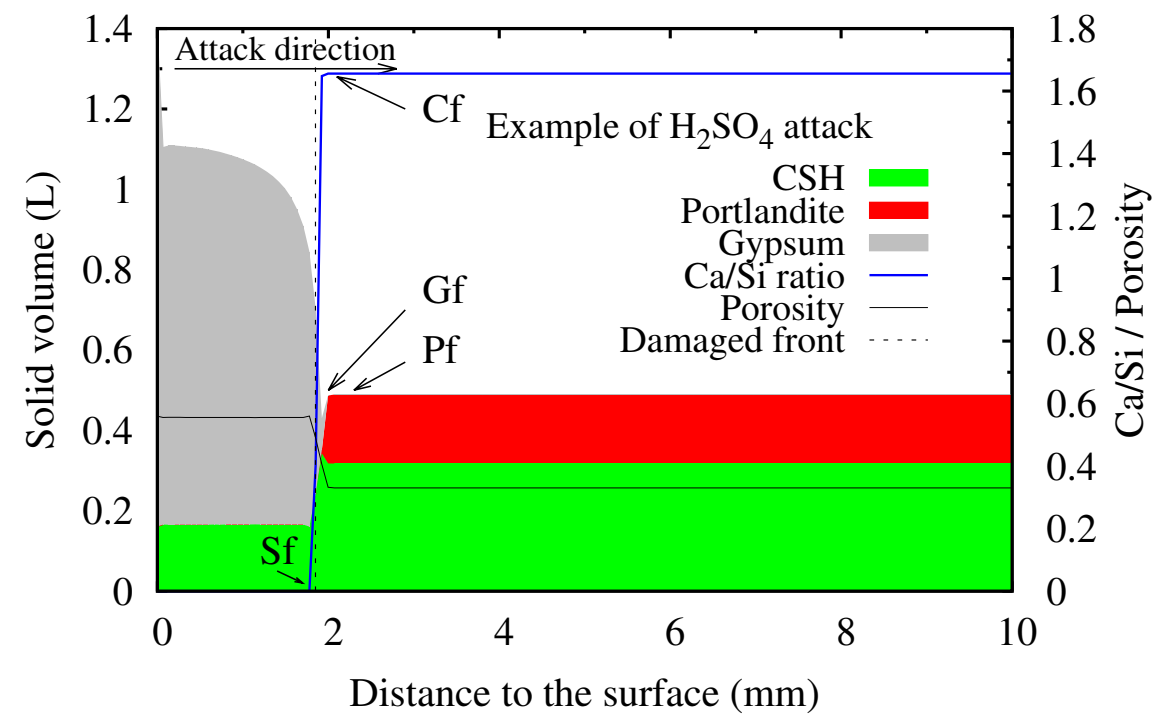

Figure 5.3: Solid profiles after 15 days immersion

reaches to 0.556 . Since the characteristic time $\tau_{\mathrm{CS} H 2}$ is very short and the pores fail abruptly, the process of porosity change caused by inner pressure is not clear in Fig. 5.3. Thus, the evolution of porosity and solid compositions at the position of $2 \mathrm{~mm}$ away from the right surface versus time are presented in Fig.5.4.

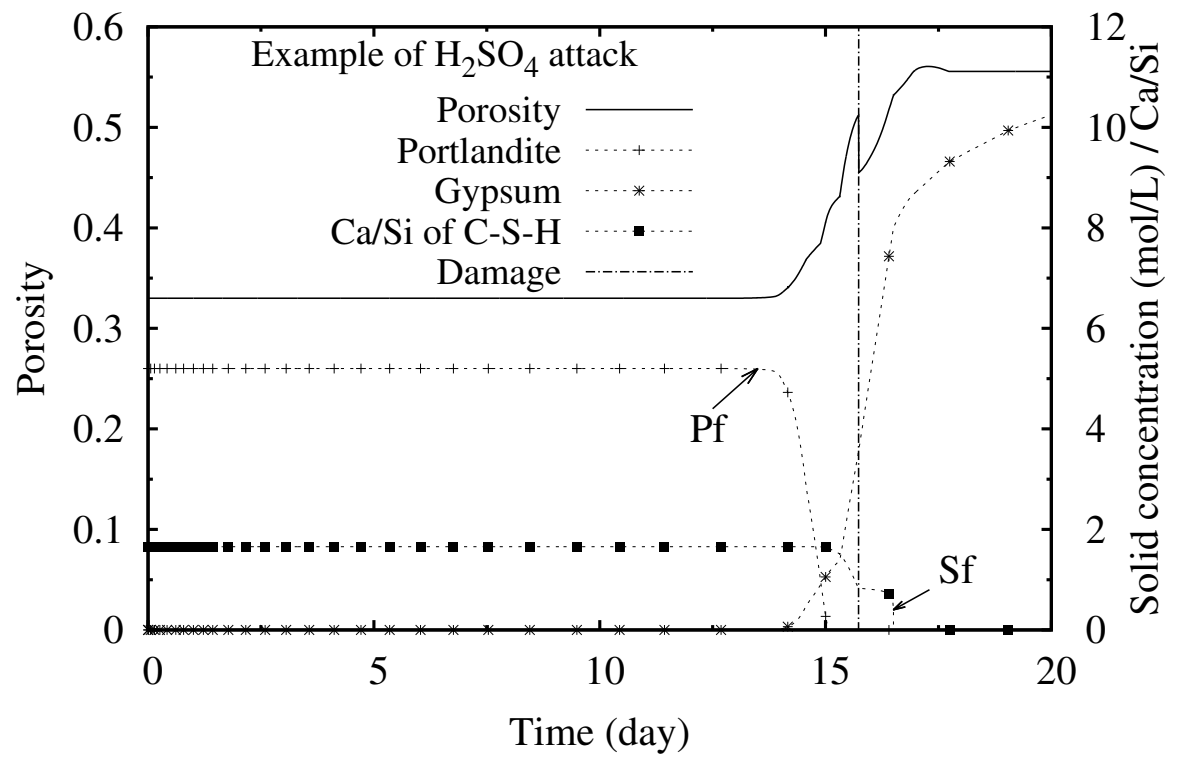

Figure 5.4: Evolution of porosity and solid compositions of material versus immersion time.

From the $\mathrm{CH}$ dissolution front to the damage front, the porosity increases from 0.33 to 0.47 due to $\mathrm{CH}$ dissolution as well as C-S-H decalcification. Along with gypsum forming, pores are filled up. Given that gypsum gel is compressed by the inner pressure, the porosity decreases then sharply to 0.43. The inner 
pressure exceeds the strength of the material very fast. Thereafter, the pore structure is damaged and the porosity turns back to rise until C-S-H is fully decalcificated indicated by Sf. In the fully degraded zone, porosity reaches to 0.556 .

As introduced before, the equilibrium between $\mathrm{CH}$ and $\mathrm{C} \overline{\mathrm{S}} \mathrm{H} 2$ is controlled by the concentration of $\mathrm{H}_{2} \mathrm{SO}_{4}$ and the content of $\mathrm{CH}$ and $\mathrm{CS} H 2$ can be addressed by $\zeta_{\mathrm{Ca}}$. The relationship between the content of $\mathrm{CH}$ and $\mathrm{C} \overline{\mathrm{S}} \mathrm{H} 2$ and $\log \left(z_{\mathrm{H}_{2} \mathrm{SO}_{4}}\right)\left(z_{\mathrm{H}_{2} \mathrm{SO}_{4}}=\frac{\rho_{\mathrm{H}_{2} \mathrm{SO}_{4}}}{\rho_{\mathrm{H}_{2} \mathrm{SO}_{4}}^{\mathrm{CH}}}\right)$ is shown in Fig.5.5, where the CH dissolution front doesn't appear until $z_{\mathrm{H}_{2} \mathrm{SO}_{4}}>1$. Thus, the region where $\log \left(z_{\mathrm{H}_{2} \mathrm{SO}_{4}}\right)=0$ is the uncorroded zone. Resulting from the $\mathrm{CH}$ dissolution, $\zeta_{\mathrm{Ca}}$ decreases from 1 at first. While at the $\mathrm{C} \overline{\mathrm{S}} \mathrm{H} 2$ precipitation front, $\zeta_{\mathrm{Ca}}$ starts to rise sharply. Along with the accumulation of $\mathrm{C} \overline{\mathrm{S}} \mathrm{H} 2, \zeta_{\mathrm{Ca}}$ increases in gypsum layer.

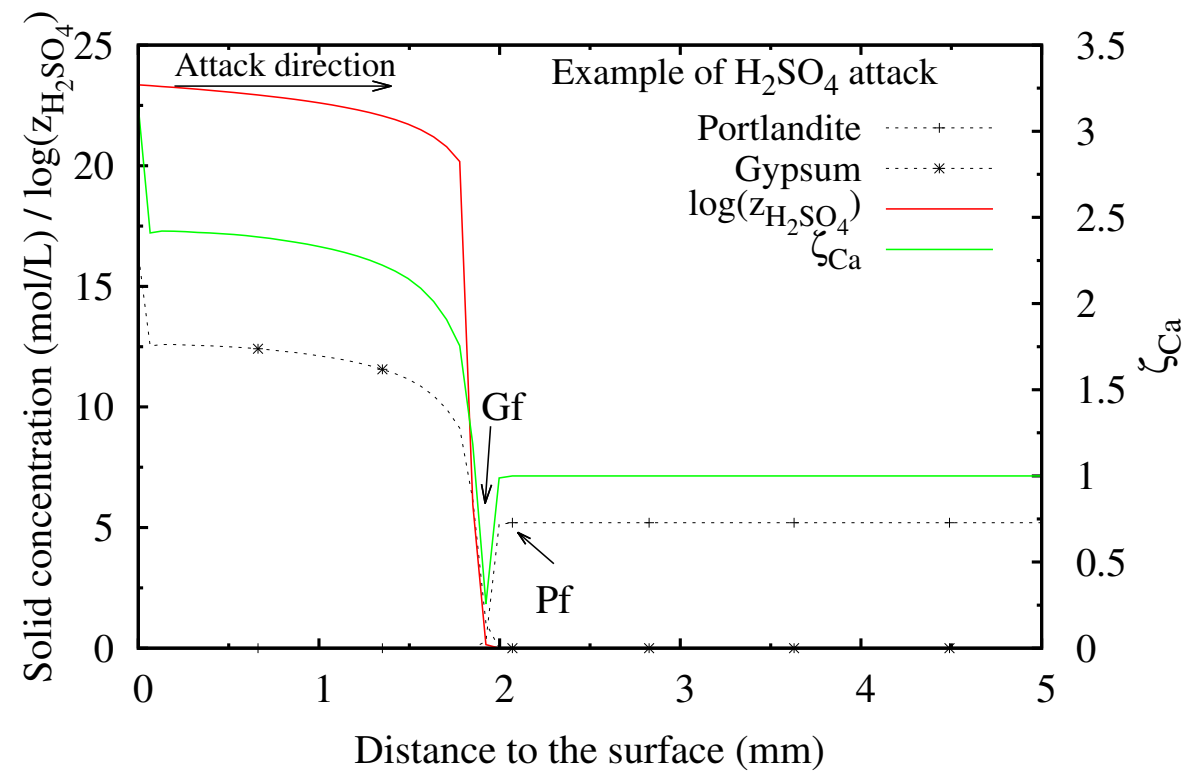

Figure 5.5: $\mathrm{CH}$ and $\mathrm{CS} H 2$ content, $\zeta_{\mathrm{Ca}}$ and $\log \left(z_{\mathrm{H}_{2} \mathrm{SO}_{4}}\right)$ after 15 days immersion

It should be noticed that $\mathrm{C} \overline{\mathrm{S}} \mathrm{H} 2$ starts to precipitate after $\mathrm{CH}$ dissolution front and lots of $\mathrm{C} \overline{\mathrm{S}} \mathrm{H} 2$ accumulates at surface. Such phenomenon is related to the difference between the diffusion of different aqueous species. As shown in Fig.5.6, $\mathrm{SO}_{4}^{2-}$ is consumed at $\mathrm{C} \overline{\mathrm{S}} \mathrm{H} 2$ precipitation front, while not enough $\mathrm{SO}_{4}^{2-}$ transports to the $\mathrm{CH}$ dissolution front to form $\mathrm{C} \overline{\mathrm{S}} \mathrm{H} 2$. Thus, $\mathrm{Ca}^{2+}$ transports from $\mathrm{CH}$ dissolution front to $\mathrm{C} \overline{\mathrm{S}} \mathrm{H} 2$ precipitation front and meet the $\mathrm{SO}_{4}^{2-}$ which diffuses from acid solution into material (see Fig5.7). At the initial time (1 day for example), the flux of sulfur at surface is fast due to high concentration

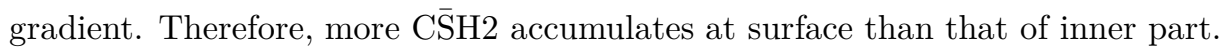

For the dissolution of C-S-H, Ca/Si ratio and molar volume of C-S-H are governed by the saturation degree of dissolved $\mathrm{CH}, q_{\mathrm{CH}}$. After 15 days immersion, $\log \left(q_{\mathrm{CH}}\right)$, Ca/Si ratio and molar volume of C-S-H are plotted in Fig.5.8 and Fig.5.9. From Fig.5.8, the C-S-H dissolution front can be distinguished clearly as the point where $\log \left(q_{\mathrm{CH}}\right)$ becomes negative. In the C-S-H decalcification zone, the $\mathrm{Ca} / \mathrm{Si}$ ratio drops 


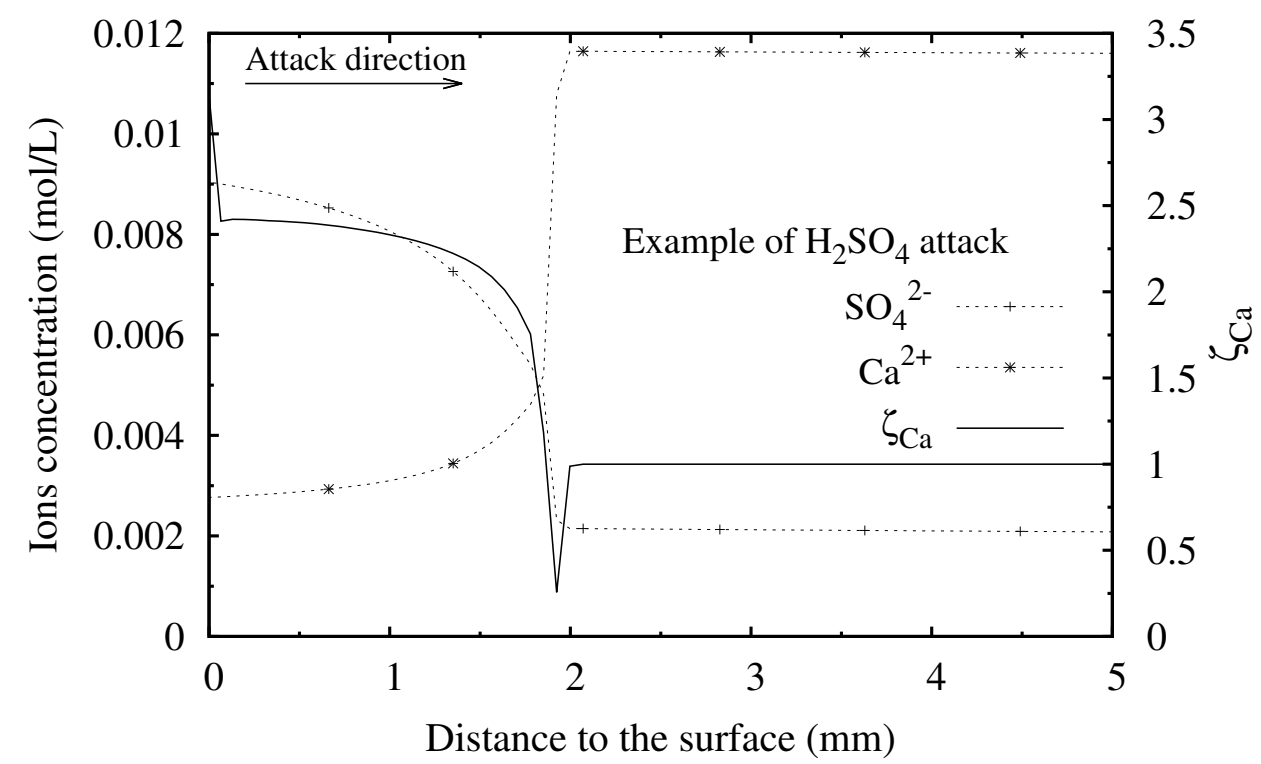

Figure 5.6: Concentration of $\mathrm{SO}_{4}^{2-}$ and $\mathrm{Ca}^{2+}$ and $\zeta_{\mathrm{Ca}}$ after 15 days immersion

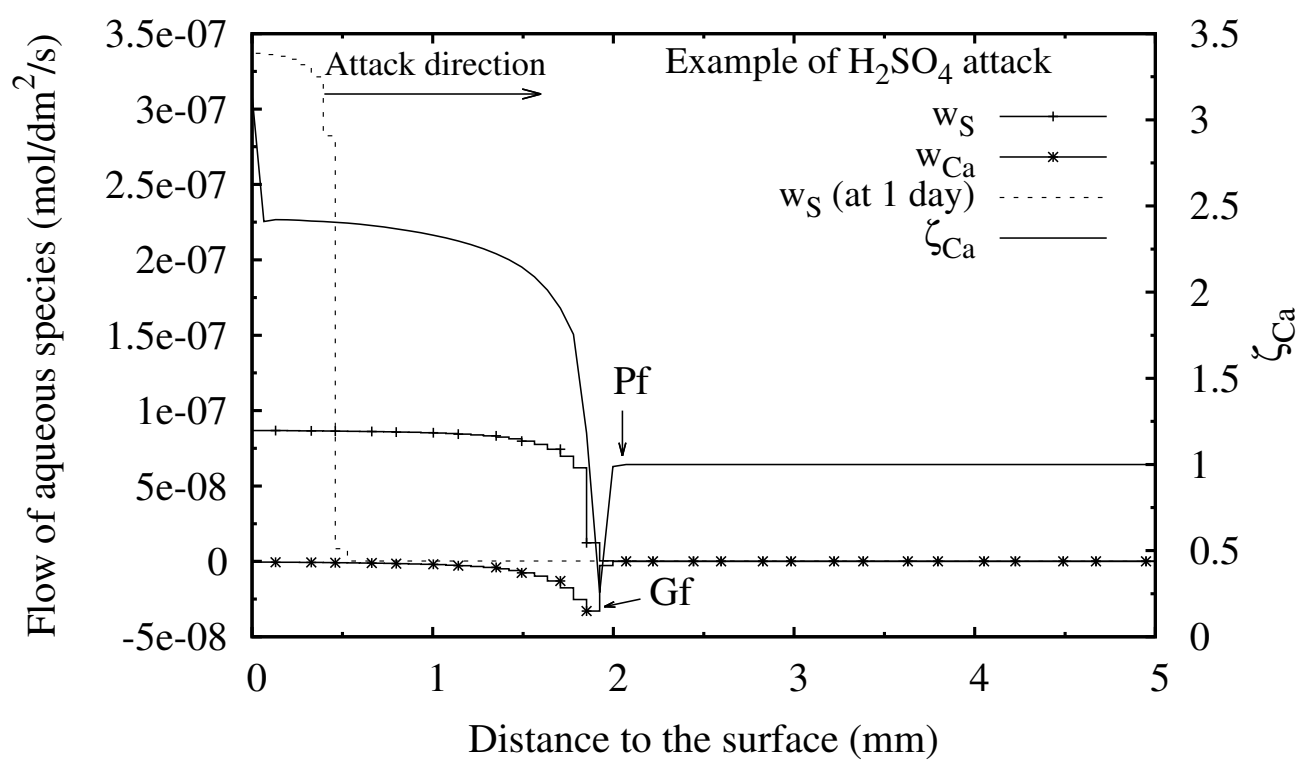

Figure 5.7: Flow of calcium and sulfur and $\zeta_{\mathrm{Ca}}$ after 15 days immersion 
from 1.67 to 0 , and the molar volume $V_{\mathrm{C}-\mathrm{S}-\mathrm{H}}$ decreases from $0.081 \mathrm{~L} / \mathrm{mol}$ to $0.043 \mathrm{~L} / \mathrm{mol}$.

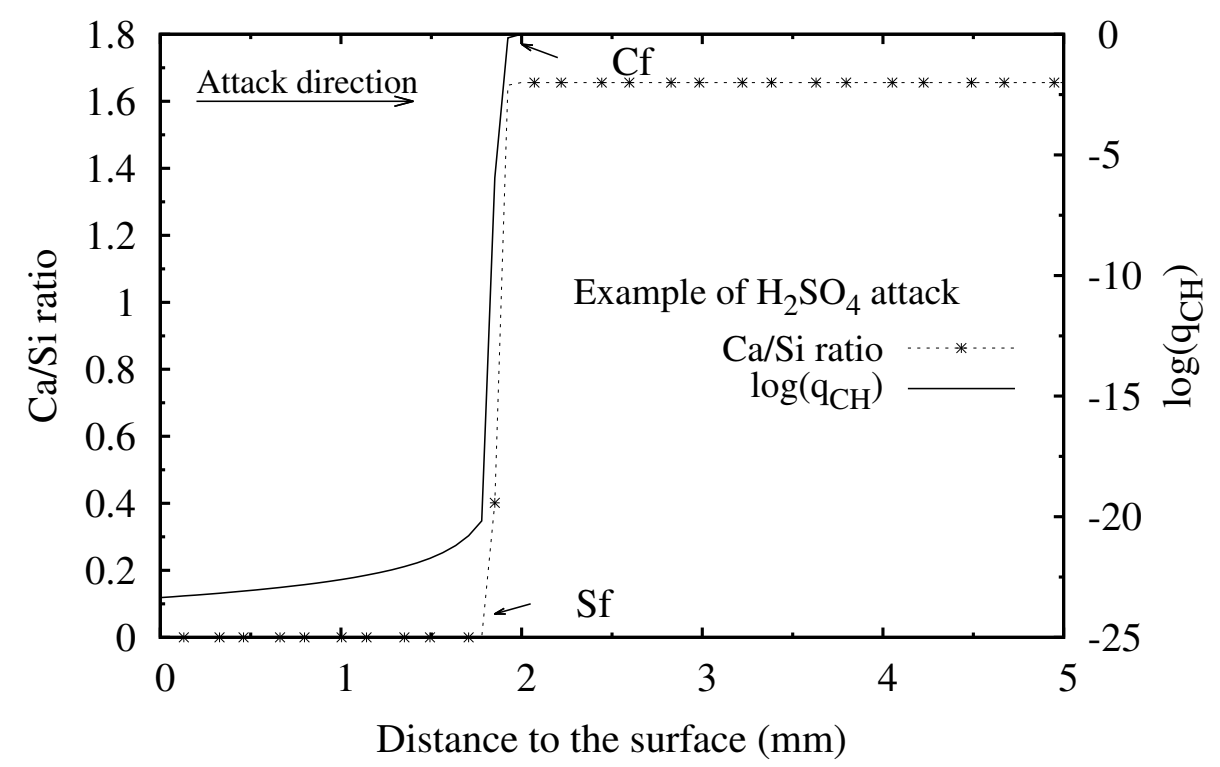

Figure 5.8: Ca/Si ratio of C-S-H and $\log \left(q_{\mathrm{CH}}\right)$ after 15 days immersion

\subsubsection{Coupling of bio-chemical process and chemical process}

To illustrate the coupling of bio-chemistry process and chemistry process, we simply consider a cement paste cube immersed in $500 \mathrm{~mL}$ of the solution containing idealized sulfur-oxidizing bacteria (SOB). The cement paste sample is the same as in the previous section. And the idealized SOB solution is considered as in contact with cement paste cube. Assuming an enough source of sulfur, the idealized SOB solution produces $\mathrm{H}_{2} \mathrm{SO}_{4}$ at a constant volumetric rate. Initially, $\mathrm{H}_{2} \mathrm{SO}_{4}, \mathrm{HSO}_{4}^{-}$and $\mathrm{SO}_{4}^{2-}$ are the only aqueous species in SOB solution, where the initial concentration of $\mathrm{H}_{2} \mathrm{SO}_{4}{ }^{0}$ is $1 \times 10^{-25.5} \mathrm{~mol} / \mathrm{L}$ (i.e., the approximate $p \mathrm{H}$ is 7 ). Since the income of sulfur is neglected, there is no mass transfer at the boundary of the solution, while aqueous species can diffuse across the interface between cement paste and SOB solution. The schematic of the sample and the initial/boundary conditions are summarized in Table 5.6.

Table 5.6: Boundary and initial conditions of the biogenic $\mathrm{H}_{2} \mathrm{SO}_{4}$ attack example

\begin{tabular}{|c|c|c|c|}
\hline Balance & Boundary conditions & \multicolumn{2}{|c|}{ Initial conditions } \\
Equation & Surface & SOB solution & Cement paste \\
\hline Sulfur (S) & no flow & $\rho_{\mathrm{H}_{2} \mathrm{SO}_{4}}=$ & $\rho_{\mathrm{H}_{2} \mathrm{SO}}=$ \\
$10^{-20} \mathrm{~mol} / \mathrm{L}$ & $10^{-31.5} \mathrm{~mol} / \mathrm{L}$ \\
\hline Calcium (Ca) & no flow & $\zeta_{\mathrm{Ca}}=0$ & $\zeta_{\mathrm{Ca}}=1$ \\
\hline Silicon $(\mathrm{Si})$ & no flow & $\zeta_{\mathrm{Si}}=0$ & $\zeta_{\mathrm{Si}}=1$ \\
\hline Sodium/Potassium & no flow & $\rho_{\mathrm{K}}^{+}=0$ & $\rho_{\mathrm{K}}^{+}=0$ \\
\hline Chlorine $(\mathrm{Cl})$ & no flow & $\rho_{\mathrm{Cl}}^{-}=0$ & $\rho_{\mathrm{Cl}}^{-}=0$ \\
\hline Charge & no current & $\psi=0$ & $\psi=0$ \\
\hline
\end{tabular}




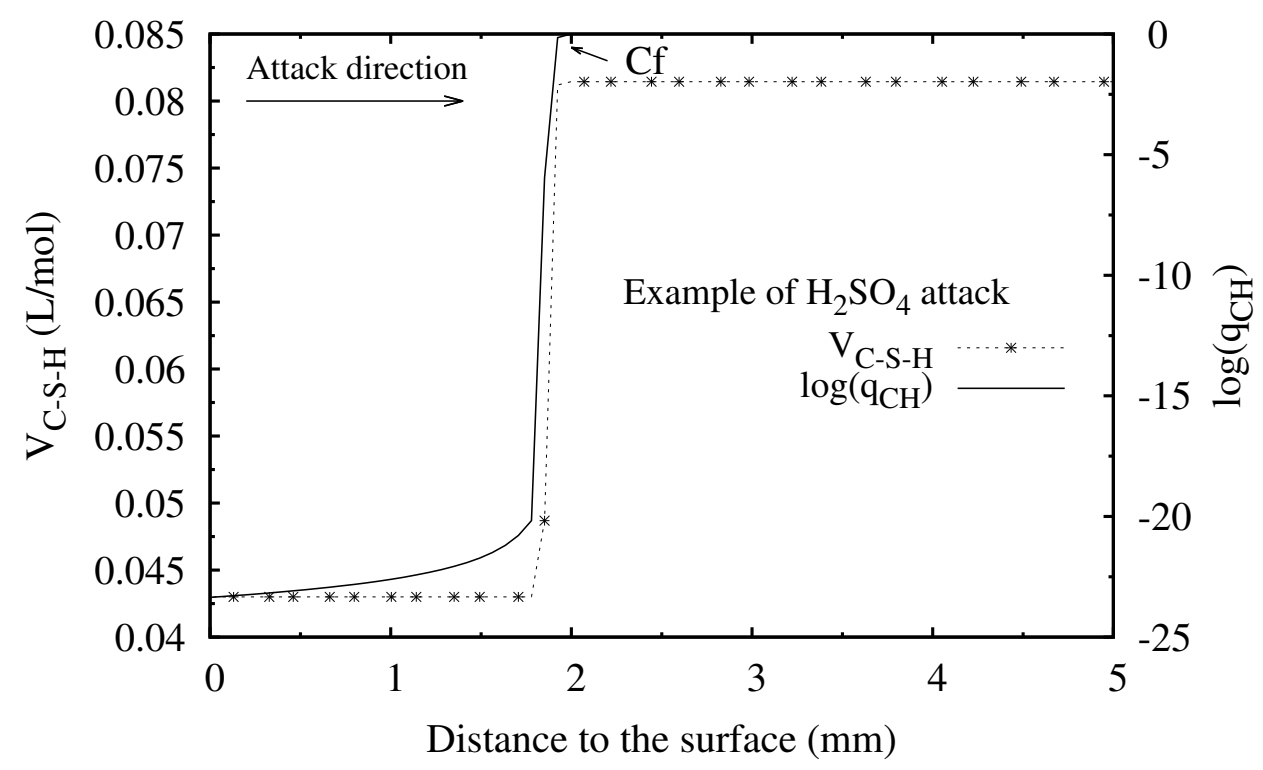

Figure 5.9: $V_{\mathrm{C}-\mathrm{S}-\mathrm{H}}$ of C-S-H and $\log \left(q_{\mathrm{CH}}\right)$ after 15 days immersion

To provide a severe environment, the production rate $\mathrm{H}_{2} \mathrm{SO}_{4}, a_{\mathrm{H}_{2} \mathrm{SO}_{4}}$, keeps at $8 \times 10^{-8} \mathrm{~mol} / \mathrm{L} \cdot \mathrm{s}$ regardless the change of $p \mathrm{H}$ in SOB solution. The evolution of $p \mathrm{H}$ and $\mathrm{H}_{2} \mathrm{SO}_{4}$ concentration in pure SOB solution, where no cement paste is immersed, are plotted in Fig 5.10. Due to the high $K_{s p}$ of $\mathrm{H}_{2} \mathrm{SO}_{4}, p \mathrm{H}$ drops sharply during the early time. Since the production rate of $\mathrm{H}_{2} \mathrm{SO}_{4}$ keeps constant, it takes several days to reduce $p \mathrm{H}$ below 1 .

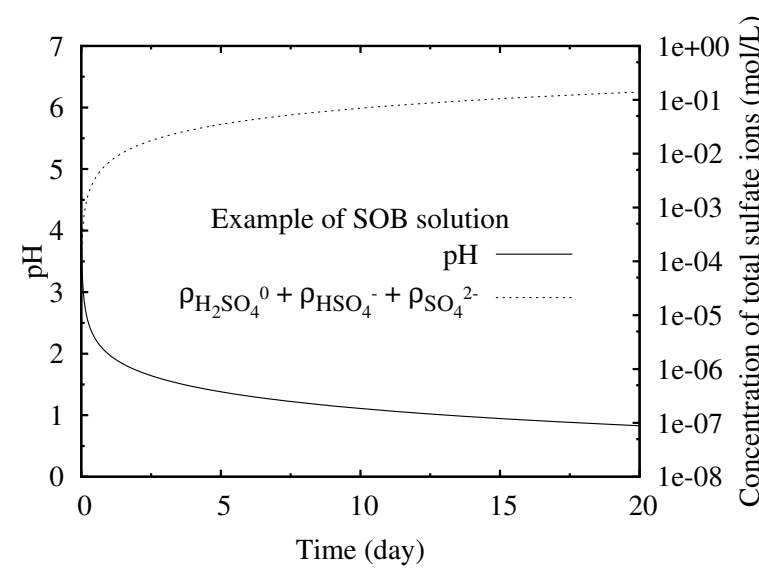

(a)

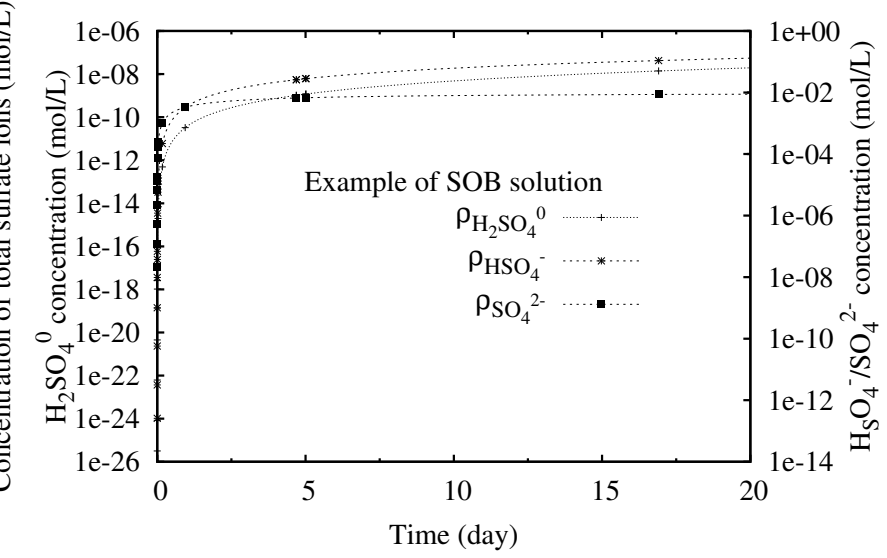

(b)

Figure 5.10: In SOB solution without cement paste: (a) $p \mathrm{H}$ and the concentration of total sulfate ions ; (b) Concentration of $\mathrm{H}_{2} \mathrm{SO}_{4}{ }^{0}, \mathrm{HSO}_{4}^{-}$and $\mathrm{SO}_{4}^{2-}$

When in contact with cement paste, $\mathrm{H}_{2} \mathrm{SO}_{4}$ in the SOB solution penetrates into material rather than accumulates in solution. Thus, $\mathrm{H}_{2} \mathrm{SO}_{4}$ concentration in the SOB solution, where cement paste is immersed in, does not increases until 1 day (see Fig.5.11). Consequently, $p \mathrm{H}$ increases during initial time caused by 
the alkalinity of cement paste. Longer time is taken to reduce $p \mathrm{H}$ to 1 compared to that of pure SOB solution. At the interface between cement paste and SOB solution, the aqueous species related with sulfur diffuses from SOB solution to cement paste as shown in Fig.5.12.

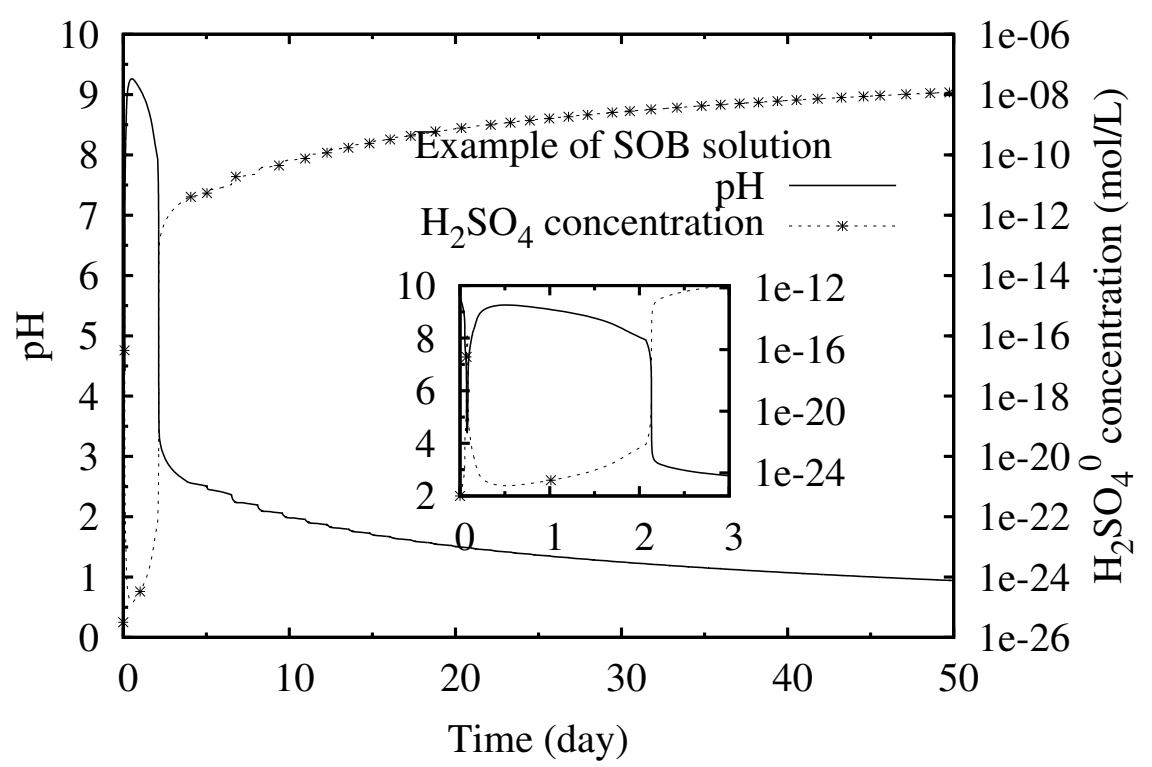

Figure 5.11: $p \mathrm{H}$ and $\mathrm{H}_{2} \mathrm{SO}_{4}$ concentration in SOB solution containing cement paste

With the $\mathrm{H}_{2} \mathrm{SO}_{4}$ diffusion, the cement paste is acidified gradually as shown in Fig.5.13. Comparing with that of $\mathrm{H}_{2} \mathrm{SO}_{4}$ solution attack (see Fig.5.2), the $p \mathrm{H}$ reduction rate of SOB solution attack is much slower due to the lower $\mathrm{H}_{2} \mathrm{SO}_{4}$ concentration at the material surface during early time.

Fig.5.14 indicates the solid volume and composition in the cement paste after 15 days of immersion. Almost the same fronts and zones can be observed in SOB solution attack as those in $\mathrm{H}_{2} \mathrm{SO}_{4}$ attack (see Fig.5.3). However, a gypsum dissolution front (noted as Gdf) appears close to the cement surface. To make sure neither $\mathrm{CH}$ nor C-S-H exist in SOB solution part, the initial $\zeta_{\mathrm{Ca}}$ in $\mathrm{SOB}$ solution is set to $<0$. Thus, a few of gypsum leaches out. The flux of aqueous species related with calcium from cement paste to SOB solution can be found in Fig.5.12. 


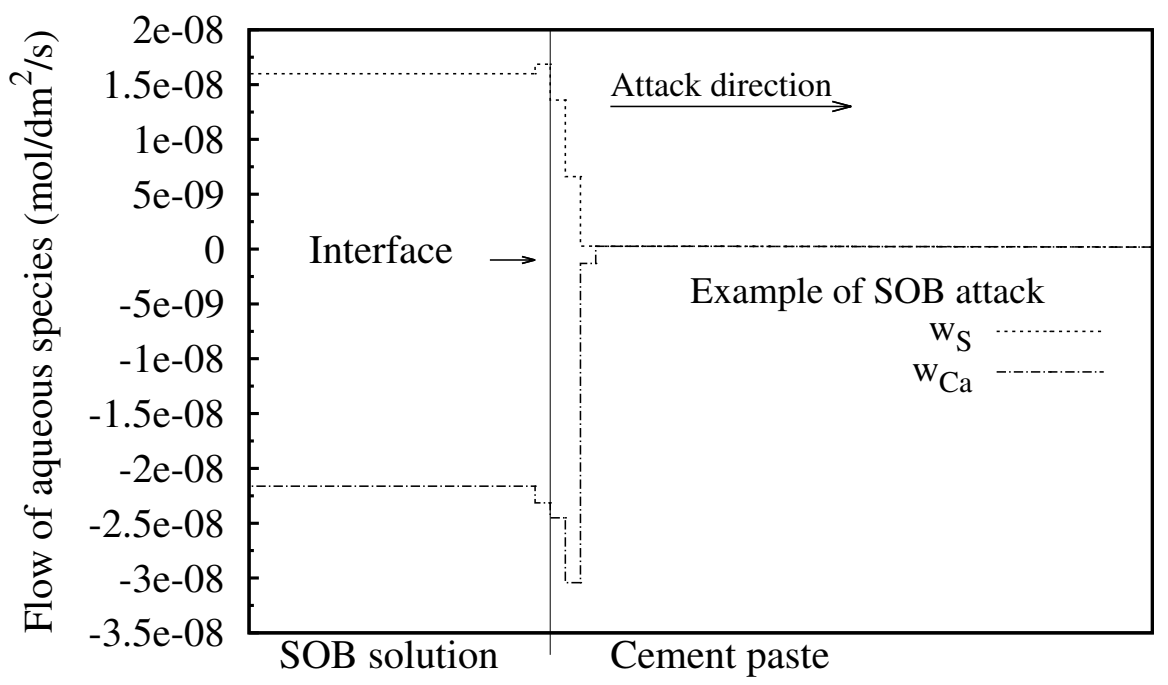

Figure 5.12: Flow of aqueous species across the interface at 1 day

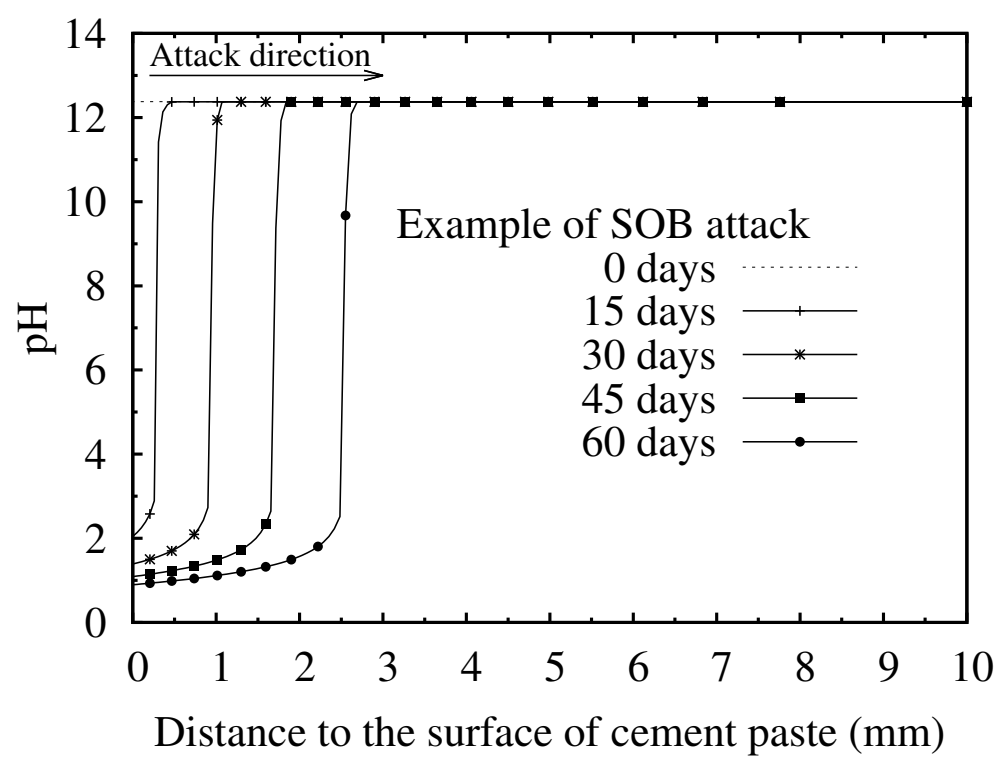

Figure 5.13: $p \mathrm{H}$ value profiles from 0 day to 60 days. 


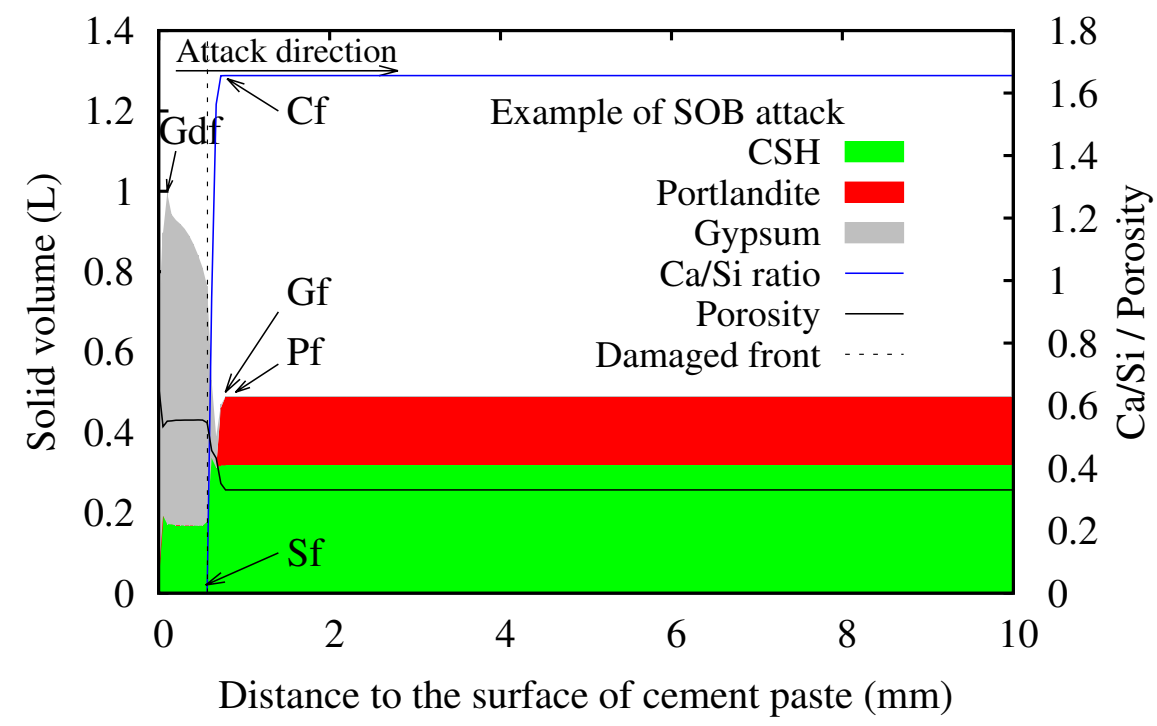

Figure 5.14: Solid profiles after 15 day

\subsection{Conclusion}

In this chapter, the field equations which govern the mass and charge balance are introduced. The transport of aqueous species are considered as diffusion in saturated porous media. The different diffusion coefficients are employed for various species. Moreover, the effect of porosity on the diffusion coefficients are taken into account.

Afterwards, the numerical procedures for the couplings between transport and reaction equations have been introduced. Brief introductions of the principle of the finite volume method and the modeling platform, Bil are given. The method to calculate the dissolution and precipitation of solid components, as well as the kinetics effects, have been presented.

For a better understanding of our modeling, two simulation examples of cement paste in contact with constant $\mathrm{H}_{2} \mathrm{SO}_{4}$ solution and idealized SOB solution are illustrated respectively. The evolution of $p \mathrm{H}$ in cement paste and SOB solution is predicted. Suffering from $\mathrm{H}_{2} \mathrm{SO}_{4}$ attack, regardless pure $\mathrm{H}_{2} \mathrm{SO}_{4}$ solution or biogenic $\mathrm{H}_{2} \mathrm{SO}_{4}$, similar solid dissolution/precipitation fronts are observed in cement paste via the profile of solid compositions. The porosity evolution caused by the special properties of gypsum precipitation is predicted. Furthermore, the damage position is identified by the method introduced in Chapter 4. With the help of these fronts, several zones (e.g., uncorroded zone, C-S-H decalcification zone, gypsum layer, damaged zone) can be distinguished.

Besides simple conditions, such as constant $\mathrm{H}_{2} \mathrm{SO}_{4}$ solution and idealized SOB solution, our modeling can work with complex boundary condition and real biofilms. In the following chapters, laboratory 
experiments with various conditions are simulated and long time predictions are conducted. 


\section{Chapter 6}

\section{Simulation in the case of constant $\mathrm{H}_{2} \mathrm{SO}_{4}$ solution}

\subsection{Introduction}

In order to predict the deterioration rate of cementitious materials, some experiments have been done to simulate the corrosion process of sewer pipe (Gutiérrez-Padilla et al., 2010; De Muynck et al., 2009; Alexander and Fourie, 2011).

Based on laboratory tests where specimens are continuously immersed in acid solutions over a specified period of time, it is understood that the depth of deterioration of concrete due to sulfuric acid attack is proportional to the square root of the exposure time. But in actual structures, concrete is often exposed to flowing water that contains an acid solution such as sewage. In other words, concrete is subjected to the shearing force of fluid that erodes the surface areas of deteriorated concrete.

For cementitious materials in static solution environment and flowing solution environment, two calculations are carried out to simulate experimental works of Kawai, et al. (Kawai et al., 2005). The influence of different $\mathrm{H}_{2} \mathrm{SO}_{4}$ concentrations of the solution on the corrosion is studied. Furthermore, in order to understand the difference between the experimental results and simulation results, the effect of carbonated layer and initial porosity of materials are analysed. At last, a long term prediction of $\mathrm{H}_{2} \mathrm{SO}_{4}$ attack is conducted. 


\subsection{High $\mathrm{H}_{2} \mathrm{SO}_{4}$ concentration condition $(p \mathrm{H}=1)$}

In the experiment of (Kawai et al., 2005), mortar samples in size of $40 \times 40 \times 160 \mathrm{~mm}$ were made of ordinary Portland cement (OPC) of various water/cement ratios. After cured for 28 days, the samples were immersed in sulfuric acid of various concentrations. The sulfuric acid solution was static (noted as Method 1) or circulated onto specimens (noted as Method 2). To keep the concentration of sulfuric acid solution constant, sulfuric acid was added suitably to the solution. A $p \mathrm{H}$ meter was used to measure the value of $p \mathrm{H}$ and during the experiment the concentration of sulfuric acid solution was adjusted to the initial value of $p \mathrm{H}$. In both instances, the depths of corroded zones were measured with a vernier micrometer every seven days. The corrosion depth was defined as a distance between the initial surface and current surface. Before every measurement, intentional removal of deteriorated zones on the surfaces was not carried out. The zones of deteriorated concrete were analysed with XRD and ion chromatoanalyzer.

In this section, we simulate the experiments where mortar samples with $\mathrm{W} / \mathrm{C}=0.35$ were immersed in static and circulated $\mathrm{H}_{2} \mathrm{SO}_{4}$ solution whose $p \mathrm{H}$ is kept at 1 for 90 days.

To simulate the experiments, mortar samples with the same size as that in experiments are considered. The samples are divided in 720 nodes. For numerical stability, the initial $\mathrm{H}_{2} \mathrm{SO}_{4}$ concentration in the pore solution of sample is $1 \times 10^{-31.5} \mathrm{~mol} / \mathrm{L}$, while at the right boundary the concentration of unionized molecules of $\mathrm{H}_{2} \mathrm{SO}_{4}, \rho_{\mathrm{H}_{2} \mathrm{SO}_{4}}^{0}$, is set to $1 \times 10^{-8} \mathrm{~mol} / \mathrm{L}$ (i.e., $p \mathrm{H}=1$ ).

The content of sand and other composition information (such as the content of CH and C-S-H and the initial porosity) were not given by the authors. By collecting and adjusting the data of Portland cement hydration (Garboczi et al., 2005; Voigt and Shah, 2004; Maruyama and Igarashi, 2010), which can be simulated by hydration models (e.g., CEMHYD3D (Bentz, 2005) and HYMOSTRUC3D (Ye et al., 2004)), the solid compositions of samples can reasonably be assumed. For the $\mathrm{OPC}$ mortar with $\mathrm{W} / \mathrm{C}=0.35$ of 28 days the cement hydrates contains initially $5.2 \mathrm{~mol} / \mathrm{L}$ of portlandite and $5 \mathrm{~mol} / \mathrm{L}$ of C-S-H as jennite. The initial porosity is $30 \%$.

From the measurement of experiments (Brouwers and VanEijk, 2003), the alkali concentrations (i.e., $\mathrm{K}^{+}$ and $\mathrm{Na}^{+}$) in the pore solution of cement paste cured for 28 days is about $0.5 \mathrm{~mol} / \mathrm{L}$. Since these two ions have almost the same diffusion coefficient, $\mathrm{K}^{+}$and $\mathrm{Na}^{+}$are combined as one ion for the sake of simplicity. For the electroneutrality, the same amount of anions which are not involved in any chemical reaction, is introduced. Thus, an unified form as $\mathrm{KCl}$ is considered. Thus, $0.5 \mathrm{~mol} / \mathrm{L} \mathrm{KCl}$ is added in the simulated pore solution, while no $\mathrm{KCl}$ exists in the external $\mathrm{H}_{2} \mathrm{SO}_{4}$ solution. 


\subsubsection{Static solution environment (Method 1)}

With Method 1, corrosion of specimens was visible after immersion of dozens of days. A white layer of reaction products was observed on the surface of samples as Fig.6.1a. The XRD patterns of this degraded layer (see Fig.6.1b) indicated that reaction products of sulfuric acid attack are mainly gypsum, portlandite and quartz.

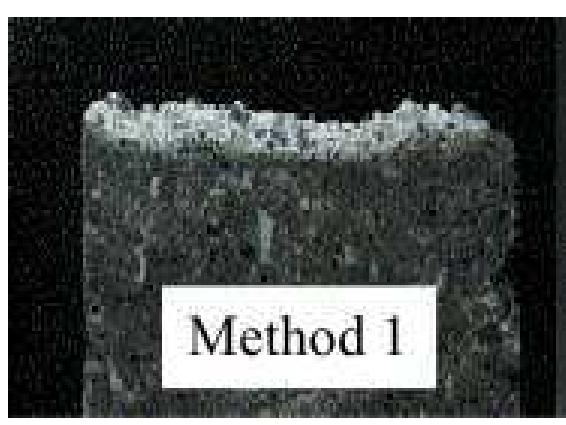

(a)

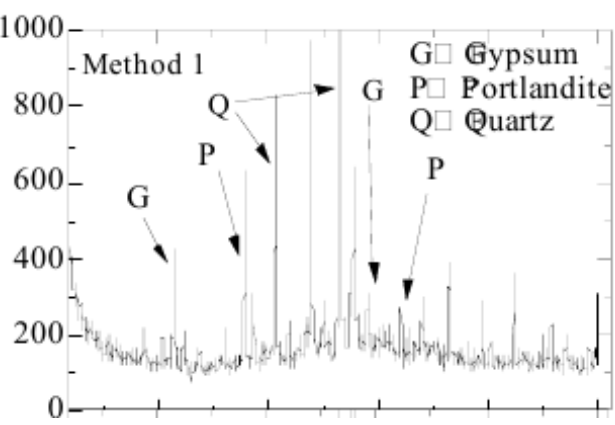

(b)

Figure 6.1: After 90 days immersion test: (a) Observation of deterioration of sample; (b) XRD patterns of surface area of sample. (Method 1, $p \mathrm{H}=1$ ) (Kawai et al., 2005)

To simulation the precipitating of the reaction products at the surface of specimen, no $\mathrm{Ca}^{2+}$ and $\mathrm{Si}^{4+}$ flow across the boundary. Boundary and initial conditions of our modeling are summarized in Table 6.1.

Table 6.1: Boundary and initial conditions of the $\mathrm{H}_{2} \mathrm{SO}_{4}$ attack with Method 1

\begin{tabular}{|c|c|c|}
\hline $\begin{array}{c}\text { Balance } \\
\text { Equation }\end{array}$ & $\begin{array}{c}\text { Boundary conditions } \\
\text { Left surface }\end{array}$ & $\begin{array}{c}\text { Initial conditions } \\
\text { Mortar }\end{array}$ \\
\hline Sulfur $(\mathrm{S})$ & $\begin{array}{c}\text { diffusion allowed } \\
\rho_{\mathrm{H}_{2} \mathrm{SO}_{4}{ }^{0}}=10^{-8} \mathrm{~mol} / \mathrm{L}\end{array}$ & $\rho_{\mathrm{H}_{2} \mathrm{SO}_{4}{ }^{0}}=10^{-31.5} \mathrm{~mol} / \mathrm{L}$ \\
\hline Calcium $(\mathrm{Ca})$ & no diffusion & $\zeta_{\mathrm{Ca}}=1$ \\
\hline Silicon $(\mathrm{Si})$ & no diffusion & $\zeta_{\mathrm{Si}}=1$ \\
\hline Potassium $(\mathrm{K})$ & diffusion allowed $\rho_{\mathrm{K}^{+}}=0 \mathrm{~mol} / \mathrm{L}$ & $\rho_{\mathrm{K}^{+}}=0.5 \mathrm{~mol} / \mathrm{L}$ \\
\hline Chlorine $(\mathrm{Cl})$ & diffusion allowed $\rho_{\mathrm{Cl}^{-}}=0 \mathrm{~mol} / \mathrm{L}$ & $\rho_{\mathrm{Cl}^{-}}=0.5 \mathrm{~mol} / \mathrm{L}$ \\
\hline Charge & no current & $\psi=0$ \\
\hline
\end{tabular}

After immersion of 90 days, the calculated penetration of $\mathrm{H}_{2} \mathrm{SO}_{4}$ and $p \mathrm{H}$ evolution are shown in Fig.6.2. At the surface, the $\mathrm{H}_{2} \mathrm{SO}_{4}{ }^{0}$ concentration is $1 \times 10^{-8} \mathrm{~mol} / \mathrm{L}$ as set in boundary conditions. The surface $p \mathrm{H}$ keeps at 1 which was measured during experiments as well. As expected, $\mathrm{H}_{2} \mathrm{SO}_{4}$ penetrates into sample and leads to the acidification of cementitious materials, whose $p \mathrm{H}$ decreases form 12.35 to 1 . Due to the low concentration and high ionization constant of $\mathrm{H}_{2} \mathrm{SO}_{4}$, the transition zone between the $\mathrm{H}_{2} \mathrm{SO}_{4}$ penetration front (where $p \mathrm{H}$ is less than 2), and the unneutralized zone (where $p \mathrm{H}$ is close to 12.4) is not very remarkable.

The calculated profiles of the concentration and volume of solid compounds, as well as porosity profiles 


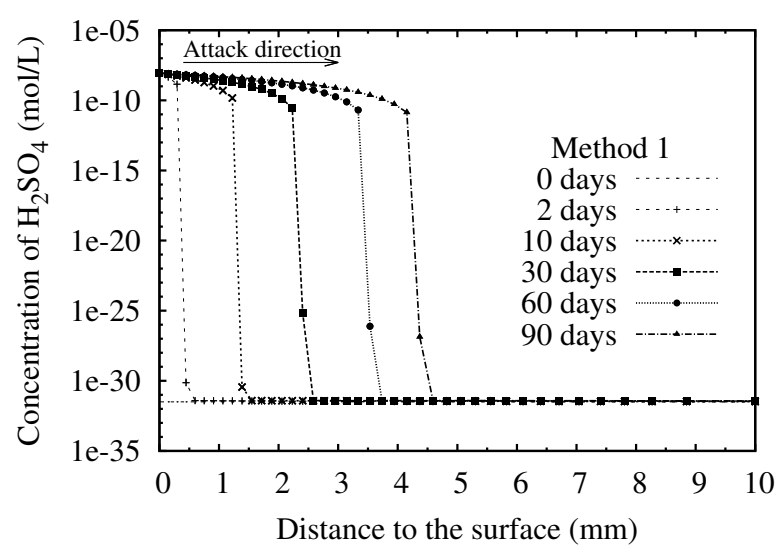

(a)

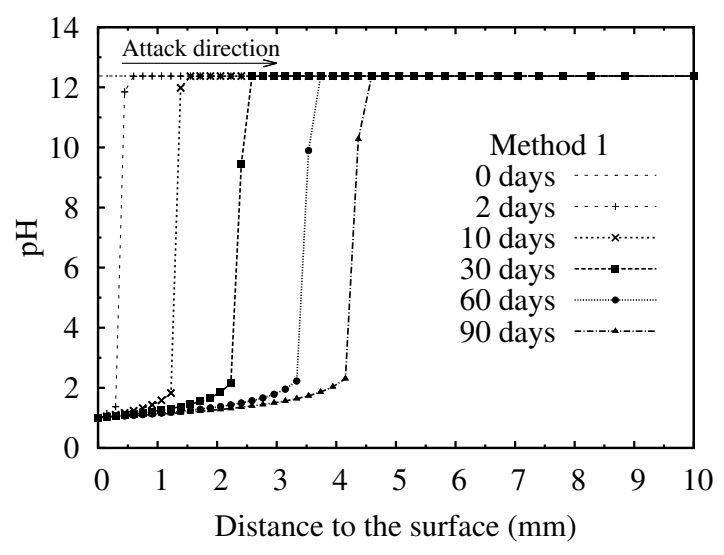

(b)

Figure 6.2: The calculated penetration of $\mathrm{H}_{2} \mathrm{SO}_{4}$ and $p \mathrm{H}$ evolution profiles from 0 days to 90 days: (a) $\mathrm{H}_{2} \mathrm{SO}_{4}$ concentration; (b) $p \mathrm{H}$ value. (Method $1, p \mathrm{H}=1$ )

and damaged zone from 10 days to 90 days are plotted in Fig. 6.3 to Fig. 6.5. These figures present several successive zones from the surface to the core of sample.

The corroded sample starts with a non-uniform gypsum-rich layer, which corresponds to the white part in Fig.6.1a. At the surface, gypsum accumulates resulting from the diffusion of $\mathrm{Ca}^{2+}$ as described in Section 5.5.1. Consequently, the volume of this layer expands more than the inner gypsum-rich zone. At the place just below the surface, the content of gypsum decreases slightly due to deplete of $\mathrm{Ca}^{2+}$ which has transported to the surface. In the gypsum layer, Ca/Si ratio of C-S-H is zero (Fig. 6.3b). Thus, only silica gel and unreactive phases are contained in the gypsum layer, which is defined as the fully degraded zone in Section 5.5.1. The porosity of this zone reaches nearly 0.6. The evolution of porosity is plotted in Fig.6.7a.

Following this layer, a region containing $\mathrm{C} \overline{\mathrm{S}} \mathrm{H} 2, \mathrm{CH}$ and $\mathrm{C}-\mathrm{S}-\mathrm{H}$ is observed. The $\mathrm{H}_{2} \mathrm{SO}_{4}$ attack is taking place in this region which represents the $\mathrm{C}-\mathrm{S}-\mathrm{H}$ decalcification zone, where $\mathrm{Ca} / \mathrm{Si}$ ratio drops from 1.67 to 0 , as well as the $\mathrm{C} \overline{\mathrm{S}} \mathrm{H} 2$ precipitation front and $\mathrm{CH}$ dissolution front. With the change in solid phases, porosity of this region increases from 0.3 to 0.56 , and the sample starts to expands. The damage of pores happens in this region as well. In this paper, the corrosion depth is defined as the distance between the initial surface and the location where the pore structure is damaged following the simplified damage model introduced in Chapter 4.

To illustrate the damage process of pore structure, the evolution of solid compositions and inner pressure at $5 \mathrm{~mm}$ depth of sample are plotted in Fig.6.6. From 105 days, the porosity starts to increase due to the dissolution of $\mathrm{CH}$ and C-S-H. From about 120 days, C-S-H and $\mathrm{CH}$ are dissolved completely, while CS̄H2 continues to form. At that time, the porosity decrease a little temporally until 120 days (see Fig.6.6a). Indicated by Fig.6.6b, inner pressure rises sharply during this period due to the compression of gypsum. 


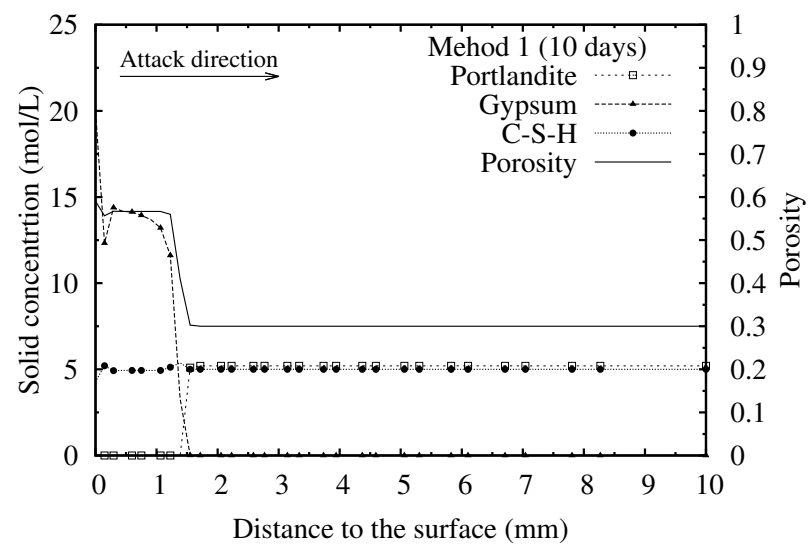

(a)

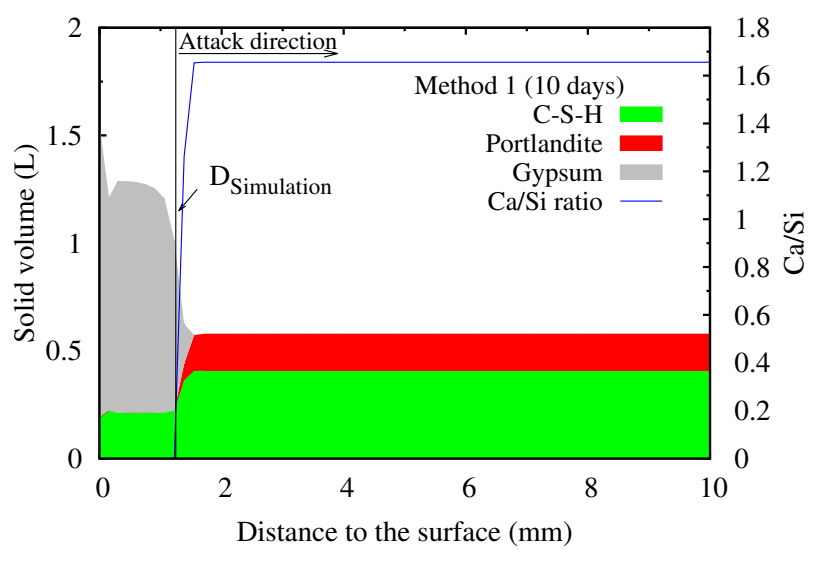

(b)

Figure 6.3: After 10 days of immersion: (a) Solid concentration and porosity ; (b) Solid volume and Ca/Si ratio of C-S-H . $\mathrm{D}_{\text {Simulation }}$ and $\mathrm{D}_{\text {Experiment }}$ represent the degradation depth of the sample in simulation and experiment individually. (Method $1, p \mathrm{H}=1$ )

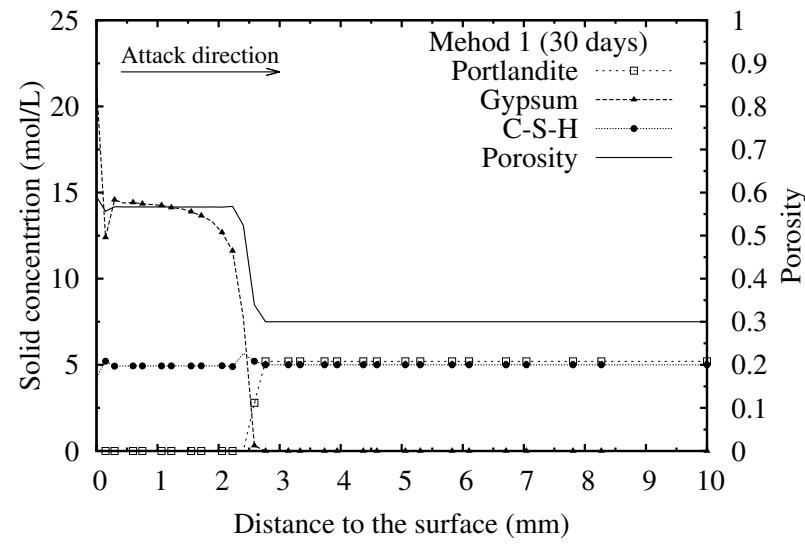

(a)

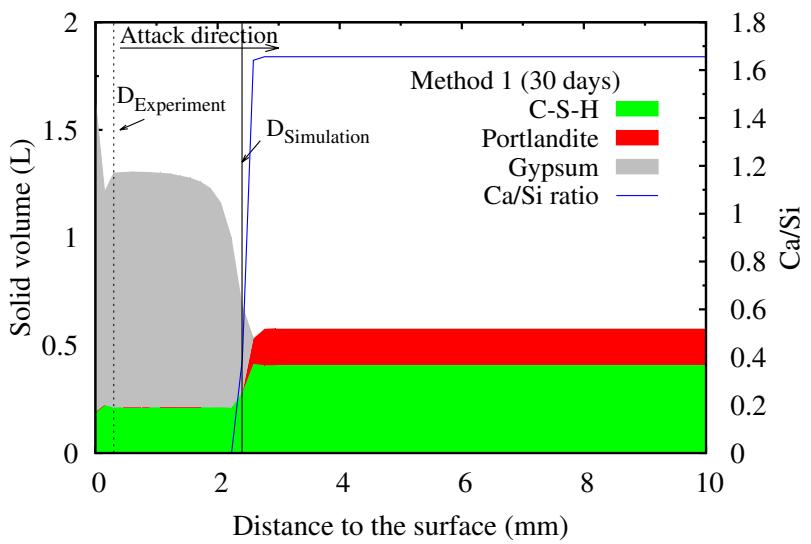

(b)

Figure 6.4: After 30 days of immersion: (a) Solid concentration and porosity ; (b) Solid volume and Ca/Si ratio of C-S-H . D Simulation and $\mathrm{D}_{\text {Experiment }}$ represent the degradation depth of the sample in simulation and experiment individually. (Method $1, p \mathrm{H}=1$ ) 




(a)

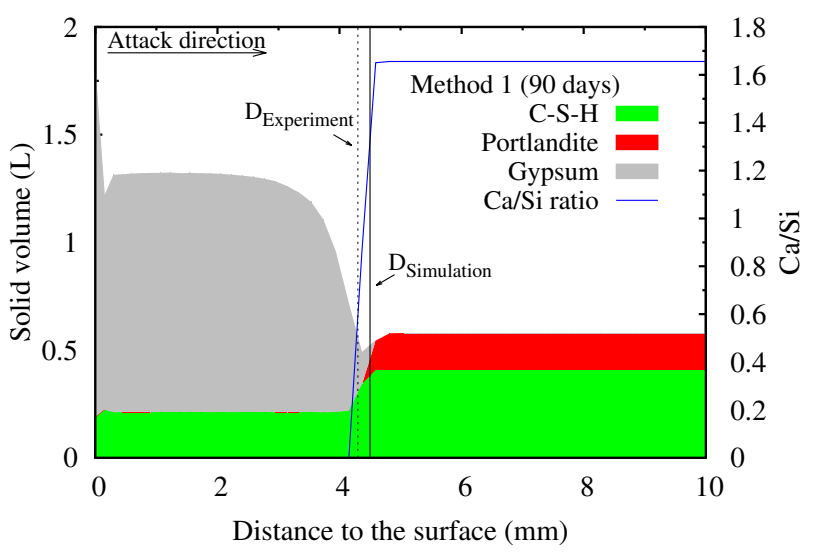

(b)

Figure 6.5: After 90 days of immersion: (a) Solid concentration and porosity ; (b) Solid volume and Ca/Si ratio of C-S-H . D $\mathrm{D}_{\text {Simulation }}$ and $\mathrm{D}_{\text {Experiment }}$ represent the degradation depth of the sample in simulation and experiment individually. (Method $1, p \mathrm{H}=1$ )

During this period, the total volume of gypsum gel decreases while the amount increases. At 120 days, the inner pressure drops to 0 once it reaches 3.5 MPa which is the strength of pores. The release of inner pressure indicates the failure of pores. Meanwhile, the porosity and volume of gypsum gel increases again.

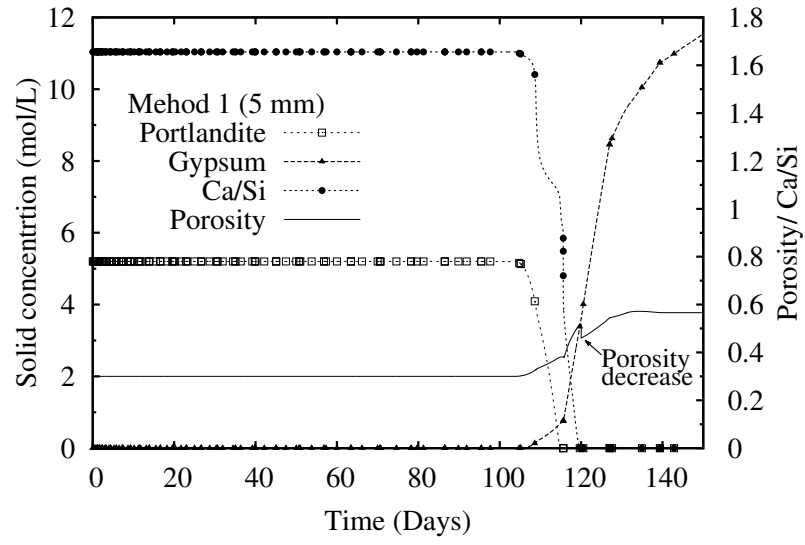

(a)

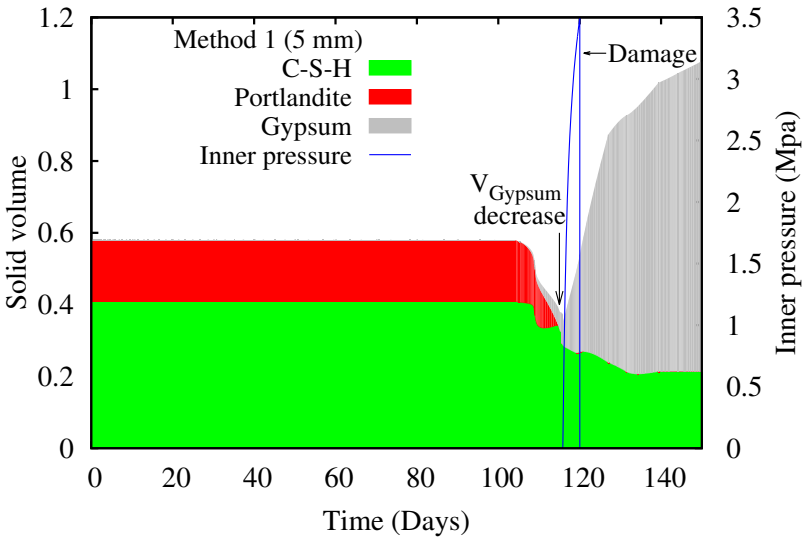

(b)

Figure 6.6: At $5 \mathrm{~mm}$ depth of sample (a) Solid concentration, Ca/Si ratio of C-S-H and porosity ; (b) Solid volume and inner pressure . (Method $1, p \mathrm{H}=1)$

During the immersion time, the fronts of $\mathrm{C} \overline{\mathrm{S}} \mathrm{H} 2$ precipitation, $\mathrm{CH}$ dissolution and the continuous decalcification of C-S-H, move from the surface to the core of the sample. Hence the corrosion depth increases gradually (Fig.6.7b). In the experiments, corrosion was not visible until 10 days of immersion. Moreover, the corrosion depth increased very slowly before 60 days. Our simulation results overestimate the corrosion rate in the early time (see Fig.6.7b). However, at 90 days the simulation results are very close to the experimental observation. The difference between the simulated corrosion rate and that of experimental 
measurements is discussed in detail in the next section.



(a)

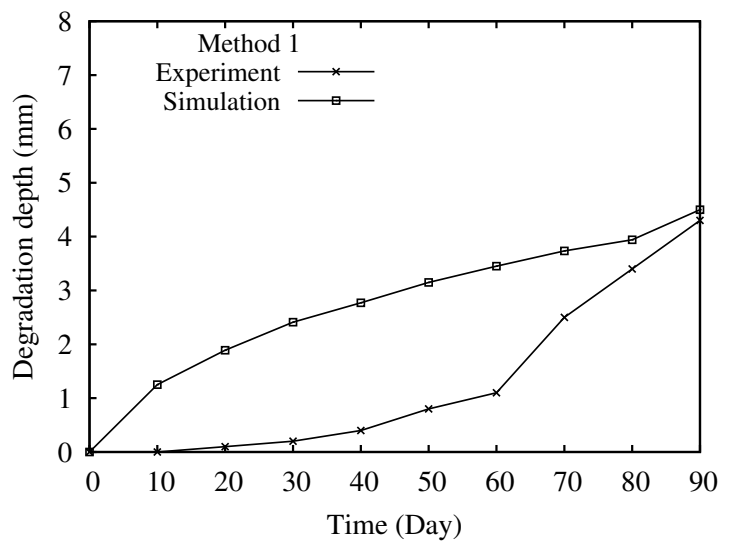

(b)

Figure 6.7: The predicted evolution of porosity and corrosion depth profiles from 0 days to 90 days: (a) Porosity; (b) Corrosion depth. (Method 1, $\mathrm{pH}=1$ )

\subsubsection{Flowing solution environment (Method 2)}

During the test with Method 2, the specimens were subjected to the shearing force of the solution flow. Therefore, parts of the reaction products (e.g., CS̄H2 and silica gel) were driven out by the flow of the solution and didn't precipitate at the surface. Comparing with Method 1, the white layer at the sample surface was almost invisible (see Fig.6.8a). The XRD patterns of the degraded layer (see Fig.6.8b) indicate that compositions of the reaction products are still gypsum and quartz.



(a)

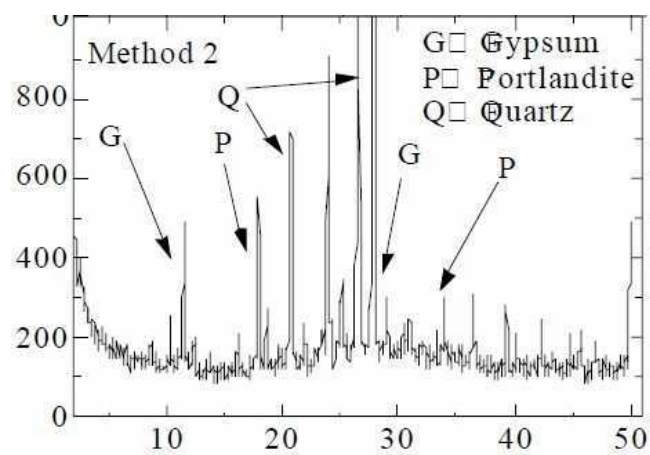

(b)

Figure 6.8: After 90 days immersion test: (a) Observation of deterioration of sample; (b) XRD patterns of surface area of sample. (Method 2, $p \mathrm{H}=1$ ) (Kawai et al., 2005)

However, both the values of the shear force on the sample surface and the strength of corroded layer are not mentioned by (Kawai et al., 2005). To simulate the removing of corrosion products, we set the saturation degree of dissolved gypsum $\left(Q_{\mathrm{CS} H 2} / K_{\mathrm{CS} H 2}\right)$ and that of dissolved silica gel $\left(Q_{\mathrm{SH}_{t}} / K_{\mathrm{SH}_{t}}\right)$ to a 
small value 0.01 at the boundary of sample. Thus, calcium and silicon will leach out and corrosion products will be dissolved rather than accumulated at the surface. The rest of the conditions are the same as those in the simulation of Method 1. Boundary and initial conditions are summarized in Table 6.2.

Table 6.2: Boundary and initial conditions of the $\mathrm{H}_{2} \mathrm{SO}_{4}$ attack with Method 2

\begin{tabular}{|c|c|c|}
\hline $\begin{array}{c}\text { Balance } \\
\text { Equation }\end{array}$ & $\begin{array}{c}\text { Boundary conditions } \\
\text { Left surface }\end{array}$ & $\begin{array}{c}\text { Initial conditions } \\
\text { Mortar }\end{array}$ \\
\hline Sulfur $(\mathrm{S})$ & $\begin{array}{c}\text { diffusion allowed } \\
\rho_{\mathrm{H}_{2} \mathrm{SO}_{4}{ }^{0}}=10^{-8} \mathrm{~mol} / \mathrm{L}\end{array}$ & $\rho_{\mathrm{H}_{2} \mathrm{SO}_{4}{ }^{0}}=10^{-31.5} \mathrm{~mol} / \mathrm{L}$ \\
\hline Calcium $(\mathrm{Ca})$ & diffusion allowed $\zeta_{\mathrm{Ca}}=-2$ & $\zeta_{\mathrm{Ca}}=1$ \\
\hline Silicon $(\mathrm{Si})$ & diffusion allowed $\zeta_{\mathrm{Si}}=-2$ & $\zeta_{\mathrm{Si}}=1$ \\
\hline Potassium $(\mathrm{K})$ & diffusion allowed $\rho_{\mathrm{K}^{+}}=0 \mathrm{~mol} / \mathrm{L}$ & $\rho_{\mathrm{K}^{+}}=0.5 \mathrm{~mol} / \mathrm{L}$ \\
\hline Chlorine $(\mathrm{Cl})$ & diffusion allowed $\rho_{\mathrm{Cl}}=0 \mathrm{~mol} / \mathrm{L}$ & $\rho_{\mathrm{Cl}}-=0.5 \mathrm{~mol} / \mathrm{L}$ \\
\hline Charge & $\psi=0$ & $\psi=0$ \\
\hline
\end{tabular}

Since reaction products are swept from the surface, the gypsum layer which could obstruct transport is removed and more reactive surface is exposed. Hence, the penetration rate of $\mathrm{H}_{2} \mathrm{SO}_{4}$ and the reduction rate of $p \mathrm{H}$ should increase. Our simulation results agree with such expectation (see Fig.6.9).



(a)



(b)

Figure 6.9: The calculated penetration of $\mathrm{H}_{2} \mathrm{SO}_{4}$ and $p \mathrm{H}$ evolution profiles from 0 days to 90 days: (a) $\mathrm{H}_{2} \mathrm{SO}_{4}$ concentration; (b) $p \mathrm{H}$ value. (Method $2, p \mathrm{H}=1$ )

From the boundary to the core of sample, successive zones different from those of Method 1 are observed (see Fig.6.10, Fig.6.11 and Fig.6.12). A leaching effect is illustrated since there is neither gypsum nor silica gel at the surface. Such result coincides with experimental observations. Moreover, the remaining unreacted solid components result in a porosity of 0.88 . This region is considered as the fully decomposed zone in the simulation of Method 2.

Due to the difference between the leaching effect of gypsum and that of silica gel, a zone containing only C-S-H, whose $\mathrm{Ca} / \mathrm{Si}$ ratio is zero (as indicated by the blue line in the following plots), is observed following the fully decomposed zone. Consequently, the porosity reaches 0.68. Following this region, a 
gypsum-rich layer is observed, where gypsum accumulates and the porosity is 0.56 which equals to the porosity of gypsum layer in the simulation of Method 1. The Ca/Si ratio of C-S-H is still 0 in this zone. Gypsum is formed at the gypsum precipitation front (the inner side of this layer) and is dissolved at gypsum dissolution front (the outside of this layer) due to the leaching simulated at the boundary condition.

The subsequent zones such as damage zone and uncorroded zone are similar to that observed in the simulation of Method 1.

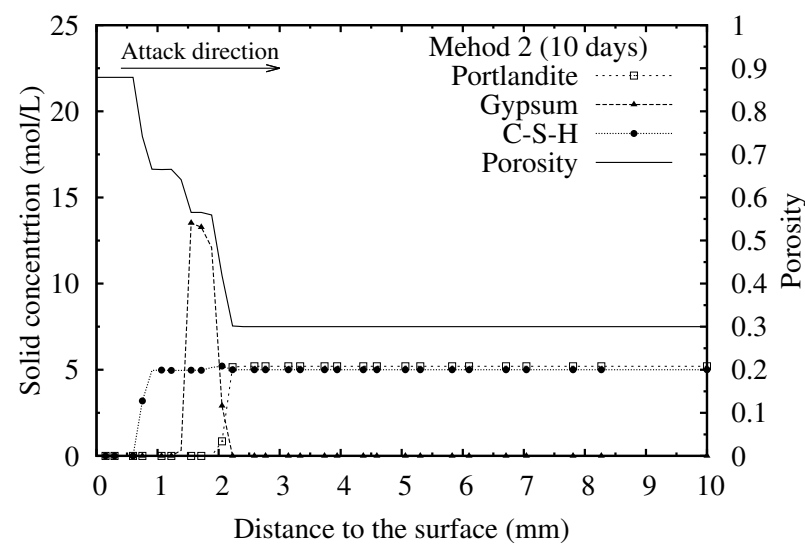

(a)



(b)

Figure 6.10: After 10 days of immersion: (a) Solid concentration and porosity ; (b) Solid volume and Ca/Si


and experiment individually. (Method 2, $\mathrm{pH}=1$ )



(a)



(b)

Figure 6.11: After 30 days of immersion: (a) Solid concentration and porosity ; (b) Solid volume and Ca/Si ratio of C-S-H . D Simulation and $\mathrm{D}_{\text {Experiment }}$ represent the degradation depth of the sample in simulation and experiment individually. (Method 2, $\mathrm{pH}=1$ )

To illustrate the leaching effect, $\mathrm{Ca}^{2+}$ concentration profiles and the total flux of calcium in the simulation of Method 1 and that of Method 2 are compared in Fig.6.13 and Fig.6.14. For both Method 1 


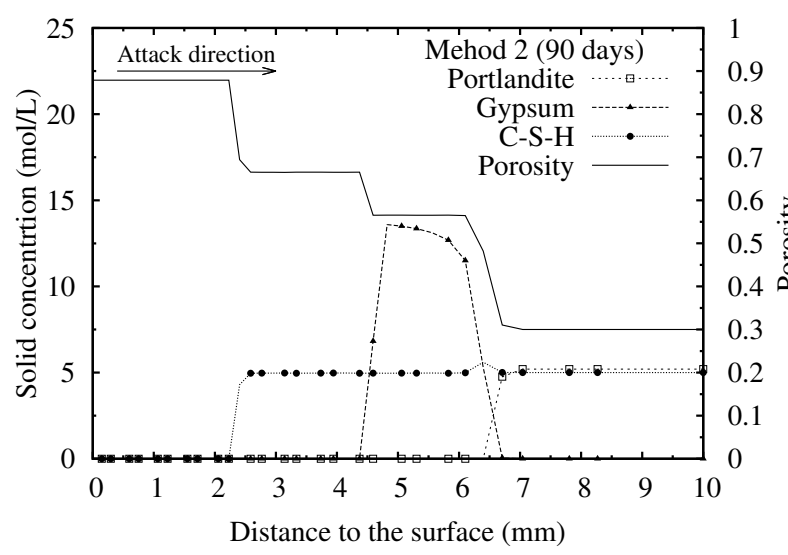

(a)

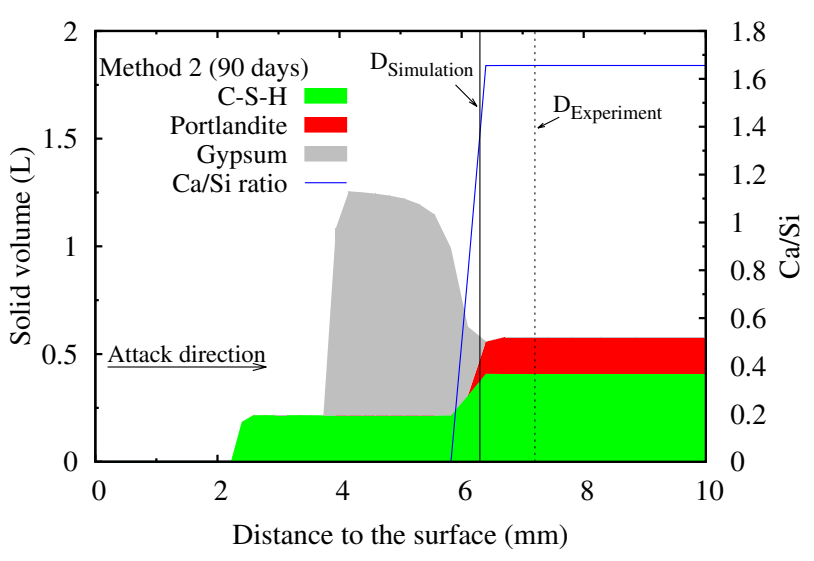

(b)

Figure 6.12: After 90 days of immersion: (a) Solid concentration and porosity ; (b) Solid volume and Ca/Si ratio of C-S-H . D Simulation and $\mathrm{D}_{\text {Experiment }}$ represent the degradation depth of the sample in simulation and experiment individually. (Method 2, $p \mathrm{H}=1$ )

and Method 2, there are positive concentration gradient of $\mathrm{Ca}^{2+}$ between the gypsum precipitation front and the core of sample. Thus the diffusion of $\mathrm{Ca}^{2+}$ toward the gypsum precipitation front results in the accumulation of gypsum. However, for Method 2, between the surface and dissolution front of gypsum there is another positive concentration gradient of $\mathrm{Ca}^{2+}$, which is not observed in simulation of Method 1. $\mathrm{Ca}^{2+}$ concentration in this region decreases from $0.003 \mathrm{~mol} / \mathrm{L}$, which is equal to $\mathrm{Ca}^{2+}$ concentration at the surface of Method 1, to 0. The diffusion of $\mathrm{Ca}^{2+}$ toward the surface (see Fig.6.14) causes a leaching effect.

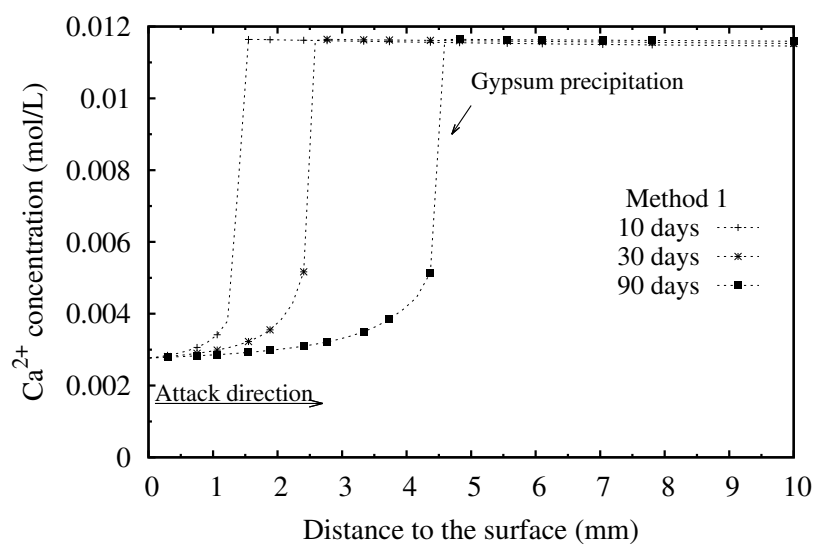

(a)

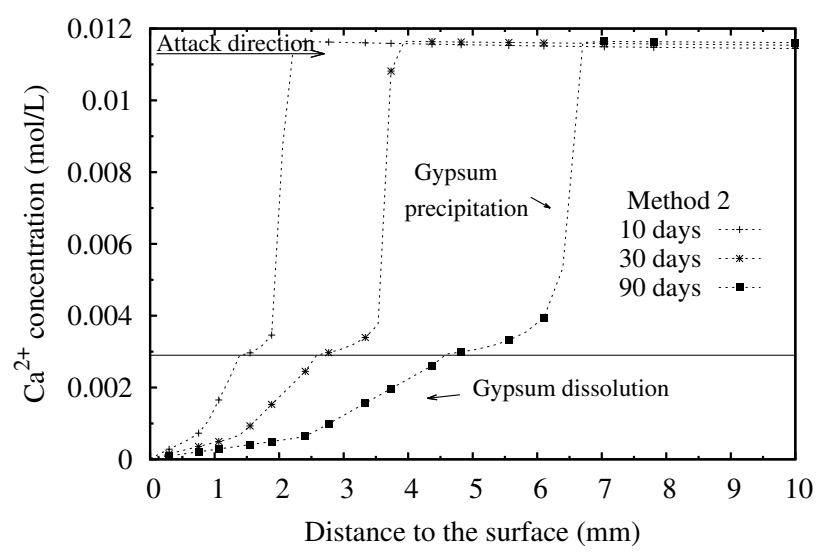

(b)

Figure 6.13: The calculated $\mathrm{Ca}^{2+}$ concentration profiles during immersion: (a) Method 1 ; (b) Method 2 . $(p \mathrm{H}=1)$

The corrosion depth calculated from the model and that measured from experiment are compared in Fig.6.15b. Since the solution flow washes the reaction surface, the samples immersed with Method 2 degraded much deeper and faster than those with Method 1. Like simulation of Method 1, corrosion with 




(a)

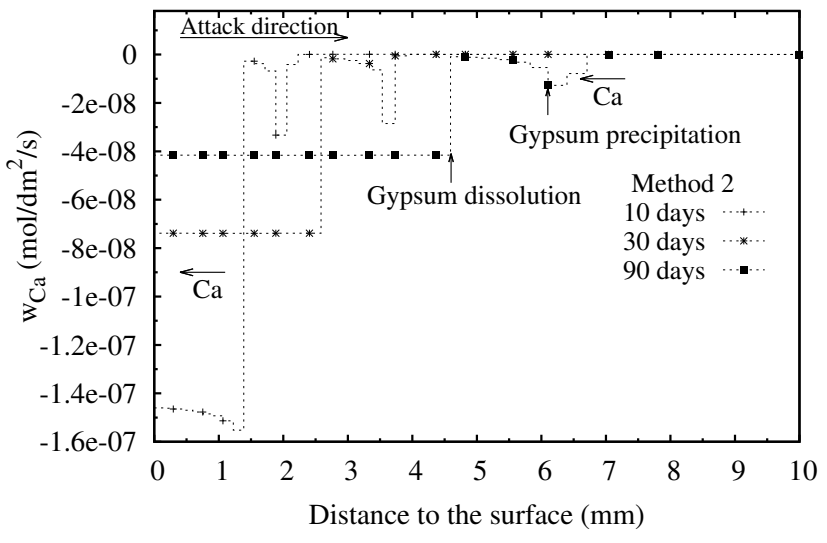

(b)

Figure 6.14: The calculated diffusion of calcium during immersion: (a) Method 1 ; (b) Method 2 . $(p \mathrm{H}=$ 1)

Method 2 was not measured until 10 days of immersion, and the predicted corrosion rate is overestimated during the early time. However, comparing with the experimental results, less material is corroded during simulation from 70 days to 90 days. The difference probably results from the effect of the solution flow which, in our model, was simulated by leaching out of gypsum and silica gel. Thus, some unreactive solid phases still remain in the fully decomposed zone which were completely washed away in experiment. Therefore, the porosity of fully decomposed zone is 0.88 rather than 1 (see Fig.6.15a). According to the experimental measurements, the sulphate ions concentration around the uncorroded surface was equal to that in the solution. But in our simulation, the sulphate concentration decreased gradually in the fully decomposed zone as shown in Fig.6.16.

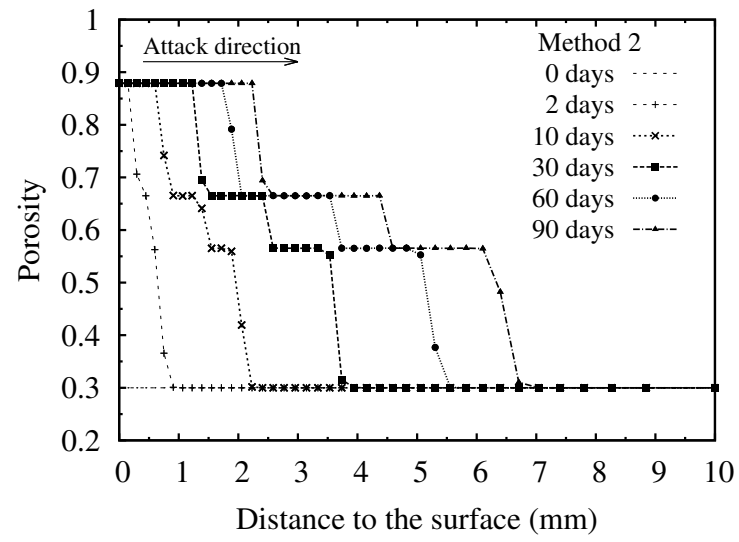

(a)

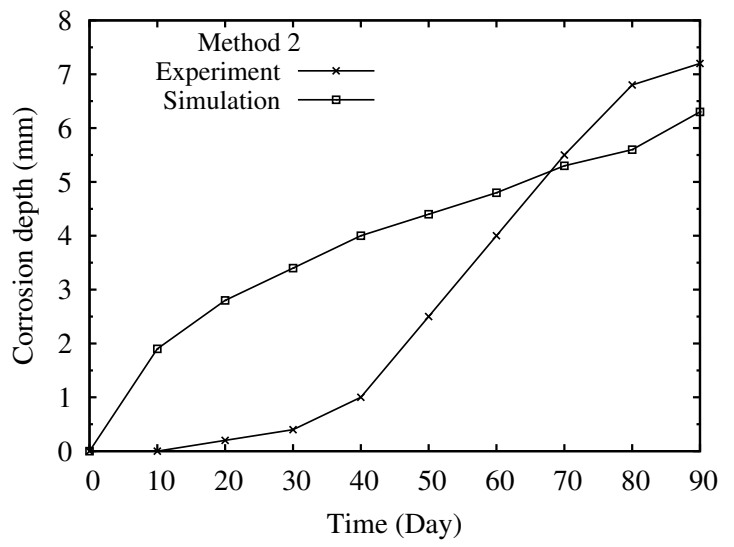

(b)

Figure 6.15: The predicted evolution of porosity and corrosion depth profiles from 0 days to 90 days: (a) Porosity; (b) Corrosion depth. (Method 2, $p \mathrm{H}=1$ ) 


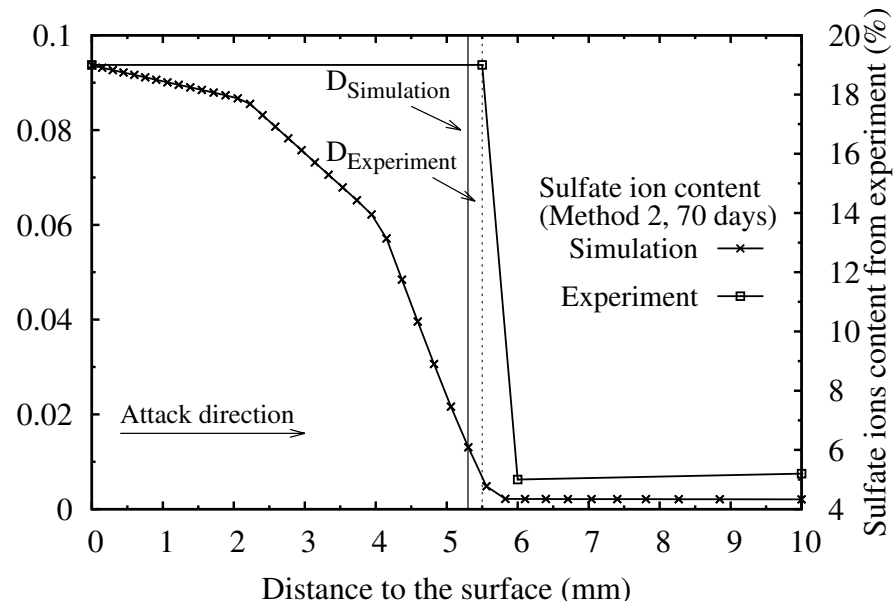

Figure 6.16: The concentration of $\mathrm{HSO}_{4}^{-}$and $\mathrm{SO}_{4}^{2-}$ in the sample after 70 days immersion. (Method 2, $p \mathrm{H}$ $=1)$

\subsection{Low $\mathrm{H}_{2} \mathrm{SO}_{4}$ concentration condition $(p \mathbf{H}=2)$}

In Kawai's experiment, another immersion test using a solution with lower $\mathrm{H}_{2} \mathrm{SO}_{4}$ concentration $(p \mathrm{H}=$ 2) was carried out as well. It turned out that corrosion process is very sensitive to $\mathrm{H}_{2} \mathrm{SO}_{4}$ concentration: all of the samples immersed in a $\mathrm{H}_{2} \mathrm{SO}_{4}$ solution at $p \mathrm{H}=2$ was almost uncorroded with either Method 1 or Method 2.

We simulated this experiment by decreasing the $\mathrm{H}_{2} \mathrm{SO}_{4}$ concentration at the right boundary to achieve $p \mathrm{H}=2$. Boundary and initial conditions are summarized in Table 6.3. Since the concentration of $\mathrm{H}_{2} \mathrm{SO}_{4}$ is low, the characteristic time (i.e., $\tau_{\mathrm{CH}}$ and $\tau_{\mathrm{CS} H 2}$ ) are extended to $200000 \mathrm{~s}$.

Table 6.3: Boundary and initial conditions of the $\mathrm{H}_{2} \mathrm{SO}_{4}$ attack with $(p \mathrm{H}=2)$

\begin{tabular}{|c|c|c|}
\hline $\begin{array}{c}\text { Balance } \\
\text { Equation }\end{array}$ & $\begin{array}{c}\text { Boundary conditions } \\
\text { Left surface }\end{array}$ & $\begin{array}{c}\text { Initial conditions } \\
\text { Mortar }\end{array}$ \\
\hline Sulfur $(\mathrm{S})$ & $\begin{array}{c}\text { diffusion allowed } \\
\rho_{\mathrm{H}_{2} \mathrm{SO}_{4}{ }^{0}}=10^{-10} \mathrm{~mol} / \mathrm{L}\end{array}$ & $\rho_{\mathrm{H}_{2} \mathrm{SO}_{4}{ }^{0}}=10^{-31.5} \mathrm{~mol} / \mathrm{L}$ \\
\hline Calcium $(\mathrm{Ca})$ & $\begin{array}{c}\text { Method } 1: \text { no diffusion } \\
\text { Method } 2: \text { diffusion allowed } \zeta_{\mathrm{Ca}}=-2\end{array}$ & $\zeta_{\mathrm{Ca}}=1$ \\
\hline Silicon $(\mathrm{Si})$ & $\begin{array}{c}\text { Method } 1: \text { no diffusion } \\
\text { Method } 2: \text { diffusion allowed } \zeta_{\mathrm{Si}}=-2\end{array}$ & $\zeta_{\mathrm{Si}}=1$ \\
\hline Potassium $(\mathrm{K})$ & diffusion allowed $\rho_{\mathrm{K}+}=0 \mathrm{~mol} / \mathrm{L}$ & $\rho_{\mathrm{K}^{+}}=0.5 \mathrm{~mol} / \mathrm{L}$ \\
\hline Chlorine $(\mathrm{Cl})$ & diffusion allowed $\rho_{\mathrm{Cl}}=0 \mathrm{~mol} / \mathrm{L}$ & $\rho_{\mathrm{Cl}^{-}}=0.5 \mathrm{~mol} / \mathrm{L}$ \\
\hline Charge & $\begin{array}{c}\text { Method } 1: \text { no current } \\
\text { Method } 2: \psi=0\end{array}$ & $\psi=0$ \\
\hline
\end{tabular}

The concentration of unionized molecules of $\mathrm{H}_{2} \mathrm{SO}_{4}, \rho_{\mathrm{H}_{2} \mathrm{SO}_{4}}^{0}$, is $1 \times 10^{-10} \mathrm{~mol} / \mathrm{L}$ in the solution with $p \mathrm{H}$ $=2$. Comparing with the solution with $p \mathrm{H}=1$, the penetration of $\mathrm{H}_{2} \mathrm{SO}_{4}{ }^{0}$ with the solution with $p \mathrm{H}=$ 2 is much slower (see Fig.6.17). Therefore the acidification of cement paste is slow as shown in Fig.6.18. For both Method 1 and Method 2, the acidification front of the solution with $p \mathrm{H}=2$ at 90 days does not 
even reach that of solution with $p \mathrm{H}=1$ at 30 days. For Method 2, the difference between the attack of $p \mathrm{H}$ $=1$ and that of $p \mathrm{H}=2$ is even bigger than that simulated with Method 1 due to the removing of reaction products which obstructs the transport of $\mathrm{H}_{2} \mathrm{SO}_{4}$.



(a)



(b)

Figure 6.17: The calculated penetration of $\mathrm{H}_{2} \mathrm{SO}_{4}$ with different $p \mathrm{H}$ : (a) Method 1; (b) Method 2.

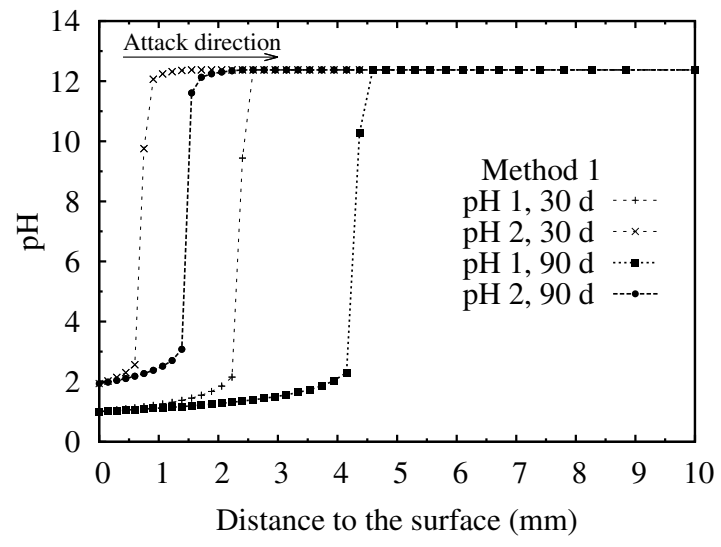

(a)



(b)

Figure 6.18: The evolution of $p \mathrm{H}$ with different $p \mathrm{H}$ : (a) Method 1; (b) Method 2.

For $p \mathrm{H}=2$, the same zones as those observed in the simulation of $p \mathrm{H}=1$ are presented in Fig.6.19 to Fig.6.21. Due to the low concentration of $\mathrm{H}_{2} \mathrm{SO}_{4}$, the corrosion rate are slow for both Method 1 and Method 2. In the experiment, corrosion is almost undetectable with Method 1 and very little corrosion was observed after 90 days of immersion of Method 2. The predicted corrosion rate is overestimated, yet much slower than that of the simulation of $p \mathrm{H}=1$.

Due to the high first order ionization constant of $\mathrm{H}_{2} \mathrm{SO}_{4}$, the concentrations of $\mathrm{HSO}_{4}^{-}$and $\mathrm{SO}_{4}^{2-}$ are much higher than $\mathrm{H}_{2} \mathrm{SO}_{4}$ concentration. Hence the source of sulfur in gypsum is provided mainly by the diffusion of $\mathrm{HSO}_{4}^{-}$and $\mathrm{SO}_{4}^{2-}$. Taking the immersion after 90 days for example, the concentration of $\mathrm{HSO}_{4}^{-}$ 




(a)

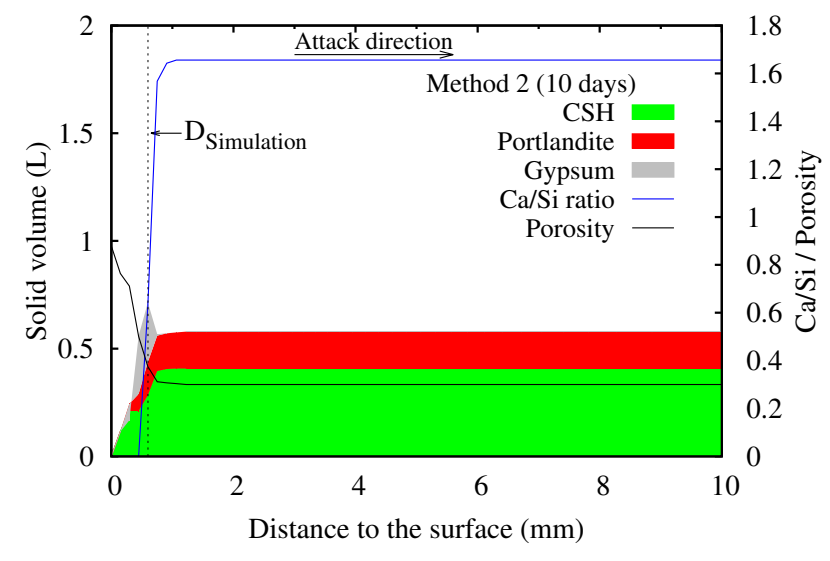

(b)

Figure 6.19: The evolution of solid volume, Ca/Si ration of C-S-H and porosity after 10 days immersion : (a) Method 1; (b) Method 2. $(p \mathrm{H}=2)$

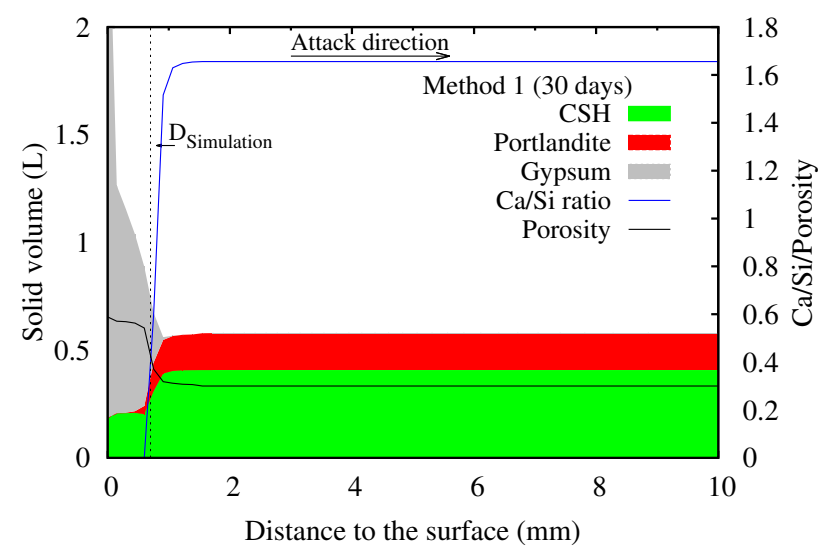

(a)

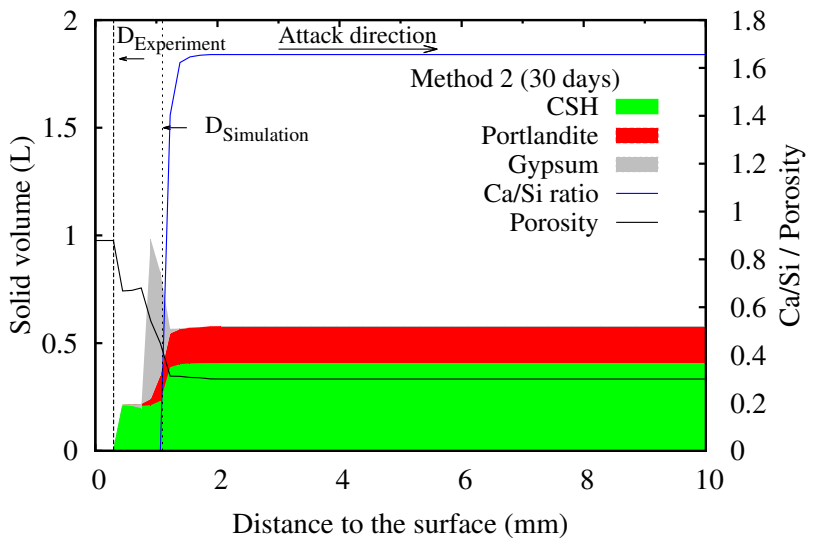

(b)

Figure 6.20: The evolution of solid volume, $\mathrm{Ca} / \mathrm{Si}$ ration of C-S-H and porosity after 30 days immersion : (a) Method 1; (b) Method 2. $(p \mathrm{H}=2)$ 


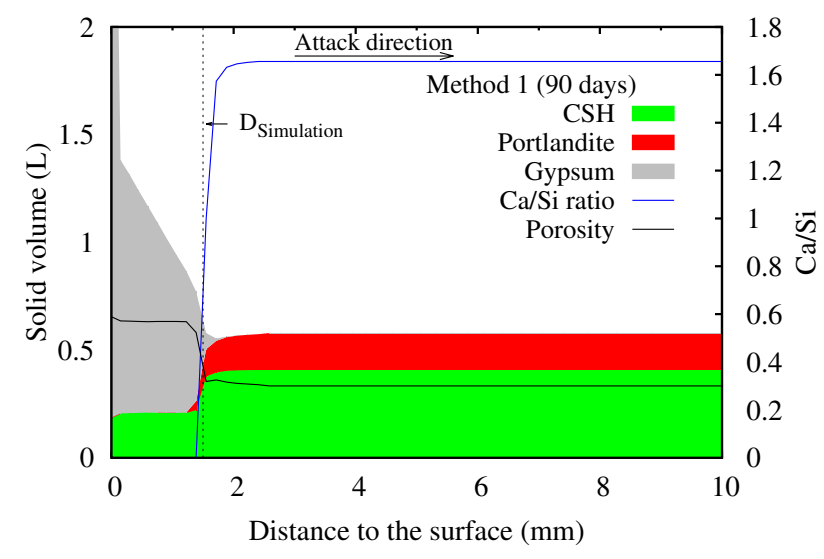

(a)

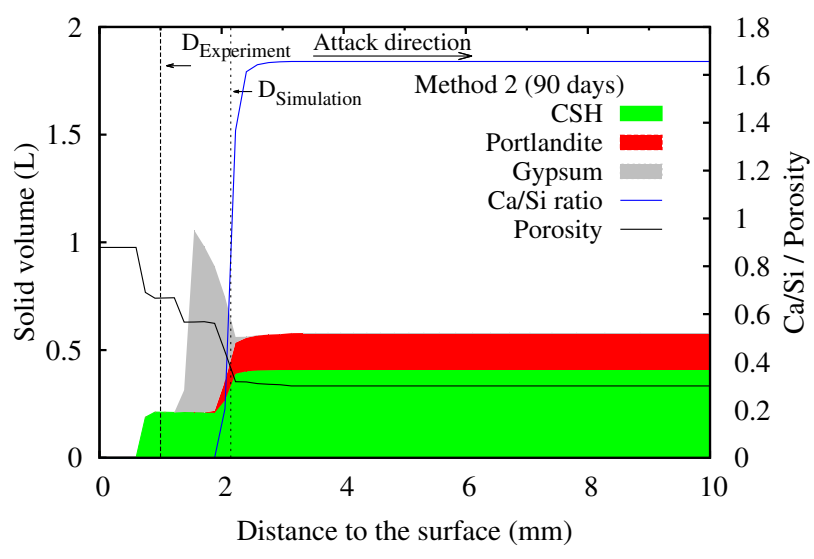

(b)

Figure 6.21: The evolution of solid volume, Ca/Si ration of C-S-H and porosity after 90 days immersion : (a) Method 1; (b) Method 2. $(p \mathrm{H}=2)$

and $\mathrm{SO}_{4}^{2-}$ of the immersion of $p \mathrm{H}=2$ are much less than that of the immersion with $p \mathrm{H}=1$ (see Fig.6.22). For $p \mathrm{H}=2$, due to the smaller concentration gradients of both $\mathrm{HSO}_{4}^{-}$and $\mathrm{SO}_{4}^{2-}$, the flux of sulfur is much lower than that under high $\mathrm{H}_{2} \mathrm{SO}_{4}$ concentration condition as shown in Fig.6.23.

For Method 2, in the zone where gypsum accumulates, the concentration gradients of both $\mathrm{HSO}_{4}^{-}$and $\mathrm{SO}_{4}^{2-}$ are negative. Thus sulfur diffuses from the gypsum dissolved front to the gypsum precipitate front. For the condition of $p \mathrm{H}=1$, concentration gradient of $\mathrm{SO}_{4}^{2-}$ is positive in the fully decomposed zone, while for $p \mathrm{H}=2$ condition it is negative. Therefore, when $\mathrm{H}_{2} \mathrm{SO}_{4}$ is few the $\mathrm{SO}_{4}^{2-}$ released from the gypsum dissolution front is not sufficient for gypsum precipitation. The reason could be that the difference of $\mathrm{Ca}^{2+}$ concentration at $p \mathrm{H}=2$ condition and that at $p \mathrm{H}=1$ condition is smaller than the difference of $\mathrm{SO}_{4}^{2-}$ concentration.

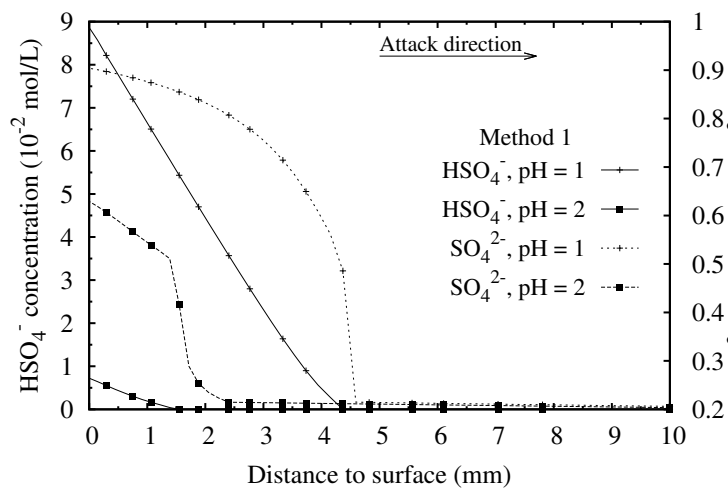

(a)

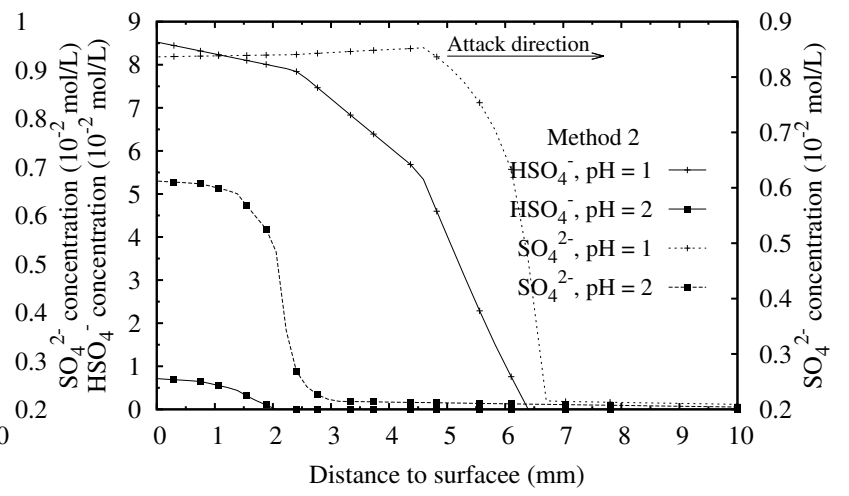

(b)

Figure 6.22: The concentration of $\mathrm{HSO}_{4}^{-}$and $\mathrm{SO}_{4}^{2-}$ after 90 days immersion with different $p \mathrm{H}$ : (a) Method 1; (b) Method 2. 


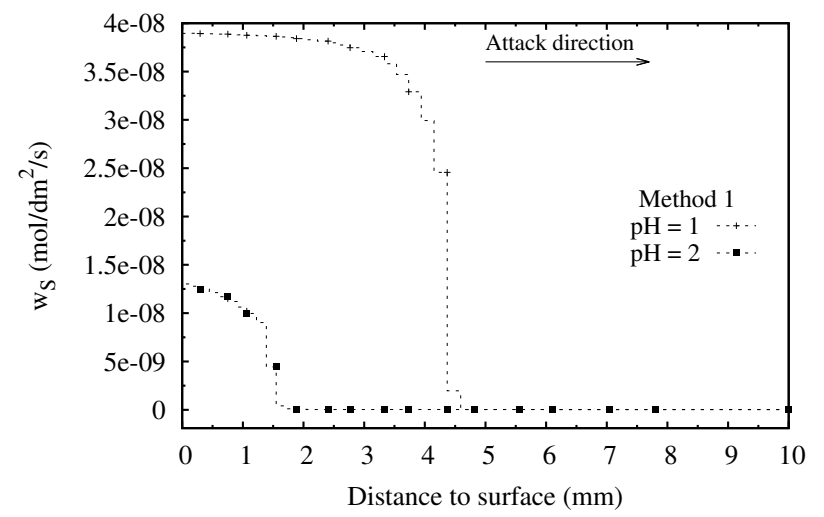

(a)

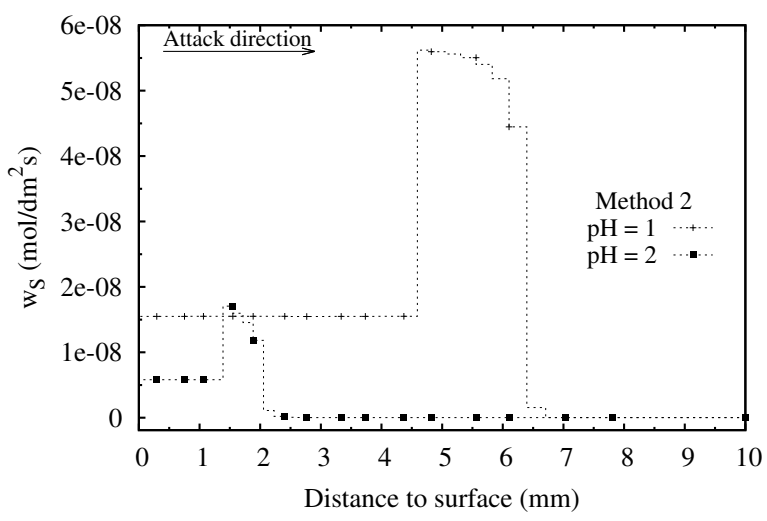

(b)

Figure 6.23: The flux of sulfur after 90 days immersion with different $p H$ : (a) Method 1; (b) Method 2.

For Method 1, comparing with the simulation results of $p H=1$, more gypsum accumulates at the surface. As discussed in Section 5.4.1, the saturation degree of $\mathrm{C} \overline{\mathrm{S}} \mathrm{H} 2\left(Q_{\mathrm{C} \overline{\mathrm{S}} \mathrm{H} 2} / K_{\mathrm{CS} H 2}\right)$ in gypsum-rich layer is 1. For the lower $\mathrm{H}_{2} \mathrm{SO}_{4}$ condition, the concentration of $\mathrm{SO}_{4}^{2-}$ is low (see Fig.6.22a). Thus, more $\mathrm{Ca}^{2+}$ ion diffuse toward the surface. Consequently, more gypsum accumulate at surface portion. Taking the simulation of Method 1 after 90 days for instance, the concentration of $\mathrm{Ca}^{2+}$ and flux of calcium for different $p \mathrm{H}$ value are plotted in Fig.6.24.

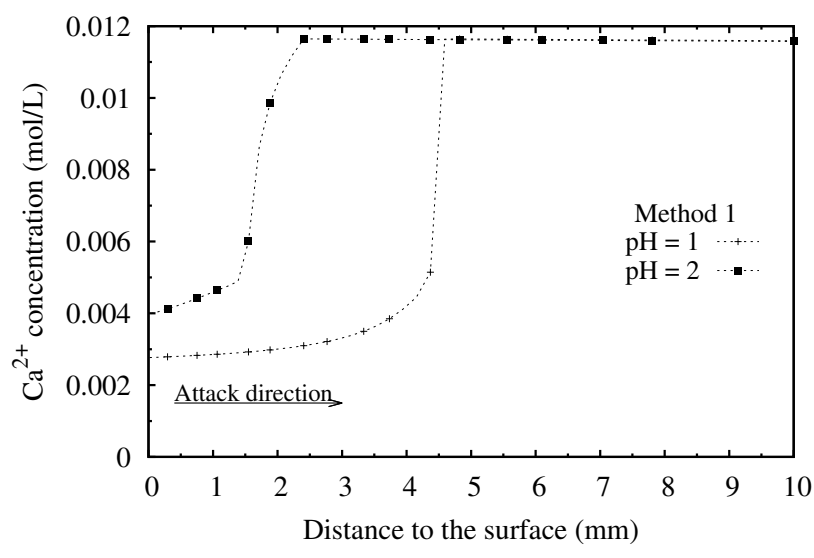

(a)



(b)

Figure 6.24: After 90 days immersion : (a) The concentration of $\mathrm{Ca}^{2+} 1$; (b) Flux of calcium (Method 1) 


\subsection{Analysis of the discrepancy between simulation results and experimental results}

\subsubsection{Effect of carbonated layer}

The degradation depth measured in the experiment was about $4.2 \mathrm{~mm}$ and $7.2 \mathrm{~mm}$ with Method 1 and Method 2 respectively after 90 days immersion test which is close to our predictions (indicated by vertical lines in Fig.6.5b and Fig.6.12b). However, predicted degradation depth is not always consistent with experimental results as shown in in Fig.6.7b and Fig.6.15b. The corrosion rate in the experiments increased during immersion time, while in the early time the predicted corrosion rate is much higher than experimental results.

This may be justified by several reasons, such as inaccurate parameters in model, different conditions between simulation and experiment and carbonation occurring during the initiation stage of biodeterioration (Hudon et al., 2011; Magniont et al., 2011; Joseph et al., 2012). Normally, overestimated/ underestimated diffusion coefficients would affect the corrosion rate during the whole process. However, in Fig.6.7b and Fig.6.15b the corrosion rate of simulation is higher than that of experiment only during early time. This suggests that carbonation must be taken into account in our model.

During the curing time the samples were subjected to carbonation, which could clog the pores of the surface of sample. According to the experiments on the effect of carbonation on porosity (Thiéry et al., 2011; Van Gerven et al., 2007), carbonation could decrease the average porosity of mortar by more than 15\%. In some extreme cases, the pores of surface could be clogged (Shen, 2012). In that case, it would have taken long time for $\mathrm{H}_{2} \mathrm{SO}_{4}$ to penetrate into pores at the early time. After the surface area was corroded, more reactive surface was exposed, thus the degradation process accelerated. Therefore, we take carbonation as the most suspected reason leading such discrepancy.

To verify this explanation, we conducted a preliminary investigation. From the experiment results shown in Fig.6.7b, the degradation rate accelerated after corroded depth reached to $1 \mathrm{~mm}$. Thus, a simulation of the sample with a simplified carbonated layer, whose thickness is $1 \mathrm{~mm}$, is carried out. During carbonation, portlandite and C-S-H gel dissolves and calcite $\left(\mathrm{CaCO}_{3}\right.$, noted as $\left.\mathrm{C} \overline{\mathrm{C}}\right)$ precipitates as the reactions Eq.(6.1) and Eq.(6.2). We assume that this layer is homogeneous and fully carbonated. Since the initial material contains portlandite $(5.2 \mathrm{~mol} / \mathrm{L})$ and $\mathrm{C}_{1.66} \mathrm{SH}_{2.6}(5 \mathrm{~mol} / \mathrm{L})$, the solid compositions of the fully carbonated layer are calcite $(13.3 \mathrm{~mol} / \mathrm{L})$ and silica gel $(5 \mathrm{~mol} / \mathrm{L})$. Given that the molar volume of calcite is $37 \mathrm{~cm}^{3} / \mathrm{mol}$ (Shen, 2012), the porosity of carbonated layer decreases from 0.3 to 0.166 by a simple balance of volume.

It is known that a reduction of porosity in cementitious materials increases its strength in general (Yudenfreund et al., 1972; Pantazopoulou and Mills, 1995). The physical properties of carbonated layer 
is considered to be similar with that of normal cement paste for simplification. According to the study of (Chen et al., 2013), the tensile strength of cement mortar whose porosity is 0.166 is about 1.4 times of that of the cement mortar with porosity $=0.3$. Therefore the damage criterion is set as $5 \mathrm{MPa}$.

$$
\begin{aligned}
\mathrm{CH}+\mathrm{CO}_{2} & \rightleftharpoons \mathrm{C} \overline{\mathrm{C}}+\mathrm{H}_{2} \mathrm{O} \\
\mathrm{C}_{x} \mathrm{~S}_{y} \mathrm{H}_{z}+x \mathrm{CO}_{2} & \rightleftharpoons x \mathrm{C} \overline{\mathrm{C}}+y \mathrm{H}_{4} \mathrm{SiO}_{4}^{0}+(z-2 y) \mathrm{H}_{2} \mathrm{O}
\end{aligned}
$$

Since the materials is saturated with water in our modeling, the $\mathrm{H}_{2} \mathrm{SO}_{4}$ attack product of the carbonated layer is only gypsum.

Since we didn't take the calcite into our modeling yet, we consider the reaction of $\mathrm{H}_{2} \mathrm{SO}_{4}$ and $\mathrm{C} \overline{\mathrm{C}}$ as same as that of $\mathrm{CH}$ in carbonated layer. Thus, the equilibrium concentration of $\mathrm{H}_{2} \mathrm{SO}_{4}$ in carbonated layer is equals to that of initial cement paste. Boundary and initial conditions are summarized in Table 6.4.

\begin{tabular}{|c|c|c|c|}
\hline Balance & Boundary conditions & \multicolumn{2}{|c|}{ Initial conditions } \\
\hline Equation & Left surface & Carbonated layer & Mortar \\
\hline Sulfur (S) & $\begin{array}{c}\text { diffusion allowed } \\
\rho_{\mathrm{H}_{2} \mathrm{SO}_{4}{ }^{0}}=10^{-8} \mathrm{~mol} / \mathrm{L} \\
\end{array}$ & $\rho_{\mathrm{H}_{2} \mathrm{SO}_{4}{ }^{0}}=10^{-31.5} \mathrm{~mol} / \mathrm{L}$ & $\rho_{\mathrm{H}_{2} \mathrm{SO}_{4}{ }^{0}}=10^{-31.5} \mathrm{~mol} / \mathrm{L}$ \\
\hline Calcium (Ca) & $\begin{array}{c}\text { Method 1:no diffusion } \\
\text { Method 2: diffusion allowed }\end{array}$ & $\begin{array}{c}\zeta_{\mathrm{Ca}}=1 \\
\mathrm{C} \overline{\mathrm{C}} 13.3 \mathrm{~mol} / \mathrm{L}\end{array}$ & $\begin{array}{c}\zeta_{\mathrm{Ca}}=1 \\
\mathrm{CH} 5.2 \mathrm{~mol} / \mathrm{L}\end{array}$ \\
\hline Silicon (Si) & $\begin{array}{c}\text { Method 1:no diffusion } \\
\text { Method 2: diffusion allowed }\end{array}$ & $\begin{array}{c}\zeta_{\mathrm{Si}}=1 \\
\mathrm{SH}_{t} 5 \mathrm{~mol} / \mathrm{L}\end{array}$ & $\begin{array}{c}\zeta_{\mathrm{Si}}=1 \\
\text { Jennite } 5 \mathrm{~mol} / \mathrm{L}\end{array}$ \\
\hline Potassium (K) & diffusion allowed $\rho_{\mathrm{K}^{+}}=0 \mathrm{~mol} / \mathrm{L}$ & $\rho_{\mathrm{K}^{+}}=0.5 \mathrm{~mol} / \mathrm{L}$ & $\rho_{\mathrm{K}^{+}}=0.5 \mathrm{~mol} / \mathrm{L}$ \\
\hline Chlorine $(\mathrm{Cl})$ & diffusion allowed $\rho_{\mathrm{Cl}^{-}}=0 \mathrm{~mol} / \mathrm{L}$ & $\rho_{\mathrm{Cl}-}=0.5 \mathrm{~mol} / \mathrm{L}$ & $\rho_{\mathrm{Cl}-}=0.5 \mathrm{~mol} / \mathrm{L}$ \\
\hline Charge & $\begin{array}{l}\text { Method 1: no current } \\
\text { Method 2: } \psi=0\end{array}$ & $\psi=0$ & $\psi=0$ \\
\hline
\end{tabular}

Table 6.4: Boundary and initial conditions of the $\mathrm{H}_{2} \mathrm{SO}_{4}$ attack of the sample with carbonated layer

The diffusion rate of species was expected to decrease during early time due to lower porosity. Therefore the $p \mathrm{H}$ reduction rate of both Method 1 and Method 2 are slowed down as in Fig.6.25. Before 30 days, the acidification front of carbonated sample is behind that of fresh sample. However, after 60 days the diffusion of $\mathrm{H}_{2} \mathrm{SO}_{4}$ in carbonated sample catches up that of fresh sample due to the fully degradation of carbonated layer.

The solid compositions of samples with carbonated layer at the early time of immersion are plotted in Fig.6.26. At 10 days of Method 1, some Calcite still remains in the carbonated layer, where porosity keeps at 0.166 . For Method 2, all of the calcite is gone due to a faster corrosion rate. At 90 days, the solid compositions are almost the same with that of normal samples.

The predicted degradation depth of the sample with carbonated layer (as shown in Fig.6.27) indicates that the carbonated layer could reduce the degradation rate at early time. However, the carbonated layer 


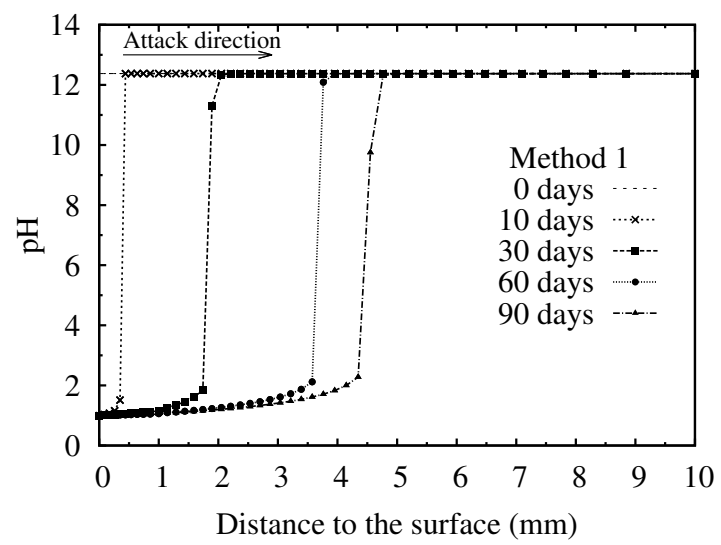

(a)

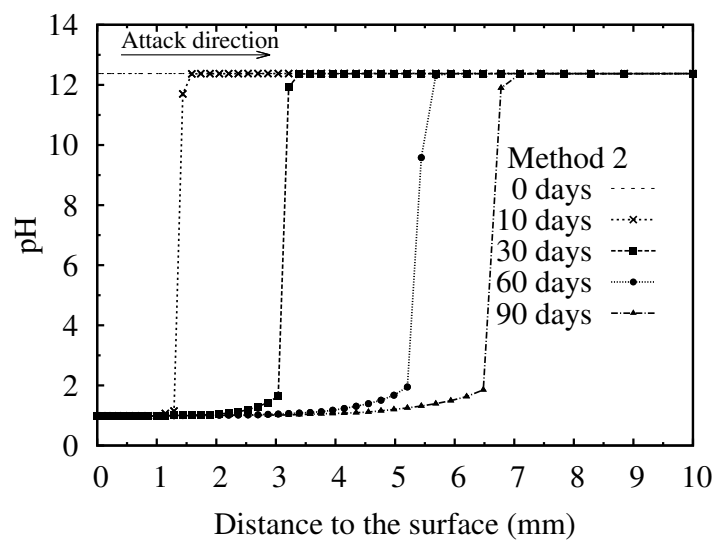

(b)

Figure 6.25: The evolution of $p \mathrm{H}$ from 10 days to 90 days for the sample with carbonated layer: (a) Method 1; (b) Method 2. $(p \mathrm{H}=1)$

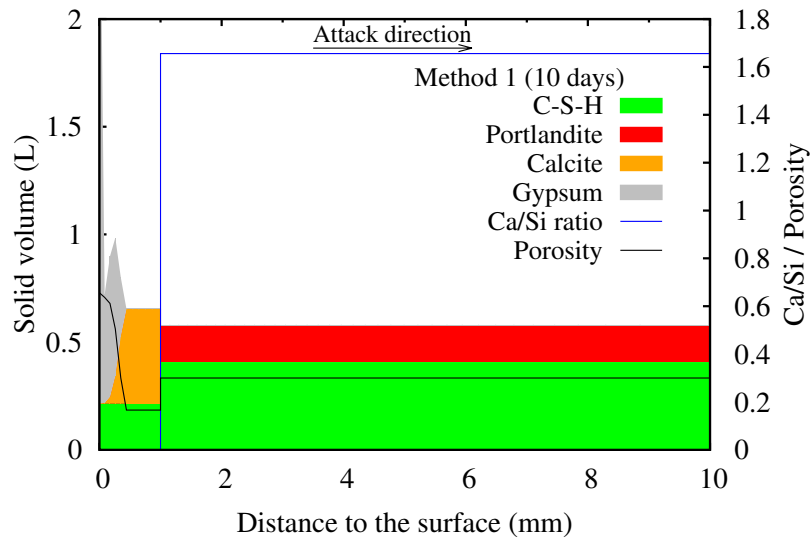

(a)

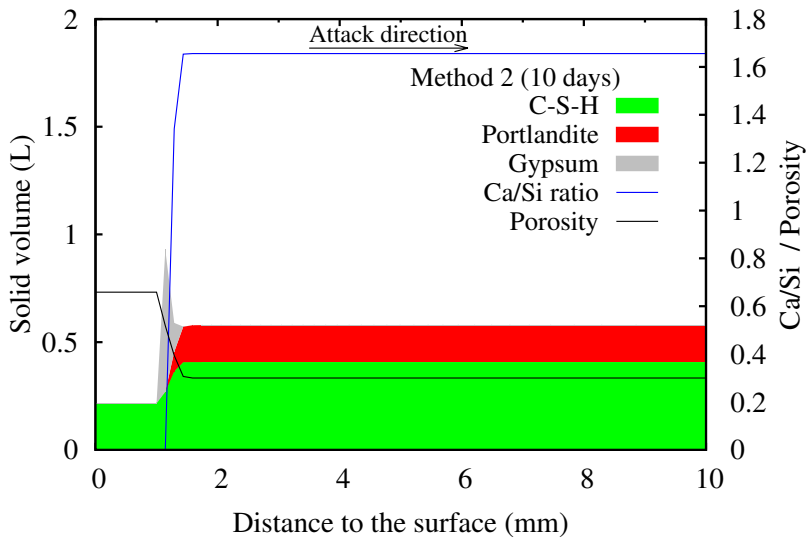

(b)

Figure 6.26: The evolution of solid volume, Ca/Si ration of C-S-H and porosity of samples with carbonated layer after 10 days immersion : (a) Method 1; (b) Method 2. $(p \mathrm{H}=1)$ 
is still corroded too fast comparing with experimental observation. This difference may be caused by the difference between the chemical reaction of $\mathrm{CH}$ and that of $\mathrm{C} \overline{\mathrm{C}}$. To further address this discrepancy, a real carbonated layer should be taken into account. In this study, all of the simulations in the other parts are conducted on fresh cement paste.



(a)

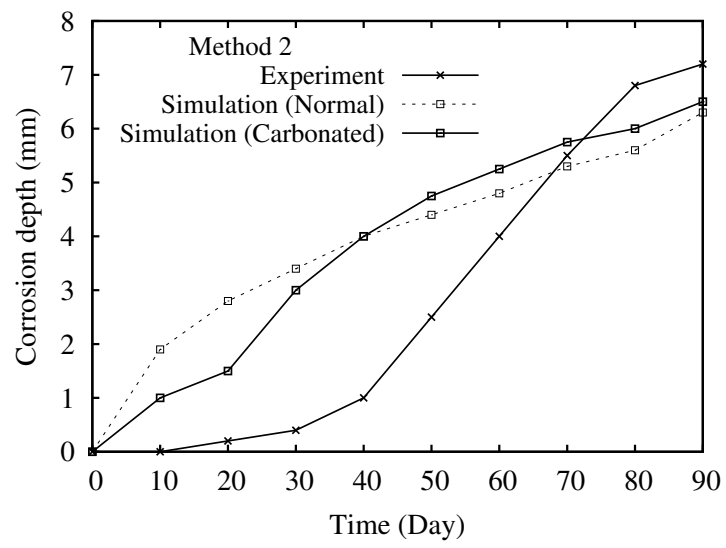

(b)

Figure 6.27: The corrosion depth profiles of simulation and experiments from 10 days to 90 days: (a) Method 1; (b) Method 2

\subsubsection{Effect of water-cement ratio of cemment paste}

In Kawai's experiments, the degradation rate of mortar samples with different W/C ratio were compared. It is remarkable that the degradation depth of samples with low W/C ratios was deeper than those with high $\mathrm{W} / \mathrm{C}$ ratios. This phenomenon was explained as follows (Kawai et al., 2005):

Concrete with a high water cement ratio has larger and more pores than that with a low water cement ratio. These pores play the role of a capacity to absorb expansion caused by the production of gypsum. Therefore concrete with a high water cement ratio has a higher capacity to absorb the expansion of production reaction of gypsum than that with a low water cement ratio, that is to say, concrete with a low water cement ratio erodes earlier than that with a high water cement ratio.

Such results were found by other researchers as well: Attacks with $2 \% \mathrm{H}_{2} \mathrm{SO}_{4}$ solution showed no differences between degradation of high and low porosity mortar paste sample (Israel et al., 1997); 1\% $\mathrm{H}_{2} \mathrm{SO}_{4}$ solution showed greater degradation for low W/C ratios than high W/C ratios samples (Fattuhi and Hughes, 1988); low $\mathrm{H}_{2} \mathrm{SO}_{4}$ concentration (0.0016 and 0.02\%) showed greater deterioration depth for samples with low W/C ratios than with high W/C ratios (Hughes and Guest, 1978).

For high $\mathrm{H}_{2} \mathrm{SO}_{4}$ concentration condition, we conducted two simulations of immersion test (Method 1 and $p \mathrm{H}=0.5$ ) of cement mortars whose $\mathrm{W} / \mathrm{C}$ ratios are 0.35 and 0.5 respectively. For the sample with 
$\mathrm{W} / \mathrm{C}$ ratio of 0.5 , we consider that the cement hydration contains initially $3.9 \mathrm{~mol} / \mathrm{L}$ of portlandite and $3.7 \mathrm{~mol} / \mathrm{L}$ of $\mathrm{C}-\mathrm{S}-\mathrm{H}$ as jennite. The initial porosity is 0.45 . The initial condition and boundary condition is same with that in Table 6.1. The profiles of solid compositions after 30 days (see Fig.6.28) shows that the predicted degradation rate for samples with high $\mathrm{W} / \mathrm{C}$ ratio is greater than that with $\mathrm{W} / \mathrm{C}$ ratio.



(a)

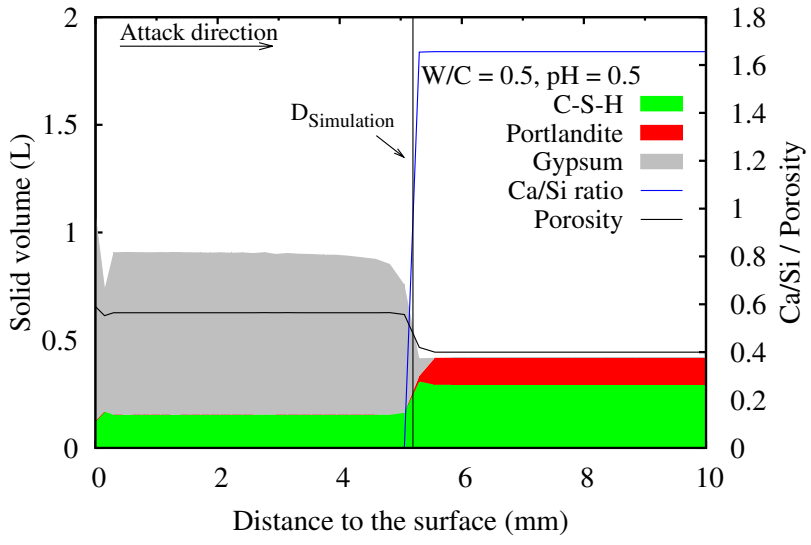

(b)

Figure 6.28: Solid compositions, Ca/Si ratio of C-S-H and porosity profiles after 30 days of immersion under high $\mathrm{H}_{2} \mathrm{SO}_{4}$ concentration condition $(p \mathrm{H}=0.5)$ : (a) W/C $=0.35$; (b) W/C $=0.5$

For low $\mathrm{H}_{2} \mathrm{SO}_{4}$ concentration condition, similar simulations (Method 1 and $p \mathrm{H}=2$ ) were conducted to cement mortar with $\mathrm{W} / \mathrm{C}$ ratios of 0.35 and 0.5. Fig.6.29 shows that under low $\mathrm{H}_{2} \mathrm{SO}_{4}$ concentration condition the predicted degradation rate for samples with high $\mathrm{W} / \mathrm{C}$ ratio is still greater than that with low $\mathrm{W} / \mathrm{C}$ ratio. When $\mathrm{H}_{2} \mathrm{SO}_{4}$ is few, the corrosion rate is slow. Thus the difference between low $\mathrm{W} / \mathrm{C}$ and high $\mathrm{W} / \mathrm{C}$ is not as significant as that for high $\mathrm{H}_{2} \mathrm{SO}_{4}$ concentration condition.

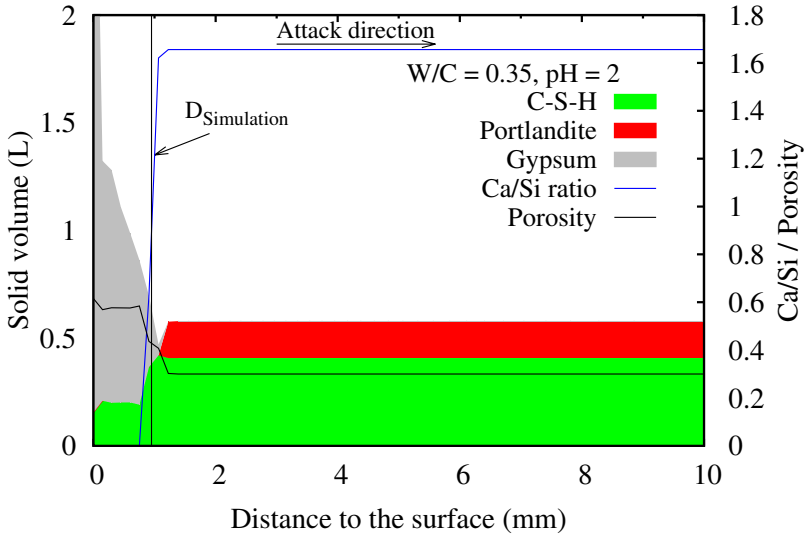

(a)



(b)

Figure 6.29: Solid compositions, $\mathrm{Ca} / \mathrm{Si}$ ratio of C-S-H and porosity profiles after 30 days of immersion high $\mathrm{H}_{2} \mathrm{SO}_{4}$ concentration condition $(p \mathrm{H}=2)$ : (a) initial porosity $=0.3$; (b) initial porosity $=0.4$ 
The simulation results could be explained because the diffusion of sulfate species $\left(\mathrm{H}_{2} \mathrm{SO}_{4}, \mathrm{HSO}_{4}^{-}, \mathrm{SO}_{4}^{2-}\right)$ is very fast and sensitive to the porosity. Thus the degradation process is diffusion controlled. However, Ueda, et al. (Ueda and Tatematsu, 1996) claimed that sulfuric acid hardly penetrates into hardened cement. The reactions of cement hydrates and sulfuric acid should occur just beneath the surface portion of specimens. This may be caused by the production of gypsum in the surface portion which is faster than the penetration rate of sulfate ions into the specimen. In other words, the corrosion process is governed by reaction rather than diffusion. And in the simulation study of Jahani, et al. (Jahani et al., 2005), it was indicated that the diffusion coefficient of sulphate ions in the corrosion products layer is $7.70 \times 10^{-4}$ $\mathrm{cm}^{2} /$ day, while the reaction rate constant of precipitation of gypsum is about $112 \mathrm{~cm}^{2} /$ day according to the simulation of Bouchelaghem (Bouchelaghem, 2010). Therefore, further investigations about the damage mechanism and diffusion of sulfate ion in cementitious materials should be carried out.

\subsection{Long-term prediction}

Besides short-term predictions, long-term simulation should be conducted to assess the relevance of the model. Kawai's experiments only lasted 90 days, yet it is one of the longest experiments where enough information is available for simulation. It is generally believed that the degradation depth of concrete due to acid attack including sulfuric acid attack is proportional to the square root of the exposure time Pavlik (1994) as follows:

$$
y=b \sqrt{t}
$$

where, $y$ is the degradation depth. $t$ represents the exposure time in acid solution and $b$ is constant. According to this equation, the rate of degradation is dominated by the diffusion rate of acid under the assumption that corrosion products remain on surface.

Two simulations of sulfuric acid attack $(p \mathrm{H}=1$ and $p \mathrm{H}=2)$ of Method 1 was conducted for 2 years. The carbonated layer is taken into account. The predicted corrosion depth versus time are shown in Fig.6.30, where the relationship between exposure time and degradation coincides with Eq.(6.3). For the condition of $p \mathrm{H}=1$, the constant $b$ is about $2.5 \mathrm{~mm} / \sqrt{\text { month }}$. For the condition of $p \mathrm{H}=2$, the constant $b$ is 1.2 $\mathrm{mm} / \sqrt{\text { month}}$, which is about 2 times less than that for $p \mathrm{H}=1$.

In sewer pipes severely corroded, the $p \mathrm{H}$ at the concrete surface is normally less than 2 (Okabe et al., 2007; Islander et al., 1991). According to the long term prediction, under such condition the corrosion rate is more than $4 \mathrm{~mm} /$ year, which is agreement with $\mathrm{in}$-situ and laboratory observations (Mori et al., 1992; Vincke et al., 1999; Okabe et al., 2007). 


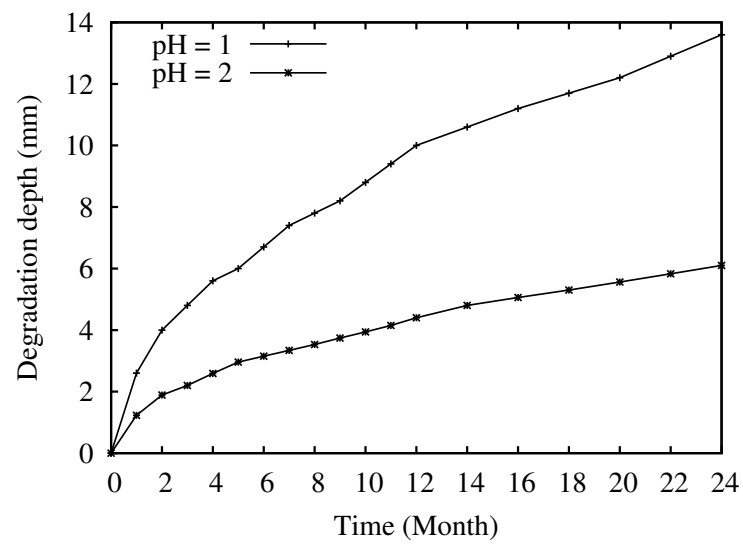

Figure 6.30: Prediction of degradation depth of long exposure time.

\subsection{Conclusion}

In this chapter, the experiments of sulfuric acid attack of cement mortar conducted by (Kawai et al., 2005) was simulated. The evolution of solid compositions and porosity of materials were addressed. Moreover, the model has provided a prediction of the deterioration depth.

Exposed to high concentration of sulfuric acid $(p \mathrm{H}=1)$, cementitious materials would be corroded heavily. In statical solution condition, a porous layer containing gypsum and silica gel can be found in both of experiments and simulations. In the flowing solution condition, no corrosion products layer exists due to the removing of corrosion products by the shear force of flowing solution. However, low concentration of sulfuric acid $(p \mathrm{H}=2)$ cannot cause significant corrosion. Indeed the solubility product of $\mathrm{H}_{2} \mathrm{SO}_{4}$ is so high that when $p \mathrm{H}$ is 2 , too few acid penetrating into concrete is available to form gypsum. Therefore, sewer pipes will not be corroded unless enough $\mathrm{H}_{2} \mathrm{SO}_{4}$ is produced by bacteria.

The degradation depth measured in the experiments after 90 days immersion test are close to our predictions. However, the modeled corrosion was faster than that measured in experiments during the early time. According to experimental results, the corrosion rate is quite slow during the early time. Such phenomenon draws attention to the effect of carbonation. We believe that carbonated layer slowed down the corrosion. By adjusting the porosity and initial solid compositions in the surface region of the sample, the effect of carbonated layer can be handled. Besides porosity, $p \mathrm{H}$ in carbonated layer is lower than that in the core of sample, which can affect the $\mathrm{H}_{2} \mathrm{SO}_{4}$ flux into materials. Such influence should be investigated as well as the influence of porosity.

Furthermore, according to the simulation results, the degradation rate of samples with high porosity is greater than that with low porosity, thereby disagreeing with some experiment observations. Thus, more accurate estimation of some parameters (e.g., the precipitation kinetics of gypsum, the diffusion coefficient of sulfate ions) should be employed to investigate the possible reasons. 
For the long-term prediction of corrosion depth, the thickness of the corroded layer increases linearly with the square root of time, which is typical of a diffusion-controlled acid attack profile. The long-term predicted corrosion rate is roughly in agreement with experimental observations.

In the next chapter, a set of biogenic $\mathrm{H}_{2} \mathrm{SO}_{4}$ attack experiments are simulated in order to take into account the bacterial activity producing sulfuric acid on the pipe surface. 


\section{Chapter 7}

\section{Simulation in the case of biofilms}

\section{condition}

\subsection{Introduction}

In order to predict the deterioration rate of concrete subjected to bio-degradation, laboratory experiments have been done to simulate the corrosion process of concrete in different environments (Ehrich et al., 1999; Vincke et al., 2000; Gutiérrez-Padilla et al., 2010), as well as in-situ experiments (Monteny et al., 2000; Herisson et al., 2013).

Comparing with chemical corrosion by constant $\mathrm{H}_{2} \mathrm{SO}_{4}$ solution, the supply of $\mathrm{H}_{2} \mathrm{SO}_{4}$ during the biodeterioration process is neither given nor constant, but governed by SOB activity. Some laboratory experiments were carried out with mixed culture of several types of SOB containing elemental sulfur, biomass and other nutrient components (Tichỳ et al., 1994). The mixed cultures of SOB were produced from laboratory or directly obtained from the biofilms of corroded sewer pipes (Vincke et al., 2000; De Muynck et al., 2009). After incubation in $\mathrm{H}_{2} \mathrm{~S}$ atmosphere, the cementitious samples were immersed in the aqueous solution of the SOB suspension (see Fig.7.1). The $p \mathrm{H}$ evolution in SOB suspension was measured during immersion.

In some other laboratory experiments, simulation reactors were built to simulate the environment in sewer pipes. In the simulation reactors, $\mathrm{H}_{2} \mathrm{~S}$ gas and wastewater, which provides the strain of $\mathrm{SOB}$, were circulated (see Fig.7.2). The content of $\mathrm{H}_{2} \mathrm{~S}$ gas was adjusted to different levels. The cementitious samples were exposed to $\mathrm{H}_{2} \mathrm{~S}$ atmosphere rather than immersed in $\mathrm{SOB}$ suspension. Thus, $\mathrm{H}_{2} \mathrm{SO}_{4}$ was produced from biofilms which formed on the sample surface. After a certain time, the corrosion state was illustrated by measurement of corrosion depth or weight loss.

In this chapter, the experiments of the immersion method (De Muynck et al., 2009) and the simulation 


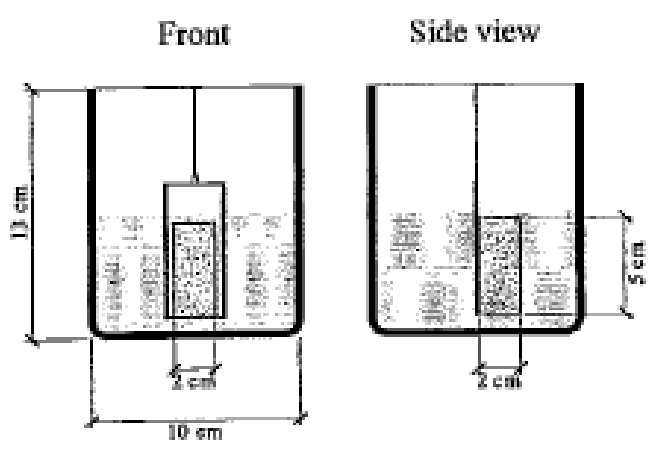

(a)

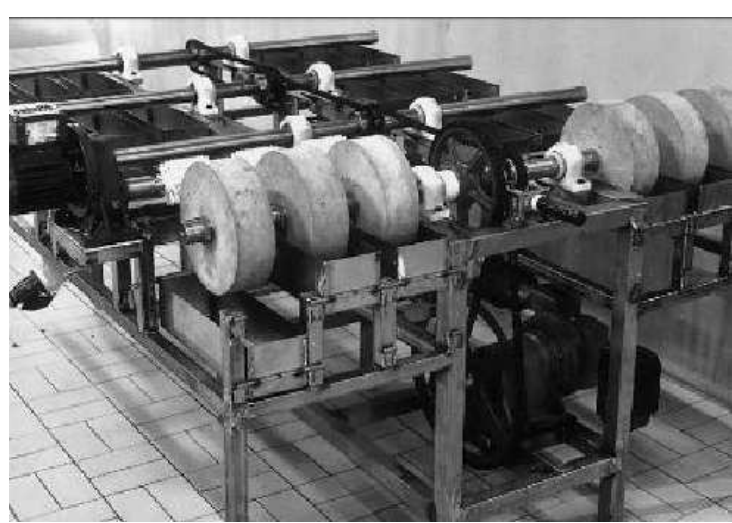

(b)

Figure 7.1: Experiment setup of immersion test of biodeterioration: (a) (Vincke et al., 2000); (b) (De Belie et al., 2004).

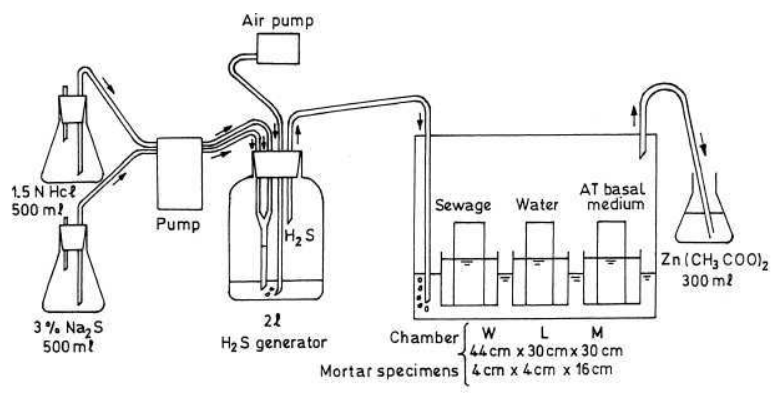

(a)

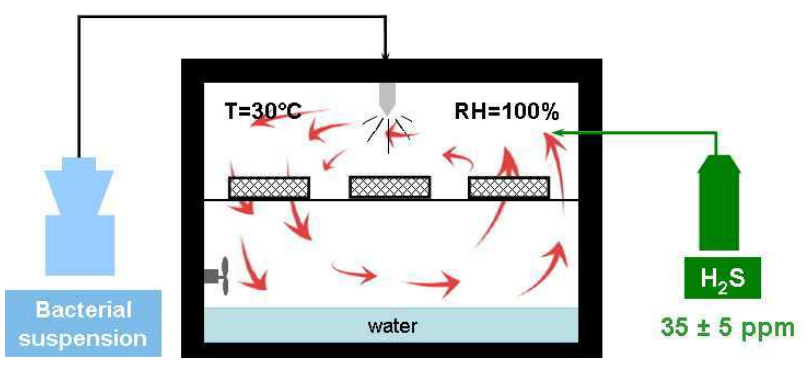

(b)

Figure 7.2: Experiment setup of biodeterioration by simulation reactors: (a) (Mori et al., 1992); (b) (Herisson, 2012). 
reactor method (Mori et al., 1992) are simulated. The neutralization of sample surface by $\mathrm{H}_{2} \mathrm{~S}$ gas is considered. The $\mathrm{H}_{2} \mathrm{SO}_{4}$ production from biological activity is calculated by the methods introduced in Chapter 2. Similar with the simulation of $\mathrm{H}_{2} \mathrm{SO}_{4}$ chemical solution corrosion in Chapter 6, the evolution of solid compositions, corrosion depth and porosity of samples are illustrated. Furthermore, the effect of different $\mathrm{H}_{2} \mathrm{~S}$ gas level is studied.

\subsection{Immersion test condition}

To study the effectiveness of different admixtures and surface treatments against biogenic sulfuric acid attack of concrete, the biodeterioration of different types of mortar were measured by means of microbiological tests in lab (De Muynck et al., 2009), where the specimens were drilled from sewer pipe made with CEM I cement, whose $\mathrm{W} / \mathrm{C}=0.37$. The specimens with polished surfaces were cylinders with $\mathrm{H}=15 \mathrm{~mm}$, $\mathrm{D}=80 \mathrm{~mm}$. In the experiments, the specimens with or without protection (e.g., epoxy coating, polyurea lining) were subjected to 8 cycles of accelerate test. Each cycle consisted of 4 steps:

(1) As $p \mathrm{H}$ of fresh concrete specimen was too high to incubate SOB, specimens were subjected to $\mathrm{H}_{2} \mathrm{~S}$-incubation in a vessel containing $200 \mathrm{ppm}$ of $\mathrm{H}_{2} \mathrm{~S}$ gas for 2 days at beginning;

(2) Immersion in a vessel containing 1.5 L of mixed cultures of SOB obtained from biofilms of insitu sewer pipe (medium composition: $10 \mathrm{~g} / \mathrm{L}$ elemental sulfur, $3 \mathrm{~g} / \mathrm{L} \mathrm{KH}_{2} \mathrm{PO}_{4}, 0.1 \mathrm{~g} / \mathrm{L} \mathrm{NH} 4 \mathrm{Cl}, 0.1 \mathrm{~g} / \mathrm{L}$ $\mathrm{MgCl} \cdot \mathrm{H} 2 \mathrm{O})$ for 10 days;

(3) Immersion in a vessel containing distilled water for 2 days;

(4) Drying at room temperature for 1 day.

During the second step of every cycle, the $p \mathrm{H}$ in SOB suspensions was measured at a regular basis. Since water was rotated by a rotary shaker at $90 \mathrm{rpm}$, the degradation products were removed in the third step. The last step could eliminate SOB remaining on the samples surfaces. The corrosion depth of the specimens at the end of each cycle was measured using the automated laser measurement system.

Since the cycles are equal to each other, we simulate the first and second step in this section separately, while the removing of corrosion products and SOB are neglected. To simulate the test, concrete samples with the same size as that in experiments are considered. Comparing with the mortar specimens in Chapter 6 , the concrete specimens in this experiment contains coarse aggregates. However, the amount of coarse aggregates are unknown. From the visual observations (see Fig.7.3) of experiments, it can be seen that the material loss was mainly attributable to the attack of the cement paste part. Thus, we neglect the corrosion of aggregate and assume that the hydration products in the samples are $70 \%$ of those in the samples of Chapter 6, i.e., $3.7 \mathrm{~mol} / \mathrm{L}$ of portlandite and $3.5 \mathrm{~mol} / \mathrm{L}$ of C-S-H as jennite. The initial porosity is $30 \%$. 

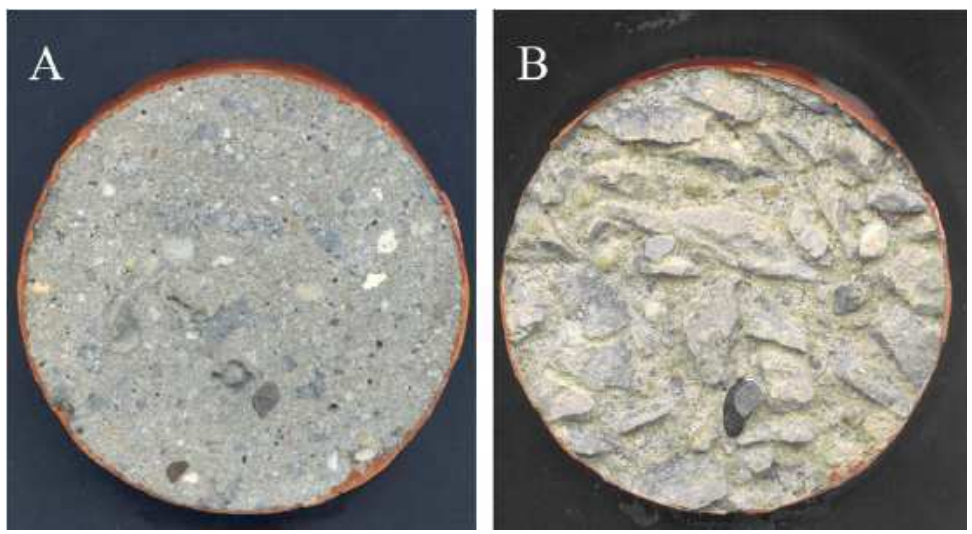

Figure 7.3: A sample of the concrete before (A) and after (B) eight cycles of the microbiological test. A loss of cement paste is clearly visible, while the aggregates remain relatively unaffected. (De Muynck et al., 2009).

\subsubsection{Neutralization process}

To simulate the $\mathrm{H}_{2} \mathrm{~S}$ attack, the samples are divided in 300 nodes. We consider the boundary conditions of constant $\mathrm{H}_{2} \mathrm{~S}$ gas level (200 ppm), while no $\mathrm{H}_{2} \mathrm{SO}_{4}$ is present. For numerical stability, the initial aqueous $\mathrm{H}_{2} \mathrm{~S}$ concentration in concrete sample is $1 \times 10^{-9} \mathrm{~mol} / \mathrm{L}$, i.e., $p \mathrm{H}=12.4$. Boundary and initial conditions of our modeling are summarized in Table.7.1.

Table 7.1: Boundary and initial conditions of the $\mathrm{H}_{2} \mathrm{~S}$ attack (200 ppm)

\begin{tabular}{|c|c|c|}
\hline $\begin{array}{c}\text { Balance } \\
\text { Equation }\end{array}$ & $\begin{array}{c}\text { Boundary conditions } \\
\text { Left surface }\end{array}$ & $\begin{array}{c}\text { Initial conditions } \\
\text { Concrete }\end{array}$ \\
\hline Sulfur $(\mathrm{S})$ & $\begin{array}{c}\text { Absorption allow } \\
p_{\mathrm{H}_{2} \mathrm{~S}, \text { gas }}=200 \mathrm{ppm}\end{array}$ & $\rho_{\mathrm{H}_{2} \mathrm{~S}^{0}}=10^{-9} \mathrm{~mol} / \mathrm{L}$ \\
\hline Calcium $(\mathrm{Ca})$ & no diffusion & $\zeta_{\mathrm{Ca}}=1$ \\
\hline Silicon $(\mathrm{Si})$ & no diffusion & $\zeta_{\mathrm{Si}}=1$ \\
\hline Potassium $(\mathrm{K})$ & no diffusion & $\rho_{\mathrm{K}^{+}}=0.5 \mathrm{~mol} / \mathrm{L}$ \\
\hline Chlorine $(\mathrm{Cl})$ & no diffusion & $\rho_{\mathrm{Cl}^{-}}=0.5 \mathrm{~mol} / \mathrm{L}$ \\
\hline Charge & no current & $\psi=0$ \\
\hline
\end{tabular}

$\mathrm{H}_{2} \mathrm{~S}$ gas is absorbed into pore solution of concrete from the left surface, and the absorption rate is governed by Eq.(2.1). Since no $\mathrm{H}_{2} \mathrm{SO}_{4}$ is present during the neutralization process, CaS is considered as the only corrosion products. The dissolution of $\mathrm{CH}$ and $\mathrm{C}-\mathrm{S}-\mathrm{H}$, and the precipitation of CaS are described by the model introduced in Chapter 2 and Chapter 3. After exposure of 2 days, the calculated absorption of $\mathrm{H}_{2} \mathrm{~S}$ and $p \mathrm{H}$ evolution of concrete sample are shown in Fig.7.4.

As expected, $\mathrm{H}_{2} \mathrm{~S}$ in gas phase is absorbed into pore solution of concrete to neutralize the sample surface, where $p \mathrm{H}$ decreases form 12.35 to 9.5 gradually. The change of aqueous $\mathrm{H}_{2} \mathrm{~S}$ concentration and $p \mathrm{H}$ in the pore solution of surface part are plotted in Fig.7.5a. Due to the low ionization constant of $\mathrm{H}_{2} \mathrm{~S}$, the neutralization rate of surface is low even if the $\mathrm{H}_{2} \mathrm{~S}$ gas level is quite high at surface. Since $\mathrm{H}_{2} \mathrm{~S}$ gas level keeps constant, the absorption of $\mathrm{H}_{2} \mathrm{~S}$ at surface is constant (see Fig.7.5b). 


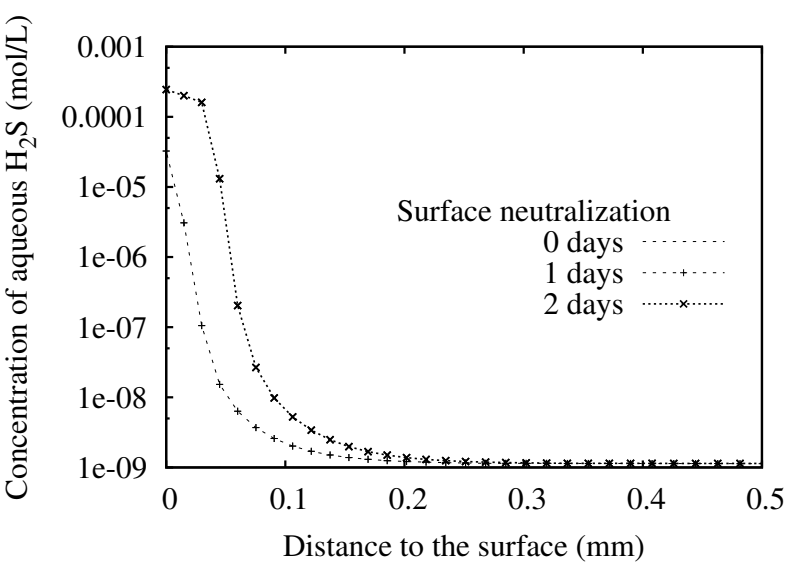

(a)

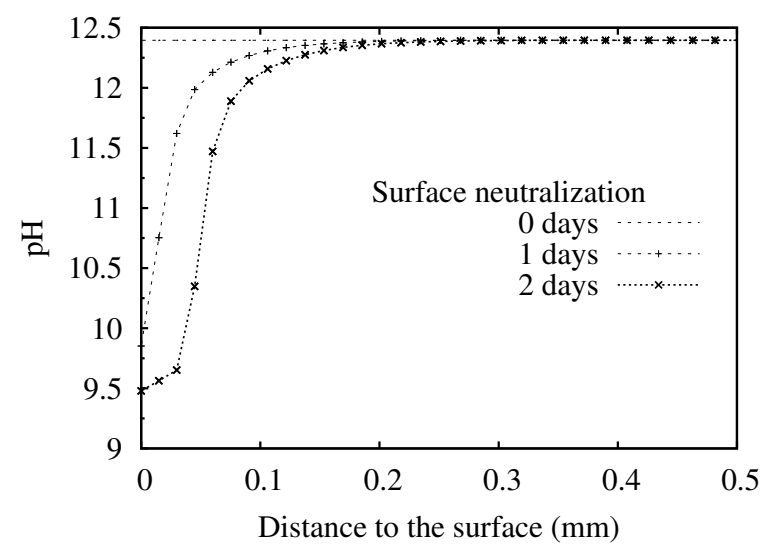

(b)

Figure 7.4: The calculated absorption of $\mathrm{H}_{2} \mathrm{~S}$ and $p \mathrm{H}$ evolution profiles from 0 days to 2 days: (a) Aqueous $\mathrm{H}_{2} \mathrm{~S}$ concentration; (b) $p \mathrm{H}$ value. $\left(\mathrm{H}_{2} \mathrm{~S}\right.$ level $\left.=200 \mathrm{ppm}\right)$

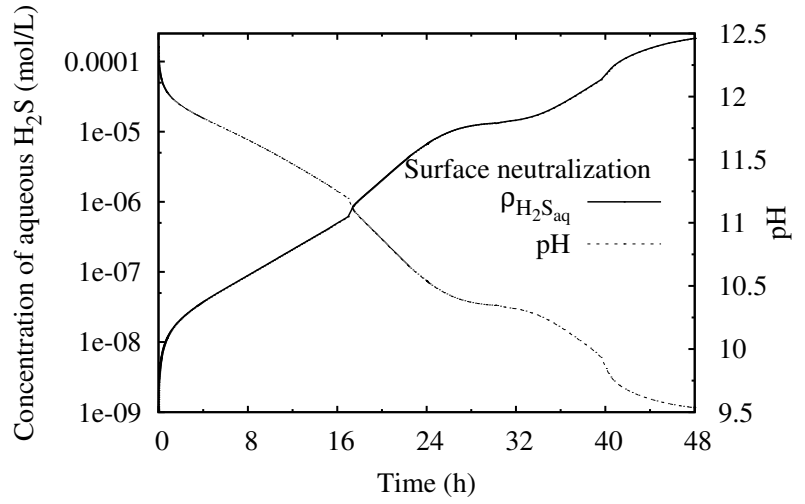

(a)

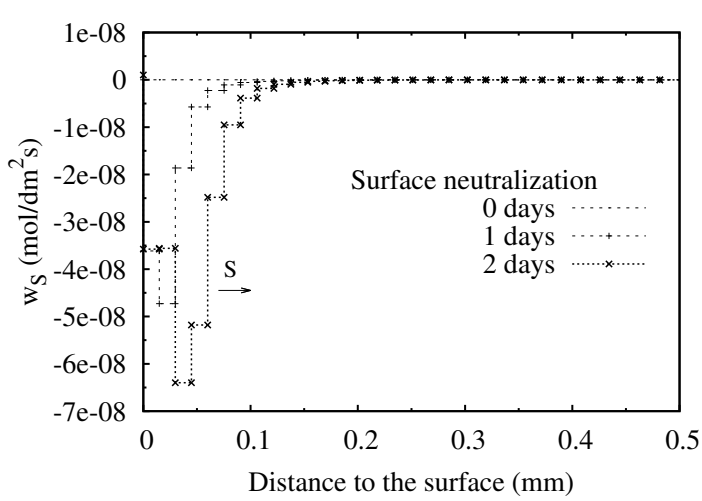

(b)

Figure 7.5: The calculated absorption of $\mathrm{H}_{2} \mathrm{~S}$ profiles from 0 days to 2 days: (a) Aqueous $\mathrm{H}_{2} \mathrm{~S}$ concentration and $p \mathrm{H}$ evolution at surface; (b) Diffusion of sulfur. $\left(\mathrm{H}_{2} \mathrm{~S}\right.$ level $\left.=200 \mathrm{ppm}\right)$ 
The change in the concentration and volume of solid compounds, as well as porosity profiles after 1 days and 2 days of exposure are plotted in Fig.7.6 and Fig.7.7. After 1 day, the sample surface turns to a CaS-rich layer, where parts of $\mathrm{CH}$ and C-S-H are dissolved. Even if the molar volume of CaS is smaller than that of $\mathrm{CH}$ and $\mathrm{C}-\mathrm{S}-\mathrm{H}$, the porosity decreases due to $\mathrm{CaS}$ accumulation in pores, which results from the diffusion of $\mathrm{Ca}^{2+}$ as described in Section 5.5.1. Thus, the solid volume at the surface increases. For the position just under the CaS-rich layer, the porosity slightly increases due to the small molar volume of $\mathrm{CaS}$ and the solid volume of concrete sample is slightly less than initial value.

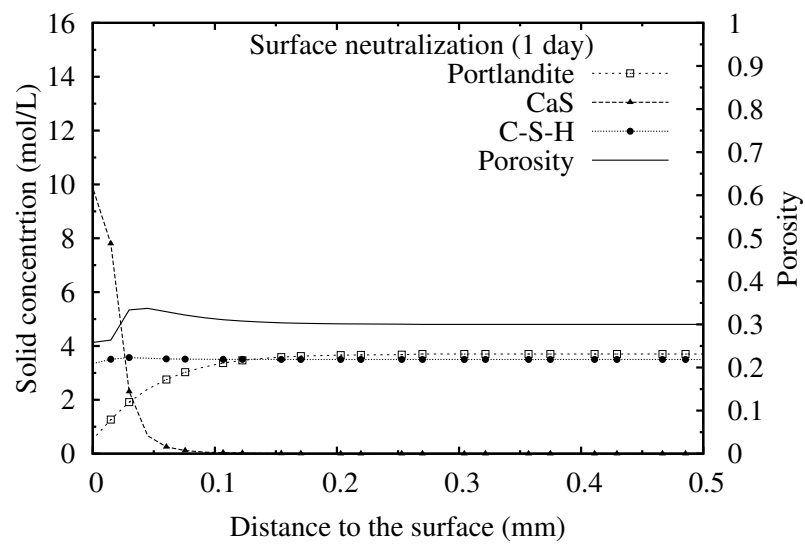

(a)

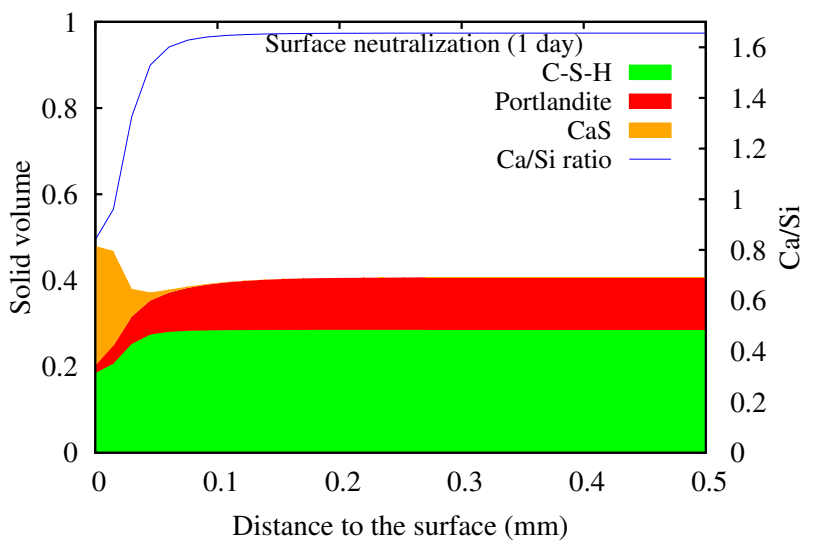

(b)

Figure 7.6: After 1 day of exposure: (a) Solid concentration and porosity ; (b) Solid volume and Ca/Si ratio of C-S-H. $\left(\mathrm{H}_{2} \mathrm{~S}\right.$ level $\left.=200 \mathrm{ppm}\right)$

After 2 days, the CaS-rich layer is thicker than that of 1 day exposure (see Fig.7.7). More CaS precipitating deeper, causes the further reduction of porosity and the rising of solid volume of the CaS-rich layer. Thus, about $0.1 \mathrm{~mm}$ of sample is neutralized by $\mathrm{H}_{2} \mathrm{~S}$. CH at surface is completely dissolved while C-S-H is just partly decalcified because of the lack of aqueous $\mathrm{H}_{2} \mathrm{~S}$. However, the amount of aqueous $\mathrm{H}_{2} \mathrm{~S}$ at surface is enough to dissolve the CaS precipitation after 2 days of gas $\mathrm{H}_{2}$ Sabsorption. Therefore, CaS at surface starts to dissolve.

To illustrate the dissolution of $\mathrm{CaS}$, the concentration of $\mathrm{CaS}$ and aqueous $\mathrm{H}_{2} \mathrm{~S}$ at surface versus exposure time are plotted in Fig.7.8. When aqueous $\mathrm{H}_{2} \mathrm{~S}$ is absorbed into concrete, CaS starts to precipitate until $\rho_{\mathrm{H}_{2} \mathrm{~S}^{0}}$ increases to $7 \times 10^{-4.9} \mathrm{~mol} / \mathrm{L}$. When aqueous $\mathrm{H}_{2} \mathrm{~S}$ is more than that critical value, CaS starts to dissolve.

Furthermore, a simulation of 10 days of exposure is conducted. According to the solid profiles in Fig.7.9, the corroded sample starts with a completely degraded layer, where CH, CaS and C-S-H are fully dissolved. Consequently, the porosity of the completely degraded layer is high, while that in the CaS-rich layer is below 0.1 . 


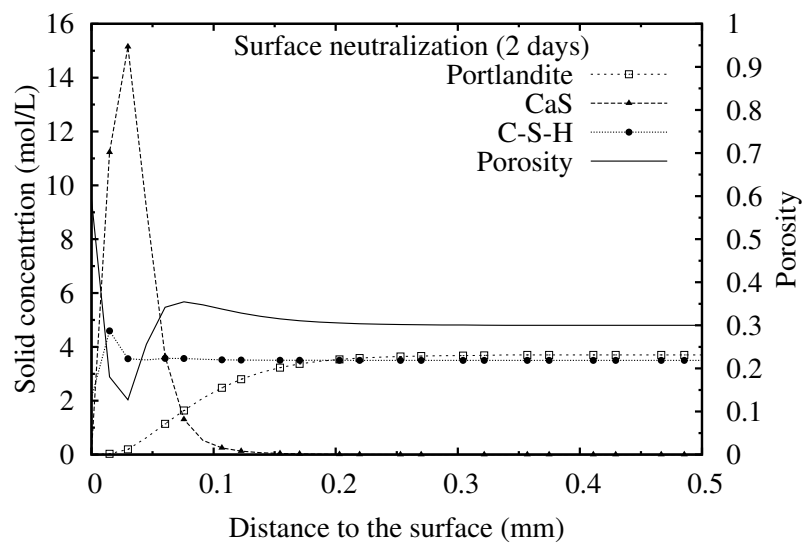

(a)

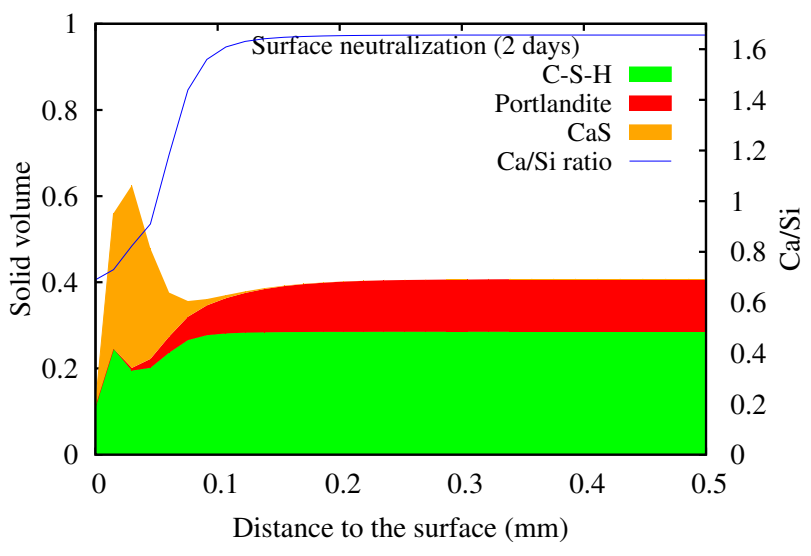

(b)

Figure 7.7: After 2 days of exposure: (a) Solid concentration and porosity ; (b) Solid volume and Ca/Si ratio of C-S-H. $\left(\mathrm{H}_{2} \mathrm{~S}\right.$ level $\left.=200 \mathrm{ppm}\right)$

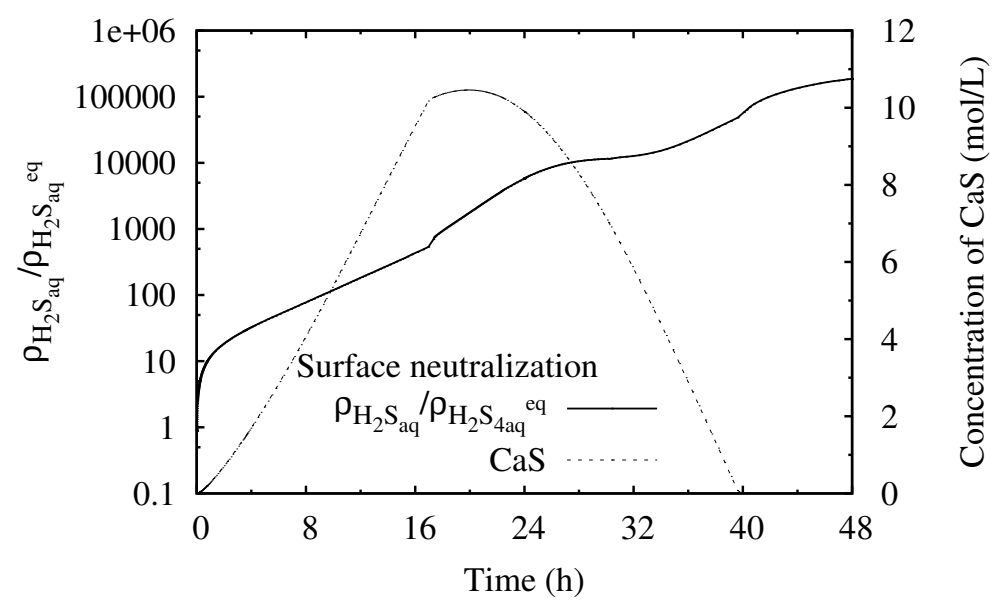

Figure 7.8: The concentration of $\mathrm{CaS}$ and aqueous $\mathrm{H}_{2} \mathrm{~S}$ at surface from 0 days to 2 days $\left(\mathrm{H}_{2} \mathrm{~S}\right.$ level $=200$ ppm) 


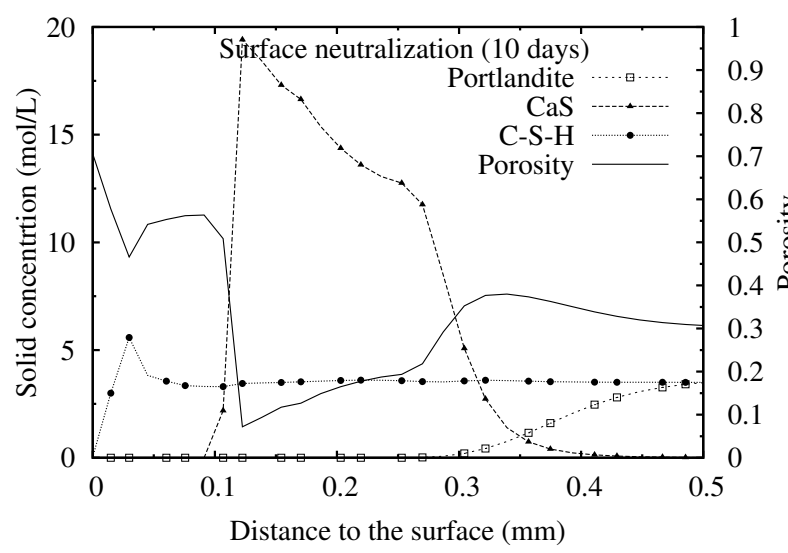

(a)

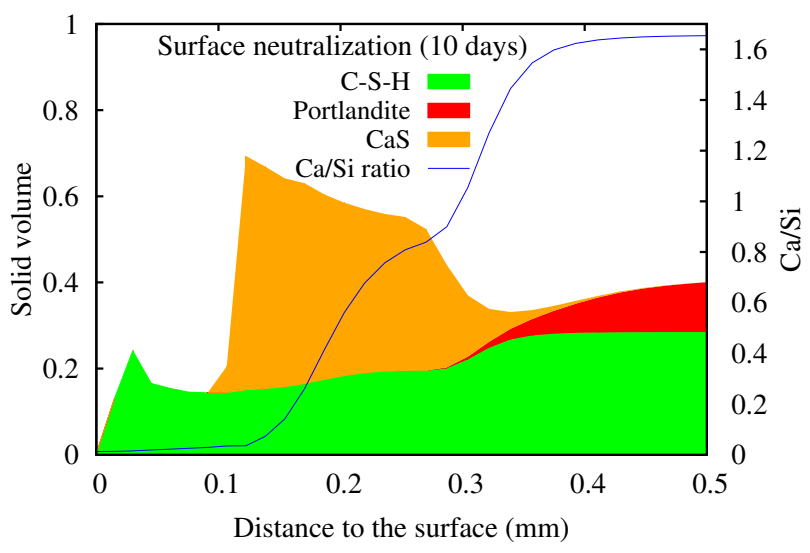

(b)

Figure 7.9: After 10 days of exposure: (a) Solid concentration and porosity ; (b) Solid volume and Ca/Si ratio of C-S-H. $\left(\mathrm{H}_{2} \mathrm{~S}\right.$ level $\left.=200 \mathrm{ppm}\right)$

\subsubsection{Evolution of $p \mathrm{H}$ in $\mathrm{SOB}$ suspensions}

In the set of experiments conducted by (De Muynck et al., 2009), concrete samples with polyurethane lining were immersed into SOB suspension. However, no degradation could be observed for the specimens after 8 test cycles. Therefore, we consider that no mass exchange takes place between samples with polyurethane lining and SOB suspension. In such SOB suspension, the $p \mathrm{H}$ evolution is equal to that in pure SOB suspensions. Thus we simulate the SOB activity in a pure SOB suspension sample by the model of $\mathrm{H}_{2} \mathrm{SO}_{4}$ production introduced in Section 2.3.1 (see Eq.(2.11) and (2.12)). The initial $p \mathrm{H}$ of SOB suspension is $7 . \mathrm{H}_{2} \mathrm{SO}_{4}$ is produced in the $\mathrm{SOB}$ suspension is governed by Eq.(7.1) which is determined by fitting measurements as follows:

$$
R_{\mathrm{H}_{2} \mathrm{SO}_{4}}=\left\{\begin{array}{lr}
\frac{8 \times 10^{-7} \mathrm{~mol} / \mathrm{L} \cdot \mathrm{s}}{0.48 \sqrt{2 \pi}} \times e^{-\frac{1}{0.96} \times 10^{2.5-p \mathrm{H}}} & p \mathrm{H}>2.5 \\
\frac{8 \times 10^{-7} \mathrm{~mol} / \mathrm{L} \cdot \mathrm{s}}{0.48 \sqrt{2 \pi}} \times e^{-\frac{(p \mathrm{H}-1.5)^{2}}{0.96}} & 1.5 \leq p \mathrm{H} \geq 2.5 \\
\frac{8 \times 10^{-7} \mathrm{~mol} / \mathrm{L} \cdot \mathrm{s}}{0.48 \sqrt{2 \pi}} \times e^{-\frac{(p \mathrm{H}-1.5)^{2}}{0.48}} & p \mathrm{H}<1.5
\end{array}\right.
$$

The $p \mathrm{H}$ evolution obtained from both simulation and experiment are plotted in Fig.7.10. In the experiment, as a result of the conversion of elemental sulfur to sulfuric acid by cultures of NSOB, $p \mathrm{H}$ decreases slightly during early time. However, a sharp reduction of $p \mathrm{H}$ was observed after 4 days of submersion due to the activity of ASOB. With $\mathrm{H}_{2} \mathrm{SO}_{4}$ production by ASOB whose activity is suppressed when $p \mathrm{H}$ is below 1.5, the $p \mathrm{H}$ continues to decrease to around 1 after 10 days of testing. The comparison between the results of model and the experiment results is fairly good. 


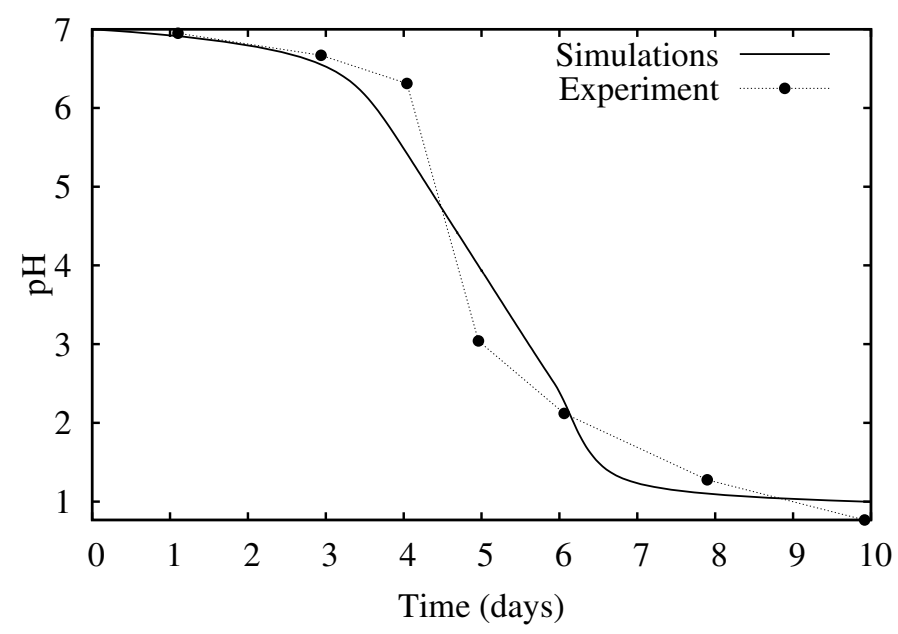

Figure 7.10: The evolution of $p \mathrm{H}$ in pure SOB suspension from 0 days to 10 days

\subsubsection{Biodeterioration of concrete immersed in SOB suspension}

To simulate the second step of the experiment, we consider the concrete sample with neutralized surface in contact with the $\mathrm{SOB}$ suspension where $\mathrm{H}_{2} \mathrm{SO}_{4}$ is produced and penetrates into concrete. For now, we are not able to merge the process of $\mathrm{H}_{2} \mathrm{~S}$ attack and $\mathrm{H}_{2} \mathrm{SO}_{4}$ attack into one modeling. Thus, neutralized layer is considered as another material whose thickness and solid compositions are determined by the modeling of $\mathrm{H}_{2} \mathrm{~S}$ attack. According to the simulation results of the fist step in the previous section, after 2 days of exposure to $\mathrm{H}_{2} \mathrm{~S}$ gas of $200 \mathrm{ppm}$, the thickness of neutralized layer is $0.1 \mathrm{~mm}$. For numerical stability, the initial porosity of neutralized layer is equalized to 0.15 , and the $p \mathrm{H}$ value and CaS concentration in neutralized layer are simplified to vary linearly.

Therefore, the fresh concrete core, neutralized surface and SOB suspension are combined together as Table.7.2. The solid compositions, $p \mathrm{H}$ and porosity of the initial concrete sample with neutralized layer are indicated in Fig.7.11

Table 7.2: Boundary and initial conditions of biodeterioration by SOB suspension

\begin{tabular}{|c|c|c|c|c|}
\hline \multicolumn{5}{|c|}{ Initial conditions } \\
\hline \multirow{2}{*}{ Balance Equation } & \multicolumn{4}{|c|}{ Neutralized layer } \\
\hline & & $\begin{array}{l}\text { SOB } \\
\text { suspension }\end{array}$ & Concrete & \\
\hline & SOB suspension & \multicolumn{2}{|c|}{ Neutralized layer } & Concrete \\
\hline Sulfur (S) & $\rho_{\mathrm{H}_{2} \mathrm{SO}_{4}}=10^{-20.3}$ & \multicolumn{2}{|c|}{$\rho_{\mathrm{H}_{2} \mathrm{SO}_{4}}=10^{-31.5}-10^{-20.3} \mathrm{~mol} / \mathrm{L}$} & $\rho_{\mathrm{H}_{2} \mathrm{SO}_{4}}=10^{-31.5} \mathrm{~mol} / \mathrm{L}$ \\
\hline Calcium $(\mathrm{Ca})$ & $\zeta_{\mathrm{Ca}}=0$ & \multicolumn{2}{|c|}{$\zeta_{\mathrm{Ca}}=1$} & $\zeta_{\mathrm{Ca}}=1$ \\
\hline Silicon (Si) & $\zeta_{\mathrm{Si}}=0$ & \multicolumn{2}{|c|}{$\zeta_{\mathrm{Si}}=1$} & $\zeta_{\mathrm{Si}}=1$ \\
\hline Potassium (K) & $\rho_{\mathrm{K}^{+}}=0.5 \mathrm{~mol} / \mathrm{L}$ & \multicolumn{2}{|c|}{$\rho_{\mathrm{K}^{+}}=0.5 \mathrm{~mol} / \mathrm{L}$} & $\rho_{\mathrm{K}^{+}}=0.5 \mathrm{~mol} / \mathrm{L}$ \\
\hline Chlorine $(\mathrm{Cl})$ & $\rho_{\mathrm{Cl} l^{-}}=0.5 \mathrm{~mol} / \mathrm{L}$ & \multicolumn{2}{|c|}{$\rho_{\mathrm{Cl}-}=0.5 \mathrm{~mol} / \mathrm{L}$} & $\rho_{\mathrm{Cl}-}=0.5 \mathrm{~mol} / \mathrm{L}$ \\
\hline Charge & $\psi=0$ & \multicolumn{2}{|c|}{$\psi=0$} & $\psi=0$ \\
\hline
\end{tabular}




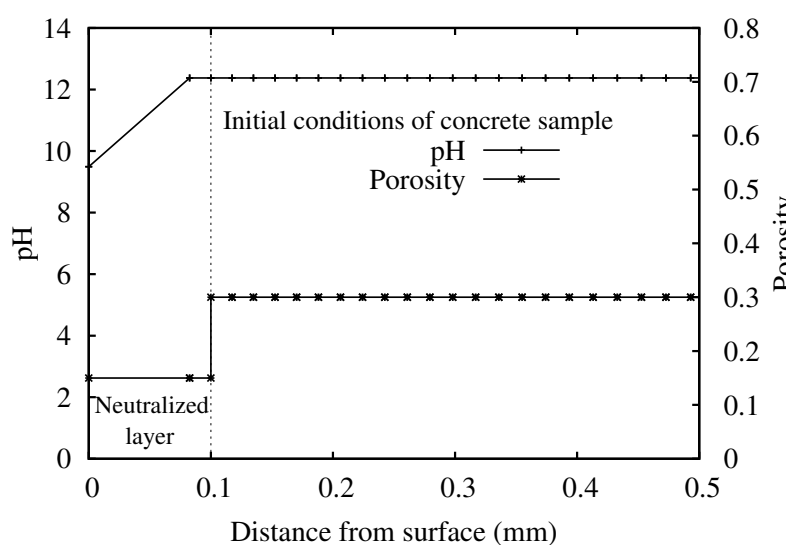

(a)

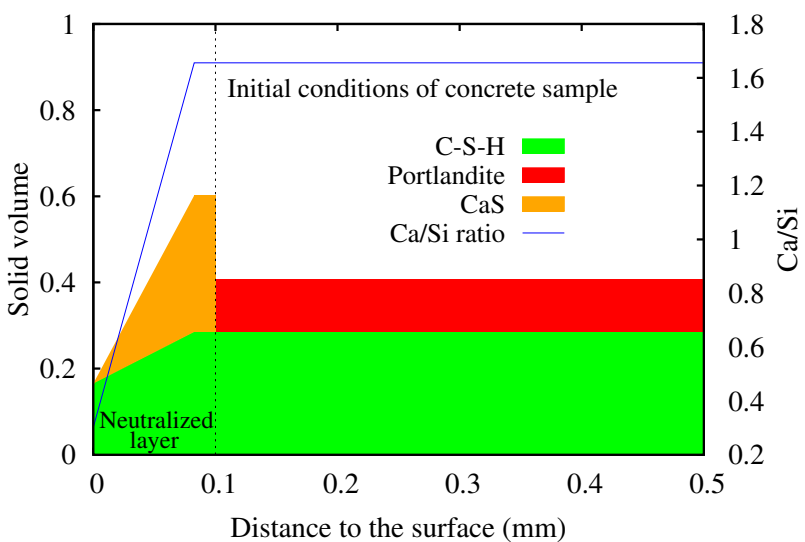

(b)

Figure 7.11: Initial concrete sample with neutralized surface: (a) $p \mathrm{H}$ and porosity ; (b) Solid volume and $\mathrm{Ca} / \mathrm{Si}$ ratio of $\mathrm{C}-\mathrm{S}-\mathrm{H}$.

During immersion of 10 days, the alkalinity of concrete is reduced by the penetration of $\mathrm{H}_{2} \mathrm{SO}_{4}$ which is produced in SOB suspension. The evolution of $\mathrm{H}_{2} \mathrm{SO}_{4}$ concentration and $p \mathrm{H}$ in both concrete and the SOB suspension close to concrete surface are shown in Fig.7.12. Due to the low gradient of $\mathrm{H}_{2} \mathrm{SO}_{4}$ between SOB suspension and concrete surface, $p \mathrm{H}$ in the concrete surface decreases very few until 8 days.

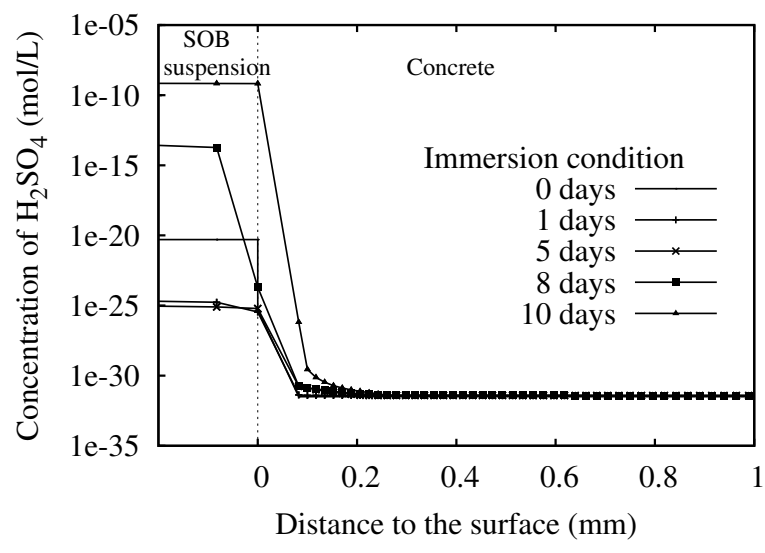

(a)

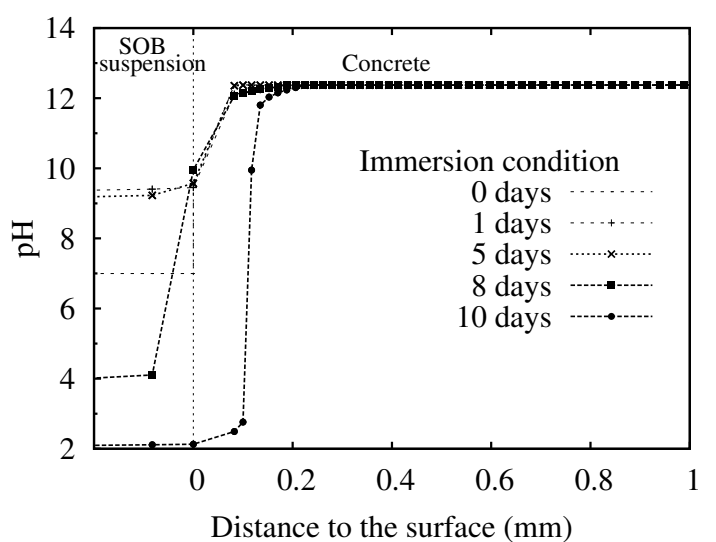

(b)

Figure 7.12: The calculated $\mathrm{H}_{2} \mathrm{SO}_{4}$ and $p \mathrm{H}$ evolution profiles in SOB suspension and concrete from 0 days to 10 days: (a) $\mathrm{H}_{2} \mathrm{SO}_{4}$ concentration; (b) $p \mathrm{H}$ value.

The $p \mathrm{H}$ evolution in bulk SOB suspension, which refers to that part of suspension not influenced by concrete, is plotted in Fig.7.13a. Due to that NSOB produce $\mathrm{H}_{2} \mathrm{SO}_{4}$ very slow, $p \mathrm{H}$ in $\mathrm{SOB}$ suspension decreases very few during early time. Since lower $p \mathrm{H}$ causes higher in-situ $\mathrm{H}_{2} \mathrm{SO}_{4}$ production rate, $p \mathrm{H}$ starts to decrease sharply after several days. When $p \mathrm{H}$ reaches $1.5, \mathrm{H}_{2} \mathrm{SO}_{4}$ production starts to slow down. The change in $p \mathrm{H}$ of SOB suspension was measured during the experiments (see Fig.7.13). The simulation 
results coincide with experimental results.

$p \mathrm{H}$ is almost uniform in bulk SOB suspension where $p \mathrm{H}$ decreases from the very beginning. However, during the early time $p \mathrm{H}$ in SOB suspension close to concrete surface increases from 7 to about 9 due to the alkalinity of concrete and the low production rate of $\mathrm{H}_{2} \mathrm{SO}_{4}$ (see Fig.7.13b), i.e., the acid production is slower than the acid consumption. A decrease of bacterial activity is expected. Thus, the production rate of $\mathrm{H}_{2} \mathrm{SO}_{4}$ is too low to cause further deterioration of concrete. However, after about 8 days, $p \mathrm{H}$ starts to decrease by the $\mathrm{H}_{2} \mathrm{SO}_{4}$ produced from bulk suspension.

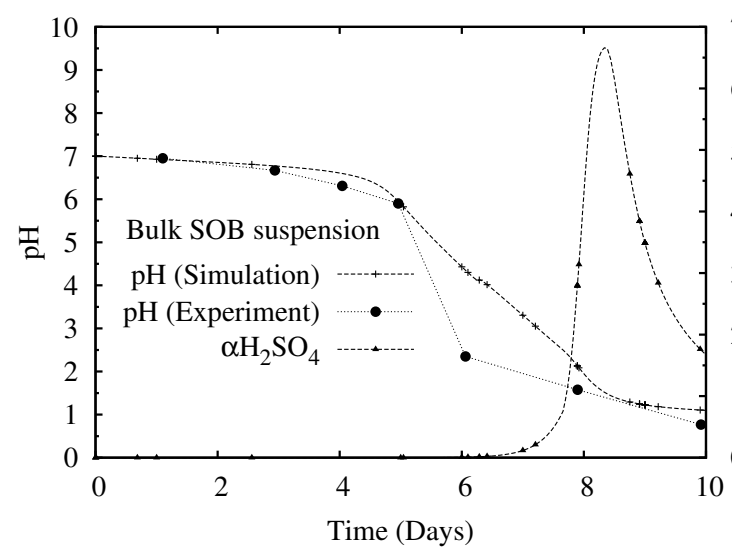

(a)

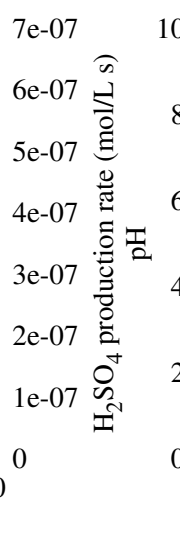

(0)

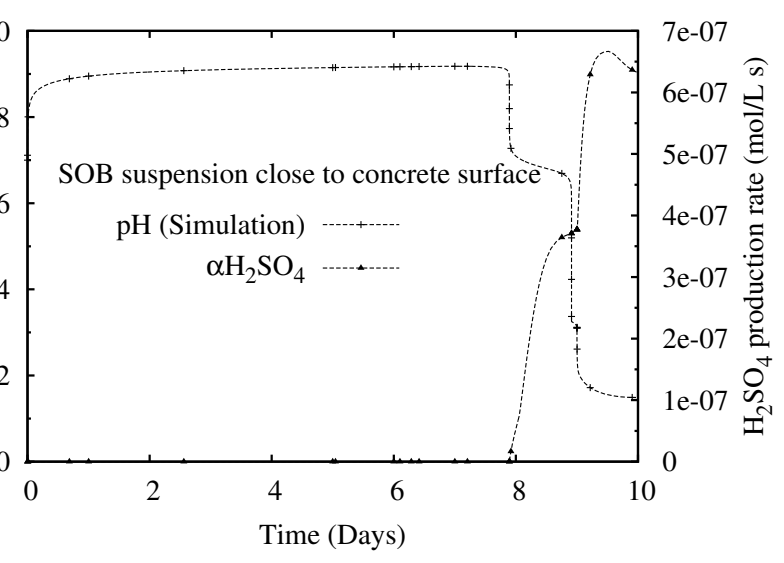

(b)

Figure 7.13: The $p \mathrm{H}$ evolution and production rate of $\mathrm{H}_{2} \mathrm{SO}_{4}$ from 0 to 10 days: (a) bulk SOB suspension; (b) SOB closed to concrete surface.

After immersion of 10 days, similar zones as those in the simulation of $\mathrm{H}_{2} \mathrm{SO}_{4}$ solution condition are observed in SOB immersion test (see Fig.7.14). Not only neutralized layer, but also concrete core is degraded by biogenic $\mathrm{H}_{2} \mathrm{SO}_{4}$. Due to the diffusion of $\mathrm{Ca}^{2+}$ towards the gypsum precipitation front, lots of gypsum accumulates at concrete surface. At the interface between neutralized layer and concrete core, the amount of C-S-H is discontinuous. That is probably caused by the discontinuity of initial porosity in the initial conditions.

In the experiments (De Muynck et al., 2009), shaking in the distilled water resulted in both the removal of aggregate and reaction products. Drying removes all the remaining SOB at the concrete surface. Thus we consider that all the cycles are identical. Consequently, the deterioration depth of all cycles are the same. The predicted corrosion depth and that measured during experiments are compared in Fig.7.15. The predicted corrosion rate is $0.22 \mathrm{~mm} /$ cycle, which coincide with experimental results. However, no corrosion depth was measured out in the first cycle of the experiments. Carbonated layer is probably responsible for that as described in Chapter 6. 


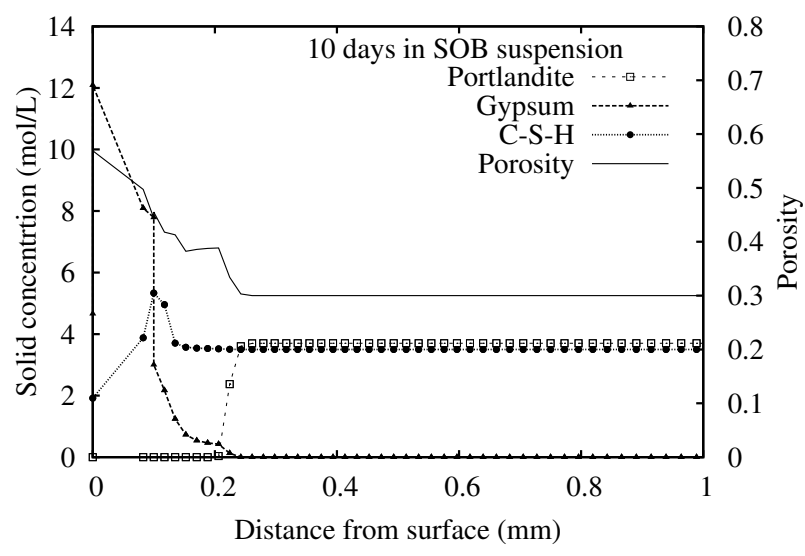

(a)

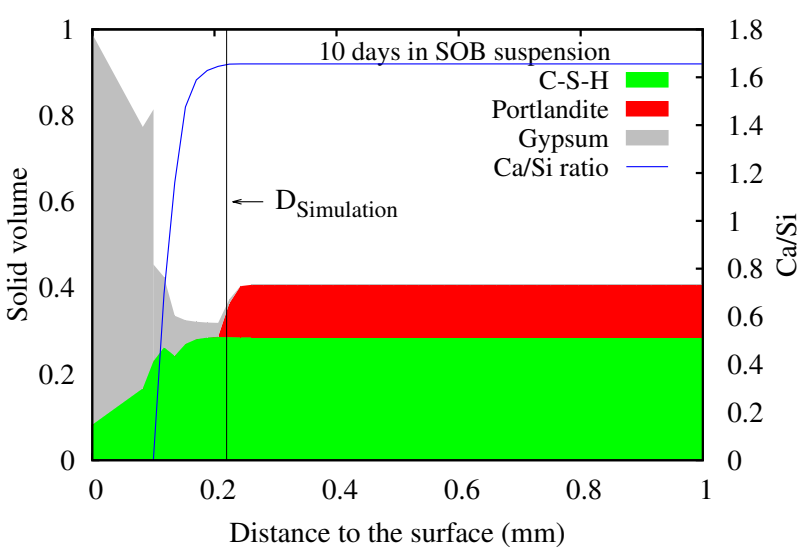

(b)

Figure 7.14: After 10 days of immersion in SOB suspension: (a) Solid concentration and porosity ; (b) Solid volume and $\mathrm{Ca} / \mathrm{Si}$ ratio of C-S-H. $\mathrm{D}_{\text {Simulation }}$ represents the degradation depth of the sample in simulation

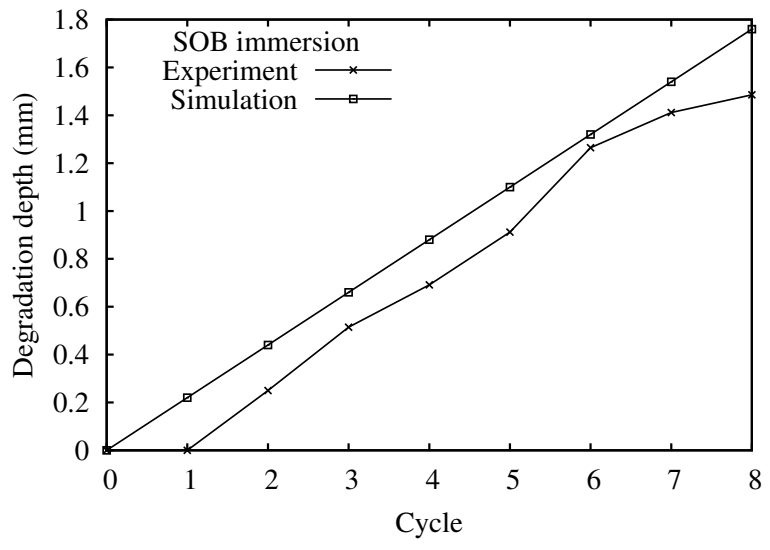

Figure 7.15: The predicted and measured corrosion depth. 


\subsection{Simulation reactor condition}

In the real sewer pipes, heavy degradation was not observed in the part immersed in waste water but in the part above the water level (Davis et al., 1998). As the deterioration of concrete is a slow process with corrosion rate typically ranging from $1 \mathrm{~mm} /$ year to $5 \mathrm{~mm} /$ year (Mori et al., 1991), long time test which simulate the real deterioration conditions are required to investigate the durability of concrete in sewer environment. Furthermore, the biogenic $\mathrm{H}_{2} \mathrm{SO}_{4}$ attack is a very complex process, involving microbiological factors (such as biomass and substrate available) and chemical factors (such as $\mathrm{H}_{2} \mathrm{~S}$ gas level and solid compositions of concrete). Therefore, (Mori et al., 1992) designed a simulation chamber, where optimal conditions for the bacterial growth are controlled, to investigate the biodeterioration of concrete in sewer pipes. The schematic diagram of the simulation chamber is shown in Fig.7.2a.

In the experiment conducted by (Mori et al., 1992), the chamber consisted of a plastic box with size of $44 \mathrm{~cm} \times 30 \mathrm{~cm} \times 30 \mathrm{~cm}$. The $\mathrm{H}_{2} \mathrm{~S}$ concentration was $400 \mathrm{ppm}$ by regulating the flow rate of $4 \%$ of $\mathrm{Na}_{2} \mathrm{~S}$ solution and $1.5 \mathrm{~N} \mathrm{HCl}$ solution. The mortar specimens with size of $4 \mathrm{~cm} \times 4 \mathrm{~cm} \times 16 \mathrm{~cm}$ were placed in sewage of $6 \mathrm{~cm}$ depth and distilled water as reference. During the corrosion test of 6 months, Thiobacillus thiooxidans isolated from corroded materials in the concrete sewer pipes were inoculated on the surface of the mortar specimen every 2 weeks for the first 2 months.

After about 6 months, the $p \mathrm{H}$ of the corrosion products were determined using a $p \mathrm{H}$ meter after $1 \mathrm{~g}$ of sample was suspended in $1 \mathrm{~mL}$ of distilled water. The corrosion depth at different places of mortar samples were measured. The place under the sewage level was not corroded, while the portion just above the sewage level was more corroded than portion further above the sewage level. No corrosion occurred when mortar specimens were placed in distilled water (see Fig.7.16).

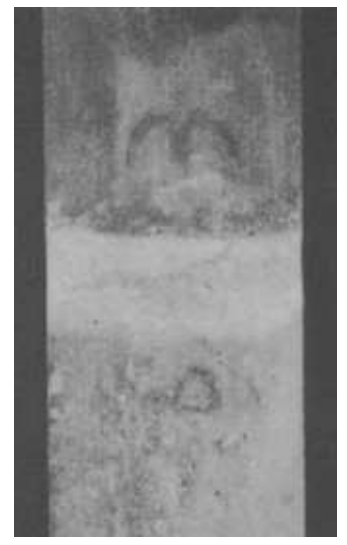

(a)

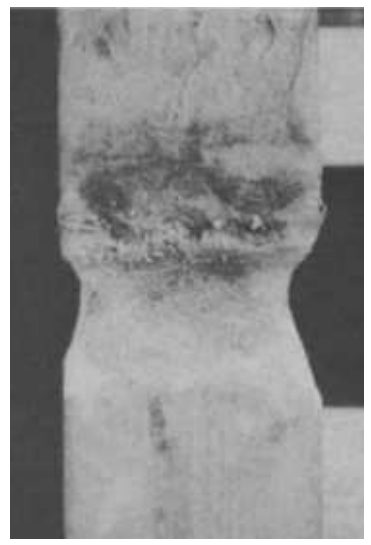

(b)

Figure 7.16: Mortar specimens exposed to $\mathrm{H}_{2} \mathrm{~S}$ gas: (a) Water; (b) Sewage. (Mori et al., 1992).

In this study, the corrosion process of the mortar near sewage level is simulated by our modeling. 
According to the analysis of (Mori et al., 1992), this location provided a constant supply of moisture and nutrients by splashing, immersion and/or capillary action from the water. In addition, dissolved oxygen from the atmosphere is provided at this location. Thus, we assume that the biofilm and mortar are both saturated and nutrients and oxygen are both sufficient for the growth of SOB. Therefore, modeling of $\mathrm{H}_{2} \mathrm{SO}_{4}$ production with given $\mathrm{H}_{2} \mathrm{~S}$ content in gas phase introduced in Section 2.3.2 is employed. Since the $\mathrm{W} / \mathrm{C}$ ratio of mortar samples are 0.6 , the solid compositions are assumed to be 3.7 mol/L of Portlandite and $3.5 \mathrm{~mol} / \mathrm{L}$ of $\mathrm{C}-\mathrm{S}-\mathrm{H}$ as jennite. The initial porosity is 0.35 . Moreover, SOB was incubated on the mortar surface during experiments. Thus, the succession of SOB is neglected and we assumed that SOB species in biofilm starts to produce $\mathrm{H}_{2} \mathrm{SO}_{4}$ as long as the $p \mathrm{H}$ in mortar surface is reduced to 9.5 by $\mathrm{H}_{2} \mathrm{~S}$ gas.

The surface neutralization process is simulated firstly as described in Section 7.2.1. After 40 hours, the $p \mathrm{H}$ in mortar surface decreases to 9.5 (see Fig.7.17a). As shown in previous section, with $\mathrm{H}_{2} \mathrm{~S}$ of $200 \mathrm{ppm}$ the surface $p \mathrm{H}$ decreases to 9.5 after 48 hours. Higher $\mathrm{H}_{2} \mathrm{~S}$ level results in faster surface neutralization rate. However, the difference between $200 \mathrm{ppm}$ and $400 \mathrm{ppm}$ is not significant. The solid compositions of mortar sample is plotted in Fig.7.17b which indicates a neutralized layer of approximate $0.1 \mathrm{~mm}$.

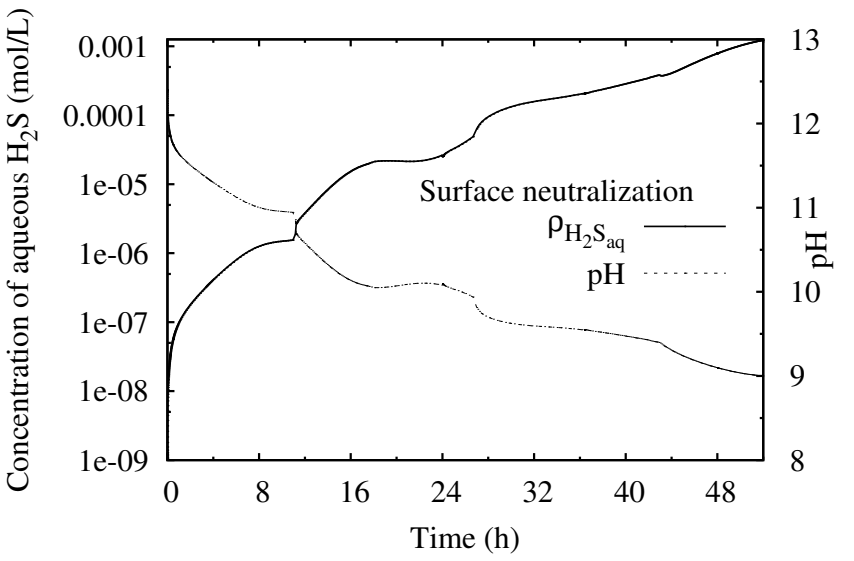

(a)

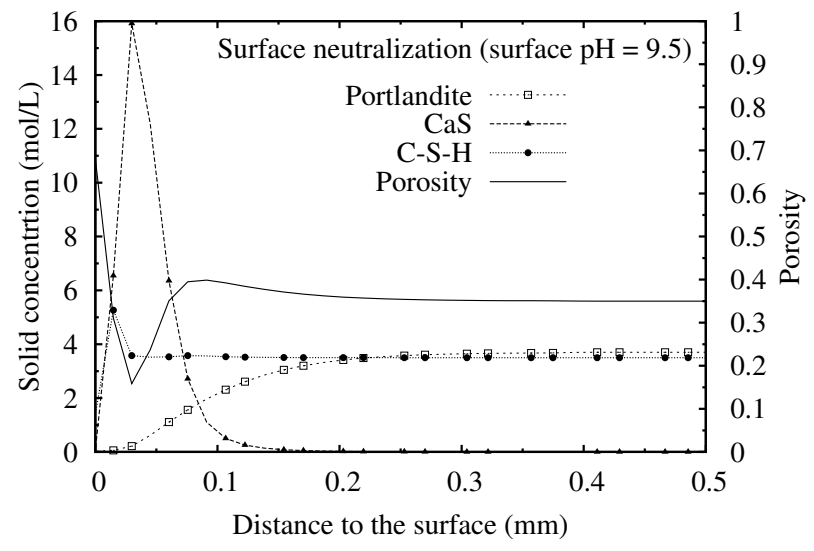

(b)

Figure 7.17: When surface $p \mathrm{H}$ decreases to 9.5: (a) Aqueous $\mathrm{H}_{2} \mathrm{~S}$ concentration and $p \mathrm{H}$ evolution at surface; (b) Solid concentration and porosity of mortar sample. $\left(\mathrm{H}_{2} \mathrm{~S}\right.$ level $\left.=400 \mathrm{ppm}\right)$

Hereafter, $\mathrm{H}_{2} \mathrm{~S}$ oxidation process is started by $\mathrm{SOB}$ in biofilms on the mortar surface. In this model, biofilms are considered covering on the neutralized surface. In the initial biofilms, we assume a presence of $0.005 \mathrm{~mol} / \mathrm{L}$ of element sulfur, which is formed by the chemical oxidation of $\mathrm{H}_{2} \mathrm{~S}$ during the neutralization process (Joseph et al., 2012). The initial and boundary conditions of the core part of mortar, neutralized surface and biofilm are considered as Table.7.3.

According to the modeling of $\mathrm{H}_{2} \mathrm{SO}_{4}$ production with a given $\mathrm{H}_{2} \mathrm{~S}$ content in gas phase as Eq.7.2 
Table 7.3: Boundary and initial conditions of biodeterioration by biofilms

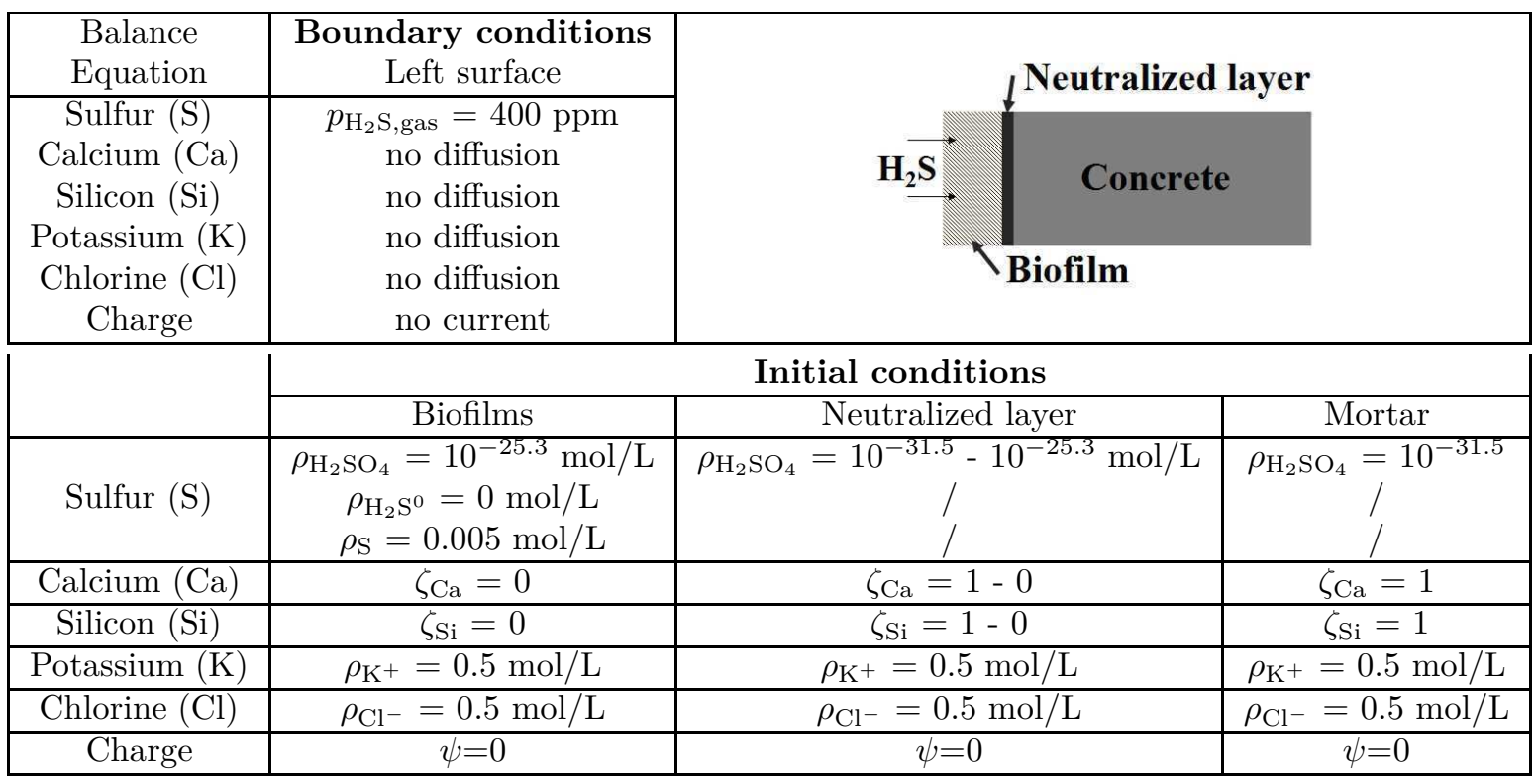

and Eq.7.3, $\mathrm{H}_{2} \mathrm{SO}_{4}$ production directly depends on the amount of element $\mathrm{S}$ which is controlled by the absorption and oxidation of $\mathrm{H}_{2} \mathrm{~S}$.

$$
\begin{array}{ccc}
\mathrm{H}_{2} \mathrm{~S} \text { oxidation : } & R_{\mathrm{H}_{2} \mathrm{~S}-\mathrm{oxi}}= & 6.714 \times 10^{-7} \mathrm{~mol} / \mathrm{L} \cdot \mathrm{s} \times \frac{\rho_{\mathrm{H}_{2} \mathrm{~S}}}{\rho_{\mathrm{H}_{2} \mathrm{~S}}+8.0 \times 10^{-4} \mathrm{~mol} / \mathrm{L}} \\
\text { S oxidation : } & R_{\mathrm{S}-\mathrm{oxi}}= & 2.526 \times 10^{-7} \mathrm{~mol} / \mathrm{L} \cdot \mathrm{s} \times \frac{\rho_{\mathrm{S}}}{\rho_{\mathrm{S}}+2.8 \times 10^{-5} \mathrm{~mol} / \mathrm{L}}
\end{array}
$$

The oxidation rate of $\mathrm{H}_{2} \mathrm{~S}$ and $\mathrm{S}$ in the biofilms during the first week are plotted in Fig.7.18. For $\mathrm{H}_{2} \mathrm{~S}$, oxidation rate of $\mathrm{H}_{2} \mathrm{~S}$ is zero because there is no $\mathrm{H}_{2} \mathrm{~S}$ in biofilm at the very beginning. According to the absorption kinetics, aqueous $\mathrm{H}_{2} \mathrm{~S}$ increases sharply in biofilm with $400 \mathrm{ppm}$ of $\mathrm{H}_{2} \mathrm{~S}$ gas. Thus, $\mathrm{H}_{2} \mathrm{~S}$ oxidation rate rises until $\rho_{\mathrm{H}_{2} \mathrm{~S}^{0}}$ reaches about $0.0017 \mathrm{~mol} / \mathrm{L}$. Since element $\mathrm{S}$ is produced before the biofilm formation by chemical oxidation of $\mathrm{H}_{2} \mathrm{~S}$ (Bagreev and Bandosz, 2005), we consider that the initial concentration of element $\mathrm{S}$ is $0.005 \mathrm{~mol} / \mathrm{L}$. Thus $\mathrm{H}_{2} \mathrm{SO}_{4}$ is produced from the beginning, which results in a slightly decreasing of element $\mathrm{S}$ during early time. Since $\mathrm{H}_{2} \mathrm{~S}$ oxidation is faster than $\mathrm{S}$ oxidation, the formation of element $\mathrm{S}$ is faster than its consumption. Hence, element $\mathrm{S}$ starts to accumulate in the biofilm very soon and $\mathrm{H}_{2} \mathrm{SO}_{4}$ is produced at a constant rate after about 6 days.

Compared to the early time during the immersion test, biofilms in the simulation reactor starts to produce $\mathrm{H}_{2} \mathrm{SO}_{4}$ with a higher rate as shown in Fig.7.18b. Thus, the $p \mathrm{H}$ in biofilms decreases from the beginning (see Fig.7.19a) without the time lag observed in the simulation of immersion test of De Muynck et al. (2009). $p \mathrm{H}$ in biofilms is rapidly reduced to 2. With $\mathrm{H}_{2} \mathrm{SO}_{4}$ production in biofilms, the alkalinity of 


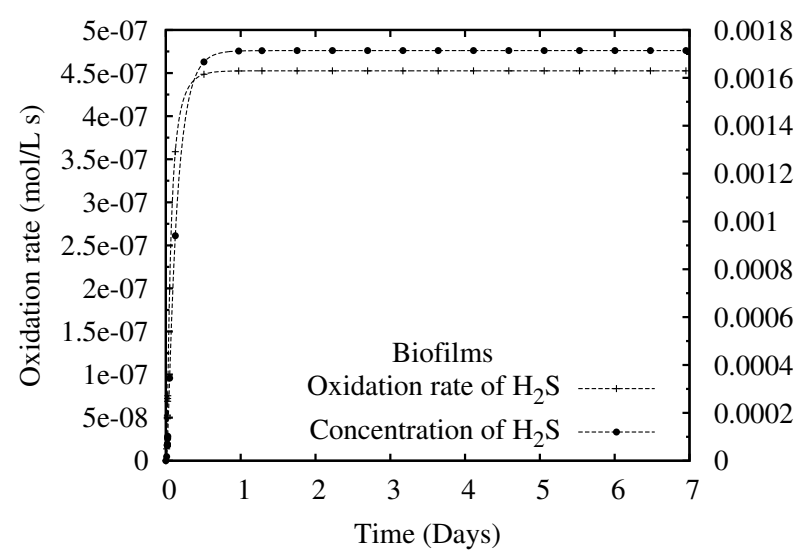

(a)

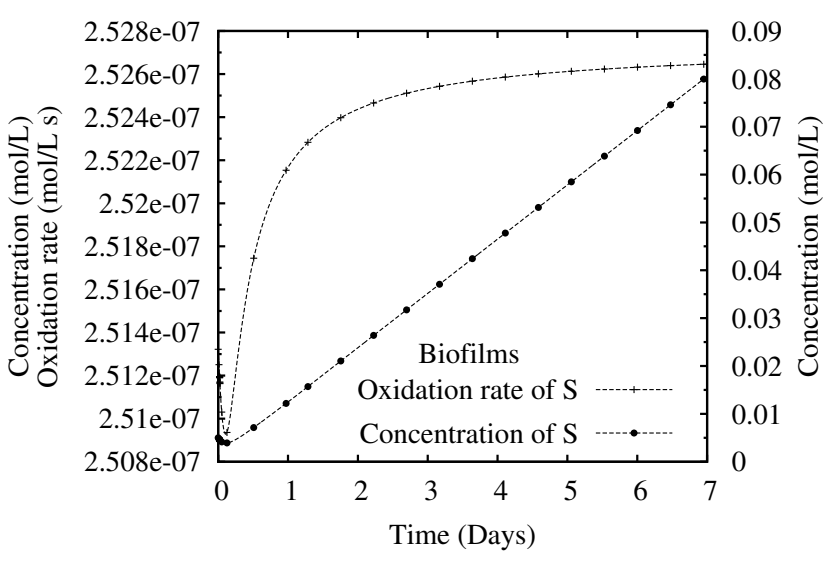

(b)

Figure 7.18: The oxidation of $\mathrm{H}_{2} \mathrm{~S}$ and $\mathrm{S}$ versus their concentration in the biofilms: (a) Aqueous $\mathrm{H}_{2} \mathrm{~S}$; (b) Element S. $\left(\mathrm{H}_{2} \mathrm{~S}\right.$ level $\left.=400 \mathrm{ppm}\right)$

mortar is reduced by the penetration of $\mathrm{H}_{2} \mathrm{SO}_{4}$. After 1 year, the profile of $p \mathrm{H}$ in both mortar and biofilm are plotted in Fig.7.19b.

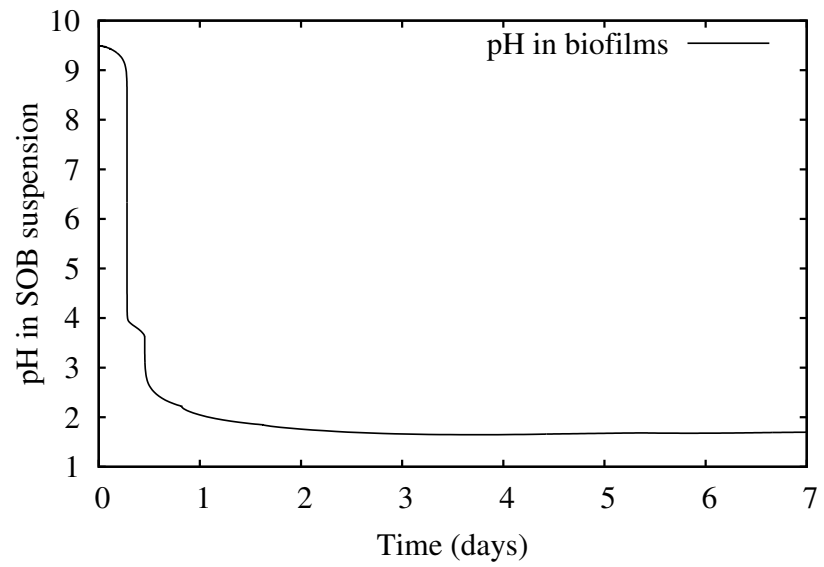

(a)

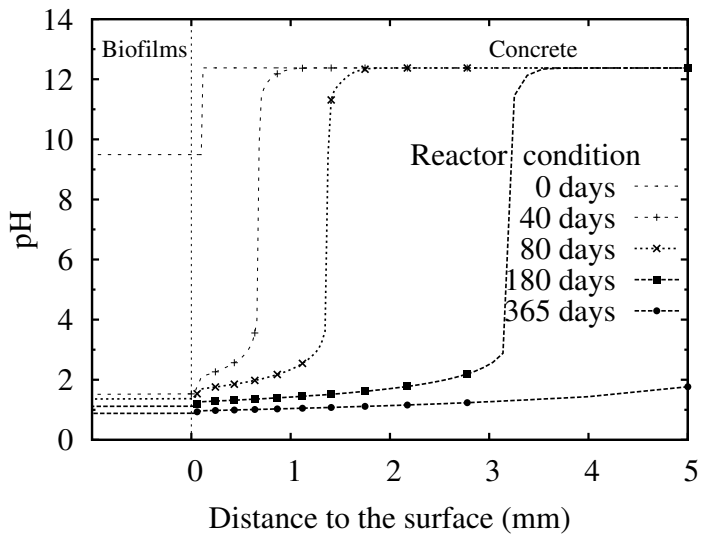

(b)

Figure 7.19: The calculated $p \mathrm{H}$ evolution profiles (a) $p \mathrm{H}$ evolution in biofilms ; (b) $p \mathrm{H}$ change in biofilms and mortar. $\left(\mathrm{H}_{2} \mathrm{~S}\right.$ level $\left.=400 \mathrm{ppm}\right)$

In the experiment, the $p \mathrm{H}$ at different depth of corroded specimens was examined. The surface portions showed a very low $p \mathrm{H}$ of 1.9. In the middle portions and the portions close to the uncorroded core, acidic conditions of $p \mathrm{H} \mathrm{2-3}$ and 11-12 were present. From the simulation results, similar zones are observed in Fig.7.19b. The solid compositions and porosity of these zones during test time are plotted in Fig.7.20 to Fig.7.23

Due to the same mechanisms of chemical $\mathrm{H}_{2} \mathrm{SO}_{4}$ solution attack of cement hydrates, similar zones can be observed. Corroded material starts with a gypsum - rich layer. Unlike immersion test, a gypsum 


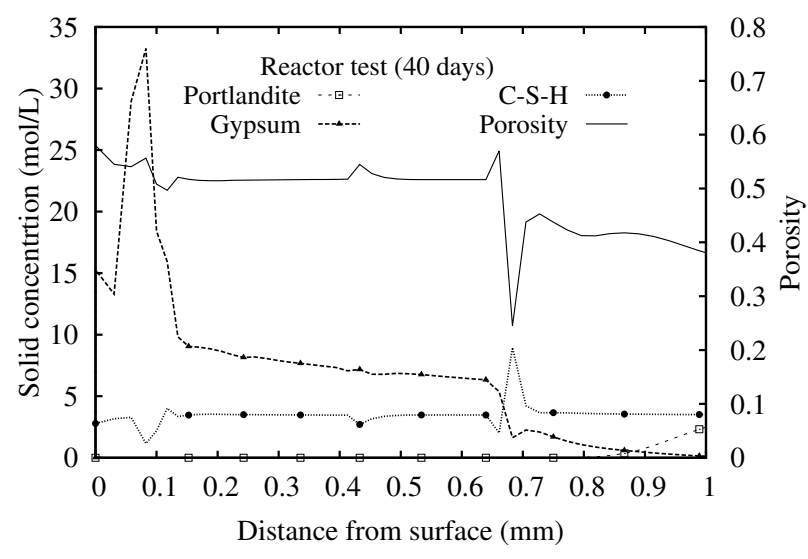

(a)

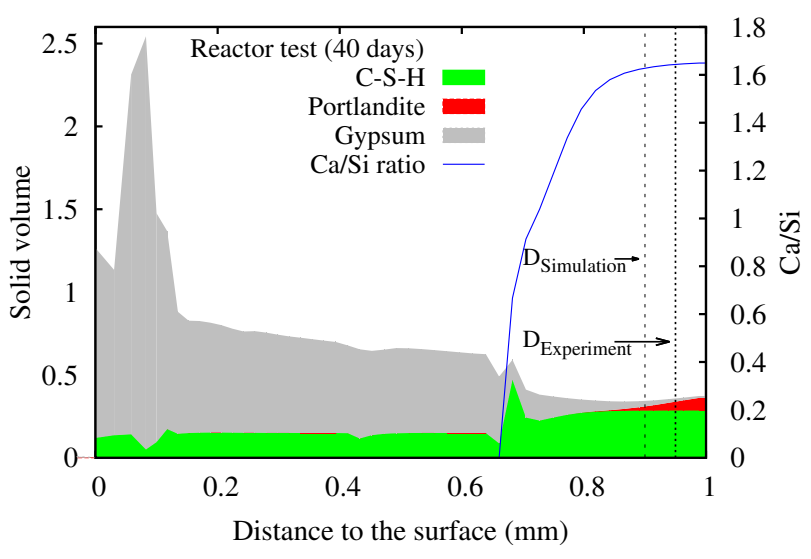

(b)

Figure 7.20: After 40 days of test in simulation reactor: (a) Solid concentration and porosity ; (b) Solid volume and $\mathrm{Ca} / \mathrm{Si}$ ratio of C-S-H. $\left(\mathrm{H}_{2} \mathrm{~S}\right.$ level $\left.=400 \mathrm{ppm}\right)$

accumulation peak is present at $0.1 \mathrm{~mm}$ from the surface rather than at the top surface. Such difference is caused by the surface neutralization process. With a higher $\mathrm{H}_{2} \mathrm{~S}$ gas level, more CaS dissolves. Therefore, very few calcium solid phase is present at the top surface at the initial time of $\mathrm{H}_{2} \mathrm{SO}_{4}$ attack. In our modeling the material is initially at equilibrium condition. Thus less calcium solid means less concentration of $\mathrm{Ca}^{2+}$, which results in less gypsum accumulation.

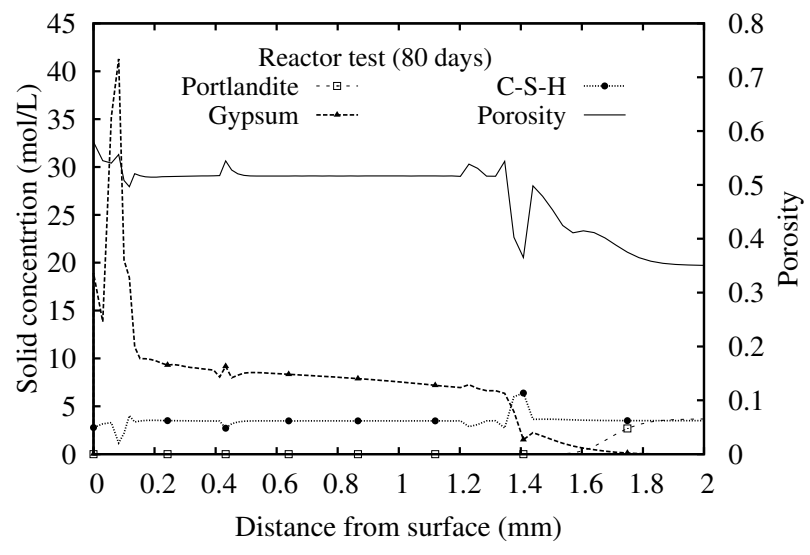

(a)

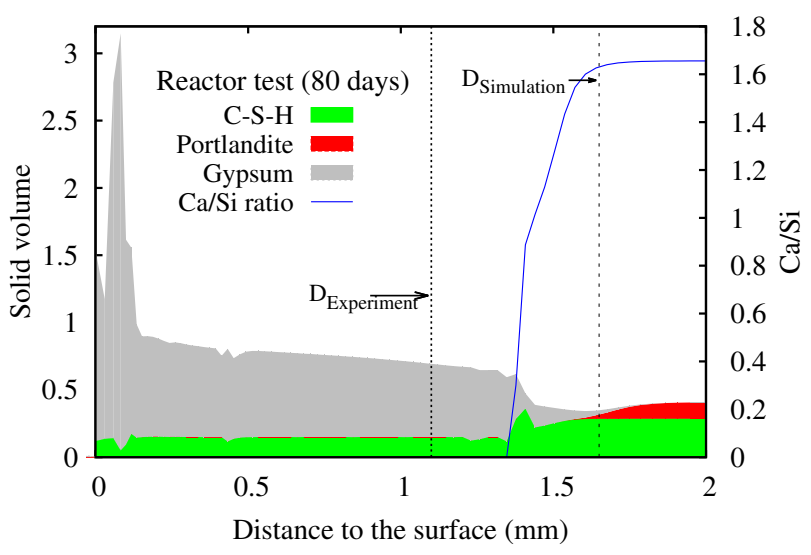

(b)

Figure 7.21: After 80 days of test in simulation reactor: (a) Solid concentration and porosity ; (b) Solid volume and $\mathrm{Ca} / \mathrm{Si}$ ratio of C-S-H. $\left(\mathrm{H}_{2} \mathrm{~S}\right.$ level $\left.=400 \mathrm{ppm}\right)$

The change of thickness in the area around the sewage level were measured at 40, 80 and 180 days. The predicted corrosion depth by our modeling agrees with the experimental results.

The experiments lasted for 180 days. Thus the maximum corrosion rate of the specimens exposed to sewage was calculated to be $6.1 \mathrm{~mm} /$ year. By our modeling long term prediction is possible. After 1 year 


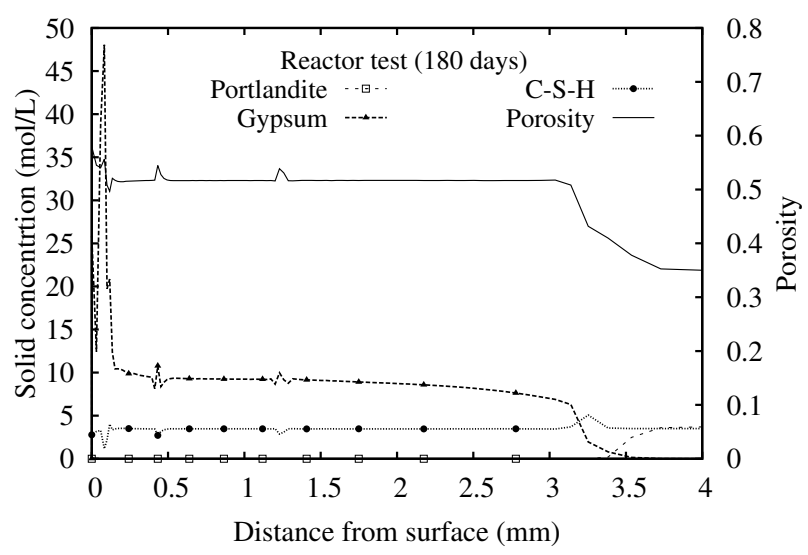

(a)

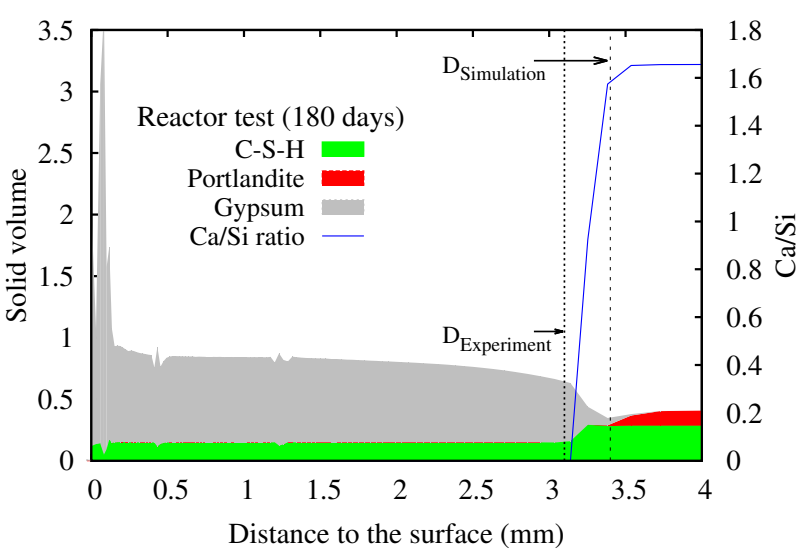

(b)

Figure 7.22: After 180 days of test in simulation reactor: (a) Solid concentration and porosity ; (b) Solid volume and $\mathrm{Ca} / \mathrm{Si}$ ratio of C-S-H. $\left(\mathrm{H}_{2} \mathrm{~S}\right.$ level $\left.=400 \mathrm{ppm}\right)$

of test, about $6.8 \mathrm{~mm}$ of mortar was corroded (see Fig.7.23). Hence, the corrosion rate is $6.8 \mathrm{~mm} /$ year which is close to the experimental calculation.

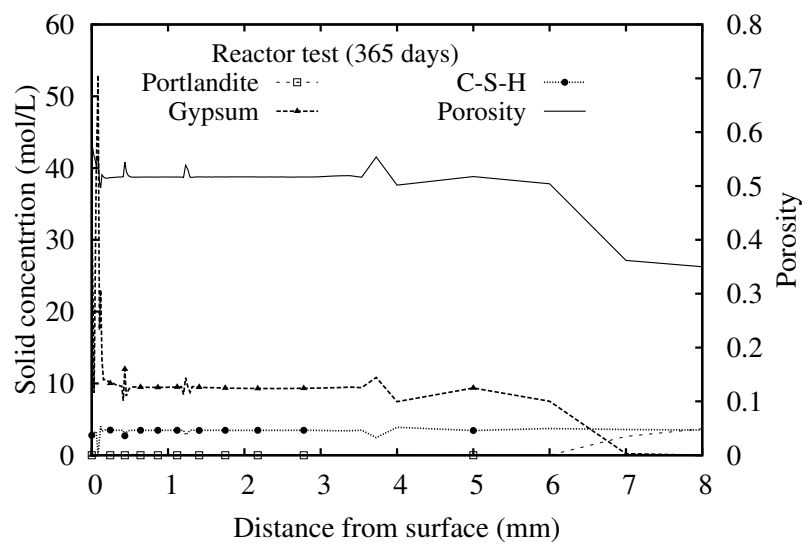

(a)

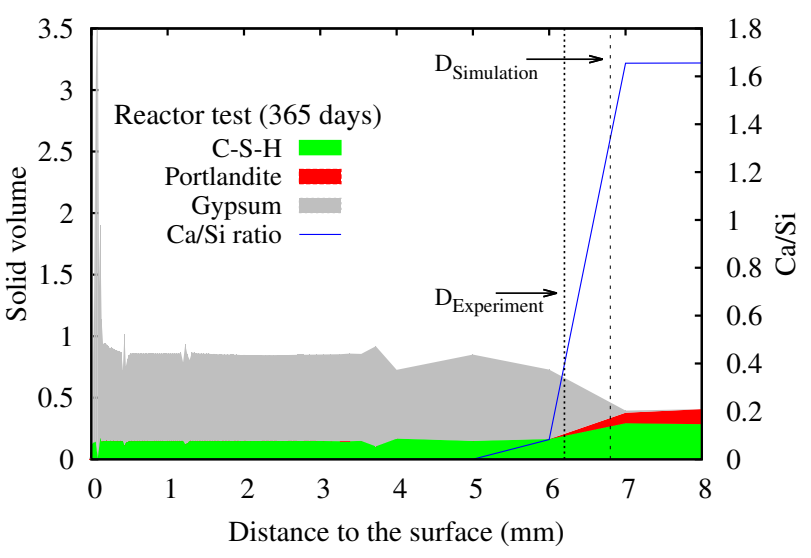

(b)

Figure 7.23: After 1 year of test in simulation reactor: (a) Solid concentration and porosity ; (b) Solid volume and $\mathrm{Ca} / \mathrm{Si}$ ratio of C-S-H. $\left(\mathrm{H}_{2} \mathrm{~S}\right.$ level $\left.=400 \mathrm{ppm}\right)$

\subsection{Effect of $\mathrm{H}_{2} \mathrm{~S}$ gas level}

The difference of $\mathrm{H}_{2} \mathrm{~S}$ gas level in sewer pipes could influence both of surface neutralization process and $\mathrm{H}_{2} \mathrm{SO}_{4}$ production in biofilms.

However, in our modeling we consider constant biomass in biofilms where $\mathrm{SOB}$ produce $\mathrm{H}_{2} \mathrm{SO}_{4}$ at high rate. In fact, the activity and the amount of $\mathrm{SOB}$ is controlled by the content of $\mathrm{H}_{2} \mathrm{~S}$ in biofilms. Due to the lack of quantitative relationship between the content of $\mathrm{H}_{2} \mathrm{~S}$ and the activity of SOB, the effect of $\mathrm{H}_{2} \mathrm{~S}$ 
gas level on the $\mathrm{H}_{2} \mathrm{SO}_{4}$ production process is difficult to illustrate by our modeling.

For the surface neutralization process, the decrease of $p \mathrm{H}$ at surface is directly governed by $\mathrm{H}_{2} \mathrm{~S}$ level. Lower $\mathrm{H}_{2} \mathrm{~S}$ level leads to longer lag time of biogenic $\mathrm{H}_{2} \mathrm{SO}_{4}$ attack. For most of the in-situ conditions, corrosion materials are removed by flow of sewage periodically and new surface where $p \mathrm{H}$ is too high for SOB growth is exposed cyclically. Thus, the lag time is crucial for biodeterioration of sewer pipes. We conduct simulations of surface neutralization with different $\mathrm{H}_{2} \mathrm{~S}$ gas level. We consider the lag time as the time of the decrease of surface $p \mathrm{H}$ from 12.4 to 9 . The lag time of biogenic $\mathrm{H}_{2} \mathrm{SO}_{4}$ attack with different $\mathrm{H}_{2} \mathrm{~S}$ gas level is plotted in Fig.7.24.

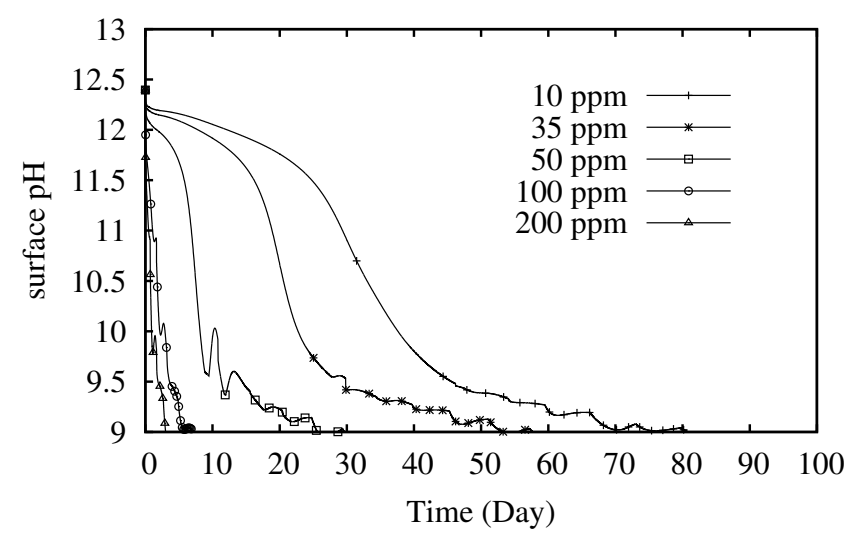

Figure 7.24: The lag time of surface neutralization process with different $\mathrm{H}_{2} \mathrm{~S}$ level.

From Fig.7.24, it is clear that more time is needed to prepare the proper environment for SOB with less $\mathrm{H}_{2} \mathrm{~S}$ gas. For the condition of $10 \mathrm{ppm}$, biofilms even could not form if the period of flow is less than 80 days. When the $\mathrm{H}_{2} \mathrm{~S}$ gas reaches more than $100 \mathrm{ppm}$, SOB could start to grow on the surface in few days.

\subsection{Conclusion}

In the cases where the activity of SOB is involved, our modelling coupled the process of surface neutralization, the production of biogenic $\mathrm{H}_{2} \mathrm{SO}_{4}$ and the deterioration of concrete. We modeled the laboratory experiments of biodeterioration of cementitous materials conducted by (De Muynck et al., 2009) and (Mori et al., 1992). The decrease of surface $p \mathrm{H}$ and the depth of neutralized layer during the stage of $\mathrm{H}_{2} \mathrm{~S}-$ incubation were determined. For different test conditions, the production of $\mathrm{H}_{2} \mathrm{SO}_{4}$ in SOB suspension and biofilms were calculated by different methods. With the amount of biogenic $\mathrm{H}_{2} \mathrm{SO}_{4}$, the evolution of solid compositions and porosity of materials were addressed. Like the modeling of chemical $\mathrm{H}_{2} \mathrm{SO}_{4}$ attack, the modeling of biogenic $\mathrm{H}_{2} \mathrm{SO}_{4}$ attack provides a prediction of the deterioration depth of materials.

Exposed to the gas with high $\mathrm{H}_{2} \mathrm{~S}$ level, concrete surface would absorb $\mathrm{H}_{2} \mathrm{~S}$ gas into pore solution very 
fast. Consequently, Portlandite and C-S-H are dissolved by aqueous $\mathrm{H}_{2} \mathrm{~S}$ and CaS precipitates. Thus, the alkalinity of concrete surface is neutralized in few days, which is called lag time in this paper. For the same type of concrete, the lag time is controlled by the $\mathrm{H}_{2} \mathrm{~S}$ gas level and temperature, which vary in sewer pipes. The effect of $\mathrm{H}_{2} \mathrm{~S}$ level on the surface neutralization process is studied by our modeling as well.

For the immersion test condition, $\mathrm{H}_{2} \mathrm{SO}_{4}$ is produced in $\mathrm{SOB}$ suspension where the activity of $\mathrm{SOB}$ is governed by $p \mathrm{H} . p \mathrm{H}$ in SOB suspension decreases very few until 4 days. However, during the later time of immersion, $p \mathrm{H}$ in SOB suspension is reduced to 1 which could result in heavily corrosion of concrete. After immersion of 10 days, the deterioration depth is about $0.22 \mathrm{~mm}$. The predicted corrosion rate of each cycle coincides with that of experimental measurements.

For the simulation reactor condition, the production of $\mathrm{H}_{2} \mathrm{SO}_{4}$ is calculated by the oxidation of $\mathrm{H}_{2} \mathrm{~S}$ in biofilms. Due to the continuously supply of $\mathrm{SOB}$ and high $\mathrm{H}_{2} \mathrm{~S}$ gas level, $\mathrm{H}_{2} \mathrm{SO}_{4}$ is produced quite fast from the beginning. Since the oxidation rate of element $\mathrm{S}$ is lower than that of $\mathrm{H}_{2} \mathrm{~S}$, element $\mathrm{S}$ accumulates in biofilms. After simulation of 1 year, the predicted corrosion depth reaches about $6.8 \mathrm{~mm}$ which agrees the experimental results.

However, the SOB activity in our modeling is still relatively crude. Further research is needed to get the knowledge of the exact $\mathrm{SOB}$ ecology supporting long-term $\mathrm{H}_{2} \mathrm{SO}_{4}$ production and the growth of the different types of SOB. 


\section{Chapter 8}

\section{Conclusions and further discussion}

\subsection{Summary of the thesis}

In order to assess the deterioration process of sewer pipes, a reactive transport model is built. This model could be used to predict the deterioration depth and solid compounds of cementitious materials in contact with sulfuric acid solution or sulfur-oxidizing bacteria (SOB). In this study, the biodeterioration of concrete are divided in three parts: the neutralization of concrete surface, the production of sulfuric acid by $\mathrm{SOB}$ and $\mathrm{H}_{2} \mathrm{SO}_{4}$ attack of concrete.

- The neutralization of concrete surface is caused by $\mathrm{H}_{2} \mathrm{~S}$ attack of concrete. The model of this attack developed in the thesis considers the absorption of $\mathrm{H}_{2} \mathrm{~S}$ gas in pore solution of concrete and the chemical reactions between aqueous $\mathrm{H}_{2} \mathrm{~S}$ and concrete. Thus, the times of neutralization and the thickness of neutralized layer of concrete under different $\mathrm{H}_{2} \mathrm{~S}$ levels can be calculated.

- For the production of $\mathrm{H}_{2} \mathrm{SO}_{4}$ by $\mathrm{SOB}$, the quantitative understanding is still very poor. In this study, the production rate of $\mathrm{H}_{2} \mathrm{SO}_{4}$ under different conditions are calculated by fitting experimental measurements or WATS model. Thus, the amount of $\mathrm{H}_{2} \mathrm{SO}_{4}$ which could deteriorate concrete can be determined.

- Dealing with $\mathrm{H}_{2} \mathrm{SO}_{4}$ attack process, the dissolution of portlandite and C-S-H gel, and the precipitation of gypsum are considered. Due to the swelling of gypsum, a simplified damage model is employed to calculate the porosity change during degradation. Thus, the solid composites evolution and deterioration depth of concrete can be predicted.

The three parts of biodeterioration of concrete were programmed as a coupled process thanks to Bil platform. Thus this platform is able to simulate the whole process of biodeterioration of concrete. Some experiments were simulated by this model and the simulation results have been compared with experimental 
observations.

In the modelling, we consider homogeneous chemical reactions in the pore solution. The equilibrium of different solid phases (i.e., portlandite, C-S-H gel, gypsum and calcium sulfide) and aqueous species in concrete are considered as well. A generalization of the mass action law is used to describe the decalcification of C-S-H. This theory encompasses the solid solution model and is easy to implement in transport-reaction modeling. The diffusion of aqueous species is introduced into the model by Nernst-Planck equation, and the numerical method couples the transport equations and the chemical reactions.

Precipitation and dissolution reactions could result in a porosity increase or drop, due to the volume difference between cement hydrates and corrosion products. Thus, the changes in porosity have also been taken into account by the balance of volume on the solid phases and a model was developed to handle the swelling of gypsum induced by the damage of concrete. During $\mathrm{H}_{2} \mathrm{~S}$ attack, the smaller molar volume and the dissolution of CaS cause the reduction of solid volume which is responsible for the increase of porosity. During the early time of $\mathrm{H}_{2} \mathrm{SO}_{4}$ attack, the porosity will decrease as the formation of gypsum, whose molar volume is bigger than that of $\mathrm{CH}$. Then the accumulation of gypsum could fill pores and increase the inner pressure. When the inner pressure exceeds the strength of concrete, pore structure fails and porosity increases. The formed gypsum could dissolve under peculiar boundary conditions and cause a further increase in porosity.

Thus, the model can predict the chemical composites and corrosion depth of cementitious materials immersed in static or flowing $\mathrm{H}_{2} \mathrm{SO}_{4}$ solution with different $p \mathrm{H}$. By changes in the porosity of surface layer, some differences between experimental observations and simulation results can be explained.

Not only chemical $\mathrm{H}_{2} \mathrm{SO}_{4}$ attack, but also biogenic $\mathrm{H}_{2} \mathrm{SO}_{4}$ attack can be simulated by this modelling. We can deal with the biodeterioration of concrete in contact with two different SOB media: SOB suspension where the evolution of $p \mathrm{H}$ is given and biofilm where the type of $\mathrm{SOB}$ and $\mathrm{H}_{2} \mathrm{~S}$ gas level are given. For the SOB suspension condition, $\mathrm{H}_{2} \mathrm{SO}_{4}$ production rate is modeled by a function of $p \mathrm{H}$ to fit the measurement of $p \mathrm{H}$ evolution in suspension. The succession and activity of SOB in different $p \mathrm{H}$ range are considered. For the biofilm, the amount and activity of SOB are constant. By WAST model (Jensen et al., 2009), the oxidation rate of $\mathrm{H}_{2} \mathrm{~S}$ and that of element $\mathrm{S}$ are governed by functions of concentration of $\mathrm{H}_{2} \mathrm{~S}$ and $\mathrm{S}$ respectively.

In this study, this model is applied to simulate the experimental works on the neutralization of concrete surface (Joseph et al., 2012), chemical $\mathrm{H}_{2} \mathrm{SO}_{4}$ attack (Kawai et al., 2005) and biogenic $\mathrm{H}_{2} \mathrm{SO}_{4}$ attack (De Muynck et al., 2009; Mori et al., 1992).

For $\mathrm{H}_{2} \mathrm{~S}$ attack, a CaS-rich layer where $\mathrm{CH}$ and C-S-H are dissolved can be observed. When $p \mathrm{H}$ at the surface decreases to 9 , SOB could start to grow. Then the width of neutralized layer is about $0.1 \mathrm{~mm}$. The 
accumulation of $\mathrm{CaS}$ could reduce the porosity at surface to protect inner part of the sample from aqueous $\mathrm{H}_{2} \mathrm{~S}$ penetration. However, if there is enough $\mathrm{H}_{2} \mathrm{~S}$ the accumulated $\mathrm{CaS}$ would be dissolved. We consider the time for $p \mathrm{H}$ at surface to decrease to 9 as the neutralization time which is governed by the $\mathrm{H}_{2} \mathrm{~S}$ gas level. When the amount of $\mathrm{H}_{2} \mathrm{~S}$ gas is higher than $100 \mathrm{ppm}, \mathrm{H}_{2} \mathrm{~S}$ is absorbed into pore solution of concrete quite fast and $p \mathrm{H}$ at concrete surface could be reduced from about 12.4 to 9 in 2 days. While for $\mathrm{H}_{2} \mathrm{~S}$ gas less than $50 \mathrm{ppm}$, this time could be more than 1 month. Thus, the neutralization time is crucial for biodeterioration of sewer pipes. By our model, the proper time of $\mathrm{H}_{2} \mathrm{~S}$ incubation step of accelerate test can be determined.

When immersed in a static $\mathrm{H}_{2} \mathrm{SO}_{4}$ solution, a porous layer containing gypsum and silica gel can by observed at the surface of cement paste sample. Meanwhile, the C-S-H decalcification zone and CH dissolution zone are observed between the surface and the uncorroded zone. The diffusion of $\mathrm{Ca}^{2+}$ from the $\mathrm{CH}$ dissolution front to the $\mathrm{C} \overline{\mathrm{S}} \mathrm{H} 2$ precipitation front results in the accumulation of $\mathrm{C} \overline{\mathrm{S}} \mathrm{H} 2$ at the surface. Hence the volume of gypsum-rich layer expands a lot due to the accumulation of gypsum whose molar volume is large. Due to the inner pressure caused by the precipitation of gypsum, damage of materials happens in the overlap region of gypsum-rich zone and dissolution zone. Thus, the deterioration depth is defined as the distance between the initial surface and the damage place of concrete sample.

In the flowing solution condition, the effect of flowing solution is modeled by the leaching effect which removes the corrosion products. We consider that the external solution is free of calcium and silicon. Consequently, calcium and silicon released from the dissolution front leave the material as a result of concentration gradient. Thus, no significant gypsum layer can be observed at the surface where cement paste is fully degraded. Compared to static solution condition, sample is corroded much heavier when it is immersed in flowing solution which exposes more reactive surface for $\mathrm{H}_{2} \mathrm{SO}_{4}$ attack. Therefore, during accelerate test the intensity of brush or flush is an important factor which should be controlled.

$\mathrm{H}_{2} \mathrm{SO}_{4}$ attack of concrete is very sensitive to the concentration of $\mathrm{H}_{2} \mathrm{SO}_{4}$. For the solution with lower $\mathrm{H}_{2} \mathrm{SO}_{4}$ concentration, less acid penetrating into concrete is available to form gypsum. Thus the cement paste is corroded slower. Long-term simulation showed that the corrosion rate of concrete under the condition of $p \mathrm{H}=2$ is about 2 time less than that of $p \mathrm{H}=1$. The corrosion depth increases linearly with the square root of time. Hence the environmental acidity in sewer pipes is a key factor which influence the service life.

For biogenic $\mathrm{H}_{2} \mathrm{SO}_{4}$ attack, the activity of $\mathrm{SOB}$ and the cementitious material samples with neutralized layer are involved. For the immersion test condition, $p \mathrm{H}$ in SOB suspension decreases very few during early time due to the slow $\mathrm{H}_{2} \mathrm{SO}_{4}$ production rate of NSOB (Neutrophilic Sulfur-Oxidizing Bacteria). Due to the alkalinity of concrete, $p \mathrm{H}$ in the SOB suspension near the concrete surface even increases at first. 
During the later time of immersion, ASOB (Acidophilic Sulfur-Oxidizing Bacteria) rather than NSOB is producing $\mathrm{H}_{2} \mathrm{SO}_{4}$ with a much higher rate. For the simulation reactor condition, $\mathrm{H}_{2} \mathrm{~S}$ is absorbed into biofilm where oxidation of $\mathrm{H}_{2} \mathrm{~S}$ and element $\mathrm{S}$ are conducted by SOB. Since the oxidation rate of element $\mathrm{S}$ is lower than that of $\mathrm{H}_{2} \mathrm{~S}$, element $\mathrm{S}$ accumulates in the biofilm. Due to the continuous supply of SOB and $\mathrm{H}_{2} \mathrm{~S}, \mathrm{H}_{2} \mathrm{SO}_{4}$ is produced fast from the beginning. Hence $p \mathrm{H}$ in SOB suspensions or biofilms could be reduced to 1-2 which results in heavy corrosion of concrete. Therefore, applying antibacterial materials in sewer pipes (e.g., calcium aluminate cement) is a method to restrict the activity and amount of SOB in biofilm (Alexander and Fourie, 2011; Herisson, 2012).

Under different conditions of biogenic $\mathrm{H}_{2} \mathrm{SO}_{4}$ attack, similar zones as those in chemical $\mathrm{H}_{2} \mathrm{SO}_{4}$ attack condition are observed. Not only neutralized layer, but also concrete core is degraded by biogenic $\mathrm{H}_{2} \mathrm{SO}_{4}$. Due to the diffusion of calcium towards the gypsum precipitation front, lots of gypsum accumulates at concrete surface.

By adjusting the porosity and initial solid compositions in the surface region of the sample, the effect of carbonated layer is investigated. Due to calcite accumulation at surface, the carbonated layer where porosity is smaller than that of concrete core (Shen, 2012) protects the concrete core from $\mathrm{H}_{2} \mathrm{SO}_{4}$ penetration. In this high density layer, the $\mathrm{H}_{2} \mathrm{SO}_{4}$ penetration is slowed down and the reactions are restricted. Thus the corrosion rate is quite slow during the early time.

\subsection{Further discussion and perspective}

This model is able to predict the corrosion depth and service life of OPC concrete sewer pipes subjected to biogenic $\mathrm{H}_{2} \mathrm{SO}_{4}$ attack. The change of solid compositions of concrete during biodeterioration can be calculated. The influence of environmental and chemical factors can be indicated by this model. However, there are still some developments could be conducted to improve the understanding of biodeterioration of concrete.

Some modifies of modeling should be given priority for more accurate estimation:

- In this study, we assume infinite dilution approximation for aqueous species. Thus, the activity of each aqueous species is equal to the molar concentration and that of solid component equals 1 . Due to the high ionization constant, this hypothesis is acceptable for $\mathrm{H}_{2} \mathrm{SO}_{4}$. However, for high $\mathrm{H}_{2} \mathrm{~S}$ gas level such approximation may be criticized since the concentrations of the aqueous species could become quite high. An improved model considering the effects of the chemical activity could be developed in a future work.

- For now, we cannot address the coupling of $\mathrm{H}_{2} \mathrm{~S}$ attack and $\mathrm{H}_{2} \mathrm{SO}_{4}$ attack in one step. Thus, the effect of neutralization process is taken into account by considering the sample as fresh concrete with a neutralized layer whose properties are determined by a separate simulation of $\mathrm{H}_{2} \mathrm{~S}$ attack. Continuously 
simulation of the whole process of deterioration should be achieved in future work.

Due to the complex of biodeterioration process, we make some simplifying assumptions which should be reconsidered in future works:

- For the neutralization process, the absorption of $\mathrm{H}_{2} \mathrm{~S}$ gas is calculated by the empirical equation of (Nielsen et al., 2012) rather than Henry's law which is commonly used to describe the solubility of a gas in a liquid. The exact mechanism of $\mathrm{H}_{2} \mathrm{~S}$ absorption in sewer pipes should be studied. The temperature dependence is neglected in the absorption of $\mathrm{H}_{2} \mathrm{~S}$ gas in this study. According to (Vollertsen et al., 2008), higher temperature accelerates $\mathrm{H}_{2} \mathrm{~S}$ absorption. Such phenomena was tested by the experimental works of (Joseph et al., 2012). Moreover, chemical oxidation of sulfide to element S may occur during the neutralization process (Bagreev and Bandosz, 2005). Such reaction can provide the source of S for biofilm formation during early time of biodeterioration. Thus, it is necessary to consider chemical oxidation of sulfide in future modelling.

- For the failure of pore structure, we applied a simplified damage model. To make a more precise prediction, a more detailed description of the physical behaviour of gypsum precipitation may also be implemented. For example, according to (Azam, 2007), for gypsum gel the relationship between log of pressure and reduction of porosity is linear. Furthermore, as more and more cement hydrates dissolve, the cementitious materials is soften gradually, while in this study the materials is soften abruptly. Thus the damage model part should be modified.

Due to the lack of understanding about the mechanism of $\mathrm{H}_{2} \mathrm{SO}_{4}$ attack of concrete, some experimental observation can not be explained by this model:

- According to some experimental observations of $\mathrm{H}_{2} \mathrm{SO}_{4}$ attack (Kawai et al., 2005; Israel et al., 1997; Fattuhi and Hughes, 1988), the corrosion rate of concrete with low W/C ratio is greater than that with high $\mathrm{W} / \mathrm{C}$ ratio, thereby disagreeing with our simulation results. In our model, the corrosion process is diffusion controlled rather than reaction controlled which is claimed by (Ueda and Tatematsu, 1996). Furthermore, diffusion coefficient of some species (e.g., $\mathrm{SO}_{4}^{2-}$ ) in concrete is not determined by measurement. Therefore, the mechanism of $\mathrm{H}_{2} \mathrm{SO}_{4}$ attack should be investigated further. And more accurate parameters should be collected.

To refine the model, more experimental results should be collected:

- To calculate the production of $\mathrm{H}_{2} \mathrm{SO}_{4}$ by $\mathrm{SOB}$ media, we employ a regression equation which is only suitable for specific experiment condition and empirical model where the activity of SOB is constant. Dealing with such a complex process, lots of work could be conducted to dispose of a more accurate description of biodeterioration of sewer pipes. Further experimental study could be done to improve the understanding of the biogenic oxidation of sulfide and get more quantitative information about the effect 
of microbiological/chemical factors (such as biomass, $p \mathrm{H}$, temperature) on the production of $\mathrm{H}_{2} \mathrm{SO}_{4}$.

- To validate the modelling, the corrosion depth of simulation results is compared to experimental results. Since change of solid compositions can be calculated by the model, some micro measurements of the corroded layer, such as the solid phases profile and the porosity evolution of the samples, should be conducted and compared with simulation results.

Moreover, the model could be used to describe the biodeterioration process of other types of concrete:

- The chemistry process of the biodeterioration of OPC concrete and that of concrete made by other blended cement with additions (like slag, fly ash and silica fume) is similar. Thus modelling of the biodeterioration of other type of cementitious materials can be achieved by changing the content of $\mathrm{CH}$ and $\mathrm{C}-\mathrm{S}-\mathrm{H}$ and the initial porosity. To provide assist in rational choice of adapted materials for sewage environment, such study will be worth in future. 


\section{Bibliography}

Alexander, M. and Fourie, C. Performance of sewer pipe concrete mixtures with portland and calcium aluminate cements subject to mineral and biogenic acid attack. Materials and structures, 44(1):313-330, 2011.

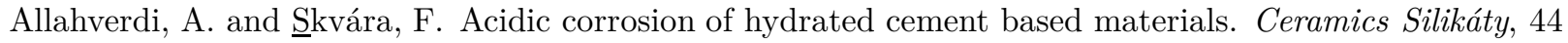
(4):152-160, 2000.

Allsopp, D., Seal, K. J., and Gaylarde, C. C. Introduction to biodeterioration. Cambridge University Press, 2004.

Apgar, D., Witherspoon, J., Easter, C., Corsi, R., Forbes, B., Quigley, C., Ward, M., Morton, R., Weiss, J., Bowker, R. P., et al. Minimization of odors and corrosion in collection systems: Phase i. Water Environ. Res. Found. Rep, 2007.

Atkinson, A., Hearne, J. A., and Knights, C. F. Aqueous chemistry and thermodynamic modelling of cao-sio2-h2o gels. J. Chem. Soc., Dalton Trans., (12):2371-2379, 1989.

Azam, S. Study on the geological and engineering aspects of anhydrite/gypsum transition in the arabian gulf coastal deposits. Bulletin of engineering geology and the environment, 66(2):177-185, 2007.

Bagreev, A. and Bandosz, T. J. On the mechanism of hydrogen sulfide removal from moist air on catalytic carbonaceous adsorbents. Industrial \&3 engineering chemistry research, 44(3):530-538, 2005.

Barton, L. and Tomei, F. Characteristics and activities of sulfate-reducing bacteria. Biotechnology Handbooks, 8:1-1, 1995.

Bassuoni, M. and Nehdi, M. Resistance of self-consolidating concrete to sulfuric acid attack with consecutive ph reduction. Cement and concrete research, 37(7):1070-1084, 2007.

Beddoe, R. E. and Dorner, H. W. Modelling acid attack on concrete: Part i. the essential mechanisms. Cement and Concrete Research, 35(12):2333-2339, 2005. 
Bentz, D. Cemhyd3d: A three-dimensional cement hydration and microstructure development modeling package. version 3.0, nistir 7232. US Department of Commerce, 2005.

Bielefeldt, A., Gutierrez-Padilla, M. G. D., Ovtchinnikov, S., Silverstein, J., and Hernandez, M. Bacterial kinetics of sulfur oxidizing bacteria and their biodeterioration rates of concrete sewer pipe samples. Journal of Environmental Engineering, 136(7):731-738, 2009.

Bock, E. and Sand, W. Applied electron microscopy on the biogenic destruction of concrete and blocks. use of the transmission electron microscope for identification of mineral acid producing bacteria. In $8 t h$ International Conference on Cement Microscopy, Duncanville, Texas, 1986.

Böhm, M., Devinny, J., Jahani, F., and Rosen, G. On a moving-boundary system modeling corrosion in sewer pipes. Applied Mathematics and Computation, 92(2):247-269, 1998.

Börjesson, S., Emrén, A., and Ekberg, C. A thermodynamic model for the calcium silicate hydrate gel, modelled as a non-ideal binary solid solution. Cement and Concrete Research, 27(11):1649-1657, 1997.

Bouchelaghem, F. A numerical and analytical study on calcite dissolution and gypsum precipitation. Applied Mathematical Modelling, 34(2):467-480, 2010.

Brouwers, H. and VanEijk, R. Alkali concentrations of pore solution in hydrating opc. Cement and concrete research, 33(2):191-196, 2003.

Carey, J. and Lichtner, P. Calcium silicate hydrate (csh) solid solution model applied to cement degradation using the continuum reactive transport model flotran. Transport Properties and Concrete Quality: Materials Science of Concrete, pages 73-106, 2007.

CEB-FIP, M. C. Comite euro-international du beton. Bulletin d'information, 195:196, 1990.

Chalupeckỳ, V., Fatima, T., Kruschwitz, J., and Muntean, A. Macroscopic corrosion front computations of sulfate attack in sewer pipes based on a micro-macro reaction-diffusion model. arXiv preprint arXiv:1201.6460, 2012.

Chen, J. J., Thomas, J. J., Taylor, H. F., and Jennings, H. M. Solubility and structure of calcium silicate hydrate. Cement and Concrete Research, 34(9):1499-1519, 2004.

Chen, X., Wu, S., and Zhou, J. Influence of porosity on compressive and tensile strength of cement mortar. Construction and Building Materials, 40:869-874, 2013.

Cho, K.-S. and Mori, T. A newly isolated fungus participates in the corrosion of concrete sewer pipes. Water Science and Technology, 31(7):263-271, 1995. 
Cohen, M. D. and Mather, B. Sulfate attack on concrete: research needs. ACI Materials Journal, 88(1), 1991.

Constantinides, G. and Ulm, F.-J. The effect of two types of csh on the elasticity of cement-based materials: Results from nanoindentation and micromechanical modeling. Cement and concrete research, 34(1):6780, 2004.

Conway, B. and Conway, B. Ionic hydration in chemistry and biophysics, volume 741. Elsevier Amsterdam, 1981.

Cragnolino, G. and Tuovinen, O. H. The role of sulphate-reducing and sulphur-oxidizing bacteria in the localized corrosion of iron-base alloys. a review. International biodeterioration, 20(1):9-26, 1984.

Cwalina, B. Biodeterioration of concrete. Architecture Civil Engineering Environment, 1(4):133-140, 2008.

Davis, J., Nica, D., Shields, K., and Roberts, D. Analysis of concrete from corroded sewer pipe. International biodeterioration 83 biodegradation, 42(1):75-84, 1998.

De Belie, N., Monteny, J., Beeldens, A., Vincke, E., Van Gemert, D., and Verstraete, W. Experimental research and prediction of the effect of chemical and biogenic sulfuric acid on different types of commercially produced concrete sewer pipes. Cement and concrete research, 34(12):2223-2236, 2004.

De Muynck, W., De Belie, N., and Verstraete, W. Effectiveness of admixtures, surface treatments and antimicrobial compounds against biogenic sulfuric acid corrosion of concrete. Cement and Concrete Composites, 31(3):163-170, 2009.

De Windt, L. and Devillers, P. Modeling the degradation of portland cement pastes by biogenic organic acids. Cement and Concrete Research, 40(8):1165-1174, 2010.

Diercks, M., Sand, W., and Bock, E. Microbial corrosion of concrete. Cellular and Molecular Life Sciences, 47(6):514-516, 1991.

Edyvean, R. Biodeterioration problems of north sea oil and gas production - a review. International biodeterioration, 23(4):199-231, 1987.

Ehrich, S. Investigation into the corrosion of cement-bound construction materials by biogenic sulfuric acid. Hamburg:Lafarge, 1998.

Ehrich, S., Helard, L., Letourneux, R., Willocq, J., and Bock, E. Biogenic and chemical sulfuric acid corrosion of mortars. Journal of materials in civil engineering, 11:340, 1999. 
EPA, U. Process Design Manual for Sulfide Control in Sanitary Sewerage Systems. United States. Environmental Protection Agency. Office of Technology Transfer and Pomeroy, Richard D, 1974.

Fatima, T. and Muntean, A. Sulfate attack in sewer pipes: derivation of a concrete corrosion model via two-scale convergence. Nonlinear Analysis: Real World Applications, 2012.

Fattuhi, N. and Hughes, B. The performance of cement paste and concrete subjected to sulphuric acid attack. Cement and Concrete Research, 18(4):545-553, 1988.

Flemming, H.-C. Relevance of biofilms for the biodeterioration of surfaces of polymeric materials. Polymer degradation and stability, 59(1):309-315, 1998.

Fujii, K. and Kondo, W. Heterogeneous equilibrium of calcium silicate hydrate in water at 30 c. J. Chem. Soc., Dalton Trans., (2):645-651, 1981.

Gabrisova, A., Havlica, J., and Sahu, S. Stability of calcium sulphoaluminate hydrates in water solutions with various ph values. Cement and Concrete Research, 21(6):1023-1027, 1991.

Galíndez, J. and Molinero, J. Assessment of the long-term stability of cementitious barriers of radioactive waste repositories by using digital-image-based microstructure generation and reactive transport modelling. Cement and Concrete Research, 40(8):1278-1289, 2010.

Garboczi, E. J., Bentz, D. P., Snyder, K. A., Martys, N. S., Stutzman, P. E., Ferraris, C. F., and Bullard, J. An electronic monograph: Modeling and measuring the structure and properties of cement-based materials. NIST, Materials and Construction Research Division," http://ciks. cbt. nist. gov/monograph, 2005 .

Geuzaine, C. and Remacle, J. Gmsh: A 3-d finite element mesh generator with built-in pre-and postprocessing facilities. International Journal for Numerical Methods in Engineering, 79(11):1309-1331, 2009 .

Gollop, R. and Taylor, H. Microstructural and microanalytical studies of sulfate attack iii. sulfate-resisting portland cement: reactions with sodium and magnesium sulfate solutions. Cement and concrete research, $25(7): 1581-1590,1995$

Greenberg, S. and Chang, T. Investigation of Colloidal Hydrated Calcium Silicates: Pt. II. Solubility Relationships in the Calcium Oxide-silica-water System at 259. Bulletin, 1965.

Gu, J.-D., Ford, T. E., Berke, N. S., and Mitchell, R. Biodeterioration of concrete by the fungus fusarium. International biodeterioration $\&$ biodegradation, 41(2):101-109, 1998. 
Guezennec, J., Ortega-Morales, O., Raguenes, G., and Geesey, G. Bacterial colonization of artificial substrate in the vicinity of deep-sea hydrothermal vents. FEMS microbiology ecology, 26(2):89-99, 2006.

Gutiérrez-Padilla, M. G. D., Bielefeldt, A., Ovtchinnikov, S., Hernandez, M., and Silverstein, J. Biogenic sulfuric acid attack on different types of commercially produced concrete sewer pipes. Cement and Concrete Research, 40(2):293-301, 2010.

Gutiérrez-Padilla, M. G. D., Bielefeldt, A., Ovtchinnikov, S., Hernandez, M., and Silverstein, J. Biogenic sulfuric acid attack on different types of commercially produced concrete sewer pipes. Cement and Concrete Research, 40(2):293-301, 2010.

Hall, C., Marchand, J., Gerard, B., and Sosoro, M. Transport of fluids in homogeneous isotropic cementitious materials. RILEM REPORT, pages 5-6, 1997.

Harrison Jr, A. P. The acidophilic thiobacilli and other acidophilic bacteria that share their habitat. Annual Reviews in Microbiology, 38(1):265-292, 1984.

Herisson, J. Biodétérioration des matériaux cimentaires dans les ouvrages d'assainissement: étude comparative du ciment d'aluminate de calcium et du ciment Portland. PhD thesis, Université Paris-Est, 2012.

Herisson, J., van Hullebusch, E. D., Moletta-Denat, M., Taquet, P., and Chaussadent, T. Toward an accelerated biodeterioration test to understand the behavior of Portland and calcium aluminate cementitious materials in sewer networks. International Biodeterioration \&3 Biodegradation, 84:236-243, 2013.

Hudon, E., Mirza, S., and Frigon, D. Biodeterioration of concrete sewer pipes: State of the art and research needs. Journal of Pipeline Systems Engineering and Practice, 2(2):42-52, 2011.

Hueck, H. The biodeterioration of materials-an appraisal. In Biodeterioration of materials. Microbiological and allied aspects. Proceedings of the 1st international symposium. Southampton, 9th-14th September, 1968, pages 6-12. Elsevier Publishing Co., 1968.

Huet, B., Prevost, J., and Scherer, G. Quantitative reactive transport modeling of portland cement in co2-saturated water. International Journal of Greenhouse Gas Control, 4(3):561-574, 2010.

Hughes, B. and Guest, J. Limestone and siliceous aggregate concretes subjected to sulphuric acid attack. Magazine of Concrete Research, 30(102):11-18, 1978.

Hughes, P., Fairhurst, D., Sherrington, I., Renevier, N., Morton, L., Robery, P., and Cunningham, L. Microscopic study into biodeterioration of marine concrete. International Biodeterioration $\&$ Biodegradation, 79:14-19, 2013. 
Hvitved-Jacobsen, T., Vollertsen, J., and Tanaka, N. Wastewater quality changes during transport in sewers - an integrated aerobic and anaerobic model concept for carbon and sulfur microbial transformations. Water Science and Technology, 38(10):257-264, 1998.

Idriss, A., Negi, S., Jofriet, J., and Hayward, G. Effect of hydrogen sulphide emissions on cement mortar specimens. Canadian Biosystems Engineering, 43:5, 2001.

Islander, R. L., Devinny, J. S., Mansfeld, F., Postyn, A., and Shih, H. Microbial ecology of crown corrosion in sewers. Journal of Environmental Engineering, 117(6):751-770, 1991.

Ismail, N., Nonaka, T., Noda, S., and Mori, T. Effect of carbonation on microbial corrosion of concrete. Journal of Construction Management and Engineering, 20:133-138, 1993.

Israel, D., Macphee, D., and Lachowski, E. Acid attack on pore-reduced cements. Journal of materials science, 32(15):4109-4116, 1997.

Jahani, F., Devinny, J., Mansfeld, F., Rosen, I., Sun, Z., and Wang, C. Investigations of sulfuric acid corrosion of concrete. ii: electrochemical and visual observations. Journal of environmental engineering, $127(7): 580-584,2001$

Jahani, F., Devinny, J., et al. Investigation of sulfuric acid corrosion of concrete: Part i. modeling and chemical observations. ASCE: J. Envir. Engrg, 127(7):572-279, 2005.

Jennings, H. Colloid model of $\mathrm{c}-\mathrm{s}-\mathrm{h}$ and implications to the problem of creep and shrinkage. Materials and structures, 37(1):59-70, 2004.

Jensen, H., Nielsen, A., Hvitved-Jacobsen, T., and Vollertsen, J. Modeling of hydrogen sulfide oxidation in concrete corrosion products from sewer pipes. Water Environment Research, 81(4):365-373, 2009.

Jensen, H. S. Hydrogen sulfide induced concrete corrosion of sewer networks. Videnbasen for Aalborg UniversitetVBN, Aalborg UniversitetAalborg University, De Ingeniør-, Natur-og Sundhedsvidenskabelige FakulteterFaculties of Engineering, Science and Medicine, Sektion for MiljøteknologiSection of Environmental Engineering, 2008.

Jensen, H. S., Nielsen, A. H., Hvitved-Jacobsen, T., and Vollertsen, J. Hydrogen sulfide initiated corrosion in concrete sewers-a conceptual approach for prediction. In Proceedings from 11th International Conference of Urban Drainage, Edinburgh, 2008.

Joseph, A. P., Keller, J., Bustamante, H., and Bond, P. L. Surface neutralization and h2s oxidation at early stages of sewer corrosion: Influence of temperature, relative humidity and h2s concentration. Water research, 2012. 
Kaempfer, W. and Berndt, M. Polymer modified mortar with high resistance to acid to corrosion by biogenic sulfuric acid. In Proceedings of the IXth ICPIC Congress, Bologna, Italy, 14th-18th September, 1998, pages 681-687, 1998 .

Kaempfer, W. and Berndt, M. Estimation of service life of concrete pipes in sewer networks. In Proceedings of the 8th Conference on Durability of Building Materials and Components, Vancouver, pages 36-45, 1999.

Kalousek, G. Application of differential thermal analysis in a study of the system lime-silica-water. In Proceedings of the Third International Symposium on the Chemistry of Cement, London, pages 296-311, 1952.

Kawai, K., Yamaji, S., and Shinmi, T. Concrete deterioration caused by sulfuric acid attack. In 10 th DBMC International Conference On Durability of Building Materials and Component, 2005.

Kempner, E. S. Acid production by thiobacillus thiooxidans. Journal of Bacteriology, 92(6):1842-1843, 1966.

Kersten, M. Aqueous solubility diagrams for cementitious waste stabilization systems. 1. the csh solidsolution system. Environmental science \& technology, 30(7):2286-2293, 1996.

Kulik, D. and Kersten, M. Aqueous solubility diagrams for cementitious waste stabilization systems: Ii, end-member stoichiometries of ideal calcium silicate hydrate solid solutions. Journal of the American Ceramic Society, 84(12):3017-3026, 2001.

Lawrence, C. Sulphate attack on concrete. Magazine of Concrete Research, 42(153):249-264, 1990.

Lichtner, P. Flotran user's manual. Rep. LA-UR-02, 2349, 2001.

Lide, D. CRC handbook of chemistry and physics: a ready-reference book of chemical and physical data. CRC Pr I Llc, 2004.

Lothenbach, B., Matschei, T., Möschner, G., and Glasser, F. P. Thermodynamic modelling of the effect of temperature on the hydration and porosity of portland cement. Cement and Concrete Research, 38(1): $1-18,2008$.

Magniont, C., Coutand, M., Bertron, A., Cameleyre, X., Lafforgue, C., Beaufort, S., and Escadeillas, G. A new test method to assess the bacterial deterioration of cementitious materials. Cement and Concrete Research, 41(4):429-438, 2011. 
Mainguy, M., Tognazzi, C., Torrenti, J.-M., and Adenot, F. Modelling of leaching in pure cement paste and mortar. Cement and Concrete Research, 30(1):83-90, 2000.

Maruyama, I. and Igarashi, G. Hydration model of portland cement for structural integrity analysis. In Proceedings of International Symposium on the Ageing Management $\mathcal{G}$ Maintenance of Nuclear Power Plant, pages 123-144, 2010.

Milde, K., Sand, W., Wolff, W., and Bock, E. Thiobacilli of the corroded concrete walls of the hamburg sewer system. Journal of General Microbiology, 129(5):1327-1333, 1983.

Mitchell, R. and Gu, J.-D. Changes in the biofilm microflora of limestone caused by atmospheric pollutants. International biodeterioration \& biodegradation, 46(4):299-303, 2000.

Monteny, J., Vincke, E., Beeldens, A., De Belie, N., Taerwe, L., Van Gemert, D., and Verstraete, W. Chemical, microbiological, and in situ test methods for biogenic sulfuric acid corrosion of concrete. Cement and Concrete Research, 30(4):623-634, 2000.

Morandeau, A., Thiéry, M., and Dangla, P. An original use of carbonation profiles to investigate kinetics, microstructurale changes and released water for type-i cement-based materials. In 3rd International conference on the durability of concrete structures, Queen's University Belfast, 2012.

Mori, T., Koga, M., Hikosaka, Y., Nonaka, T., Mishina, F., Sakai, Y., and Koizumi, J. Microbial corrosion of concrete sewer pipes, h2s production from sediments and determination of corrosion rate. Water Science \& Technology, 23(7-9):1275-1282, 1991.

Mori, T., Nonaka, T., Tazaki, K., Koga, M., Hikosaka, Y., and Noda, S. Interactions of nutrients, moisture and ph on microbial corrosion of concrete sewer pipes. Water research, 26(1):29-37, 1992.

Nesic, S., Wang, S., Fang, H., Sun, W., and Lee, J. K. A new updated model of co2/h2s corrosion in multiphase flow. CORROSION 2008, 2008.

Nica, D., Davis, J., Kirby, L., Zuo, G., and Roberts, D. Isolation and characterization of microorganisms involved in the biodeterioration of concrete in sewers. International biodeterioration 83 biodegradation, 46(1):61-68, 2000.

Nielsen, A., Hvitved-Jacobsen, T., and Vollertsen, J. Kinetics and stoichiometry of sulfide oxidation by sewer biofilms. Water research, 39(17):4119-4125, 2005.

Nielsen, A. H., Vollertsen, J., Jensen, H. S., Wium-Andersen, T., and Hvitved-Jacobsen, T. Influence of pipe material and surfaces on sulfide related odor and corrosion in sewers. Water research, 42(15): 4206-4214, 2008. 
Nielsen, A. H., Hvitved-Jacobsen, T., and Vollertsen, J. Effect of sewer headspace air-flow on hydrogen sulfide removal by corroding concrete surfaces. Water Environment Research, 84(3):265-273, 2012.

Okabe, S., Odagiri, M., Ito, T., and Satoh, H. Succession of sulfur-oxidizing bacteria in the microbial community on corroding concrete in sewer systems. Applied and Environmental Microbiology, 73(3): 971-980, 2007.

Olmstead, W. and Hamlin, H. Converting portions of the los angeles outfall sewer into a septic tank. Engineering News and American Railway Journal, 44:317-318, 1900.

Pantazopoulou, S. and Mills, R. Microstructural aspects of the mechanical response of plain concrete. $A C I$ Materials Journal, 92(6), 1995.

Parker, C. The corrosion of concrete. Australian Journal of Experimental Biology and Medical Science, 23 (1):81, 1945 .

Parker, C. Mechanics of corrosion of concrete sewers by hydrogen sulfide. Sewage and Industrial Wastes, 23(12):1477-1485, 1951.

Pavlik, V. Corrosion of hardened cement paste by acetic and nitric acids part i: Calculation of corrosion depth. Cement and concrete research, 24(3):551-562, 1994.

Perry IV, T. D., McNamara, C. J., and Mitchell, R. Biodeterioration of stone. In Scientific Examination of Art: Modern Techniques in Conservation and Analysis; Sackler National Academy of Sciences Colloquium, pages 72-86, 2005.

Racine, J. gnuplot 4.0: a portable interactive plotting utility. Journal of Applied Econometrics, 21(1): $133-141,2006$.

Rahman, M. M., Nagasaki, S., and Tanaka, S. A model for dissolution of cao-sio2-h2o gel at ca/si> 1. Cement and Concrete Research, 29(7):1091-1097, 1999.

Reardon, E. An ion interaction model for the determination of chemical equilibria in cement/water systems. Cement and Concrete Research, 20(2):175-192, 1990.

Redner, J., Esfandi, E., and Hsi, R. Evaluation of protective coatings for concrete exposed to sulfide generation in wastewater treatment facilities. Journal of Protective Coatings and Linings, 8:48-58, 1991.

Redner, J., Hsi, R., and Esfandi, E. Evaluating coatings for concrete in wastewater facilities: update. Journal of Protect Coatings Linings, 11:51-61, 1994.

Rigdon, J. and Beardsley, C. Corrosion of concrete by autotrophes. Corrosion, 5:60-62, 1956. 
Robert, E., Thierry, G., and Raphaele, H. Finite volume methods. In Ciarlet, P. and Lions, J., editors, Solution of Equation in $\mathbb{R} n$ (Part 3), Techniques of Scientific Computing (Part 3), volume 7 of Handbook of Numerical Analysis. Elsevier, 2000.

Roberts, D., Nica, D., Zuo, G., and Davis, J. Quantifying microbially induced deterioration of concrete: initial studies. International biodeterioration $\&$ biodegradation, 49(4):227-234, 2002.

Sanchez-Silva, M. and Rosowsky, D. V. Biodeterioration of construction materials: state of the art and future challenges. Journal of Materials in Civil Engineering, 20(5):352-365, 2008.

Sand, W. Microbial corrosion and its inhibition. Biotechnology Set, Second Edition, pages 265-316, 2008.

Shen, J. Reactive transport modeling of CO2 through cementitious materials under CO2 geological storage conditions. Paris-est University, 2012.

Soler, J. M. Thermodynamic description of the solubility of c-s-h gels in hydrated portland cement literature review. Posiva working report, 88, 2007.

Steefel, C. Gimrt, version 1.2: Software for modeling multicomponent, multidimensional reactive transport. User's Guide: Livermore, California, Lawrence Livermore National Laboratory Report UCRL-MA143182, 2001.

Stronach, S. and Glasser, F. Modelling the impact of abundant geochemical components on phase stability and solubility of the cao-sio2-h2o system at $25^{\circ} \mathrm{c}: \mathrm{Na}+, \mathrm{k}+$, so42-, cl-and co32. Advances in cement research, 9(36):167-181, 1997.

Su, Y., Cheng, K., and Jean, Y. Amplified potentiometric determination of pk(00), pk(0), pk(l), and pk(2) of hydrogen sulfides with ag(2)s ise e. Talanta, 44(10):1757-1763, 1997.

Thiery, M. Modélisation de la carbonatation atmosphérique des matériaux cimentaires:(prise en compte des effets cinétiques et des modifications microstructurales et hydriques). École Nationale des Ponts et Chaussées, 2006.

Thiéry, M., Faure, P., Morandeau, A., Platret, G., Bouteloup, J., Dangla, P., Belin, P., and Baroghel-Bouny, V. Effect of carbonation on the microstructure and the moisture properties of cement-based materials. In International Conference on Durability of Building Materials and Components, Porto, Portugal, 2011.

Tian, B. and Cohen, M. Does gypsum formation during sulfate attack on concrete lead to expansion? Cement and Concrete Research, 30(1):117-123, 2000. 
Tichỳ, R., Janssen, A., Grotenhuis, J., Lettinga, G., and Rulkens, W. Possibilities for using biologicallyproduced sulphur for cultivation of thiobacilli with respect to bioleaching processes. Bioresource technology, 48(3):221-227, 1994.

Torii, K. and Kawamura, M. Effects of fly ash and silica fume on the resistance of mortar to sulfuric acid and sulfate attack. Cement and Concrete Research, 24(2):361-370, 1994.

Tsonopoulos, C., Coulson, D. M., and Inman, L. B. Ionization constants of water pollutants. Journal of Chemical and Engineering Data, 21(2):190-193, 1976.

Ueda, H. and Tatematsu, H. Deterioration mechanism of hardened cement paste by various acids. Proceedings of Japan Concrete Institute, 18(1):879-887, 1996.

Van Gerven, T., Cornelis, G., Vandoren, E., and Vandecasteele, C. Effects of carbonation and leaching on porosity in cement-bound waste. Waste management, 27(7):977-985, 2007.

Viitanen, H., Vinha, J., Salminen, K., Ojanen, T., Peuhkuri, R., Paajanen, L., and Lähdesmäki, K. Moisture and bio-deterioration risk of building materials and structures. Journal of Building Physics, 33 (3):201-224, 2010.

Vincke, E., Verstichel, S., Monteny, J., and Verstraete, W. A new test procedure for biogenic sulfuric acid corrosion of concrete. Biodegradation, 10(6):421-428, 1999.

Vincke, E., Monteny, J., Beeldens, A., Belie, N., Taerwe, L., Van Gemert, D., and Verstraete, W. Recent developments in research on biogenic sulfuric acid attack of concrete. Environmental Technologies to treat Sulfur Pollution-Principles and Engineering, IWA Publishing, pages 515-541, 2000.

Vincke, E., Boon, N., and Verstraete, W. Analysis of the microbial communities on corroded concrete sewer pipes-a case study. Applied microbiology and biotechnology, 57(5):776-785, 2001.

Voigt, T. and Shah, S. P. Properties of early-age portland cement mortar monitored with shear wave reflection method. ACI Materials Journal, 101(6), 2004.

Vollertsen, J., Nielsen, A. H., Jensen, H. S., Wium-Andersen, T., and Hvitved-Jacobsen, T. Corrosion of concrete sewers - the kinetics of hydrogen sulfide oxidation. Science of the total Environment, 394(1): $162-170,2008$.

Vollertsen, J., Nielsen, A. H., Jensen, H. S., Rudelle, E. A., and Hvitved-Jacobsen, T. Modeling the corrosion of concrete sewers. 2011. 
Warscheid, T. and Braams, J. Biodeterioration of stone: a review. International Biodeterioration E Biodegradation, 46(4):343-368, 2000.

Weast, R., Astle, M., and Beyer, W. CRC handbook of chemistry and physics, volume 69. CRC press Boca Raton, FL, 1988.

Westall, J., Zachary, J., and Morel, F. MINEQL: A computer program for the calculation of chemical equilibrium composition of aqueous systems. Water Quality Laboratory, Ralph M. Parsons Laboratory for Water Resources and Environmental Engineering, Department of Civil Engineering, Massachusetts Institute of Technology, 1976.

Wiberg, N. Holleman-wiberg's inorganic chemistry. Academic Press, New York, 2001.

Wood, A. P., Woodall, C. A., and Kelly, D. P. Halothiobacillus neapolitanus strain oswa isolated from "the old sulphur well" at harrogate (yorkshire, england). Systematic and applied microbiology, 28(8):746-748, 2005.

Xu, T., Sonnenthal, E., Spycher, N., and Pruess, K. Toughreact user's guide: A simulation program for non-isothermal multiphase reactive geochemical transport in variably saturated geologic media, v1. 2.1. Technical report, Ernest Orlando Lawrence Berkeley National Laboratory, Berkeley, CA (US), 2008.

Ye, G., Sun, Z., Voigt, T., van Breugel, K., and Shah, S. A micromechanic model for characterization of cement paste at early age validated with experiments. In International Symposium: Advances in Concrete through Science and Engineering, Evanston, IL, 2004.

Yongsiri, C., Vollertsen, J., and Hvitved-Jacobsen, T. Effect of temperature on air-water transfer of hydrogen sulfide. Journal of environmental engineering, 130(1):104-109, 2004.

Yudenfreund, M., Odler, I., and Brunauer, S. Hardened portland cement pastes of low porosity i. materials and experimental methods. Cement and Concrete Research, 2(3):313-330, 1972.

Zekker, I., Tenno, T., Selberg, A., and Uiga, K. Dissolution modeling and experimental measurement of cas-h2o binary system. Chinese Journal of Chemistry, 29(11):2327-2336, 2011.

Zherebyateva, T., Lebedeva, E., and Karavako, G. Microbiological corrosion of concrete structures of hydraulic facilities. Geomicrobiology Journal, 9(2-3):119-127, 1991.

Zivica, V. and Bajza, A. Acidic attack of cement-based materials - a review part 2. factors of rate of acidic attack and protective measures. Construction and building materials, 16(4):215-222, 2002. 


\section{Appendix A}

\section{Introduction of discrete and solid}

\section{solution models of C-S-H dissolution}

There are different types of C-S-H, e.g. jennite with $\mathrm{Ca} / \mathrm{Si}$ ratio of approximately 1.7 , tobermorite with $\mathrm{Ca} / \mathrm{Si}$ ratio of approximately 0.83 and amorphous silica gel with $\mathrm{Ca} / \mathrm{Si}$ ratio of 0 . Table A.1 lists different forms of C-S-H and their thermodynamical properties proposed by (Lothenbach et al., 2008).

Table A.1: Different C-S-H type proposed by (Lothenbach et al., 2008).

\begin{tabular}{llll}
\hline C-S-H type & $\mathrm{Ca} / \mathrm{Si}$ & $(x, y, z)$ & $\log K$ \\
\hline Amorphous silica gel & 0 & $(0,1,0)$ & -2.713 \\
Tobermorite & 0.83 & $(0.83,1,1.3)$ & -12.19 \\
Jennite & 1.67 & $(1.67,1,2.1)$ & -17.36 \\
\hline
\end{tabular}

In discrete method, to describe the dissolution of C-S-H, we can use the same approach as the one adopted for the CH dissolution (see Eq. (3.3) and Section 3.3),

$$
\frac{Q_{\mathrm{C}_{x} \mathrm{~S}_{y} \mathrm{H}_{z}}}{K_{\mathrm{C}_{x} \mathrm{~S}_{y} \mathrm{H}_{z}}}=\frac{\left(K_{\mathrm{CH}}\right)^{x}\left(K_{\mathrm{SH}_{t}}\right)^{y}}{K_{\mathrm{C}_{x} \mathrm{~S}_{y} \mathrm{H}_{z}}}\left(\frac{Q_{\mathrm{CH}}}{K_{\mathrm{CH}}}\right)^{x}\left(\frac{Q_{\mathrm{SH}_{t}}}{K_{\mathrm{SH}_{t}}}\right)^{y}
$$

where $Q_{\mathrm{SH}_{t}}=\rho_{\mathrm{H}_{4} \mathrm{SiO}_{4}^{0}}$ is the activity product of amorphous silica. From Eq. (A.1), we can deduce the stability domains for the amorphous silica $\mathrm{SH}_{t}$ and the different types of C-S-H. Taking jennite as example (see Table A.1), the equilibrium equation for jennite and amorphous silica is in the following form:

$$
\frac{Q_{\mathrm{Jen}}}{K_{\mathrm{Jen}}}=\frac{\left(K_{\mathrm{CH}}\right)^{1.67}\left(K_{\mathrm{SH}_{t}}\right)}{K_{\mathrm{Jen}}}\left(\frac{Q_{\mathrm{CH}}}{K_{\mathrm{CH}}}\right)^{1.67}\left(\frac{Q_{\mathrm{SH}_{t}}}{K_{\mathrm{SH}_{t}}}\right)
$$

The stability domains are shown in Fig. A.1. At the critical point (dashed line in the plot), $\log \left(\mathrm{Q}_{\mathrm{CH}} / \mathrm{K}_{\mathrm{CH}}\right)=$ -3.57. Combing with Eq. (3.13) we can get the threshold $\mathrm{H}_{2} \mathrm{SO}_{4}$ concentration $\rho_{\mathrm{H}_{2} \mathrm{SO}_{4}}^{\mathrm{SH}_{t} \text {-Jen }} \approx 1.3 \times$ 
$10^{-22} \mathrm{~mol} / \mathrm{L}$.

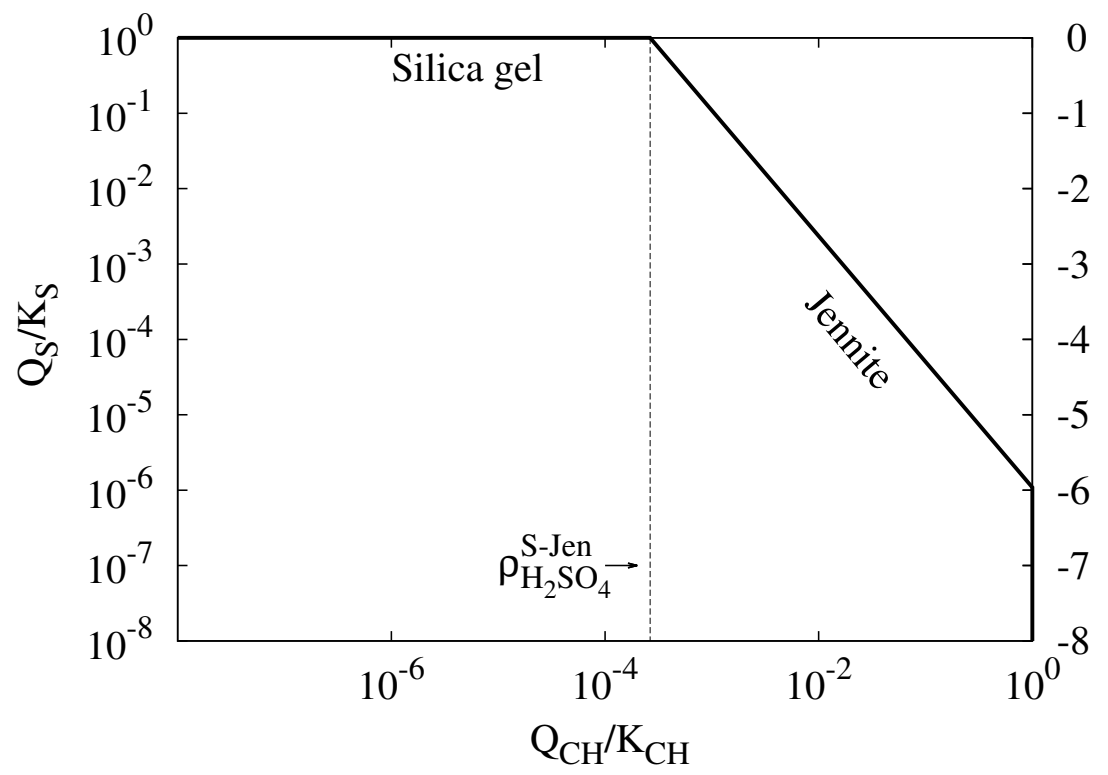

Figure A.1: Stability domains of jennite and amorphous silica gel.

Similarly we can calculate the stability domains with the system of jennite-tobermorite-silica gel, as shown in Fig. A.2. The threshold $\mathrm{H}_{2} \mathrm{SO}_{4}$ concentration for tobermorite $\rho_{\mathrm{H}_{2} \mathrm{SO}_{4}}^{\mathrm{Tob}} \approx 6.2 \times 10^{-20} \mathrm{~mol} / \mathrm{L}$ and for jennite $\rho_{\mathrm{H}_{2} \mathrm{SO}_{4}}^{\mathrm{Jen}} \approx 3.9 \times 10^{-25} \mathrm{~mol} / \mathrm{L}$. When the $\mathrm{H}_{2} \mathrm{SO}_{4}$ concentration is lower than $\rho_{\mathrm{H}_{2} \mathrm{SO}_{4}}^{\mathrm{Jen}}$, jennite is stable, when it lays between $\rho_{\mathrm{H}_{2} \mathrm{SO}_{4}}^{\mathrm{Jen}}$ and $\rho_{\mathrm{H}_{2} \mathrm{SO}_{4}}^{\mathrm{Tob}}$, tobermorite is stable, and when $\mathrm{H}_{2} \mathrm{SO}_{4}$ concentration exceeds $\rho_{\mathrm{H}_{2} \mathrm{SO}_{4}}^{\mathrm{Tob}}$, amorphous silica gel is stable.

Rather than the discrete model discussed above, a solid solution method which considers different solid poles in equilibrium, is more appropriate to describe the continuous decalcification of C-S-H. Let's consider a solid solution composed of $\mathrm{N}$ end-members, $M_{i}$ respectively $(i=1, \ldots, N)$. In the framework of the solid solution theory, a reaction between the end-members (poles) to form a solid solution can be written as:

$$
\sum_{i=1}^{N} n_{i} \mathrm{M}_{i} \rightleftharpoons\left(M_{1}\right)_{n_{1}}\left(M_{2}\right)_{n_{2}} \ldots\left(M_{N}\right)_{n_{N}}
$$

Each end-member is assumed to be in thermodynamical equilibrium with the aqueous solution. The chemical potential of the end-member $i$ in the solid solution is given by:

$$
\mu_{i}=\mu_{i}^{0}+R T \ln a_{i}
$$

where $\mu_{i}^{0}$ is the chemical potential of the pure end-member. The equilibrium between the end-member $i$ and the aqueous solution results in: 


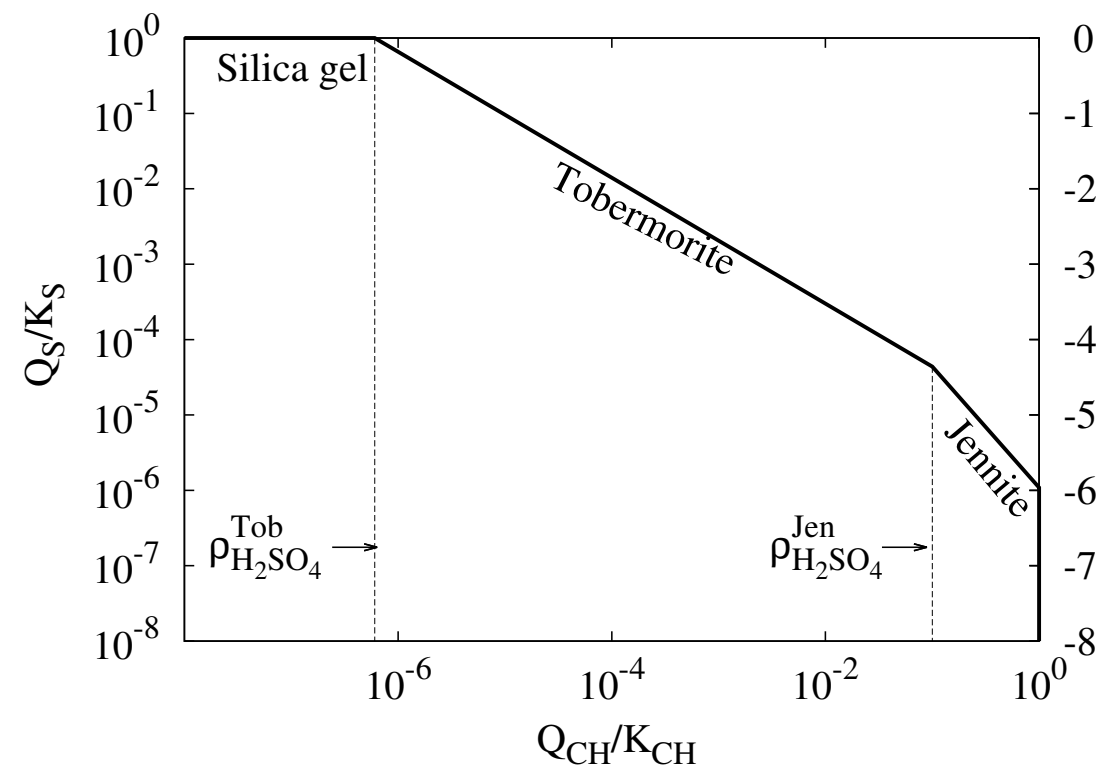

Figure A.2: Stability domains of jennite, tobermorite and amorphous silica gel.

$$
K_{i}=\frac{Q_{i}}{a_{i}}
$$

where

$$
a_{i}=\lambda_{i} X_{i}
$$

In Eqs. (A.5) and (A.6), $K_{i}$ denotes the equilibrium constant. $Q_{i}$ is the activity product. $a_{i}$ is the chemical activity. $X_{i}$ is the mole fraction of the component $i$ within the solid solution and $\lambda_{i}$ is the activity coefficient. For a pure end-member, $a_{i}$ equals to 1, while in the framework of solid solution, $a_{i}$ follows Eq. (A.6). Thus, for each end-member, the equilibrium between a solid solution and an aqueous solution can be written as

$$
\frac{Q_{i}}{K_{i}}=\lambda_{i} X_{i}
$$

For an ideal solid solution, the chemical activity $a_{i}$ equals to the mole fraction $X_{i}$, i.e., $\lambda_{i}=1$. While in the non-ideal solid solution, this two values are different. To accurately represent the C-S-H as a solid solution, the end-members and the stoichiometric coefficients should be carefully chosen. Several possible values are reported in the literature. (Atkinson et al., 1989) used two non-ideal solid solutions to describe the behavior of C-S-H, based on experimental data from (Greenberg and Chang, 1965). For $\mathrm{Ca} / \mathrm{Si} \leq 0.8$, end-members were chosen as $\mathrm{S}$ - nC.S.mH (amorphous silica - "tobermorite") and for $\mathrm{Ca} / \mathrm{Si}>0.8$, endmembers were chosen as nC.S.mH - CH ("tobermorite" - portlandite), where $\mathrm{n}=0.833$ and $\mathrm{m}=0.917$. For 
$\mathrm{Ca} / \mathrm{Si} \geq 1.8$, equilibrium with portlandite is added. (Börjesson et al., 1997) used an non-ideal solid solution of $\mathrm{CH}-\mathrm{CaH}_{2} \mathrm{SiO}_{4}$ for $1<\mathrm{Ca} / \mathrm{Si} \leq 1.43$, based on data from (Kalousek, 1952). (Rahman et al., 1999) proposed a similar model as (Börjesson et al., 1997), within the Ca/Si range from 1. to 1.5. (Kersten, 1996) proposed a non-ideal binary solid solution $\mathrm{CH}-\mathrm{CaHSiO}_{3.5} \cdot \mathrm{H} 2 \mathrm{O}$ based on the experimental data from (Greenberg and Chang, 1965) and (Fujii and Kondo, 1981). (Kulik and Kersten, 2001) described the solubility of C-S-H with a system of two ideal solid solutions: C-S-H-(I): S - tobermorite and C-S-H-(II): tobermorite - jennite. The experimental data of (Greenberg and Chang, 1965) was used to calibrate the model, and the applicable range of $\mathrm{Ca} / \mathrm{Si}$ ratio is between 0 to 1.7. (Carey and Lichtner, 2007) proposed a non-ideal binary solid solution (S - CH) calibrated with the experimental data from (Chen et al., 2004).

All the models above are able to reproduce the experimental results within the dispersion of experimental data (Soler, 2007). Therefore it is hard to say which one is better. However, the models proposed by (Atkinson et al., 1989), (Kersten, 1996), (Kulik and Kersten, 2001) and (Carey and Lichtner, 2007) are applicable over a wider range of $\mathrm{Ca} / \mathrm{Si}$ ratio than those of others.

Here we use an ideal solid solution with four poles, similar as that proposed by (Kulik and Kersten, 2001) with thermodynamical data from (Lothenbach et al., 2008). The stoichiometric and equilibrium constants for the different poles are listed in Table A.2.

Combing Eq. (A.1) and Eq.(A.7), for each pole, we get

$$
\lambda_{i} X_{i}=\frac{Q_{i}}{K_{i}}=\frac{\left(K_{\mathrm{CH}}\right)^{x_{i}}\left(K_{\mathrm{SH}_{t}}\right)^{y_{i}}}{K_{\mathrm{C}_{x_{i}} \mathrm{~S}_{y_{i}} \mathrm{H}_{z_{i}}}}\left(\frac{Q_{\mathrm{CH}}}{K_{\mathrm{CH}}}\right)^{x_{i}}\left(\frac{Q_{\mathrm{SH}_{t}}}{K_{\mathrm{SH}_{t}}}\right)^{y_{i}}
$$

Table A.2: Poles of a solid solution of C-S-H

\begin{tabular}{lll}
\hline C-S-H (pole) & $(x, y, z)$ & $\log K^{1}$ \\
\hline Amorphous Silica & $(0,1,0)$ & -2.713 \\
Tobermorite I & $(2,2.4,4)$ & -28.26 \\
Tobermorite II & $(1.5,1.8,3)$ & -21.19 \\
Jennite & $(1.5,0.9,2.4)$ & -15.62 \\
\hline
\end{tabular}

${ }^{1}$ data from (Lothenbach et al., 2008)

With the hypothesis of ideal solid solution, $\lambda_{i}=1$ and $\sum X_{i}=1$, we have the following equation:

$$
\sum A_{i}\left(q_{\mathrm{CH}}\right)^{x_{i}}\left(q_{\mathrm{S}}\right)^{y_{i}}=1
$$

where,

$$
A_{i}=\frac{\left(K_{\mathrm{CH}}\right)^{x_{i}}\left(K_{\mathrm{SH}_{t}}\right)^{y_{i}}}{K_{\mathrm{C}_{x_{i}} \mathrm{~S}_{y_{i}} \mathrm{H}_{z_{i}}}}, q_{\mathrm{CH}}=\frac{Q_{\mathrm{CH}}}{K_{\mathrm{CH}}}, q_{\mathrm{S}}=\frac{Q_{\mathrm{SH}_{t}}}{K_{\mathrm{SH}_{t}}}
$$

Eq. (A.9) indicates that $q_{\mathrm{S}}$ is a function of $q_{\mathrm{CH}}, q_{\mathrm{S}}\left(q_{\mathrm{CH}}\right)$, that we can solve. Thus, the mole fraction of each end-member can be calculated by Eq. (A.8) as a function of $q_{\mathrm{CH}}$. The Ca/Si ratio can be attained as 
a function of $q_{\mathrm{CH}}$ by using Eq. (A.11).

$$
\mathrm{Ca} / \mathrm{Si}=\frac{\sum X_{i} x_{i}}{\sum X_{i} y_{i}}=\chi\left(q_{\mathrm{CH}}\right)
$$

The calculated mole fraction for each pole and the $\mathrm{Ca} / \mathrm{Si}$ ratio as a function of $q_{\mathrm{CH}}$ are illustrated in Fig. A.3. We can see that for $q_{\mathrm{CH}}=1$, which means $\mathrm{CH}$ is in equilibrium with the aqueous solution, the C-S-H is in the form of jennite. When $q_{\mathrm{CH}}$ decreases, C-S-H will first decalcified to the form of tobermorite, and finally to amorphous silica gel. Thus, Ca/Si ratio drops continuously as $q_{\mathrm{CH}}$ decreases.

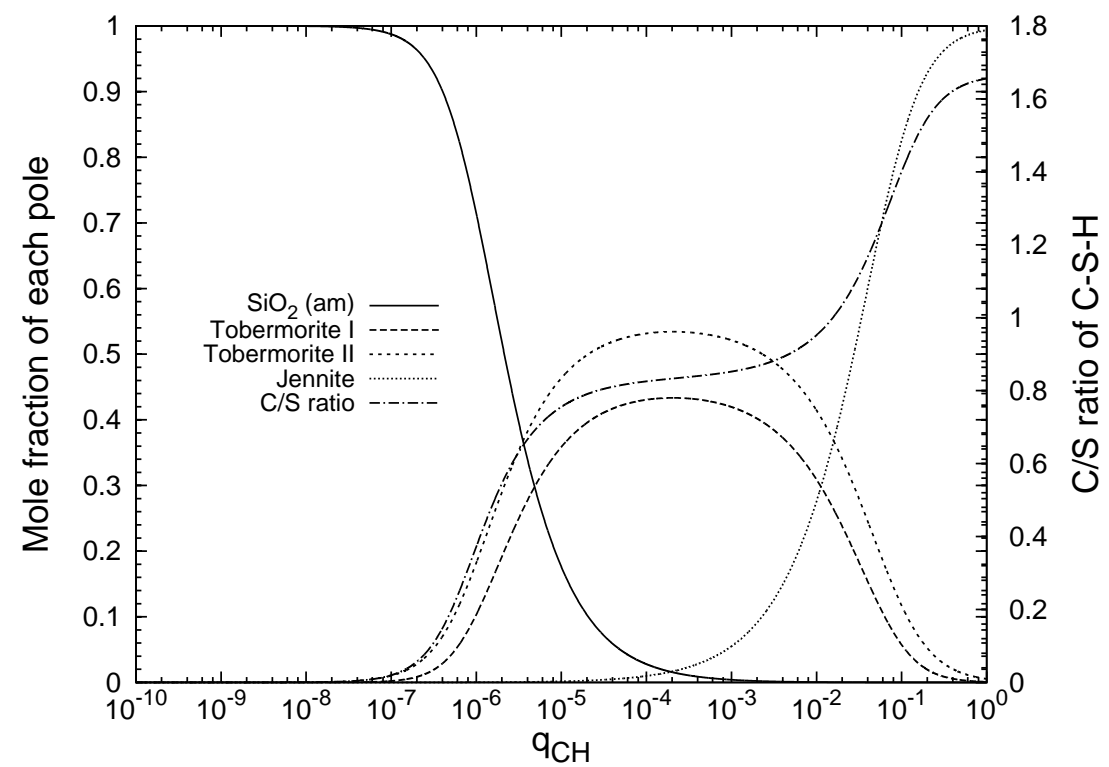

Figure A.3: Mole fraction of different poles and $\mathrm{Ca} / \mathrm{Si}$ evolution $v s . q_{\mathrm{CH}}$.

It is noteworthy that our new approach, which is introduced in Section 3.4, encompasses the solid solution model involving any number of poles with coefficient $\left(x_{i}, y_{i}, z_{i}\right)$. Indeed, the solid solution theory shows that $X_{i}=A_{i} q^{x_{i}}(F)^{y_{i}}$, where $F(q)=\frac{Q_{\mathrm{SH}_{t}}}{K_{\mathrm{SH}_{t}}}$. It is then easy to show that the average stoichiometric coefficients are given by $x=X(q)$ and $y=Y(q)$ with

$$
\begin{aligned}
& X(q)=\sum_{i}\left(x_{i} A_{i} q^{x_{i}} F^{y_{i}}\right) \\
& Y(q)=\sum_{i}\left(y_{i} A_{i} q^{x_{i}} F^{y_{i}}\right)
\end{aligned}
$$

Since the solid fraction has to satisfy $\sum X_{i}=1$, we obtain:

$$
1=\sum_{i}\left(A_{i} q^{x_{i}} F^{y_{i}}\right)
$$


14teptember 16, 2013Introduction of discrete and solid solution models of C-S-H dissolution

Hence deriving this last equation with respect to $q$ leads to:

$$
\frac{F^{\prime}}{F}=-\frac{X / Y}{q}
$$

which is akin to Eq. (3.26). Eq. (3.26) is a generalization of the mass action law for C-S-H with variable $\mathrm{Ca} / \mathrm{Si}$ ratio. 


\section{Appendix B}

\section{The finite volume method}

The finite volume method is a discretization method well suited for the numerical simulation of various types of conservation laws such as mass balance equations (Robert et al., 2000). Some of the important features of the finite volume method are similar to those of the finite element method (arbitrary geometries, structured/unstructured meshes). An additional feature is the local conservativity of the numerical fluxes at the interface of two neighoring cells. conserved from one discretization cell to its neighbor. it is based on a balance approach: a local balance is written on each discretization cell which is often called "control volume" the boundary of the control volume is then obtained.

Let us introduce the method on a simple example. Consider a mass balance equation of the form

$$
\frac{\partial m}{\partial t}=-\operatorname{div} \underline{w}
$$

where $m(\rho)$ is a mass content of a substance per unit volume of porous material and considered as a function of a primary variable $\rho$ which is typically of a concentration. The flow vector of that substance, $\underline{w}$, is assumed to be given by a transport's law, typically a the Fick's law:

$$
\underline{w}=-D \underline{\nabla \rho}
$$

The finite volume method is obtained by a discrete balance in the elements of a mesh called "control volumes". Integrating the previous equation over a control volume $K$ yields the following balance equation over $K$ :

$$
\Omega_{K} \frac{m_{K}^{n+1}-m_{K}^{n}}{\Delta t}+\sum_{K^{\prime}} w_{K K^{\prime}}=0
$$


where $w_{K K^{\prime}}$ expresses an approximation of $\int_{\partial \Omega_{K K^{\prime}}} \underline{w} \cdot \underline{n} d s$ for any $K$ and any neighor $K^{\prime}$ of $K$ :

$$
w_{K K^{\prime}}=-\left|\partial \Omega_{K K^{\prime}}\right| D \frac{\rho_{K^{\prime}}-\rho_{K}}{d_{K K^{\prime}}}
$$

where $\left|\partial \Omega_{K K^{\prime}}\right|$ is the surface area between $K$ and $K^{\prime}$ and $d_{K K^{\prime}}$ is the distance between the "centers" of $K$ and $K^{\prime}$. The surface $\partial \Omega_{K K^{\prime}}$ is also assumed to be perpendicular to the line joining the "centers" of $K$ and $K^{\prime}$ in order to be consistent with the Fick's law. The resolution of the set of equations (B.3) is performed by a Newton's iteration method until the variation of $\rho_{K}^{n+1}$ between two successive iterations, $\delta \rho_{K}^{n+1}$, is small enough and meets a convergence criterion of the form

$$
\frac{\delta \rho_{K}^{n+1}}{\Delta \rho_{\mathrm{obj}}}<\epsilon
$$

where $\Delta \rho_{\text {obj }}$ is a given objective variation of $\rho$ and $\epsilon$ a small positive number compared to unity, typically $10^{-4}$. 
